DANIEL MOURA MARTINS DA COSTA

Ensemble Baseado em Métodos de Kernel para Reconhecimento Biométrico

Multimodal

São Paulo

2016 


\title{
Ensemble Baseado em Métodos de Kernel para Reconhecimento Biométrico Multimodal
}

\author{
Versão Corrigida
}

Dissertação apresentada à Escola de Artes, Ciências e Humanidades da Universidade de São Paulo para obtenção do título de Mestre em Ciências pelo Programa de Pós-graduação em Sistemas de Informação.

Área de concentração: Metodologia e Técnicas da Computação

Versão corrigida contendo as alterações solicitadas pela comissão julgadora em 31 de Março de 2016. A versão original encontra-se em acervo reservado na Biblioteca da EACH-USP e na Biblioteca Digital de Teses e Dissertações da USP (BDTD), de acordo com a Resolução CoPGr 6018, de 13 de outubro de 2011.

Orientador: Prof. Dr. Clodoaldo Aparecido de Moraes Lima

São Paulo 
Autorizo a reprodução e divulgação total ou parcial deste trabalho, por qualquer meio convencional ou eletrônico, para fins de estudo e pesquisa, desde que citada a fonte.

CATALOGAÇÃO-NA-PUBLICAÇÃO

(Universidade de São Paulo. Escola de Artes, Ciências e Humanidades. Biblioteca)

Costa, Daniel Moura Martins da

Ensemble baseado em métodos de Kernel para reconhecimento biométrico multimodal / Daniel Moura Martins da Costa ; orientador, Clodoaldo Aparecido de Moraes Lima. - São Paulo, 2016 $145 \mathrm{f}$ : : il.

Dissertação (Mestrado em Ciências) - Programa de Pós-

Graduação em Sistemas de Informação, Escola de Artes, Ciências e Humanidades, Universidade de São Paulo Versão corrigida

1. Reconhecimento de padrões. 2. Biometria. 3. Máquinas de vetores de suporte. 4. Transformada Wavelet .5. Transformada Contourlet. 6. Transformada Curvelet. I. Lima, Clodoaldo Aparecido de Moraes, orient. II. Título

CDD 22.ed.- 006.4 
Dissertação de autoria de Daniel Moura Martins da Costa, sob o título "Ensemble Baseado em Métodos de Kernel para Reconhecimento Biométrico Multimodal", apresentada à Escola de Artes, Ciências e Humanidades da Universidade de São Paulo, para obtenção do título de Mestre em Ciências pelo Programa de Pós-graduação em Sistemas de Informação, na área de concentração Metodologia e Técnicas da Computação, aprovada em 31 de março de 2016 pela comissão julgadora constituída pelos doutores:

Prof. Dr. Clodoaldo Aparecido de Moraes Lima Presidente

Escola de Artes, Ciências e Humanidades - Universidade de São Paulo

Prof. Dr. Adilson Gonzaga

Escola de Engenharia de São Carlos - Universidade de São Paulo

Profa. Dra. Fátima de Lourdes dos Santos Nunes Marques

Escola de Artes, Ciências e Humanidades - Universidade de São Paulo 
Dedico esta dissertação aos meus pais, amigos e aos meus professores pelo apoio, incentivo e paciência que tiveram comigo durante todos os momentos deste trabalho. 


\section{Agradecimentos}

Agradeço aos meus pais, Lourdes e Pery, por todo o apoio que me deram durante o desenvolvimento deste trabalho e pela ajuda no enfrentamento dos mais diversos problemas.

Agradeço aos meus amigos Fernando, Thiago, Gustavo pela companhia e por me ajudar a superar os problemas pessoais que surgiram durante esse percurso.

Agradeço ao meu orientador, Prof. Dr. Clodoaldo Aparecido de Moraes Lima, e a minha professora, Profa. Dra. Sarajane Marques Peres, pela orientação, apoio e ajuda durante o desenvolvimento deste trabalho. Ambos sempre estiveram à disposição para esclarecer minhas dúvidas, fornecer novas ideias e conselhos que foram imprescindíveis para a elaboração deste trabalho.

Agradeço também a CAPES pelo auxílio financeiro que permitiu com que fosse possível desenvolver este trabalho.

Agradeço a Universidade de Shandong pela liberação da Base de Dados, SDUMLAHMT, que foi utilizada para a realização dos experimentos.

Por último agradeço a Deus por ter colocado todas as pessoas aqui citadas na minha vida, sem vocês eu não estaria aqui nesse momento. 
"Se enxerguei mais longe, foi porque estava sobre os ombros de gigantes."

(Isaac Newton) 


\section{Resumo}

COSTA, Daniel Moura Martins da. Ensemble Baseado em Métodos de Kernel para Reconhecimento Biométrico Multimodal. 2016. 145 f. Dissertação (Mestrado em Ciências) - Escola de Artes, Ciências e Humanidades, Universidade de São Paulo, São Paulo, 2016. Versão Corrigida.

Com o avanço da tecnologia, as estratégias tradicionais para identificação de pessoas se tornaram mais suscetíveis a falhas, de forma a superar essas dificuldades algumas abordagens vêm sendo propostas na literatura. Dentre estas abordagens destaca-se a Biometria. O campo da Biometria abarca uma grande variedade de tecnologias usadas para identificar e verificar a identidade de uma pessoa por meio da mensuração e análise de aspectos físicos e/ou comportamentais do ser humano. Em função disso, a biometria tem um amplo campo de aplicações em sistemas que exigem uma identificação segura de seus usuários. Os sistemas biométricos mais populares são baseados em reconhecimento facial ou de impressões digitais. Entretanto, existem outros sistemas biométricos que utilizam a íris, varredura de retina, voz, geometria da mão e termogramas faciais. Nos últimos anos, o reconhecimento biométrico obteve avanços na sua confiabilidade e precisão, com algumas modalidades biométricas oferecendo bom desempenho global. No entanto, mesmo os sistemas biométricos mais avançados ainda enfrentam problemas. Recentemente, esforços têm sido realizados visando empregar diversas modalidades biométricas de forma a tornar o processo de identificação menos vulnerável a ataques. Biometria multimodal é uma abordagem relativamente nova para representação de conhecimento biométrico que visa consolidar múltiplas modalidades biométricas. A multimodalidade é baseada no conceito de que informações obtidas a partir de diferentes modalidades se complementam. Consequentemente, uma combinação adequada dessas informações pode ser mais útil que o uso de informações obtidas a partir de qualquer uma das modalidades individualmente. As principais questões envolvidas na construção de um sistema biométrico unimodal dizem respeito à definição das técnicas de extração de característica e do classificador. Já no caso de um sistema biométrico multimodal, além destas questões, é necessário definir o nível de fusão e a estratégia de fusão a ser adotada. O objetivo desta dissertação é investigar o emprego de ensemble para fusão das modalidades biométricas, considerando diferentes estratégias de fusão, lançando-se mão de técnicas avançadas de processamento de imagens (tais como transformada Wavelet, Contourlet e Curvelet) e Aprendizado de Máquina. Em especial, dar-se-á ênfase ao estudo de diferentes tipos de máquinas de aprendizado baseadas em métodos de Kernel e sua organização em arranjos de ensemble, tendo em vista a identificação biométrica baseada em face e íris. Os resultados obtidos mostraram que a abordagem proposta é capaz de projetar um sistema biométrico multimodal com taxa de reconhecimento superior as obtidas pelo sistema biométrico unimodal.

Palavras-chaves: Biometria. Sistemas Biométricos Unimodais. Sistemas Biométricos Multimodais. Ensemble. Máquinas de Vetores Suporte. Máquinas de Vetores Suporte baseada em Quadrados Mínimos. Transformada Wavelet. Transformada Contourlet. Transformada Curvelet. 


\begin{abstract}
COSTA, Daniel Moura Martins da. Ensemble Based on Kernel Methods for Multimodal Biometric Recognition. 2016. 145 p. Dissertation (Master of Science) School of Arts, Sciences and Humanities, University of São Paulo, São Paulo, 2016. Corrected Version.
\end{abstract}

With the advancement of technology, traditional strategies for identifying people become more susceptible to failure, in order to overcome these difficulties some approaches have been proposed in the literature. Among these approaches highlights the Biometrics. The field of Biometrics encompasses a wide variety of technologies used to identify and verify the person's identity through the measurement and analysis of physiological and behavioural aspects of the human body. As a result, biometrics has a wide field of applications in systems that require precise identification of their users. The most popular biometric systems are based on face recognition and fingerprint matching. Furthermore, there are other biometric systems that utilize iris and retinal scan, speech, face, and hand geometry. In recent years, biometrics authentication has seen improvements in reliability and accuracy, with some of the modalities offering good performance. However, even the best biometric modality is facing problems. Recently, big efforts have been undertaken aiming to employ multiple biometric modalities in order to make the authentication process less vulnerable to attacks. Multimodal biometrics is a relatively new approach to biometrics representation that consolidate multiple biometric modalities. Multimodality is based on the concept that the information obtained from different modalities complement each other. Consequently, an appropriate combination of such information can be more useful than using information from single modalities alone. The main issues involved in building a unimodal biometric System concern the definition of the feature extraction technique and type of classifier. In the case of a multimodal biometric System, in addition to these issues, it is necessary to define the level of fusion and fusion strategy to be adopted. The aim of this dissertation is to investigate the use of committee machines to fuse multiple biometric modalities, considering different fusion strategies, taking into account advanced methods in machine learning. In particular, it will give emphasis to the analyses of different types of machine learning methods based on Kernel and its organization into arrangements committee machines, aiming biometric authentication based on face, fingerprint and iris. The results showed that the proposed approach is capable of designing a multimodal biometric System with recognition rate than those obtained by the unimodal biometrics Systems.

Keywords: Biometrics. Unimodal Biometric Systems. Multimodal Biometric Systems. Ensemble. Support Vector Machines. Least-Square Support Vector Machines. Wavelet Transform. Contourlet Transform. Curvelet Transform. 


\section{Lista de figuras}

Figura 1 - Módulos de um sistema biométrico. . . . . . . . . . . . . . 27

Figura 2 - Estrutura do modo de identificação. . . . . . . . . . . . . . . . 28

Figura 3 - Estrutura do modo de verificação. . . . . . . . . . . . . . . . . . 28

Figura 4 - Exemplo de construção de uma imagem integral. Cinza $=3$, Azul $=3+5$, Laranja $=3+4$ e Verde $=6+4+5+3 \ldots \ldots$. . . . . . . . 31

Figura 5 - Cálculo da soma de um retângulo. . . . . . . . . . . . . . . 31

Figura 6 - Exemplos das características de Haar. . . . . . . . . . . . . . . 32

Figura 7 - Arquitetura do classificador em cascata. Adaptado de (VIOLA; JONES,

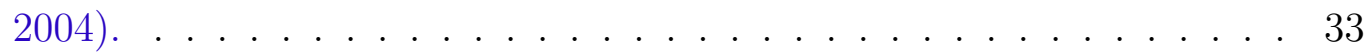

Figura 8 - Distribuição dos graus de semelhança. . . . . . . . . . . . 38

Figura 9 - Curvas de FAR, FRR e taxa de cruzamento. . . . . . . . . . . . . 39

Figura 10 - Fusão no nível sensorial. . . . . . . . . . . . . . . . . . . . . . . . 42

Figura 11 - Fusão no nível de extração de características. . . . . . . . . . . . . . . 43

Figura 12 - Fusão da pontuação obtida no nível de comparação. . . . . . . . . . . . . 45

Figura 13 - Fusão no nível da decisão. . . . . . . . . . . . . . . . . . . . . . 45

Figura 14 - Decomposição Wavelet 1-D. . . . . . . . . . . . . . . . . 48

Figura 15 - Decomposição Wavelet 2-D . . . . . . . . . . . . . . . . . 49

Figura 16 - Decomposição gerada pelo filtro quincunx. . . . . . . . . . . . . 50

Figura 17 - Partição da frequência gerada para $l=3$, gerando $2^{3}=8$ partições. . . 50

Figura 18 - Exemplo de rotação utilizando as matrizes $S_{k}^{(l)}$. Esquerda: imagem original. Direita: Imagem rotacionada e sobreamostrada. Retirado de (DO; VETTERLi, 2005). . . . . . . . . . . . . . . . 51

Figura 19 - Resultado usando detecção de contornos com diferentes transformadas. Imagem reconstruída apenas com os coeficientes de detalhes. . . . . . . 53

Figura 20 - Hiperplanos de separação ótimo (linha em vermelho) e hiperplanos de suporte (linha tracejada). Adaptado de (LIMA, 2004). . . . . . . . . . 58

Figura 21 - Estrutura de um ensemble. . . . . . . . . . . . . . . . . . . . . . 62

Figura 22 - Motivações para o uso de ensemble. Retirado de Lima(2004) (LIMA, 2004). 64

Figura 23 - Ensemble baseado na variação dos parâmetros da técnica de extração de características. . . . . . . . . . . . . . . . 70 
Figura 24 - Ensemble baseado na variação dos parâmetros da técnica de extração de características e do parâmetro do classificador. . . . . . . . . . . . 70

Figura 25 - Ensemble baseado na variação do modelo do classificador. . . . . . . . 70

Figura 26 - Ensemble baseado em diferentes técnicas de extração de características. 71

Figura 27 - Ensemble baseado em diferentes técnicas de extração de características usando o melhor classificador. . . . . . . . . . . . . . . . . . . 71

Figura 28 - Níveis de fusão em sistemas biométricos multimodais. . . . . . . . . . . 72

Figura 29 - Estratégias baseadas na troca de coeficientes extraídas da face e íris. $\quad 73$

Figura 30 - Estratégias baseadas nos coeficientes extraídos da face e íris. . . . . . . 74

Figura 31 - Ensemble baseado na variação dos parâmetros da técnica de extração de características usando o mesmo classificador e mesma estratégia de fusão. . . . . . . . . . . . . . . . . . . . . .

Figura 32 - Ensemble baseado na variação dos parâmetros da técnica de extração de característica e do parâmetro do classificador usando a mesma estratégia de fusão. . . . . . . . . . . . . . . . . . . . . . . . . . .

Figura 33 - Ensemble baseado na variação do modelo do classificador usando mesma configuração para as transformada e estratégia de fusão. . . . . . . . . .

Figura 34 - Ensemble baseado em diferentes técnicas de extração de características usando o mesmo classificador.

Figura 35 - Ensemble baseado em diferentes técnicas de extração de características usando melhor estratégia de fusão e classificador. . . . . . . . . . . . . 76

Figura 36 - Sistema multimodal usando fusão no nível de decisão baseado nas melhores SVMs construídas para face e íris. . . . . . . . . . . . . . 7

Figura 37 - Sistema multimodal usando fusão no nível de decisão baseado nas melhores LS-SVMs construídas para face e íris.

Figura 38 - Sistema multimodal usando fusão no nível de decisão baseado nos melhores classificadores obtidos para face e íris. . . . . . . . . . . . 77

Figura 39 - Imagens da face obtidas sob diferentes ângulos de visão. . . . . . . . . 78

Figura 40 - Imagens da face obtidas sob variações nas condições do ambiente. . . . 78

Figura 41 - Exemplo de imagens de íris obtidas da base de dados SDUMLA-HMT. 79 Figura 42 - Método utilizado para gerar o conjunto de dados nos sistemas multimodais. 81 Figura 43 - Curva com a Taxa de Falsa Aceitação versus Taxa de Falsa Rejeição alcançada pelo melhor sistema unimodal baseado em face. . . . . . . . 114 
Figura 44 - Distribuição das taxas de erro geradas pelo melhor sistema baseado em face para cada classe. . . . . . . . . . . . . . . . . . 114

Figura 45 - Distribuição das saídas geradas pelo melhor sistema unimodal baseado em face para a classe \#53. . . . . . . . . . . . . . . . . . . 115

Figura 46 - Distribuição das taxas de erro geradas pelo melhor sistema unimodal baseado em face para cada pose. . . . . . . . . . . . . . 115

Figura 47 - Distribuição das imagens classificadas incorretamente por classe geradas pelo melhor sistema unimodal baseado em face para a pose \#1. . . . . 116

Figura 48 - Distribuição das taxas de erro geradas pelo melhor sistema unimodal baseado em face para diferentes variações nas condições do ambiente. . 116

Figura 49 - Distribuição das imagens classificadas incorretamente por classe geradas pelo melhor sistema unimodal baseado em face para a variação no ambiente $\# 9 . \ldots \ldots \ldots$. . . . . . . . . . . . . . . . 117

Figura 50 - Curva com a Taxa de Falsa Aceitação versus Taxa de Falsa Rejeição alcançada pelo melhor ensemble envolvendo sistemas unimodais baseado em face. . . . . . . . . . . . . . . . . . . . . . 117

Figura 51 - Distribuição das taxas de erro geradas pelo melhor ensemble envolvendo sistemas unimodais baseado em face para cada classe. . . . . . . . . . . 118

Figura 52 - Distribuição das saídas geradas pelo melhor ensemble envolvendo sistemas unimodais baseado em face para a classe \#78. . . . . . . . . . . . 118

Figura 53 - Distribuição das taxas de erro geradas pelo melhor ensemble envolvendo sistemas unimodais baseado em face para cada pose. . . . . . . . . . . 119

Figura 54 - Distribuição das imagens classificadas incorretamente por classe geradas pelo melhor ensemble envolvendo sistemas unimodais baseado em face

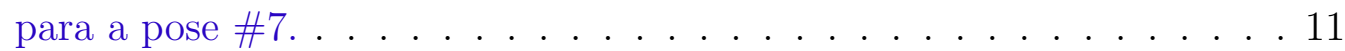

Figura 55 - Distribuição das taxas de erro geradas pelo melhor ensemble envolvendo sistemas unimodais baseado em face para diferentes variações nas condições do ambiente. . . . . . . . . . . . . . . . . . . . . . . . 119

Figura 56 - Distribuição das imagens classificadas incorretamente por classe pelo ensemble envolvendo sistemas unimodais baseado em face para a variação no ambiente \#9.

Figura 57 - Curva com a Taxa de Falsa Aceitação versus Taxa de Falsa Rejeição alcançada pelo melhor sistema unimodal baseado em íris. . . . . . . . . 12 
Figura 58 - Distribuição das taxas de erro geradas pelo melhor sistema unimodal baseado em íris para cada classe. . . . . . . . . . . . . . . . . . . . 121

Figura 59 - Distribuição das saídas geradas pelo melhor sistema unimodal baseado em íris para a classe \#89. . . . . . . . . . . . . . . . . . . . . . . . . . 121

Figura 60 - Distribuição das taxas de erro obtida pelo melhor sistema unimodal baseado em íris para íris esquerda e direita. . . . . . . . . . . . . . 122

Figura 61 - Distribuição das taxas de erro obtida pelo melhor sistema unimodal baseado na íris direita para cada classe. . . . . . . . . . . . . . . . . . 122

Figura 62 - Curva com a Taxa de Falsa Aceitação versus Taxa de Falsa Rejeição alcançada pelo melhor ensemble envolvendo sistemas unimodais baseado em íris.

Figura 63 - Distribuição das taxas de erro obtida pelo melhor ensemble envolvendo sistemas unimodais baseado em íris para cada classe. . . . . . . . . . . .

Figura 64 - Distribuição das saídas geradas pelo melhor ensemble envolvendo sistemas unimodais baseado em íris para a classe \#10. . . . . . . . . . . . . 124

Figura 65 - Distribuição das taxas de erro geradas pelo melhor ensemble envolvendo sistemas unimodais baseado em íris para íris esquerda e direita. . . . . 124

Figura 66 - Distribuição das taxas de erro geradas pelo melhor ensemble envolvendo sistemas unimodais baseado na íris direita para cada classe.

Figura 67 - Curva com a Taxa de Falsa Aceitação versus Taxa de Falsa Rejeição alcançada pelo melhor sistema multimodal. . . . . . . . . . . . . . . 125

Figura 68 - Distribuição das taxas de erro geradas pelo melhor sistema multimodal para cada classe.

Figura 69 - Distribuição das saídas geradas pelo melhor sistema multimodal para a classe \#13.

Figura 70 - Distribuição das taxas de erro obtidas pelo melhor sistema multimodal para cada pose. . . . . . . . . . . . . . . . . . 126

Figura 71 - Distribuição das imagens classificadas incorretamente por classe geradas pelo melhor sistema multimodal para a pose \#7.

Figura 72 - Distribuição das taxas de erro geradas pelo melhor sistema multimodal para diferentes variações nas condições do ambiente. . . . . . . . . . . 127

Figura 73 - Distribuição das imagens classificadas incorretamente por classe geradas pelo melhor sistema multimodal para a variação no ambiente \#7. 
Figura 74 - Curva com a Taxa de Falsa Aceitação versus Taxa de Falsa Rejeição alcançada pelo melhor ensemble envolvendo sistemas multimodais. . . . 128

Figura 75 - Distribuição das taxas de erro obtida pelo melhor ensemble envolvendo sistemas multimodais para cada classe. . . . . . . . . . . . . . . . . . 129

Figura 76 - Distribuição das saídas geradas pelo melhor ensemble envolvendo sistemas multimodais para a classe \#10. . . . . . . . . . . . . . . . . 129

Figura 77 - Distribuição das taxas de erro geradas pelo melhor ensemble envolvendo sistemas multimodais para cada pose. . . . . . . . . . . . . . . . . 130

Figura 78 - Distribuição das imagens classificadas incorretamente por classe geradas pelo melhor ensemble envolvendo sistemas multimodais para a pose \#7. 130

Figura 79 - Distribuição das taxas de erro geradas pelo melhor ensemble envolvendo sistemas multimodais para diferentes variações nas condições do ambiente.131

Figura 80 - Distribuição das imagens classificadas incorretamente por classe geradas pelo melhor ensemble envolvendo sistemas multimodais para a variação no ambiente $\# 7 . \ldots \ldots \ldots$

Figura 81 - Comparação da taxa de erro por classe gerada pelos melhores sistemas biométricos abordados nesta dissertação . . . . . . . . . . . . . . . . . 132

Figura 82 - Comparação da taxa de erro por pose gerada pelos melhores sistemas biométricos abordados nesta dissertação. . . . . . . . . . . . . . . . 133

Figura 83 - Comparação da distribuição das taxas de erro obtidas pelo melhores sistemas biométricos para diferentes variações nas condições do ambiente.133 


\section{Lista de tabelas}

Tabela 1 - Funções Kernel mais utilizadas. . . . . . . . . . . . . . . . . 57

Tabela 2 - Configurações utilizadas por cada técnica de extração de características. 80

Tabela 3 - Resultados obtidos usando a transformada Wavelet para a face. . . . . 82

Tabela 4 - Resultados obtidos usando a transformada Contourlet para a face. . . . 83

Tabela 5 - Resultados obtidos usando a transformada Curvelet para a face. . . . . 84

Tabela 6 - Resultados obtidos usando a transformada Wavelet para a íris. . . . . . 84

Tabela 7 - Resultados obtidos usando a transformada Contourlet para a íris. . . . 85

Tabela 8 - Resultados obtidos usando a transformada Curvelet para a íris. . . . . 85

Tabela 9 - Resultados obtidos usando a concatenação dos coeficientes extraídos da face e íris via transformada Wavelet. . . . . . . . . . . . . . . . . . 87

Tabela 10 - Resultados obtidos usando os coeficientes de aproximação da face e detalhes da íris extraídos via transformada Wavelet. . . . . . . . . . . . 88

Tabela 11 - Resultados obtidos usando os coeficientes de aproximação da íris e os detalhes da face extraídos via transformada Wavelet. . . . . . . . . . . 88

Tabela 12 - Resultados obtidos usando a estratégia de fusão baseada na detecção de contornos e a transformada Wavelet. . . . . . . . . . . . . . . 89

Tabela 13 - Resultados obtidos usando o mínimo dos coeficientes de aproximação e o máximo dos coeficientes de detalhes extraídos via transformada Wavelet. . . . . . . . . . . . . . . . . . . . 8 89

Tabela 14 - Resultados obtidos usando a média dos coeficientes de aproximação e o máximo dos coeficientes de detalhes extraídos via transformada Wavelet. 90

Tabela 15 - Resultados obtidos usando a soma dos coeficientes extraídos das imagens de face e íris via transformada Wavelet. . . . . . . . . . . . . . . . . . 91

Tabela 16 - Resultados obtidos usando a concatenação dos coeficientes extraídos da face e íris via transformada Contourlet. . . . . . . . . . . . . . . . . . . 91

Tabela 17 - Resultados obtidos usando os coeficientes de aproximação da face e os coeficientes de detalhes da íris extraídos via transformada Contourlet. . 92

Tabela 18 - Resultados obtidos usando os coeficientes de aproximação da íris e os coeficientes detalhes da face extraídos via transformada Contourlet. . . 93

Tabela 19 - Resultados obtidos usando a estratégia de fusão baseada na detecção de contornos e a transformada Contourlet. . . . . . . . . . . . . . . . . 93 
Tabela 20 - Resultados obtidos usando o mínimo dos coeficientes de aproximação e o máximo dos coeficientes de detalhes extraídos via transformada Contourlet. .......................... 94

Tabela 21 - Resultados obtidos usando a média dos coeficientes de aproximação e o máximo dos coeficientes de detalhes extraídos via transformada

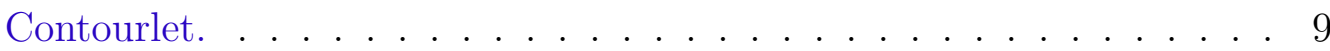

Tabela 22 - Resultados obtidos usando a soma dos coeficientes extraídos das imagens de face e íris pela transformada Contourlet. . . . . . . . . . . . . . . . 95

Tabela 23 - Resultados obtidos usando a concatenação dos coeficientes extraídos da face e íris via transformada Curvelet . . . . . . . . . . . . . . . . 96

Tabela 24 - Resultados obtidos usando os coeficientes de aproximação da face e os coeficientes de detalhes da íris extraídos via transformada Curvelet. . .

Tabela 25 - Resultados obtidos usando os coeficientes de aproximação da íris e os coeficientes de detalhes da face extraídos via transformada Curvelet. 97

Tabela 26 - Resultados obtidos usando a estratégia de fusão baseada na detecção de contornos e a transformada Curvelet. . . . . . . . . . . . . . . 97

Tabela 27 - Resultados obtidos usando o mínimo dos coeficientes de aproximação e o máximo dos coeficientes de detalhes extraídos via transformada Curvelet.

Tabela 28 - Resultados obtidos usando a média dos coeficientes de aproximação e o máximo dos coeficientes de detalhes extraídos via transformada Curvelet. 98

Tabela 29 - Resultados obtidos usando a soma dos coeficientes extraídos das imagens de face e íris via transformada Curvelet. . . . . . . . . . . . . . . . . . 99

Tabela 30 - Melhores resultados obtidos pelos sistemas biométricos multimodais. . 100

Tabela 31 - Resultados obtidos pelos ensembles usando classificadores construídos com base nos coeficientes da transformada Wavelet extraídos da face. . 101

Tabela 32 - Resultados obtidos pelos ensembles usando classificadores construídos com base nos coeficientes da transformada Contourlet extraídos da face. 101

Tabela 33 - Resultados obtidos pelos ensembles usando classificadores construídos com base nos coeficientes da transformada Curvelet extraídos da face. . 102

Tabela 34 - Resultados obtidos pelos ensembles usando classificadores construídos com base nos coeficientes de diferentes transformadas extraídos da face. 103 
Tabela 35 - Resultados obtidos pelos ensembles usando classificadores construídos com base nos coeficientes da transformada Wavelet extraídos da íris. 104

Tabela 36 - Resultados obtidos pelos ensembles usando classificadores construídos com base nos coeficientes da transformada Contourlet extraídos da íris. 104

Tabela 37 - Resultados obtidos pelos ensembles usando classificadores construídos com base nos coeficientes da transformada Curvelet extraídos da íris. 105

Tabela 38 - Resultados obtidos pelos ensembles usando classificadores construídos com base nos coeficientes de diferentes transformadas extraídos da íris. 105

Tabela 39 - Estratégias de fusão usadas nos sistemas multimodais que produziram melhor e pior desempenho. . . . . . . . . . . . . . 106

Tabela 40 - Resultados obtidos pelos ensembles envolvendo sistemas multimodais construídos usando a soma dos coeficientes da transformada de Wavelet.107

Tabela 41 - Resultados obtidos pelos ensembles envolvendo sistemas multimodais construídos usando a concatenação dos coeficientes da transformada de Wavelet. . . . . . . . . . . . . . . . . . 107

Tabela 42 - Resultados obtidos pelos ensembles envolvendo sistemas multimodais construídos usando a soma dos coeficientes da transformada de Contourlet.108

Tabela 43 - Resultados obtidos pelos ensembles envolvendo sistemas multimodais construídos usando o mínimo dos coeficientes de aproximação e máximo dos coeficientes de detalhes da transformada de Contourlet. . . . . . . 109

Tabela 44 - Resultados obtidos pelos ensembles envolvendo sistemas multimodais construídos usando a detecção de contornos e a transformada de Curvelet.110

Tabela 45 - Resultados obtidos pelos ensembles envolvendo sistemas multimodais construídos usando a concatenação dos coeficientes da transformada de Curvelet. . . . . . . . . . . . . . . . . . 110

Tabela 46 - Resultados obtidos pelos ensembles envolvendo os melhores sistemas multimodais construídos por cada transformada. . . . . . . . . . . 111

Tabela 47 - Resultados obtidos com sistemas multimodais com fusão no nível de decisão. . . . . . . . . . . . . . . . . . . . . 112

Tabela 48 - Melhores resultados obtidos com sistemas unimodais, multimodais e seus respectivos ensembles. . . . . . . . . . . . . . . . . 113

Tabela 49 - Variação da taxa de erro gerada pelos sistemas biométricos ao utilizar o ponto de cruzamento das curvas de FAR e FRR como limiar de decisão.132 


\section{Sumário}

$1 \quad$ Introdução . . . . . . . . . . . . . . . . . . . 20

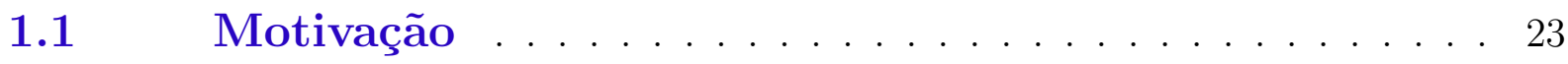

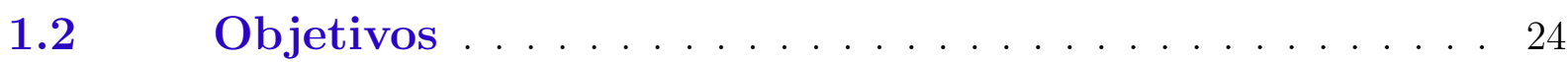

1.3 Estrutura da dissertação . . . . . . . . . . . . . . . 24

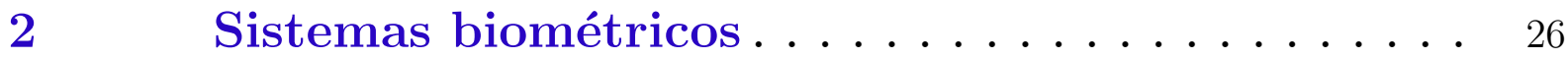

2.1 Sistemas biométricos unimodais . . . . . . . . . . 26

2.1.1 Sistemas biométricos baseados em face . . . . . . . . . . . 30

2.1.1.1 Algoritmo de Viola-Jones . . . . . . . . . . . . . . . . . . . 30

2.1.2 Sistemas biométricos baseados em íris . . . . . . . . . . 33

2.1.2.1 Operador Integro-Diferencial _ . . . . . . . . . . . . . . . . 35

2.1.2.2 Método de Wildes e Camus . . . . . . . . . . . . . . . . . . . 35

2.1.2.3 Método de Daugman . . . . . . . . . . . . . . . . . 36

2.1.2.4 Transformada circular de Hough . . . . . . . . . . . . . . . 37

2.1.3 Análise de desempenho . . . . . . . . . . . . . . . . 37

$2.2 \quad$ Sistemas biométricos multimodais . . . . . . . . . . . 39

2.2.1 Niveis de fusão . . . . . . . . . . . . . . . . . . . . . . . 41

2.2.1.1 Anterior à comparação . . . . . . . . . . . . . . . . . . . . 41

2.2.1.2 Posterior à comparação . . . . . . . . . . . . . . . . . . . . . . 43

3 Técnicas de extração de características . . . . . . . 47

3.1 Transformada Wavelet . . . . . . . . . . . . . . . 47

3.2 Transformada Contourlet . . . . . . . . . . . . . . . 49

3.3 Transformada Curvelet . . . . . . . . . . . . . . . . . . 51

3.4 Comparação de técnicas . . . . . . . . . . . . 53

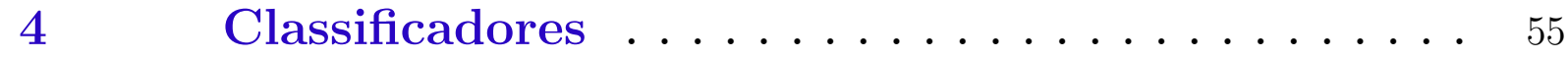

$4.1 \quad$ Máquinas de Vetores Suporte . . . . . . . . . . . 57

4.1 .1 Formulação . . . . . . . . . . . . . . . . . . . . 58

4.2 Máquina de vetores suporte baseada em quadrados mínimos . . . . . . . . . . . . . . . . . . . . . . 59 
$4.3 \quad$ Comitês de máquinas . . . . . . . . . . . . . 61

4.3.1 Ensembles . . . . . . . . . . . . . . . . . . . . . . 62

4.3.2 Geração de componentes . . . . . . . . . . . . . . . . . 64

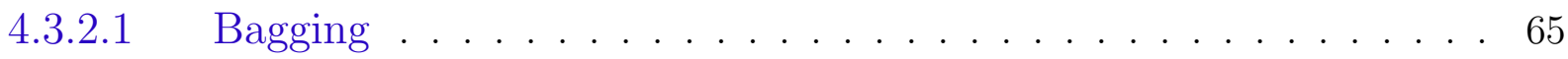

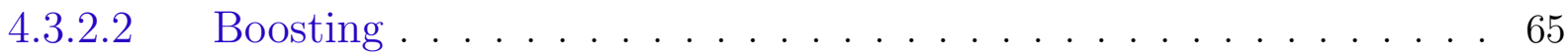

4.3.3 Seleção de classificadores . . . . . . . . . . . . . 66

4.3.3.1 Abordagem construtiva . . . . . . . . . . . . . . 67

4.3.3.2 Abordagem de poda . . . . . . . . . . . . . . . . 67

4.3.4 Combinação de Classificadores . . . . . . . . . . . . . . 67

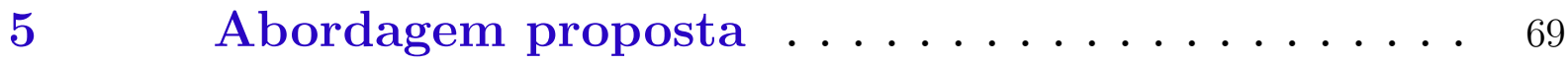

5.1 Construção dos sistemas biométricos unimodais . . . . . 69

5.2 Construção dos sistemas biométricos multimodais . . . 71

$6 \quad$ Resultados Experimentais . . . . . . . . . . 78

6.1 Experimentos Computacionais . . . . . . . . . 78

6.1.1 Base de dados utilizada . . . . . . . . . . . . . 78

6.1.2 Pré-processamento das imagens de face . . . . . . . . . . 79

6.1.3 Pré-processamento das imagens de íris . . . . . . . . . . . 79

6.1.4 Extração de características . . . . . . . . . . . . . . . . . 80

6.1.5 Configuração dos experimentos . . . . . . . . . . . . 80

6.2 Resultado para os sistemas biométricos unimodais . . 82

6.2.1 Sistemas biométricos baseados em face . . . . . . . . . . 82

6.2.2 Sistemas biométricos baseados em íris . . . . . . . . . . . 84

6.3 Resultado para os sistemas biométricos multimodais . 87

6.3.1 Transformada Wavelet . . . . . . . . . . . . . . . . 87

6.3.2 Transformada Contourlet . . . . . . . . . . . . . . . . . 91

6.3.3 Transformada Curvelet . . . . . . . . . . . . . . . . 96

6.3.4 Melhores sistemas multimodais . . . . . . . . . . . . . . 99

6.4 Resultado obtido usando Ensemble . . . . . . . . . . . 100

6.4.1 Ensemble envolvendo sistemas unimodais baseados em face . . . . . . . . . . . . . . . . . . . . 100

6.4.2 Ensemble envolvendo sistemas unimodais baseados em íris103 
6.4.3 Ensemble envolvendo sistemas multimodais . . . . . . . 106

6.4.3.1 Transformada Wavelet . . . . . . . . . . . . . . . . . . . . 106

6.4.3.2 Transformada Contourlet . . . . . . . . . . . . . . . . . . . . . . 108

6.4.3.3 Transformada Curvelet . . . . . . . . . . . . . . . . . . . . . . . . . 110

6.4.3.4 Diferentes transformadas . . . . . . . . . . . . . . . . . . 111

6.4.3.5 Fusão no Nível de decisão . . . . . . . . . . . . . . . . . . . . . . 112

6.5 Estudo comparativo envolvendo os melhores resultados112

6.5.1 Melhor sistema biométrico unimodal baseado em face . . 113

6.5.2 Melhor ensemble envolvendo sistemas biométricos unimodais baseado em face . . . . . . . . . . . . . . . . 117

6.5.3 Melhor sistema biométrico unimodal baseado em íris . . 120

6.5.4 Melhor ensemble envolvendo sistemas biométricos unimodais baseado em íris . . . . . . . . . . . . . . . . . . . 122

6.5.5 Melhor sistema biométrico multimodal . . . . . . . . . . . . 125

6.5.6 Melhor ensemble envolvendo sistemas biométricos mul-

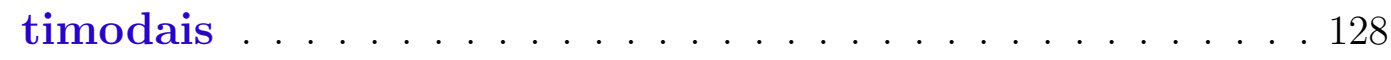

6.5.7 Taxa de Falsa Aceitação e Falsa Rejeição . . . . . . . . . . 131

6.5.8 Estudo comparativo . . . . . . . . . . . . . . . . 132

$7 \quad$ Conclusão . . . . . . . . . . . . . . . . . . . . . . 134

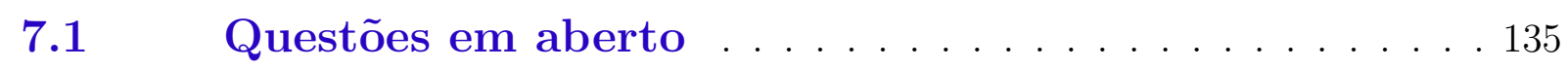

7.2 Publicações vinculadas a dissertação . . . . . . . . . 136

Referências $^{1} \ldots \ldots \ldots \ldots \ldots \ldots$

$\overline{1}$ De acordo com a Associação Brasileira de Normas Técnicas. NBR 6023. 


\section{Introdução}

Na sociedade atual, a identificação automática, precisa e rápida dos indivíduos é uma necessidade cada vez mais crescente. Estratégias tradicionais de reconhecimento de identidade incluem itens, tais como números PIN, tokens e senhas. Entretanto, com o avanço da tecnologia essas técnicas tornaram-se mais susceptíveis a fraudes, trazendo preocupações no que diz respeito à sua facilidade de aquisição e utilização por parte de terceiros não autorizados (JAIN; FLYNN; ROSS, 2007). De acordo com o relatório da CSN (Consumer Sentinel Network (THE..., 2012)) de 2012, o roubo de identidade foi o crime mais denunciado nos Estados Unidos (um milhão de casos de reclamações). Como o roubo de identidade pode assumir diferentes formas, a falsificação de documentos/benefícios públicos $(46 \%)$ foi a mais proeminente, seguida por fraude de cartão de crédito (13\%), fraude usando telefones e similares (10\%), fraudes bancárias (6\%), fraudes relacionadas ao emprego (5\%) e outras. Entre esses casos, a falsificação de identidade parece ser a maior ameaça.

Neste contexto, existe um crescente incentivo ao uso da tecnologia biométrica para melhorar, e até mesmo substituir, os métodos convencionais de segurança. De fato, sistemas de identificação baseados em biometria representam uma alternativa para abordagens convencionais. O campo da Biometria refere-se a uma variedade de tecnologias usadas para identificar uma pessoa por meio da mensuração e análise de aspectos físicos e comportamentais do ser humano (AL-RAISI; AL-KHOURI, 2008).

As modalidades físicas incluem impressão digital, geometria da mão, padrão da orelha, padrão do olho (íris e retina) e características faciais. Já as modalidades comportamentais incluem voz, assinatura, padrão de digitação e outros. O fato das modalidades biométricas estarem ligadas diretamente a alguma característica dos usuários consiste numa possibilidade extraordinária para superar os problemas de segurança causados pelas estratégias tradicionais de reconhecimento, sendo mais difíceis de serem roubadas ou falsificadas quando comparadas a técnicas convencionais.

Nos últimos anos, o reconhecimento biométrico sofreu avanços significativos em termos de confiabilidade e precisão, sendo que algumas modalidades biométricas alcançaram um bom desempenho em aplicações práticas. No entanto, mesmo os sistemas biométricos mais avançados ainda enfrentam alguns problemas, tais como (ROSS; JAIN, 2003): 
- Problemas com dados oriundos dos sensores: dados capturados pelos sensores são frequentemente afetados por ruído devido a condições do ambiente (insuficiência de luz, energia, etc) ou devido às condições fisiológicas e físicas do usuário (frio, dedos machucados, etc).

- Capacidade de distinguibilidade: nem todas as modalidades biométricas tem o mesmo grau de distinguibilidade (por exemplo, sistemas biométricos baseados na geometria da mão são menos seletivos que aqueles baseados na impressão digital).

- Falta de universalidade: todas as modalidades biométricas são universais, mas devido a grande complexidade do corpo humano nem todo mundo apresenta todas as modalidades biométricas que um sistema pode permitir.

- Variabilidade intraclasse: significa que as modalidades biométricas podem variar com o tempo para uma mesma pessoa e essa variação é imprevisível de pessoa para pessoa. Por exemplo, à medida que uma pessoa envelhece podem ocorrer mudanças na sua voz.

De forma a utilizar diferentes características biométricas em conjunto, buscando assim gerar sistemas que conseguem superar as dificuldades encontradas nos sistemas unimodais, foram propostos em (JAIN; ROSS, 2004) os sistemas biométricos multimodais. A área de biometria multimodal apresentam as seguintes vantagens em relação às abordagens unimodais:

- Melhora no desempenho de reconhecimento - diferentes modalidades medem informações complementares e por esta virtude podem encontrar melhor desempenho;

- Melhora na robustez do sistema frente a variações do ambiente - todas as modalidades biométricas sofrem com algum tipo de interferência do ambiente, logo ao se realizar a fusão de duas modalidades, espera-se uma redução no nível de interferência do ambiente;

- Diminui o problema da não-universalidade - ao se utilizar mais de uma modalidade biométrica existe uma maior probabilidade de cobertura da população;

- Gera uma boa defesa contra ataques por circunvenção e repetição - o grau de dificuldade para que mais de uma modalidade biométrica seja falsificada ao mesmo tempo é maior, além de que essas características podem ser captadas de maneira aleatória. 
Embora as necessidades de armazenamento e de tempo de processamento sejam maiores nos sistemas biométricos multimodais em relação aos sistemas biométricos unimodais, as vantagens mencionadas representam um argumento convincente para a implantação desses sistemas em aplicações de mundo real (BALA, 2008).

Para a construção de um sistema multimodal é necessário realizar a combinação de duas, ou mais, modalidades biométricas. Essa união pode ser realizada de diferentes maneiras e são categorizadas de acordo com a sua arquitetura, nível de fusão e estratégia de fusão (ROSS; JAIN, 2003). Esta divisão leva em consideração os módulos que compõem um sistema biométrico. A decisão da estratégia de combinação das modalidades trata-se de um dos principais pontos a serem considerados no projeto de um sistema biométrico multimodal (ROSS; NANDAKUMAR; JAIN, 2006).

Para a construção dos sistemas biométricos existem diferentes classificadores que podem ser utilizados sendo K-Vizinhos Mais Próximos (KNN) (WANG et al., 2009)(GUESMI et al., 2012), Redes Neurais (RNA) (JEMAA; KHANFIR, 2008), Máquinas de Vetores Suporte (SVM) (FARUQE; HASAN, 2009) e Máquinas de Vetores Suporte baseadas em Quadrados Mínimos (LS-SVM) (SHEN; LIU, 2009) os mais utilizados. Esses classificadores apresentam a necessidade de uma boa configuração dos seus parâmetros para se obter um bom desempenho sobre o problema.

De forma a superar as dificuldades da construção de um determinado classificador foi proposta por Nilsson (NILSSON et al., 1965) a abordagem chamada de Comitês de Máquinas, sendo a primeira estrutura composta por uma rede neural com uma camada de perceptrons elementares seguidos por um perceptron responsável por realizar um esquema de votação na segunda camada. Os Comitês de máquinas são aproximadores universais (HAYKIN, 2008) e podem se apresentar em versões estáticas, denominadas ensemble de componentes, ou então em versões dinâmicas, denominadas misturas de especialistas.

Nesta dissertação foi investigado o emprego de ensemble para fusão das modalidades biométricas, considerando diferentes estratégias de fusão, diferentes técnicas de processamento de imagens (tais como as transformadas Wavelet, Contourlet e Curvelet) e as Máquinas de Vetores Suporte (SVM) (VAPNIK, 1995) e Máquinas de Vetores Suporte Baseadas em Quadrados Mínimos (LS-SVM) (SUYKEnS; VANDEWALLE, 1999) como classificadores, sendo que apresentam como principal característica a utilização de uma função matemática, chamada de função Kernel, para realizar a projeção de dados não-linearmente 
separáveis em um espaço, geralmente de maior dimensionalidade, aonde esses dados podem vir a ser linearmente separáveis.

\subsection{Motivação}

Durante o levantamento de trabalhos envolvendo a construção dos sistemas biométricos unimodais foram localizadas um conjunto de técnicas de extração de características que poderiam ser utilizadas para ambas as modalidades biométricas aqui abordadas, face e íris. Com base nesse levantamento bibliográfico foram escolhidas as seguintes técnicas: transformadas Wavelet (BURRUS; GOPINATH; GUO, 1998), Contourlet (DO; VETTERLI, 2005) e Curvelet (CANDèS; DONOHO, 2000).

Essas transformadas foram utilizadas em diferentes trabalhos envolvendo a construção de sistemas unimodais baseados em face (DEZHONG; FAYI, 2008)(LIU; ZHANG; ZHU, 2012)(WANG et al., 2011)(WANG et al., 2008)(ZHANG; YU; GU, 2012), íris (BIRGALE; KOKARE, 2009)(SHI; GU, 2010)(ZHAI et al., 2010)(GUESMI et al., 2012) e sistemas multimodais (HARIPRASATH; PRABAKAR, 2012)(XU et al., 2013)(DANDAWATE; INAMDAR, 2015). Nesses trabalhos, estas transformadas obtiveram taxas de acerto superiores a $90 \%$ para as bases utilizadas independente do tipo de sistema analisado, mostrando a potencialidade dessas técnicas para a construção de sistemas biométricos.

Para a construção dos sistemas biométricos multimodais tem-se que a combinação das características pode ser realizada em dois momentos distintos:

- Anterior a Comparação - realiza a combinação dos dados de entrada (THARWAT; IBRAHIM; ALI, 2012), ou das características extraídas (ROSS; ROHIN, 2005), antes de passar para o classificador;

- Posterior a Comparação - realiza a combinação no nível de comparação (ROSS; JAIN, 2003), combina-se os valores de saída dos classificadores para a tomada da decisão final, ou no nível de decisão (KINNUNEN; HAUTAMAKI; FRANTI, 2004), realiza a combinação das saídas de cada classificador para tomar a decisão final (MONWAR; GAVRILOVA, 2009).

Apesar das áreas de ensemble e sistemas biométricos multimodais, considerando a combinação das características após a comparação, apresentarem passos em comum e buscarem agregar, de alguma forma, o conhecimento de cada sistema criado de forma 
individualmente e, possivelmente, obterem uma solução superior a obtida pelos sistemas biométricos individuais, a abordagem baseada em ensemble tem sido pouco utilizada de forma a explorar a sua potencialidade.

Imbuído deste propósito foi investigado nessa dissertação se o desempenho obtido pelos sistemas biométricos unimodais e multimodais, construídos com estratégias de combinação no nível de característica e no nível de fusão, pode ser superado pelo uso de um conjunto de ensemble baseado em SVM e LS-SVM.

\subsection{Objetivos}

O objetivo principal deste trabalho é verificar a potencialidade do uso de ensemble na construção de sistemas biométricos, unimodais ou multimodais, baseados em face e íris, utilizando classificadores baseados em métodos de Kernel. Para tal objetivo ser alcançado, foram adotados os seguintes objetivos secundários:

- Levantamento de trabalhos envolvendo sistemas biométricos unimodais e multimodais, baseados em face e íris, de forma a descobrir técnicas de extração de características que podem ser utilizadas e os métodos de combinação possíveis para a construção dos sistemas multimodais;

- Implementação de diferentes abordagens para sistemas unimodais e multimodais, envolvendo o uso das máquinas de Kernel SVM e LS-SVM, de forma a analisar o possível ganho obtido com o uso dos sistemas multimodais;

- Propor a construção de diferentes modelos de ensemble envolvendo os sistemas biométricos, unimodais e multimodais, de forma a verificar a potencialidade do uso dessa abordagem para melhorar os sistemas individuais construídos;

\subsection{Estrutura da dissertação}

Os capítulos desta dissertação descrevem a teoria necessária para que cada um dos objetivos listados acima fossem alcançados e podem ser descritos como:

- Capítulo 1 inclui uma breve introdução, motivação, justificativa, objetivos e organização do texto; 
- Capítulo 2 apresenta a teoria sobre os sistemas biométricos, unimodais e multimodais, além das etapas de pré-processamento que foram utilizadas para as imagens de face e íris que foram utilizadas nesta dissertação;

- Capítulo 3 apresenta a teoria das transformadas Wavelet, Contourlet e Curvelet que foram utilizadas para realizar a extração de características das imagens de entrada;

- Capítulo 4 busca apresentar de forma simplificada os classificadores SVM e LS-SVM que foram utilizados para a construção dos módulos de classificação aqui, além de uma breve descrição sobre comitês de máquinas e algumas das formas de construção de ensemble;

- Capítulo 5 apresenta uma breve descrição das estratégias adotadas para a construção dos ensembles aqui propostos, base de dados utilizada, pré-processamento das imagens, extração de características e as configurações dos experimentos;

- Capítulo 6 apresenta todos os resultados obtidos com os sistemas biométricos unimodais e multimodais, baseados ou não em ensembles, para todas as abordagens propostas;

- Capítulo 7 contempla os comentários finais sobre os resultados obtidos e as questões em aberto que foram levantadas ao final deste trabalho. 


\section{Sistemas biométricos}

O primeiro emprego de uma característica biométrica para identificação de pessoas data de meados do século XIX, no qual o Departamento de Polícia de Paris a fim de identificar criminosos propôs usar medidas de seus corpos como forma de identificação. Esta ideia durou pouco tempo, pois no final do século XIX foi descoberto que a impressão digital fornece características capazes de identificar um indivíduo (JAIN; ROSS; PRABHAKAR, 2004).

Para que uma determinada característica humana possa ser utilizada como uma modalidade biométrica é necessário que alguns requisitos sejam satisfeitos (JAIN; ROSS; PRABHAKAR, 2004):

- Universalidade: todas as pessoas devem possuir essa característica;

- Distinção: duas pessoas diferentes devem possuir características distintas;

- Permanência: a característica deve ser invariante durante um determinado período de tempo;

- Mensurável: é necessário que a característica possa ser medida quantitativamente.

Se uma característica física ou comportamental apresentar todos esses requisitos, esta pode vir a ser utilizada como uma característica para identificação pessoal. Entretanto, outros requisitos são necessários para que essas características possam ser utilizadas em um sistema biométrico (JAIN; ROSS; PRABHAKAR, 2004):

- Desempenho: a característica deve ser adquirida e reconhecida de forma rápida e retornar a resposta corretamente;

- Aceitabilidade: deve ser o menos invasiva possível para que o usuário não se sinta desconfortável ao fornecer a característica;

- Circunvenção: deve ter propriedades que a torne mais difícil de ser burlada por métodos fraudulentos.

\subsection{Sistemas biométricos unimodais}

A primeira categoria de sistemas biométricos diz respeito aos sistemas biométricos unimodais, estes utilizam uma única característica biométrica para realizar o reconhecimento biométrico do usuário, sendo a impressão digital, face, íris, orelha, forma da mão e 
assinatura as principais características biométricas utilizadas (JAIN; ROSS; PRABHAKAR, 2004).

De acordo com (DELAC; GRGIC, 2004) um sistema biométrico unimodal pode ser visto como um sistema de reconhecimento de padrão, que por meio de um vetor de características, construído a partir de uma característica física ou comportamental do usuário, faz a identificação do mesmo. Um sistema biométrico unimodal pode ser decomposto em um conjunto de módulos (Figura 1) descritos como:

- Módulo Sensorial: módulo de entrada do sistema, responsável por fazer a captura da característica biométrica;

- Módulo de Extração de Característica: responsável por analisar a característica adquirida pelo módulo sensorial e extrair as características que serão utilizadas na construção do vetor de características;

- Módulo de Comparação: responsável por receber o vetor de características construído e comparar com os padrões armazenados na base de dados;

- Módulo de Decisão: verifica a resposta que o módulo de comparação retornou e analisa se o usuário é aceito ou não;

- Base de Dados: é responsável por armazenar todos os padrões dos usuários que irão fazer uso do sistema e fornecê-los para o módulo de comparação.

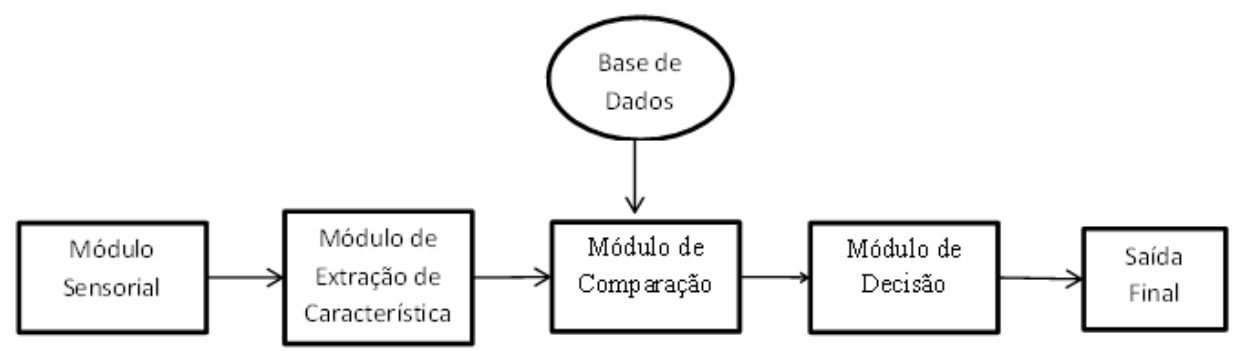

Figura 1 - Módulos de um sistema biométrico.

Para que seja possível fazer o reconhecimento de uma pessoa, é necessário que as características biométricas desta sejam previamente armazenadas para servir de modelo (padrão). Em função disso, os sistemas biométricos são constituídos de duas etapas: etapa de cadastramento e etapa de autenticação.

- Etapa de cadastramento - nesta etapa os dados biométricos do usuário são capturados, a partir dos quais são extraídas as informações relevantes para a autenticação do 
usuário gerando um padrão biométrico a ser gravado na base de dados. Este padrão é rotulado com a identidade do usuário (por exemplo com seu nome de usuário, número de identificação, etc) para facilitar sua autenticação.

- Etapa de autenticação - há dois modos de autenticação: a identificação e a verificação.

- Na identificação, o usuário fornece uma ou mais características das quais é extraído um padrão que é comparado com todos os padrões $(1: \mathrm{N})$ armazenados na base de dados, cabendo ao sistema identificar o usuário (Figura 2). A vantagem deste modo é que a autenticação é feita diretamente através do uso da biometria e verifica se o usuário está ou não presente no sistema.

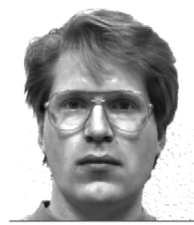

(1)

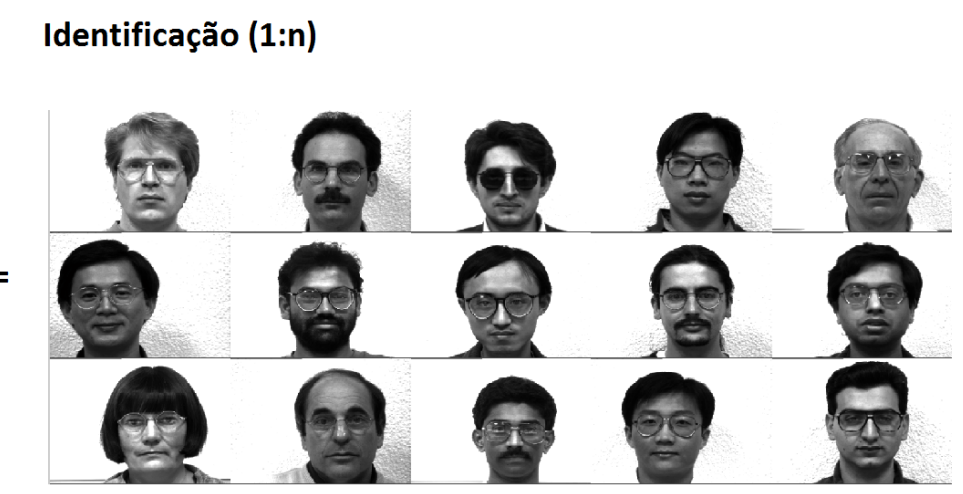

(2)

Pergunta: A imagem (1) está presente na Base de Dados (2)? Resposta: Se sim, retorna o Nome e o ID.

Figura 2 - Estrutura do modo de identificação.

- Na verificação, o usuário fornece uma ou mais característica, das quais é extraído o padrão, além de também fornecer sua identidade. Baseado nessa identidade, o sistema compara o padrão extraído com o armazenado daquela identidade (1:1) e ao final temos a confirmação ou não a identidade do usuário (Figura 3), basicamente o sistema verifica se o usuário é quem alega ser.

Embora os sistemas unimodais tenham muitas vantagens, estes podem vir a enfrentar alguns problemas (JAIN; ROSS, 2004):

- Dados ruidosos - os sensores utilizados para a captura das características podem adicionar ruído sobre os dados captados, o que dificulta a decisão correta do classificador aumentando as taxas de falsa rejeição. 


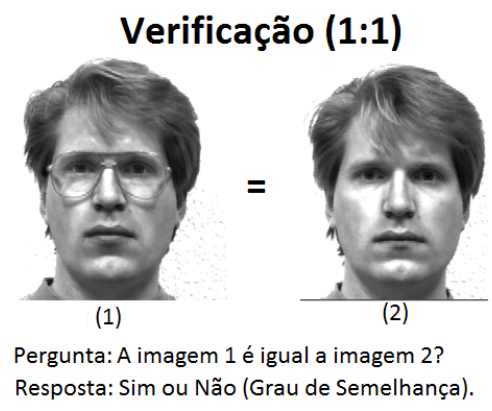

Figura 3 - Estrutura do modo de verificação.

- Variação intra-classe - os dados biométricos adquiridos durante a autenticação não serão idênticos aos dados armazenados durante o cadastro, sendo isso chamado de variação intra-classe, e geralmente é causada pelo mau uso do sistema pelo usuário ou mudança sobre o ambiente no qual o sensor está sendo utilizado.

- Distinção - mesmo que seja esperado que características biométricas apresentem uma boa variação entre usuários, pode acontecer de duas pessoas apresentarem uma grande similaridade em relação às características que são utilizadas no sistema, gerando assim possíveis falsas aceitações.

- Não universalidade - algumas pessoas podem não possuir uma característica biométrica, devido à doença ou deficiência.

- Falsificação - um impostor pode tentar falsificar uma característica biométrica de forma a obter acesso ao sistema.

Em (AKHTAR; MICHELONI; FORESTI, 2015) é realizada uma revisão sobre os tipos de ataques que os sistemas biométricos podem sofrer, além de uma breve descrição das possíveis formas de violar algumas das características biométricas mais utilizadas. Os ataques podem ser separados em ataques diretos, geralmente acontecem no módulo sensorial com a apresentação de uma característica biométrica falsificada, ou indiretos, podem atacar os módulos de extração ou de comparação, realizando manipulações sobre os padrões armazenados ou explorando pontos fracos nos canais de comunicação.

Uma das formas de tentar superar esses problemas, principalmente em relação a ataques diretos, é através do uso dos chamados sistemas biométricos multimodais que fazem o uso de duas ou mais características biométricas do usuário de forma a melhorar a segurança desses sistemas (JAIN; ROSS, 2004). 


\subsubsection{Sistemas biométricos baseados em face}

Neste tipo de sistema, a autenticação do usuário é realizada através do processamento de uma imagem contendo a sua face. Atualmente, juntamente com os sistemas baseados em impressão digital, trata-se da característica biométrica mais utilizada e foi considerado o primeiro sistema criado no século XIX (MASTALI; AGBINYA, 2010).

A primeira fase deste tipo de sistema realiza a localização da face na imagem de entrada. Após a sua localização, são aplicadas técnicas de extração de características tais como: distância entre boca e orelha, nariz e orelha, olho e nariz, olho e orelha, queixo e orelha, etc. Uma desvantagem da face é a grande variações intra-classe que pode ser causada pela presença de acessórios, causando oclusões, variação de iluminação, posicionamento da face e diferentes expressões (DHARAVATH; TALUKDAR; LASKAR, 2013).

Em (JAIN; ROSS; PRABHAKAR, 2004) e (MASTALI; AGBINYA, 2010) são levantados as principais vantagens do uso desses sistemas: (i)trata-se de um sistema não invasivo, o que aumenta o grau de aceitação dos usuários; (ii) apresentam um baixo custo para a sua implementação e (iii) consegue fornecer um bom desempenho na identificação/verificação dos usuários.

O funcionamento de um sistema baseado em face emprega no módulo sensorial uma câmera que realiza a captura da imagem. Em seguida utiliza algoritmos de detecção facial, sendo um dos mais conhecidos o Algoritmo de Viola-Jones (VIOLA; JONES, 2004), que destacam a face do usuário. Após destacar a face, as características podem ser extraídas.

\subsubsection{Algoritmo de Viola-Jones}

De forma a realizar a remoção de possíveis interferências causadas pelo ambiente nos sistemas biométricos baseados em face, geralmente são utilizados algoritmos que realização a detecção da região da face dentro de uma imagem. Esses algoritmos apresentam dificuldade para realizar a localização da face em ambientes não controlados, ou seja, com variação de iluminação, orientação, escala e pose, fazendo com que a maioria desse tipo de sistema seja construído em ambientes controlados (HONG; JAIN, 1998).

Uma das possíveis formas de realizar a detecção da face é através do Algoritmo de Viola-Jones (VIOLA; JONES, 2004). O primeiro passo desse algoritmo consiste em transformar a imagem de entrada em uma imagem integral, onde cada pixel da imagem 
integral é a soma de todos os pixels acima e a esquerda deste na imagem original, sendo definida através da Equação 1:

$$
i i(x, y)=\sum_{x^{\prime} \leq x, y^{\prime} \leq y} i\left(x^{\prime}, y^{\prime}\right),
$$

onde $i i(x, y)$ representa um pixel da imagem integral e $i\left(x^{\prime}, y^{\prime}\right)$ representa um pixel da imagem original. A Figura 4 apresenta um exemplo desse processo.
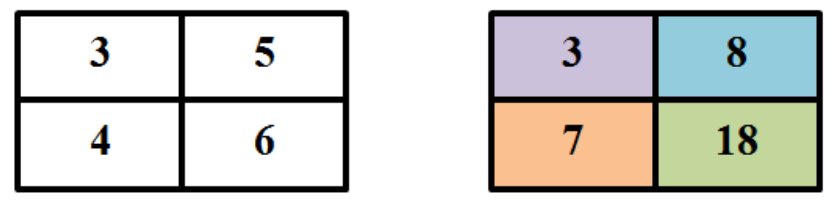

Figura 4 - Exemplo de construção de uma imagem integral. Cinza $=3$, Azul $=3+5$, Laranja $=3+4$ e Verde $=6+4+5+3$.

Ao final da construção da imagem integral é possível realizar o cálculo da soma de todos os pixels dentro de um determinado retângulo apenas através da soma de quatro valores. Este procedimento permite calcular a soma de todos os pixels dentro de qualquer retângulo usando somente quatro valores. Na Figura 5 para a descoberta do valor do pixel do quadrado $D$ na imagem original utiliza-se a Equação 2.

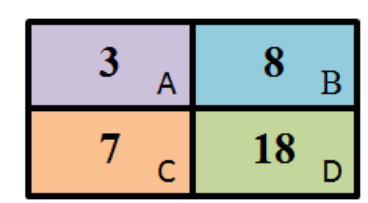

Figura 5 - Cálculo da soma de um retângulo.

$$
I(D)=D-B-C+A
$$

Dado que o retângulo $A$ está presente nos retângulos $B$ e $C$, é necessário ao final adicionar o valor de $A$, expandindo essa ideia para imagens maiores é possível verificar que o cálculo da soma dos pixels de uma determinada região pode ser realizado em um tempo linear $O(1)$.

O Algoritmo de Viola-Jones realiza a analise de uma determinada região da imagem através do uso de dois ou mais desses retângulos, sendo algumas das formas de análise apresentadas na Figura 6. Cada característica resulta em um único valor resultante da subtração dos valores dos retângulos brancos pelos valores dos retângulos pretos. 


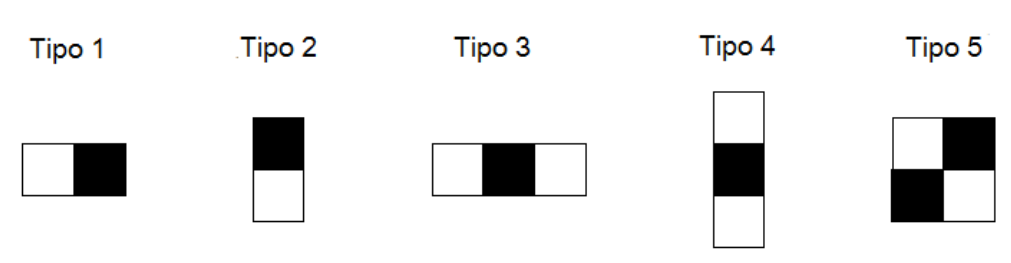

Figura 6 - Exemplos das características de Haar.

O Algoritmo de Viola-Jones foi construído com o uso de imagens de resolução de $24 \times 24$ pixels e com um total de 6060 características de Haar diferentes. Apesar do conjunto de características utilizado ser baseado nas imagens de resolução $24 \times 24$ e serem consideradas simples, elas possuem alta eficiência computacional e mesmo que uma característica de Haar seja analisada em uma imagem com resolução maior é esperado que ela apresente valor próximo ao valor obtido com essa característica nas imagens bases.

O principio básico do Algoritmo Viola-Jones é varrer a mesma imagem várias vezes, cada vez com um novo tamanho de janelas, visando localizar as faces nessa imagem. Pode-se verificar que uma grande quantidade das janelas analisadas produzirá resultados negativo, ou seja, não será uma face. Com isso, ao invés de confirmar que uma janela trata-se de uma face, este busca descartar as regiões de não faces.

Devido à natureza do problema foi verificado que a construção de um único classificador não seria capaz de alcançar o desempenho esperado. Em função disso, foi realizada a construção de um classificador em cascata baseado em uma modificação do Algoritmo Adaboost proposto por (FREUND; SCHAPIRE, 1999). Através da combinação de um conjunto de classificadores, chamados de fracos, realiza a construção de um sistema com uma alta taxa de confiabilidade.

O classificador em cascata foi treinado com diferentes quantidades de classificadores por nível, onde cada nível visa verificar se uma determinada janela trata-se de uma não face, de forma definitiva, ou de uma face. Quando uma dessas janelas é classificada, em algum dos níveis como não face, esta é automaticamente descartada. Por outro lado, quando esta é classificada como uma possível face, esta é enviada para o próximo nível da cascata. Esse procedimento é ilustrado na Figura 7

Uma das características desse classificador é que são esperados que regiões de não face fossem aceitas como face ao longo dos primeiros níveis do classificador. Entretanto, isto não deve ser um problema, já que os próximos níveis devem ser capazes de classificá-los como não face. Portanto, o algoritmo Viola-Jones produz a aceitação de muitas regiões de 


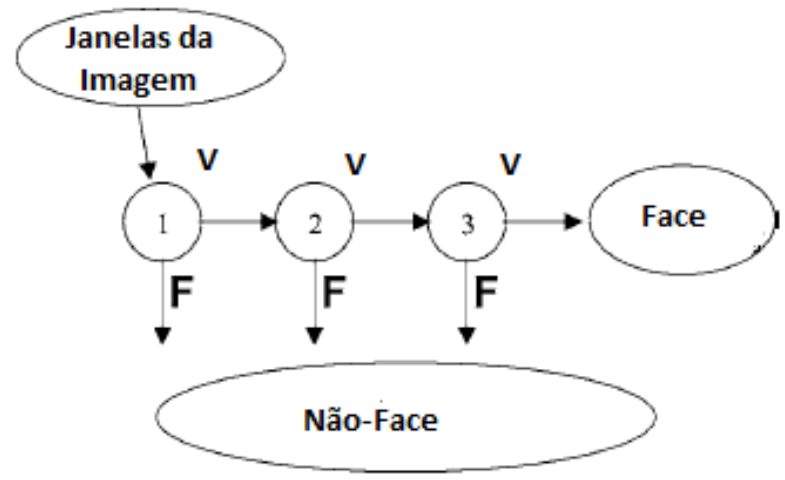

Figura 7 - Arquitetura do classificador em cascata. Adaptado de (VIOLA; JONES, 2004).

não face no estágio inicial. Consequentemente, a quantidade de não faces no estagio final de classificação deve ser muito menor.

Outra forma de classificar o Algoritmo de Viola-Jones é através do termo cascata de atenção, isto indica que uma análise com maior atenção (poder de computação) é realizada nas regiões onde tem a maior possibilidade de conter um face, para isso um determinado estágio $n$ devem ser treinados com as não faces que foram aceitas pelo estágio $n-1$.

Apesar do algoritmo Viola-Jones apresentar dificuldade na localização da face quando a imagem apresenta alguma variação em relação à pose do usuário e a iluminação do ambiente, este algoritmo apresenta um bom desempenho na detecção da face em sistemas biométricos baseados em face, visto que esses sistemas geralmente são utilizados em ambientes controlados.

Os sistemas biométricos baseados em face apresentaram um grande avanço, porém algumas dificuldades ainda são enfrentadas, tais como as dificuldades da localização da face em ambientes não controlados (DHARAVATH; TALUKDAR; LASKAR, 2013). Além das possíveis formas de falsificação que podem ser realizadas através do uso de fotografias, vídeos, máscaras, desenho, engenharia reversa baseada na face do usuário, maquiagem ou cirurgias plásticas (AKHTAR; MICHELONI; FORESTI, 2015), sendo algumas dessas possibilidades podem ser combatidas através das técnicas de deteç̧ão de presença de vida.

\subsubsection{Sistemas biométricos baseados em íris}

No ano de 1938 foi proposta por um oftalmologista a utilização da íris como um método de identificação de indivíduos. Essa ideia foi formalizada mais tarde por John Daugman (DAUGMAN, 2002), que desenvolveu algoritmos que realizam o reconhecimento 
baseado na íris. Embora o uso da íris não tenha grande destaque no cenário da biometria, esta é reconhecida como uma das modalidades mais confiáveis, pois possui uma criação morfológica completamente aleatória (PROENCA; ALEXANDRE, 2006) e permanece invariável ao longo de toda a vida humana (FLOM; SAFFIR, 1987), com exceção no caso de ocorrência de doenças.

A íris trata-se de um órgão externamente visível que possui proteção das pálpebras, sendo somente influenciada por padrões genéticos, o qual está em sua pigmentação. Apresenta as seguintes vantagens: i) não é afetada pelo envelhecimento; ii) por estar em uma região protegida, fica segura de danos ao longo da vida, ao contrário dos dedos e da face que podem sofrer danos por fazerem parte de um membro de manuseio (BLEHA; SLIVINSKY; HUSSIEN, 1990). Sendo que os principais problemas enfrentados por essa modalidade são: i) ruídos causados por reflexos na imagem; ii) pouca visibilidade dos olhos devido a cabelos, cílios ou outros objetos que possam diminuir a área visível da íris (CATARINO, 2009).

A íris começa a se formar durante o terceiro mês de gestação, sendo que ao final do oitavo mês de gestação o seu padrão já está completamente definido (BACHOO; TAPAMO, 2005). De acordo com (PROENCA; ALEXANDRE, 2006), o padrão é gerado de forma aleatória.

Apesar do uso da íris possibilitar o desenvolvimento de sistemas de alta confiabilidade, esta ainda não é amplamente utilizada. De acordo com (JAIN; ROSS; PRABHAKAR, 2004) os maiores problemas enfrentados por esta modalidade são os seguintes:

- Alto custo dos equipamentos necessários para fazer a captura da íris do usuário, sendo que recentemente esse custo vem sendo reduzido;

- Necessidade de um alto grau de envolvimento do usuário, o que em alguns casos pode causar desconforto e resistência deste, gerando assim um grau de aceitação baixo;

- Presença de ruído na captura da íris, tais como pálpebras, cílios e parte das sobrancelhas (CATARINO, 2009);

Uma das etapas mais importante para que o desempenho de um sistema biométrico baseado em íris seja satisfatório, trata-se da etapa de pré-processamento que deve ser capaz de detectar, segmentar a íris e gerar uma imagem de alta qualidade para o módulo de extração de características. Para a detecção da íris os principais métodos são o Método de 
Wildes e Camus (CAMUS; WILDES, 2002) e o Operador Integro-Diferencial(IDO) (DAUGMAN, 1993).

\subsubsection{Operador Integro-Diferencial}

O operador Integro-Diferencial (IDO) foi proposto por John Daugman (DAUGMAN, 1993). Essa técnica é a mais utilizadas em sistemas de baseados em íris, estando presente em aproximadamente 99,5\% dos sistemas comerciais (PROENCA; ALEXANDRE, 2006).

Esse algoritmo assume que a pupila e a íris do usuário apresentam forma circular e através da aplicação do operador Integro-Diferencial na imagem de entrada $I(x, y)$, é realizada a localização do máximo da derivada parcial no domínio da imagem $(x, y)$ (Equação 3):

$$
\max _{\left(r, x_{0}, y_{0}\right)}\left|G_{\sigma}(r) * \frac{\partial}{\partial r} \oint_{r, x_{0}, y_{0}} \frac{I(x, y)}{2 \pi r} d s\right|
$$

onde $*$ representa um operador de convolução, $I(x, y)$ representa a intensidade dos pixels da imagem contendo o olho, $r$ é o raio a ser procurado, $G_{\sigma}(r)$ trata-se uma função gaussiana de suavização e $s$ representa o contorno do círculo de raio $r$ com centro nas coordenadas $\left(x_{0}, y_{0}\right)$.

Este operador busca por um caminho circular, no qual há uma maior variação nos valores dos pixels para uma determinada variação no valor do raio e nas coordenadas $(x, y)$ representando o centro do círculo. O operador é aplicado ao mesmo tempo em que o grau de suavização é reduzido, isso é realizado de forma progressiva com o objetivo de conseguir uma localização precisa.

\subsubsection{Método de Wildes e Camus}

Em (CAMUS; WILDES, 2002) foi apresentada uma outra forma de realizar a detecção dos limites da íris e da pupila em uma imagem. Este algoritmo recebe uma imagem, em escala de cinza, e ao final é obtido um conjunto de pontos $\left(x, y, r_{i}, r_{p}\right)$, sendo que $(x, y)$, representa o centro da íris e da pupila, $r_{i}$, o raio da íris, $r_{p}$, o raio da pupila.

A primeira etapa do algoritmo define um conjunto de pontos candidatos de centro para cada vizinhança de $5 \times 5$ pixels, a serem analisados posteriormente, sendo selecionados todos os pixels com valores menores do que 128 e então o mínimo desses valores é marcado como ponto candidato. 
Após a definição dos pontos candidatos $C=\left[c_{1}, c_{2}, \ldots, c_{n}\right]$ é realizado para cada ponto candidato, $c_{i}$, o mapeamento da imagem original para um espaço polar $(r, \theta)$, onde $r$ representa a distância do limite até o centro $c_{i}$ e $\theta$ representa um ângulo polar. Nesse novo espaço é realizado a busca pelos possíveis limites da pupila e da íris através da Equação 4.

$$
F=\sum_{\theta=1}^{n}\left((n-1)\||g(\theta, r)|\|-\sum_{\phi=\theta+1}^{n}\||g(\theta, r)-g(\phi, r)|\|-\frac{g_{\theta, r}}{n},\right.
$$

onde $n$ representa o número de valores discretos a ser considerados na imagem polar $\theta$, e $g_{\theta, r}$ representa a derivada direcional da imagem em direções radiais. O primeiro termo da Equação 4 representa a soma ponderada dos gradientes enquanto que o segundo termo representa a uniformidade capturada nos gradientes.

De forma a localizar o possível limite da pupila $r_{p}$, para cada um dos pontos candidatos $c_{i}$, é realizado um processo de maximização da Equação 4. Com a localização do valor de $r_{p}$ é realizada novamente o mesmo processo de maximização, porém utilizando apenas pontos que estão fora do limite delimitado por $r_{p}$, de forma a localizar o valor de $r_{i}$. Para cada valor de $r_{p}$ e $r_{i}$ obtidos é verificado se $F$ teve seu valor incrementado. Caso isso aconteça, os pontos $r_{p}, r_{i}$ são atualizados e o centro $(x, y)$ é alterado para as coordenadas do ponto candidato $c_{i}$.

\subsubsection{Método de Daugman}

Após a etapa de localização e segmentação da íris, geralmente é aplicado um método de conversão da imagem da íris para um espaço de coordenadas polares, esse método foi proposto por John Daugman (DAUGMAN, 1993). Esse processo realiza a conversão da região da íris (circular) para um plano polar (retangular) através do uso das Equações 5 e $6:$

$$
\begin{gathered}
x(r, \theta)=(1-r) x_{p}(\theta)+r x_{s} \theta \\
y(r, \theta)=(1-r) y_{p}(\theta)+r y_{s}
\end{gathered}
$$

Os pontos $\left(x_{s}(\theta), y_{s}(\theta)\right)$ representam os pontos do limite da esclera e $\left(x_{p}(\theta), y_{p}(\theta)\right)$ os pontos dentro do perímetro da íris. Com isso a imagem resultante, no espaço polar, 
pode ser analisada para a extração de características e esta pode ser descrita pela Equação $7:$

$$
I(r, \theta)=I(x(r, \theta), y(r, \theta))
$$

\subsubsection{Transformada circular de Hough}

Esta é uma técnica comum no tratamento de imagem, que pode ser usada para determinar os parâmetros de objetos geométricos simples, como linha e círculos (MASEK,

2003). É uma técnica de votação, que consiste numa conversão de uma imagem binária para um espaço de parâmetros acumulador de $n$-dimensões, com $n$ igual ao número de parâmetros pelos quais o objeto é definido (CATARINO, 2009).

A técnica deve ser executada sobre uma imagem gradiente, que irá indicar se um determinado ponto pertence ou não ao objeto procurado. No caso da segmentação de íris esta imagem é um mapa de bordas, que pode ser gerado, entre outras técnicas, utilizando o operador Canny (CANNY, 1986).

Os parâmetros utilizados para definir a Transformada de Hough, são as coordenadas do centro $(x, y)$ e o raio $r$ do circulo, definido pela formula $: x^{2}+y^{2}-r^{2}=0$. O ponto máximo do espaço de Hough corresponde ao centro e raio do melhor circulo definido pelo mapa de curvas (MASEK, 2003) e pode ser utilizado para a detecção da íris.

\subsubsection{Análise de desempenho}

Como o sistema biométrico está diretamente ligado aos sensores e ao ambiente em que as características são capturadas, é possível que durante a comparação de um padrão armazenado com o capturado, esses dois padrões sejam diferentes. Uma das formas de combater essa diferença gerada e garantir um bom desempenho do sistema é através do uso de um limiar de semelhança (DELAC; GRGIC, 2004), o qual será responsável por aceitar ou não a decisão do classificador.

Em (PRABHAKAR; PANKANTI; JAIN, 2003) são apresentadas duas distribuições de semelhança diferentes que podem ser utilizadas para descobrir um bom valor para o limiar que será utilizado. A distribuição de impostores, gerada através de pares de padrões de diferentes indivíduos, e a distribuição de genuínos, gerada através de pares de padrões do mesmo indivíduo. Essas distribuições podem ser verificada na Figura 8. 


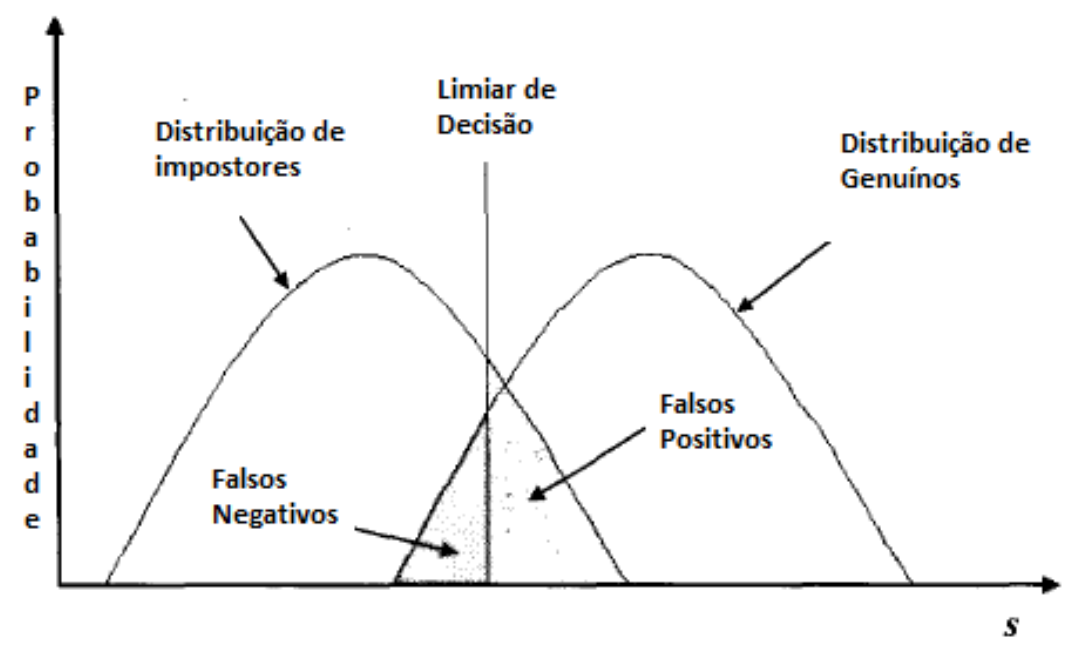

Figura 8 - Distribuição dos graus de semelhança.

Com base nisso, pode-se destacar as principais taxas de erros de um sistema de reconhecimento biométrico como sendo:

- Taxa de Falsa Aceitação (FAR): Medida que representa a quantidade de usuários que não estão presentes no sistema, porém foram aceitos.

- Taxa de Falsa Rejeição (FRR): Medida que representa a quantidade de usuários que estão presentes no sistema, porém foram rejeitados.

Em (COSTA, 2001) destaca-se a ligação direta entre FAR e FRR, onde no caso de um sistema com uma taxa de FAR alta e FRR baixa, representa que os padrões a serem comparados não precisam ser muito semelhantes para ser aceitos, tornando o sistema mais simples. Já os sistemas com FRR alta e FAR baixa, buscam padrões mais próximos com os armazenados para obter aceitação, gerando assim sistemas mais seguros.

O balanceamento entre FAR e FRR está diretamente ligado ao valor do limiar de semelhança que é utilizado no sistema, um valor de limiar baixo significa que a semelhança entre o dado sendo analisado e o padrão da classe localizada não precise ser alto, ou seja, acabará acontecendo a presença de falsas aceitação. Já a utilização de um valor de limiar alto faz com que o dado sendo analisado e o padrão da classe localizada devam ser bem semelhantes, ou seja, diminui a quantidade de falsas aceitações, porém aumenta a quantidade de falsas rejeições.

Na Figura 9 pode-se ver o comportamento de ambas as taxas e também o ponto de encontro das duas, que é chamada de taxa de cruzamento. Valores menores que esse 
ponto de encontro apresentam uma taxa de falsa aceitação maior e valores maiores que esse ponto apresentam uma taxa de falsa rejeição maior.

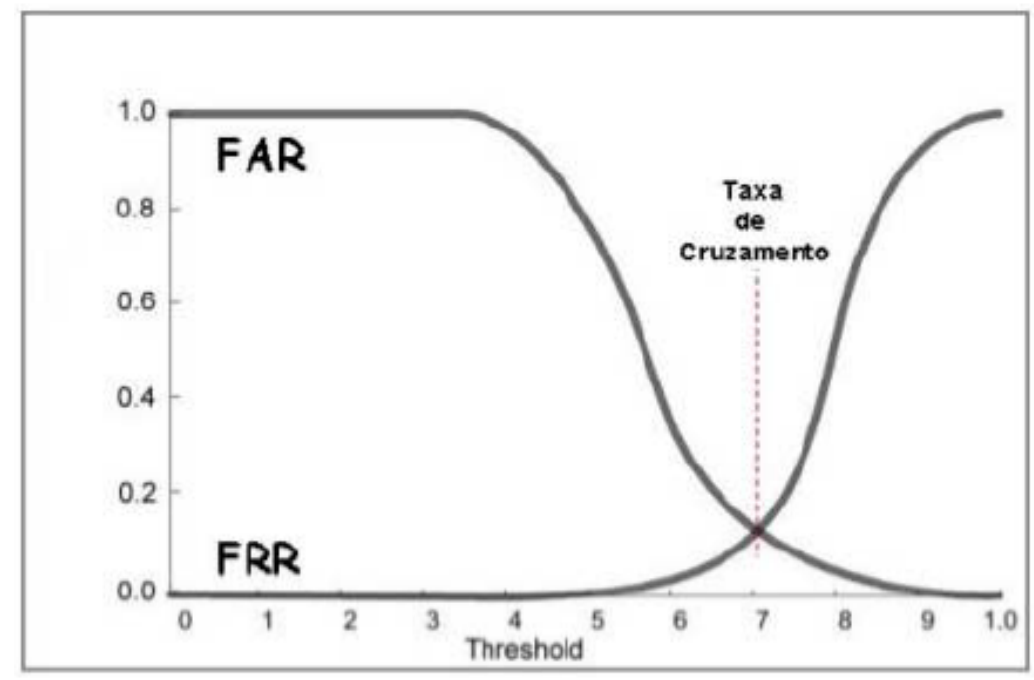

Figura 9 - Curvas de FAR, FRR e taxa de cruzamento.

\subsection{Sistemas biométricos multimodais}

Na seção anterior foi descrito os sistemas biométricos unimodais, os quais foram propostos de modo a superar as dificuldades encontradas pelos métodos tradicionais de segurança. Entretanto, alguns problemas podem dificultar o seu uso e permitir uma possível invasão. Em (JAIN; ROSS, 2004) alguns dos problemas enfrentados pelos sistemas biométricos unimodais são descritos:

- Ruído nos dados: esse tipo de problema ocorre quando alguma informação não é capturada adequadamente, por exemplo, uma cicatriz na impressão digital, sensor sujo, problemas de iluminação. Isso pode fazer com que o sistema apresente dificuldade na comparação com os padrões armazenados, podendo aceitar pessoas não cadastradas e rejeitar pessoas cadastradas;

- Variação Intra-Classe: o padrão que é capturado pelo sensor para a construção do vetor de características é muito diferente daquele armazenado no banco de dados. Isto pode ser devido a uma interação incorreta com os sensores.

- Variação Inter-Classes: mesmo que uma característica biométrica seja diferente entre algumas pessoas, pode acontecer que dependendo do tamanho da população, duas 
pessoas apresentem características muito próximas dificultando assim a identificação delas pelo sistema;

- Não-Universalidade: mesmo que uma característica biométrica esteja presente em todos os seres humanos, em alguns casos pode acontecer que estas estejam ausentes ou muito danificadas, fazendo com que essas pessoas não possam ser cadastradas pelo sistema;

- Falsificação: uma pessoa que não tem acesso ao sistema pode-se passar por uma pessoa cadastrada e assim conseguir burlar o sistema. Isto acontece com maior incidência em sistemas que empregam assinatura e fala, porém já existem técnicas que conseguem copiar impressão digital e íris.

Para combater esses problemas foram propostos os sistemas biométricos multimodais (JAIN; ROSS, 2004), os quais buscam através do uso de um conjunto de características biométricas fornecer um sistema mais confiável e robusto para o controle de acesso e proteção de informação. Os sistemas biométricos multimodais fornecem as seguintes vantagens em relação aos sistemas unimodais:

- Melhora significativa no desempenho de reconhecimento - diferentes modalidades medem informações complementares e por esta virtude podem encontrar melhor desempenho;

- Melhora na robustez do sistema frente a variações do ambiente - todas as modalidades biométricas sofrem com algum tipo de interferência do ambiente, por exemplo, o reconhecimento facial é seriamente afetado pelas condições de iluminação, energia, etc. Por outro lado, reconhecimento por impressão digital pode ser afetado pela umidade. Logo ao realizarmos a fusão destas duas modalidades, espera-se uma redução no nível de interferência do ambiente;

- Diminuição da Não-universalidade - ao utilizarmos mais de uma modalidade biométrica existe maior probabilidade de cobertura total da população;

- Garante uma boa defesa contra ataques por circunvenção e repetição - haverá um grau de dificuldade maior uma vez que mais de uma modalidade biométrica terá que ser falsificada ao mesmo tempo. Como as modalidades biométricas a serem captadas podem ser escolhidas aleatoriamente na etapa de reconhecimento, haverá uma maior necessidade da presença do indivíduo na captação, por exemplo, o sistema pode pedir certa combinação de características. 
Existe uma variedade de fatores que devem ser considerados quando se projeta um sistema biométrico multimodal. Estes fatores incluem:

- Escolha da quantidade e quais modalidades biométricas serão utilizadas;

- Em qual momento será realizado a combinação das características;

- Qual a estratégia que será utilizada para fazer essa combinação;

- Verificar se o desempenho obtido com o uso duas ou mais modalidade biométrica e o custo da sua implementação são aceitáveis.

Na próxima seção são apresentados os níveis nos quais a fusão pode ser realizada e também algumas das estratégias utilizadas em trabalhos envolvendo sistemas multimodais.

\subsubsection{Níveis de fusão}

De acordo com (MONWAR; GAVRILOVA, 2009) a fusão de características biométricas são separados em 2 grupos principais: anterior ao módulo de comparação e posterior ao módulo de comparação. Sendo que dentro de cada um desses grupos, diferentes estratégias podem ser utilizadas. Algumas dessas estratégias serão apresentadas nessa seção.

\subsubsection{Anterior à comparação}

As estratégias de fusão nessa categoria agrupam as características antes do módulo de comparação e podem ser realizadas das seguintes maneiras:

- Nível sensorial: Os dados brutos adquiridos a partir de múltiplos sensores podem ser processados e integrados para gerar novos dados, a partir dos quais as características podem ser extraídas. Um dos problemas da fusão no nível sensorial é que o dado capturado, possivelmente, conterá certo nível de ruído (variação de iluminação, interferência do fundo da imagem, etc). A Figura 10 ilustra este procedimento. Em (THARWAT; IBRAHIM; ALI, 2012) foi proposta uma combinação das imagens das juntas dos indicadores direito e esquerdo e da orelha do usuário. Ao final foi gerada uma imagem contendo as 3 informações e então foram aplicadas a Análise de Discriminante Linear, transformada Cosseno Discreta e transformada Wavelet Discreta para gerar diferentes vetores de características e 3 diferentes classificadores para averiguar o desempenho. 


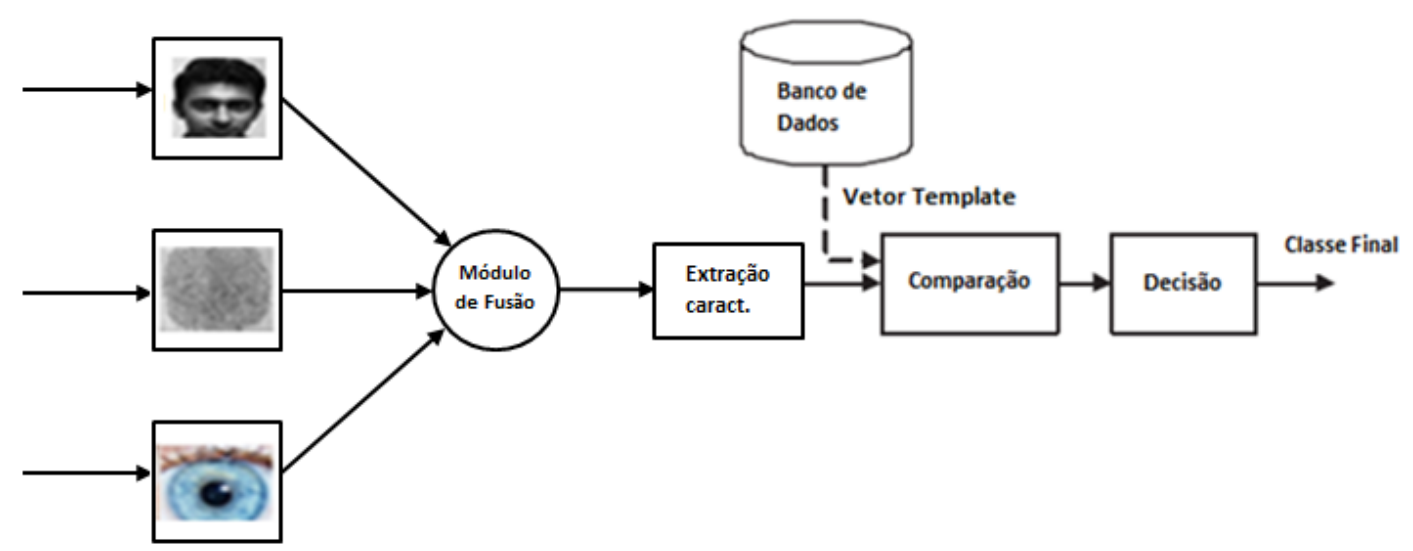

Figura 10 - Fusão no nível sensorial.

Outra estratégia de combinação foi proposta em (XU; ZHANG; YANG, 2010) onde a combinação dos dados é realizada por meio de uma matriz complexa da forma:

$$
Z=X+i Y
$$

onde $X$ e $Y$ representam imagens contendo diferentes características biométricas. Essa abordagem apresenta uma limitação no qual as imagens $X$ e $Y$ devem apresentar a mesma resolução, caso contrário, a soma $Z$ não pode ser calculada. Após a construção da matriz $Z$ é aplicada uma abordagem baseada em Análise de Componentes Principais para realizar a diminuição da dimensionalidade do vetor de característica inicial resultando num vetor de características para o classificador.

- Nível de extração de característica: o conjunto de características extraídas de múltiplas fontes de dados é usado para criar um novo conjunto de característica para representar o individuo. De acordo com (ROSS; JAIN, 2007) as estratégias desse nível apresenta um problema em relação à dimensionalidade das características biométricas utilizadas. Se a quantidade de características forem diferentes a sua combinação pode ser impossível de ser realizada.

Para que as estratégias de combinação nesse nível funcionem é necessário que os vetores de características $X_{1}=\left\{x_{1 n}, n=1, \ldots, N\right\}$ e $X_{2}=\left\{x_{2 n}, n=1, \ldots, N\right\}$, representando as características biométricas 1 e 2 , estejam normalizados da mesma 
forma. Para isso pode-se utilizar processos de normalização de forma a garantir isso. Uma das formas de normalização é apresenta a seguir:

$$
\bar{x}_{i j}=\frac{x_{i j}-\operatorname{media}\left(x_{i}\right)}{\text { desvio padrao }\left(x_{i}\right)},
$$

com isso pode-se definir $\bar{X}_{1}=\left\{\bar{x}_{1 n}\right\}$ e $\bar{X}_{2}=\left\{\bar{x}_{2 n}\right\}$ como sendo os novos vetores de características. Em seguida pode ser realizada a combinação dessas biometrias. Dependendo da abordagem de combinação utilizada nesse nível a quantidade de características pode ficar muito alta, sendo indicado o uso de estratégias de redução de dimensionalidade (CHANG et al., 2003). A Figura 11 apresenta um exemplo da combinação nesse nível.

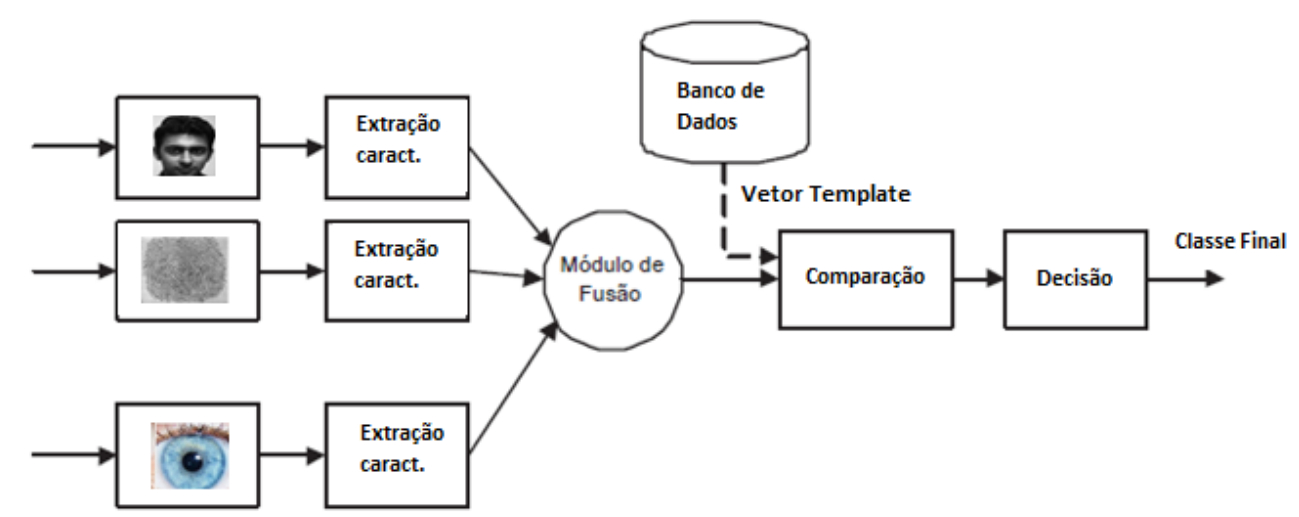

Figura 11 - Fusão no nível de extração de características.

Em (ROSS; ROHIN, 2005) foi realizada a construção dos vetores de características combinados através da concatenação simples dos coeficientes envolvendo a palma da mão, $X=\left\{x_{1}, x_{2}, \cdots, x_{n}\right\}$, e a face, $Y=\left\{y_{1}, y_{2}, \cdots, y_{m}\right\}$, do usuário. Ao final obtém-se um novo vetor $Z=\left\{x_{1}, x_{2}, \cdots, x_{n}, y_{1}, y_{2}, \cdots, y_{m}\right\}$. A principal vantagem dessa estratégia de combinação é que os vetores de características não precisam ser da mesma dimensionalidade, porém a quantidade de características pode ficar muito alta.

Em (WANG et al., 2009) foi realizada a combinação através da soma dos vetores de características individuais para íris, extraído com base no filtro Gabor e PCA, e da face, extraído com base em LDA. Desta forma mantém a mesma dimensionalidade do vetor de característica original. O vetor de característica resultante é descrito como $Z=\left\{I_{1}+i F_{1}, I_{2}+i F_{2}, \cdots, I_{d}+i F_{d}\right\}$, sendo que nesse caso ambos os vetores individuais apresentam a mesma dimensionalidade. 


\subsubsection{Posterior à comparação}

Nessa estratégia a integração da informação é realizada após a comparação, ou seja, após os vetores de características serem apresentados a classificadores individuais para cada característica biométrica. Esta categoria combina as informações do sistema biométrico multimodal da seguinte forma:

- Nível comparação baseada na pontuação : neste caso, cada modalidade fornece uma pontuação, que indica a semelhança do vetor de características com o padrão armazenado. Estas pontuações podem ser combinadas gerando um valor escalar (MARCIALIS; ROLI, 2004). Técnicas tais como regressão logística pode ser usada para combinar o vetor de pontuação oriundo das diferentes modalidades biométricas.

Para os sistemas biométricos multimodais no modo de verificação, pode-se definir um vetor $s=\left[s_{1}, s_{2}, \ldots, s_{N}\right]$, onde $s_{i}$ representa o grau de semelhança do padrão a ser testado, normalizado no intervalo $[0,1]$, onde 0 representa totalmente diferente e 1 idêntico com o seu padrão armazenado na base de dados do $i$-ésimo classificador. Com isso define-se a Equação 10.

$$
F(s)=\frac{1}{N} \sum_{n=1}^{N} s_{i},
$$

onde $F(s)$ representa a semelhança média do padrão de entrada $x$, em relação a todos os classificadores. A decisão final pode ser tomada com base na Equação 11:

$$
D(s)=\left\{\begin{array}{l}
\text { Aceito, } \operatorname{se} F(s)>r, \\
\text { Rejeitado, } \operatorname{se} F(s)<r
\end{array}\right.
$$

onde $r$ representa o limiar de decisão, sendo que esse limiar é definido previamente. Diferentes valores de $r$ podem gerar diferentes taxas de Falsa Aceitação e Falsa Rejeição para o sistema. Desta forma diferentes valores devem ser testados de forma a escolher o valor que representa melhor compromisso entre a taxa de falsa rejeição e taxa de falsa aceitação.

Uma segunda forma de realizar a decisão é através da construção de um classificador binário, responsável por separar as classes de aceito e rejeitado. Neste caso utiliza-se o vetor de semelhanças $s$ como entrada para esse classificador e ao final tem-se a resposta se a identidade deve ser aceita ou rejeitada. O problema dessa abordagem é que o 
parâmetro do classificador tem que ser bem definido, para que não ocorram grandes valores de falsa aceitação e falsa rejeição. Um exemplo desse tipo de combinação pode ser visto na Figura 12.

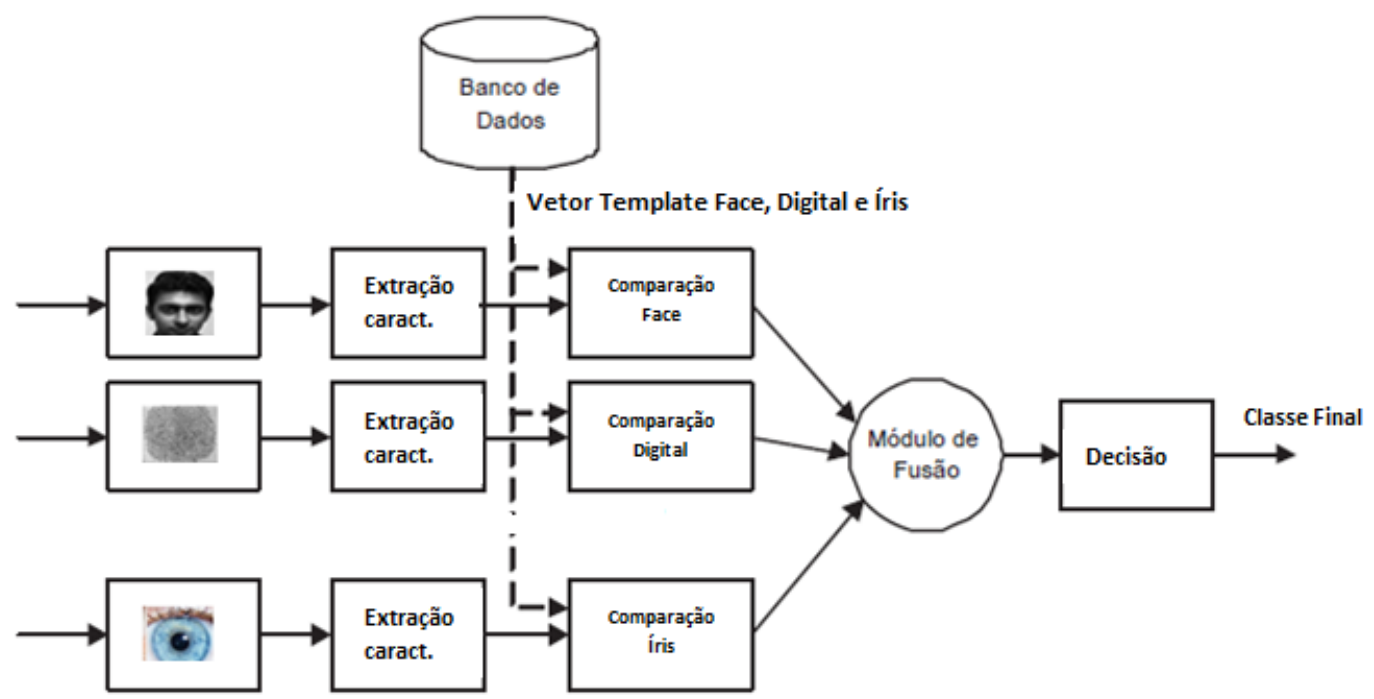

Figura 12 - Fusão da pontuação obtida no nível de comparação.

Em (ROSS; JAIN, 2003) foram apresentadas diferentes estratégias de combinação dos valores de semelhança da face e impressão digital a fim de obter a pontuação final, sendo esta utilizada no processo de tomada de decisão final com as abordagens de soma, árvores de decisão e uma função discriminante linear.

- Nível de Decisão: quando cada comparador (por exemplo, classificador) produz seu próprio rótulo de classe (isto é, aceita ou rejeita na verificação, ou a identidade de um usuário em um sistema de identificação), um único rótulo de classe pode ser obtido empregando técnicas de combinação como: regras AND, regras OR ou voto majoritário (ROSS; JAIN, 2003). Um exemplo dessa abordagem pode ser visto na Figura 13.

Na estratégia de combinação baseada em regras AND o sistema só aceita a identidade se todos os classificadores apresentarem a mesma identidade como resposta. Já a estratégia baseada em regras OR, o sistema aceita a identidade se, pelo menos, um dos classificadores identifica o padrão. Sendo essas abordagens geralmente utilizadas no modo de verificação.

A estratégia de combinação baseada em voto majoritário define um vetor $D=$ $\left[d_{1}, d_{2}, \ldots, d_{n}\right]$, onde $D$ representa a saída de todos os $N$ classificadores. Neste caso a classe será aquela que com maior ocorrência dentro do vetor $D$. Essa ocorrência deve ser maior 


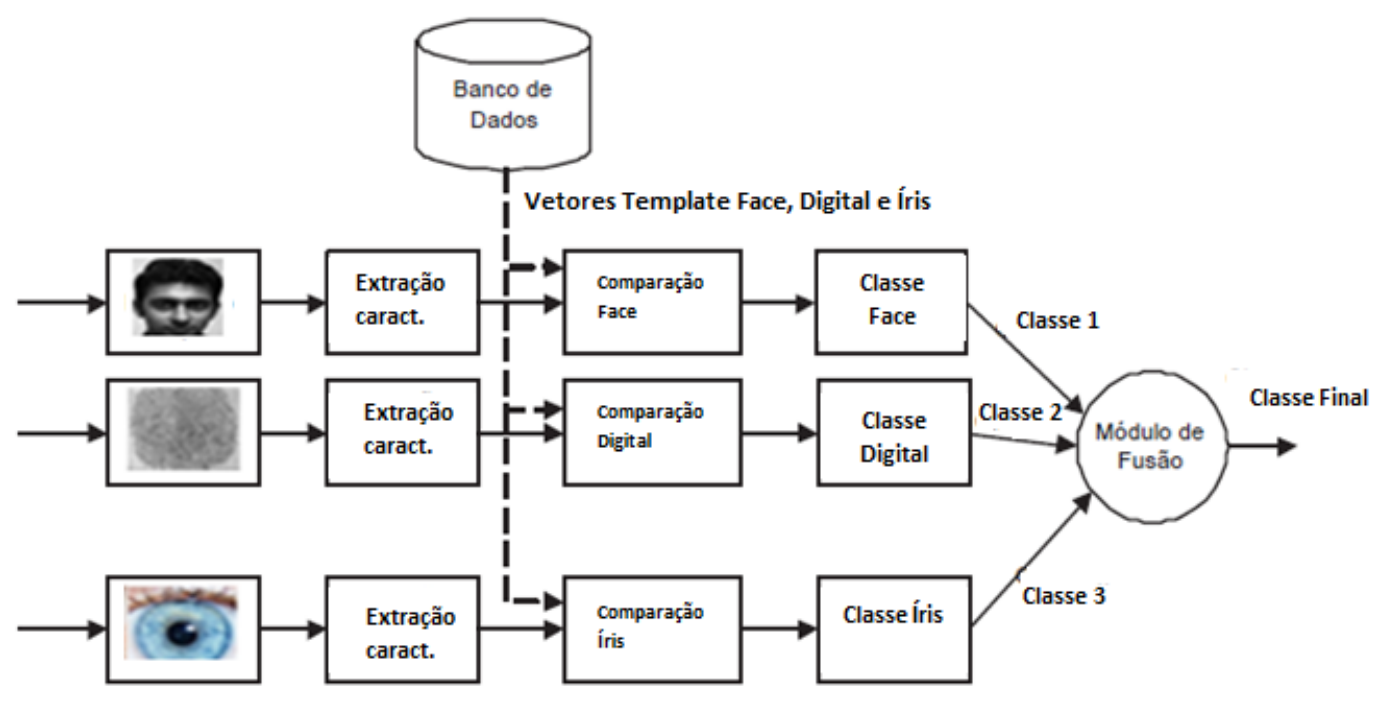

Figura 13 - Fusão no nível da decisão.

que $\frac{N}{2}$, caso isso aconteça a identidade é aceitada, caso contrário, ela é rejeitada. Algumas variações podem ser realizadas de forma a diminuir a sua rigidez.

Em (HANMANDLU et al., 2008) foi realizada a combinação no nível de decisão através de diferentes regras para obter a decisão final sobre a identidade do usuário. Neste caso, foram utilizadas as regras AND, OR, NAND, PSO, PSO Binário, PSO Híbrido, Regra de Chair-Varshney.

Em (TAO; VELDHUIS, 2009) são utilizadas diferentes abordagens de combinação nos níveis de decisão e de comparação. Os autores fizeram o uso das taxas de probabilidade de falsa aceitação e falsa rejeição dos classificadores de forma a combinar com o uso de regras AND e OR, SVMs e método de Soma. Os melhores resultados foram obtidos com o uso da regra OR. 


\section{Técnicas de extração de características}

Um dos principais módulos em um sistema biométrico é o módulo de extração de características, que é responsável por extrair as informações importantes das características biométricas do usuário. Pode-se fazer o uso dos pixels da imagem como informação de entrada, ou aplicar estratégias de extração de características que destaquem os pontos mais importantes no dado de entrada. A vantagem de se utilizar características extraídas das imagens é que estas podem gerar uma melhor separação entre-classe e uma menor variação intra-classe representando melhor o domínio da aplicação (VIOLA; JONES, 2004).

Para que uma técnica de extração de características forneça uma boa representação dos dados, independente da modalidade biométrica, é necessário que esta seja capaz de extrair características discriminantes que não são sensíveis a variação de pose, escala e iluminação (JADHAV; HOLAMBE, 2009).

Para a extração de características das modalidades biométricas aqui estudadas, no caso face e íris, foram analisadas as transformadas Wavelet (THEPADE; BIDWAI, 2013) (LIU; ZHANG; ZHU, 2012), Contourlet (XU et al., 2013)(WANG et al., 2011) e Curvelet (GUESMI et al., 2012) (ZHANG; YU; GU, 2012).

\subsection{Transformada Wavelet}

A transformada Wavelet pode ser descrita como uma técnica de processamento de sinal, que realiza uma análise de um determinado sinal nos domínio do tempo e frequência, ao contrário da transformada de Fourier que realiza apenas a análise no domínio do tempo (BURRUS; GOPINATH; GUO, 1998). Uma função Wavelet pode ser descrita como uma função que apresenta média zero e obedece a Equação 12 (MALLAT, 2008):

$$
\int_{-\infty}^{\infty} \Psi(t) d t=0
$$

A função Wavelet $\Psi$ pode sofrer dilatação por meio dos parâmetros $s$, representando a escala, e $u$, representando a translação (Equação 13.

$$
\Psi_{u, s}(t)=\frac{1}{\sqrt{s}} \Psi\left(\frac{t-u}{s}\right)
$$


Com isso pode-se definir a transformada Wavelet como sendo o seguinte produto interno:

$$
W T f(u, s)=\left\langle f, \Psi_{u, s}\right\rangle=\int_{-\infty}^{+\infty} f(t) \Psi_{u, s}(t) d t
$$

Além da utilização das funções Wavelet $\Psi$, conhecidas como função mãe, foi proposta em (MALLAT, 2008) uma outra forma de se realizar a transformada Wavelet. Essa nova abordagem utiliza um conjunto de filtros, sendo um filtro passa-baixa $g$, que representa uma aproximação do sinal original, e um filtro passa-alta $h$, representando os detalhes da imagem original. Na Figura 14 é apresentado o processo de decomposição Wavelet 1-D.

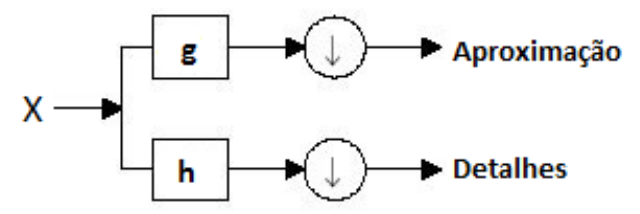

Figura 14 - Decomposição Wavelet 1-D.

Para a utilização da transformada Wavelet em sinais 2D, tal como as imagens, a ideia original foi expandida de forma a tratar as linhas e colunas da imagem como sinais independentes. Desta forma aplica-se a transformada Wavelet em sequência, sendo que esse processo pode ser visto na Figura 15(A).

Ao final da decomposição Wavelet 2D são gerados 4 subimagens, onde cada uma delas apresenta resolução $\frac{n}{2} \times \frac{n}{2}$, sendo que as imagens HL, LH e HH contém pelo menos as altas frequências em alguma das direções e podem ser descritas como contendo os detalhes horizontais, verticais e diagonais da imagem original, enquanto que a imagem LL representa uma aproximação desta.

As imagens resultantes da transformada Wavelet podem ser decompostas novamente, gerando assim um conjunto de subimagens de diferentes resoluções e diferentes frequências. O método mais comum dessa decomposição é através da utilização em um esquema de pirâmide (MALLAT, 2008), esse processo pode ser visto na Figura 15.

A transformada Wavelet gera ao final um conjunto de coeficientes que podem ser utilizados para representar a imagem original. Uma das formas mais comuns é utilizar os componentes da imagem LL, que representa uma aproximação da imagem original, e apresenta menor dimensão e boa representatividade (BURRUS; GOPINATH; GUO, 1998). 


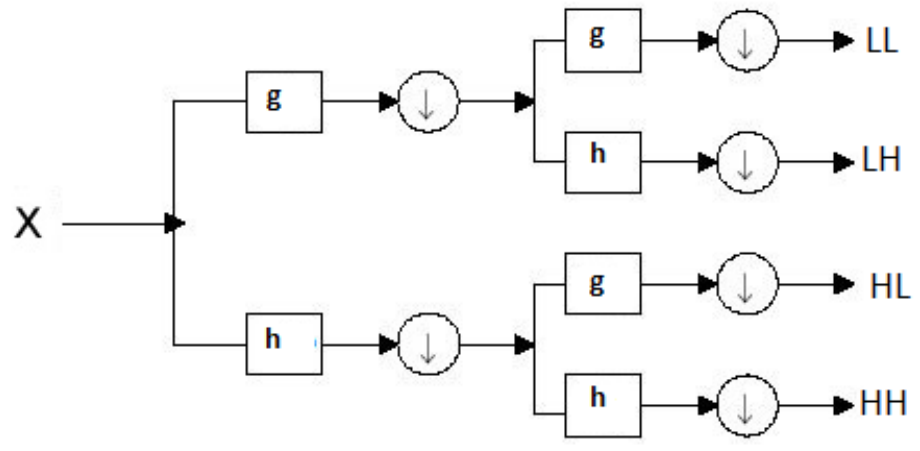

(A)

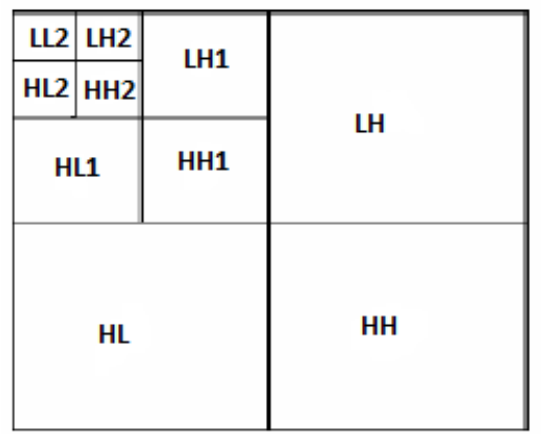

(B)

Figura 15 - Decomposição Wavelet 2-D.

\subsection{Transformada Contourlet}

A decomposição gerada pela transformada Wavelet apresenta um problema na representação de contornos das imagens em diferentes direções, geralmente representadas pelas altas frequências das imagens. De forma a superar essa limitação foi proposta por Do e Vetterli (DO; VETTERLI, 2005) a transformada Contourlet.

A transformada Contourlet utiliza duas técnicas: Banco de Filtros Direcionais (DFB) (BAMBERGER; SMITH, 1992), responsável por gerar uma estrutura com maior capacidade de extração dos contornos suaves das imagens; e a Pirâmide Laplaciana (LP) (BURT; ADELSON, 1983), responsável por fazer a separação das altas e baixas frequências da imagem através do uso de um filtro.

A Pirâmide Laplaciana é uma técnica de compactação de imagem proposta por Burt e Adelson (1983) (BURT; ADELSON, 1983). Esta realiza uma filtragem da imagem de entrada $I$ através de um filtro passa-baixa $g$ gerando a imagem passa-baixa $I_{b 1}$, sendo que $I_{b 1}$ representa uma imagem reduzida com a metade da resolução de $I$.

Através do uso de uma função de sobreamostragem sobre $I_{b 1}$ a Pirâmide Laplaciana gera uma imagem, contendo apenas os coeficientes de aproximação da imagem $I$ original, e então define-se a Imagem Laplaciana $L_{1}$ através da Equação 15:

$$
L_{1}=I-I_{b 1}
$$

A imagem resultante $L_{1}$ pode ser descrita como uma imagem contendo as altas frequências da imagem $I$ original. O processo da Pirâmide Laplaciana pode ser repetido sobre a imagem $I_{b 1}$ gerando a imagem $I_{b 2}$, e a imagem $L_{2}$ através da subtração de $I_{b 1}$ e $I_{b 2}$. Ao final do processo da Pirâmide Laplaciana para $N$ níveis tem-se uma imagem 
passa-baixa $I_{b n}$ e um conjunto de imagens contendo altas frequências $L=L_{1}, L_{2}, \ldots, L_{n}$, sendo que as imagens do conjunto $L$ serão analisadas pelo DFB para a detecção dos contornos.

A segunda etapa da transformada Contourlet é a utilização de um Banco de Filtros Direcionais nas imagens contendo as altas frequências através do uso de um Banco de Filtros Quincunx (DO; VETTERLI, 2005). Este é responsável por separar os espectros horizontais e verticais no domínio da frequência como mostrado na Figura 16.

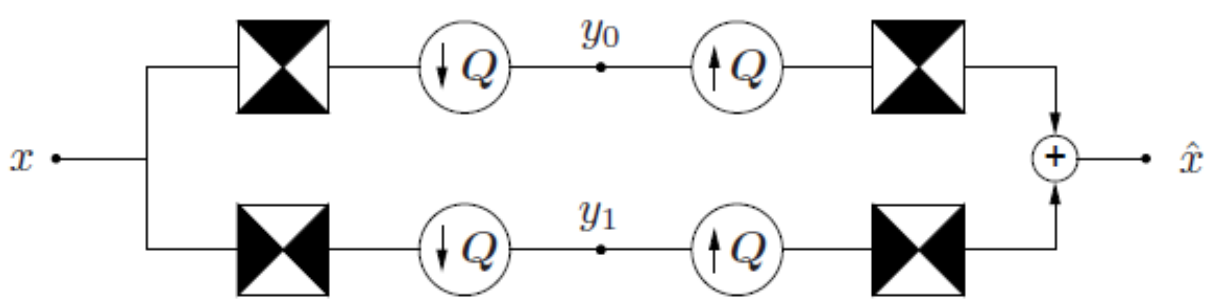

Figura 16 - Decomposição gerada pelo filtro quincunx.

Para fazer a separação das direções verticais e horizontais do Filtro Quincunx é utilizada as seguintes matrizes de rotação e subamostragem $S_{k}^{(l)}$ :

$$
\left[\begin{array}{ccc}
2^{l-1} & 0 & \\
& 0 & 2
\end{array}\right] \text { para } 0 \leq k<2^{l-1} \text { ou }\left[\begin{array}{cc}
2 & 0 \\
0 & 2^{-1}
\end{array}\right] \text { para } 2^{l-1} \leq k<2^{l} \text {, sendo que } l
$$

representa o nível a ser decomposto em $2^{l}$ partições como pode ser visto na Figura 17.

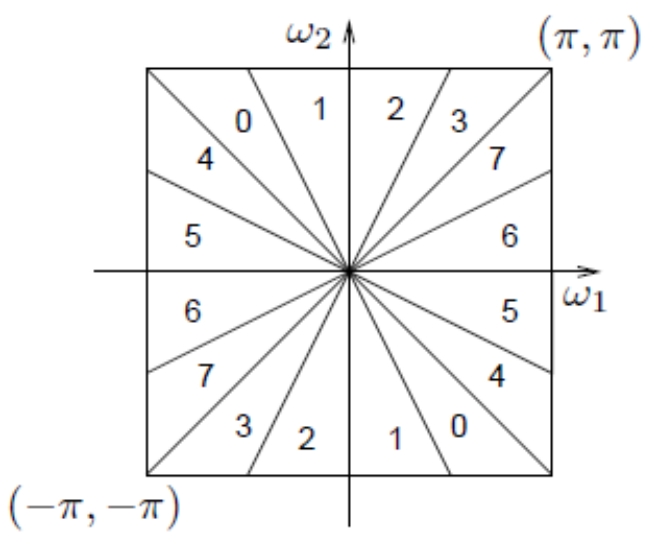

Figura 17 - Partição da frequência gerada para $l=3$, gerando $2^{3}=8$ partições.

Um exemplo da rotação gerada pelas matrizes $S_{k}(l)$ pode ser visto na Figura 18. Na decomposição Contourlet a imagem a ser rotacionada contém apenas as altas frequências da imagem original e após a rotação é aplicado um Filtro Direcional em cada uma das partições. 

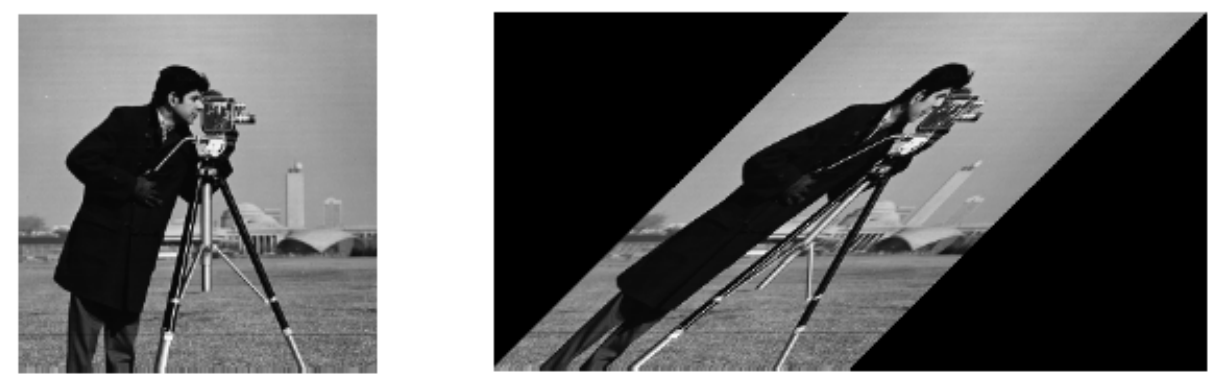

Figura 18 - Exemplo de rotação utilizando as matrizes $S_{k}^{(l)}$. Esquerda: imagem original. Direita: Imagem rotacionada e sobreamostrada. Retirado de (DO; VETTERLI, 2005).

Ao final da transformada Contourlet tem-se uma imagem passa-baixa, representando a aproximação da imagem original gerada pelo passo da Pirâmide Laplaciana, e um conjunto de imagens passa-alta, em diferentes escalas e direções, representando os contornos da imagem. Os coeficientes localizados em todas as imagens podem ser utilizados como vetor de características para o classificador.

\subsection{Transformada Curvelet}

A transformada Curvelet foi proposta por Candès e Donoho em 2000 (CANDèS; DONOHO, 2000). Da mesma forma que a transformada Contourlet, esta busca fornecer uma estratégia de análise de imagens que representasse com maior qualidade os contornos, que é uma limitação da transformada Wavelet. Essa transformada foi proposta como sendo a combinação de 3 ideias diferentes:

- Transformada Ridgelet: responsável por detectar objetos que apresentam descontinuidades;

- Ridgelets Multiescala: uma pirâmide contendo um conjunto de janelas de ridgelet, em diferentes escalas e localidades;

- Filtros passa-banda: utilizada para separar um objeto em diferentes escalas disjuntas.

O primeiro passo na transformada Curvelet consiste na filtragem da imagem de entrada $I$, através do uso de um banco de filtros $P$, gerando um conjunto de subimagens $f \rightarrow\left(P_{0} f, \delta_{1} f, \delta_{2} f, \ldots\right)$, onde $P_{0} f$ apresenta resolução $\frac{N}{2^{k}} \times \frac{M}{2^{k}}$, e $k$ representa a quantidade de níveis. $P_{0} f$ é uma aproximação da imagem original, e $\delta_{i} f$ apresenta resolução $\frac{N}{2^{i}} \times \frac{M}{2^{i}}$, onde $i$ é o nível da decomposição. 
Após a construção das subimagens é realizada a partição das imagens $\delta_{i} f$ em um conjunto de subjanelas, com diferentes escalas e direções, através do uso da Transformada Ridgelet Multiescala:

$$
\delta_{s} f \rightarrow\left(w_{Q} \delta_{s} f\right)_{Q \in Q_{2}}
$$

onde $w$ representa uma função de energia e $Q$ uma matriz Dyadic quadrada, então cada uma das partições geradas é normalizada segundo a equação:

$$
g_{Q}=2^{-s}\left(T_{Q}\right)^{-1}\left(w_{Q} \delta_{s} f\right), Q \in Q_{s}
$$

De forma a gerar os coeficientes a transformada Curvelet faz o uso da transformada Ridgelet em cada uma das janelas geradas anteriormente. Essa transformada foi proposta por Candès em 1999 (CANDèS; DONOHO, 1999) e realiza a decomposição de uma imagem através do uso da transformada de Fourier 2D, de forma a detectar as frequências da imagem, então aplica-se uma operador de janelas radiais e por último, para cada uma das linhas radiais, é utilizada a transformada inversa de Fourier detectando as informações importantes. De forma mais simplicada a transformada Curvelet pode ser descrita como (ALZUBI; ISLAM; ABBOD, 2011):

$$
\text { Curvelet }=\operatorname{IFFT}[F F T(\text { Curvelet }) \times F F T(\text { Imagem })] \text {, }
$$

onde FFT(Curvelet) representa um filtro responsável por analisar uma determinada região da imagem, FFT(Imagem) representa a região da imagem que será analisada, e então através da interpolação dessas termos e com a aplicação da transformada inversa rápida de Fourier tem-se o conjunto de coeficientes de uma determinada região, esse processo é aplicado para todas as janelas geradas pela transformada Ridgelet.

Além da abordagem proposta por Candès e Donoho (CANDèS; DONOHO, 2000), tem-se a segunda geração da transformada Curvelet proposta por Candes et al. (2005) (CANDèS et al., 2005) onde foi proposta a transformada rápida de Curvelet. Essa nova transformada possível de ser realizada de duas maneiras, uma através da utilização da transformada rápida de Fourier Não-Equidistante e a segunda através de um método de Wrapping, sendo que essas novas técnicas reduzem a redundância dos coeficientes gerados na formulação original e também apresentam uma complexidade computacional menor. 
A diferença dessas duas abordagens é o método utilizado para transformar a escala e o ângulo de cada uma das janelas geradas pela transformada Ridgelet. Neste trabalho foi utilizado o método baseado na transformada rápida de Fourier Não-Equidistante, nesse método após a aplicação da transformada rápida de Fourier 2D é aplicado um operador de interpolação e então aplica-se a transformada rápida de Fourier 2D sobre o resultado desse processo de interpolação para a detecção dos coeficientes. Já o método de Wrapping realiza o mesmo procedimento, porém ao invés de utilizar um operador de interpolação, ele utiliza um procedimento de periodização que localiza as regiões onde pode ser aplicada a transformada inversa rápida de Fourier.

\subsection{Comparação de técnicas}

A principal vantagem das transformadas Contourlet e Curvelet em relação à transformada Wavelet diz respeito a capacidade de representar contornos. Com o intuito de ilustrar esta vantagem foi escolhida uma imagem e aplicado as três transformadas. $\mathrm{O}$ resultado obtido é apresentado na Figura 19.

Analisando a Figura 19 pode-se verificar que a transformada Curvelet foi a que conseguiu representar a maior quantidade de contornos da imagem. Isso foi obtido pela forma com que o espaço de frequência é analisado, o que garante uma maior capacidade de representação das regiões de alta frequência, as quais geralmente estão relacionadas a contornos ou a pontos de variação de iluminação. Já a transformada Contourlet conseguiu representar uma boa quantidade dos contornos da imagem original, porém acaba perdendo alguns outros detalhes, principalmente no que diz respeito à variação da iluminação.

A transformada Wavelet, como discutido anteriormente, é a que apresenta a maior dificuldade na localização dos contornos, visto que a forma de análise do espaço de frequência fica restrita apenas às direções horizontal, vertical e diagonal. Isto prejudica a análise dos contornos que aparecem em outras direções no espaço de frequência. 


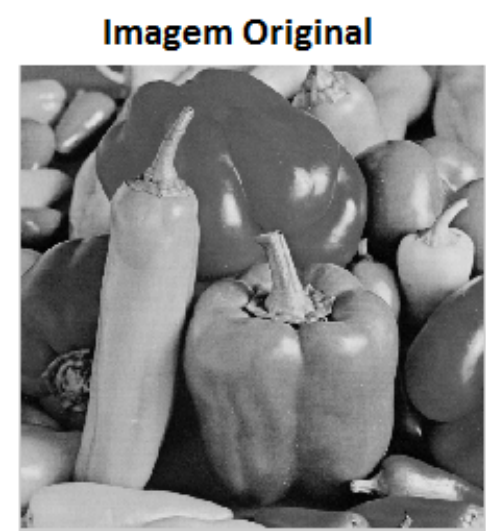

\section{Transformada Wavelet}
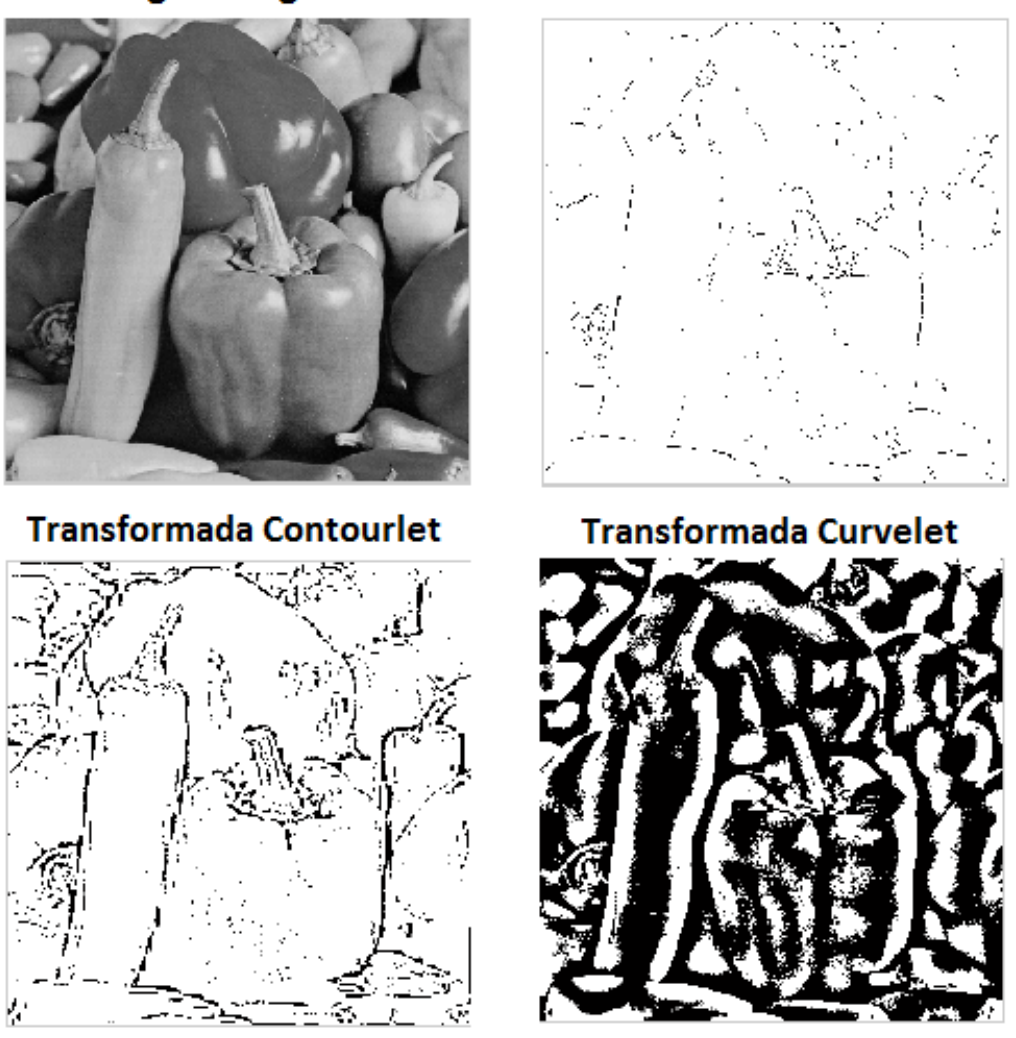

Transformada Curvelet

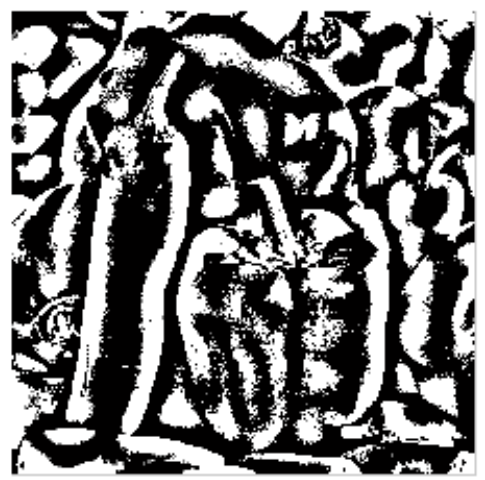

Figura 19 - Resultado usando detecção de contornos com diferentes transformadas. Imagem reconstruída apenas com os coeficientes de detalhes. 


\section{Classificadores}

Para que o sistema biométrico possa realizar o reconhecimento/identificação de um determinado usuário é necessário definir uma técnica de reconhecimento de padrões responsável para compor o módulo de comparação. Dentre as técnicas de reconhecimento de padrões destacam-se as máquinas de Kernel.

Recentemente, um novo tipo de metodologia de aprendizado, que apresenta características operacionais semelhantes aos modelos neurais, mas que implementa conceitos teóricos da área de aprendizado estatístico, vem ganhando bastante notoriedade, haja vista os ganhos propiciados em termos de acuidade e generalização (HASTIE; TIBSHIRANI; FRIEDMAN, 2009; MÜLLER et al., 2001; MüLLER et al., 2001; SHAWE-TAYLOR; CRISTIANINI, 2004; VAPNIK, 1995).

As máquinas de aprendizado induzidas por essa metodologia, denominadas máquinas de Kernel, se distinguem dos modelos conexionistas em alguns aspectos fundamentais. Por exemplo, em vez de seguirem o princípio de minimização do risco empírico, máquinas de Kernel são concordantes com o princípio de minimização do risco estrutural, que procura minimizar um limitante superior do erro de generalização no lugar de otimizar somente o erro de treinamento.

O princípio de minimização do risco estrutural apoia-se na hipótese de que a taxa de erro de uma máquina de aprendizado sobre o conjunto de teste (i.e., o erro de generalização) seja limitada pela soma entre o erro de treinamento e um termo de intervalo de confiança dependente da dimensão de Vapnik-Chervonenkis (dimensão VC) (CRISTIANINI; SHAWE-TAYLOR, 2000; VAPNIK, 1995), esta indica o grau de complexidade da máquina resultante. É com base nesse princípio que uma dada instância de máquina de Kernel consegue produzir uma estrutura otimizada de rede, mesmo não incorporando nenhuma informação acerca do domínio do problema-alvo.

Outro mérito exibido por essa nova metodologia de Aprendizado de Máquina é que o treinamento de estimadores se resume à resolução de um problema de programação quadrática com restrições lineares. Isso representa um grande avanço frente a algoritmos convencionais de treinamento de RNAs (tais como o algoritmo backpropagation (HAYKIN, 2009), que emprega otimização não-linear), já que a solução obtida é única, ótima e não acometida de mínimos locais (CRISTIANINI; SHAWE-TAYLOR, 2000; MOGUERZA; MUNõZ, 206). Basicamente, a metodologia de indução de máquinas de Kernel compreende dois 
passos seqüenciais: (i) mapear não-linearmente um vetor de entrada para um espaço de características de mais alta dimensão (que seja "escondido" tanto da entrada como da saída); e (ii) construir um hiperplano ótimo que separe as características extraídas no passo anterior. O primeiro passo é realizado mediante o emprego de funções com características especiais, denominadas funções Kernel. A tarefa básica de tais funções é extrair novas características de modo computacionalmente eficiente, a fim de se amenizar os problemas relativos à "maldição da dimensionalidade" (MÜLLER et al., 2001; MüLLER et al., 2001).

A eficácia e eficiência do processo de indução de máquinas de Kernel dependem diretamente da escolha a priori dos valores de alguns parâmetros de controle (conhecidos como hiper-parâmetros), dentre os quais os parâmetros da função Kernel e a constante de regularização (tradeoff). A calibração desses hiper-parâmetros não é uma tarefa trivial, sendo geralmente realizada manualmente, embora algumas abordagens vêm sendo propostas de modo a resolvê-la de forma automática (CHAPELLE et al., 2002; CHERKASSKY; MA, 2004).

As máquinas de Kernel mais conhecidas são as Máquinas de Vetores Suporte (SVM), cujo modelo padrão foi introduzido por Vapnik e colaboradores no início da década 1990 (CORTES; VAPNIK, 1995). A implementação dessa versão padrão implica em resolver um problema de programação quadrática que demanda alto custo computacional, com o objetivo de reduzir essa complexidade, foram propostas algumas alterações na formulação original, dentre as quais pode-se citar a Máquinas de Vetores Suporte baseada em Quadrados Mínimos (SUYKENS; VANDEWALLE, 1999) (realiza o processo de treinamento através de um sistema linear de equações), as Smooth Support Vector Machines (LEE; MANGASARIAN, ) (que empregam métodos de suavização para reformular o aprendizado como um problema de programação matemática sem restrições), as Máquinas de Vetores Suporte Lagrangeana (MANGASARIAN; MUSICANT, 2001) (que possuem um algoritmo mais simples baseado em uma formulação Lagrangiana implícita), e as Máquinas de Vetores Relevantes (TIPPING, 2000) (que empregam uma formulação bayesiana, levando a interpretações probabilísticas da saída da máquina).

Em particular, as Máquinas de Vetores Suporte Baseada em Quadrados Mínimos (LSSVM) vêm se mostrando atraentes em termos computacionais por empregarem restrições de igualdade em vez de desigualdade e uma função-custo baseada em mínimos quadrados, como comumente ocorre em redes neurais. Esta formulação simplifica o problema de tal forma que a solução é caracterizada por um sistema linear, mais precisamente um sistema 
KKT (Karush-Khun-Tucker) (SUYKENS; VANDEWALLE, 1999), sendo que este sistema pode ser eficientemente solucionado através de métodos iterativos, tais como gradiente conjugado.

Apesar dessas características atrativas, as LS-SVMs também têm alguns problemas potenciais (GESTEL et al., 2004). O primeiro é que a esparsidade da solução (modelo) é geralmente perdida, ou seja, praticamente todos os padrões de entrada passam a contribuir para a geração do modelo no papel de vetores-suporte. Um segundo problema é que o emprego da função de soma do erro quadrático sem um termo de regularização pode conduzir a estimativas menos robustas. Em (GESTEL et al., 2004), tendo em vista a resolução do segundo problema, Lima et al. (LIMA; COELHO; ZUBEN, 2002a) introduziram o conceito de misturas de especialistas localizadas baseadas em LS-SVMs ponderados.

As máquinas de Kernel utilizam uma função, chamada de função de Kernel denotada por $K$, que realiza um mapeamento $\Phi(x) k$ dos dados originais no espaço $n$-Dimensional para um espaço de alta dimensionalidade $H$, chamado de espaço de característica. De acordo com o Teorema de Cover (COVER, 1965) se a dimensão desse novo espaço $H$ é suficientemente alta, os dados originais podem ser linearmente separáveis em $H$. Alguns exemplos de funções Kernel podem ser vistas na Tabela 1.

\begin{tabular}{|l|l|}
\hline Função Kernel & Formulação \\
\hline Linear & $K_{t}(x, z)=x^{T} z$ \\
\hline Polinomial & $K_{p}(x, z)=\left(x^{T} z+1\right)^{p}$, para $\mathrm{p}=2$ \\
\hline Base Radial $(\mathrm{RBF})$ & $K_{r b f}(x, z)=\exp \left(-\frac{\|x-z\|^{2}}{2 \sigma^{2}}\right)$, para $\sigma^{2}=1$ \\
\hline Base Radial Exponencial & $K_{r b f}(x, z)=\exp \left(-\frac{\sqrt{\|x-z\|^{2}}}{2 \sigma^{2}}\right)$, para $\sigma^{2}=1$ \\
\hline Tangente Hiperbólica & $K_{t g h}(x, z)=\tanh \left(\alpha\left(x^{T} z\right)-c\right)$, para $\alpha=1, c=0$ \\
\hline
\end{tabular}

Tabela 1 - Funções Kernel mais utilizadas.

\subsection{Máquinas de Vetores Suporte}

As Máquinas de Vetores Suporte (SVMs) (VAPNIK, 1998) foram originalmente projetadas para tarefa de classificação binária, ou seja, problemas envolvendo apenas 2 Classes $\left(C_{1}, C_{2}\right)$. A SVM é conhecida como uma das principais técnicas a ser utilizada em problemas de classificação e já foi utilizada com sucesso em aplicações envolvendo sistemas biométricos baseado em íris (LIAU; ISA, 2011) e face (LIU; ZHANG; ZHU, 2012). Essa técnica é indicada para problemas em que os dados de entrada apresentam alta dimensionalidade 
(LOURENçO; SILVA; FRED, 2012), uma vez que a sua formulação não depende diretamente da dimensionalidade dos dados.

Considere o problema de classificação binária apresentado na Figura 20. Observe que existem diferentes hiperplanos que podem realizar a separação entre as classes, porém há apenas um que maximiza a distância entre as classes, sendo esse chamado de hiperplano de separação ótimo. Este hiperplano pode ser definido por dois hiperplanos suporte, conforme ilustrado na Figura 20.

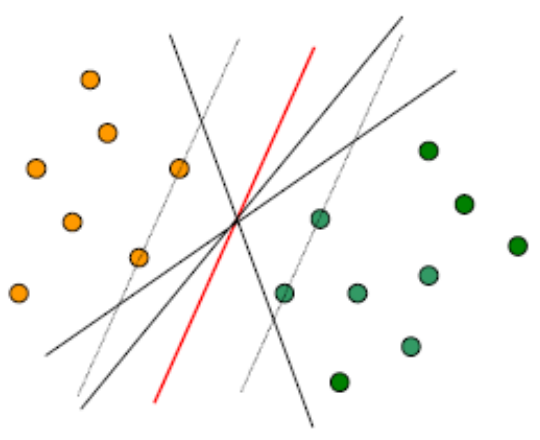

Figura 20 - Hiperplanos de separação ótimo (linha em vermelho) e hiperplanos de suporte (linha tracejada). Adaptado de (LIMA, 2004).

\subsubsection{Formulação}

Dado um problema de classificação binária com um conjunto de treinamento $\left\{\left(\mathbf{x}_{i}, y_{i}\right)\right\}_{i=1}^{N}$, com entrada $\mathbf{x}_{i} \in \mathfrak{R}^{m}$ e saída $y_{i} \in\{ \pm 1\}$, considere um mapeamento nãolinear $\phi: \mathfrak{R}^{m} \longrightarrow \mathfrak{R}^{n}$, onde $n$ é muito maior que $m$, ou seja, os dados de entrada são mapeados para um espaço com maior dimensionalidade (SCHOLKOPF; SMOLA, 2001). Nesse novo espaço (chamado de espaço de característica), a SVM busca construir um hiperplano de separação ótima, descrito pela Equação 19, onde a distância entre duas classes é maximizada.

$$
f(x ; w)=w^{T} \phi(x)+b
$$

Na formulação original das SVMs proposta por Vapnik (VAPNIK, 1998), o hiperplano ótimo w pode ser encontrado minimizando a seguinte função:

$$
\min _{w, b, \xi_{i}} J\left(w, b, \xi_{i}\right)=\frac{1}{2}\left(\mathbf{w}^{T} \mathbf{w}\right)+C \sum_{i=1}^{N} \xi_{i},
$$


sujeita às restrições:

$$
y_{i}\left[\mathbf{w}^{T} \phi\left(\mathbf{x}_{\mathbf{i}}\right)+b\right] \geq 1-\xi, i=1, \ldots, N .
$$

onde a variável $C$ representa um termo de compromisso entre a complexidade do modelo e o erro de treinamento, e $\xi_{i}, i=1, \ldots, N$, são as variáveis de folga que medem a diferença entre a saída desejada e a saída da SVM. A solução para o problema de minimização da função-objetiva apresentada na Equação 20, sujeito às restrições em 21, é dado pelo ponto de sela da função lagrangeana. O problema primal associado à minimização da função lagrangeana pode ser transformado em sua forma dual, sendo esse problema dado pela Equação 22 (VAPNIK, 1998):

$$
\max _{\alpha} J(\alpha)=\sum_{i=1}^{N} \alpha_{i}-\frac{1}{2} \sum_{i=1}^{N} \sum_{j=1}^{N} \alpha_{i} \alpha_{j} y_{i} y_{j} \phi\left(\mathbf{x}_{i}\right)^{T} \phi\left(\mathbf{x}_{j}\right)
$$

sujeito à $\sum_{i=1}^{N} \alpha_{i} y_{i}=0$ e $0 \leq \alpha_{i} \leq C$, para $i=1, \ldots, N$,onde $\alpha_{i}(i=1, \cdots, N)$ são conhecidos como multiplicadores de Lagrange.

De forma a realizar o mapeamento $\phi\left(\mathbf{x}_{i}\right)^{T} \phi\left(\mathbf{x}_{j}\right)$ na Equação 22, não é necessário calcularmos $\phi\left(\mathbf{x}_{i}\right)$ ou $\phi\left(\mathbf{x}_{j}\right)$ de forma explícita, para isso pode-se empregar as chamadas funções Kernel (Equação 23). Essas funções realizam o mapeamento não-linear dos dados de entrada para um espaço de característica de maior dimensionalidade de forma eficiente (SCHOLKOPF; SMOLA, 2001), onde os dados são linearmente separáveis.

$$
K\left(x_{i}, x_{j}\right)=<\phi\left(x_{i}\right), \phi\left(x_{j}\right)>
$$

Após o processo de treinamento, as amostras que se encontram sobre a superfície de decisão apresentam valores de $\alpha_{i}$, da Equação 22, maiores que 0 e são chamadas de vetores suporte e são utilizadas para a definição da função de decisão do classificador (VAPNIK, 1998). Um determinado exemplo de teste $\mathbf{x} \in \mathfrak{R}^{m}$ é classificado ao final de acordo com a saída da Equação 24:

$$
\left[f(n)=\operatorname{sign}\left[\mathbf{w}^{T} \phi(\mathbf{x})+b\right]=\operatorname{sign}\left(\sum_{i=1}^{N} \alpha_{i} y_{i} K\left(\mathbf{x}, \mathbf{x}_{\mathbf{i}}\right)+b\right)\right]
$$

\subsection{Máquina de vetores suporte baseada em quadrados mínimos}

Uma das variantes das SVMs foi proposta por Suykens (SUYKENS; VANDEWALLE, 1999). Nessa abordagem, ao invés de solucionar um problema de otimização quadrática, é 
realizada uma mudança na formulação do problema visando transformá-lo num sistema de equações lineares. Essa abordagem é conhecida como Máquinas de Vetores Suporte Baseada em Quadrados Mínimos (LS-SVM).

Ao final do processo de treinamento da LS-SVM os vetores suportes, que correspondem aos coeficientes de Lagrange maiores que zero $\left(\beta_{i} \neq 0\right)$, são proporcionais aos erros obtidos no treinamento, ao contrário da SVM tradicional que a maioria dos coeficientes de Lagrange são iguais a zero, ou seja, não são vetores suporte.

A formulação do problema de classificação utilizando LS-SVM pode ser definida pela Equação 25:

$$
\min _{w, b, e} \jmath_{3}(w, b, e)=\frac{1}{2} w^{T} w+\gamma \frac{1}{2} \sum_{k=1}^{N} e_{k}^{2}
$$

onde $e_{k}$ representa o erro de treinamento para $k$-ésimo ponto, sujeito às restrições da Equação 25:

$$
y_{k}\left[w^{T} \varphi\left(x_{k}\right)+b\right]=1-e_{k}, k=1, \ldots, N
$$

A formulação dual pode ser definida em termos do Lagrangeano $L$ da LS-SVM através da Equação 27:

$$
L(w, b, e, \alpha)=\jmath_{3}(w, b, e)-\sum_{k=1}^{N} \alpha_{k} y_{k}\left[w^{T} \varphi\left(x_{k}\right)+b\right]-1+e_{l}
$$

sendo que $\alpha_{k}$ representa os multiplicadores de Lagrange, que podem ser positivos ou negativos. A condição de otimalidade da Equação 27 pode ser definida como:

$$
\left\{\begin{array}{l}
\frac{\partial L}{\partial w}=0 \rightarrow w=\sum_{k=1}^{N} \alpha_{k} y_{k} \varphi\left(x_{k}\right), \\
\frac{\partial L}{\partial b}=0 \rightarrow \sum_{k=1}^{N} \alpha_{k} y_{k}=0, \\
\frac{\partial L}{\partial e_{k}}=0 \rightarrow \alpha_{k}=\gamma e_{k}, \\
\frac{\partial L}{\partial \alpha_{k}}=0 \rightarrow \gamma_{k}\left[w^{T} \varphi\left(x_{k}\right)+b\right]-1+e_{k}=0, k=1, \ldots, N
\end{array}\right.
$$


A solução desse conjunto de equações pode ser obtida através do seguinte sistema de equações lineares:

$$
\left[\begin{array}{ccc|c}
I & 0 & 0 & -Z^{T} \\
0 & 0 & 0 & -Y^{T} \\
0 & 0 & \gamma^{I} & -I \\
\hline Z & Y & I & 0
\end{array}\right]\left[\begin{array}{l}
w \\
b \\
e \\
\alpha
\end{array}\right]\left[\begin{array}{l}
0 \\
0 \\
0 \\
\overrightarrow{1}
\end{array}\right]
$$

sendo que $Z=\left[\varphi\left(x_{i}\right)^{T} y_{i} ; \ldots ; \varphi\left(x_{N}\right)^{T} y_{N}\right]$ representa a matriz de Kernel, $Y=$ $\left[y_{1}, \ldots, y_{N}\right], \overrightarrow{1}=[1 ; \ldots ; 1], e=\left[e_{1} ; \ldots ; e_{N}\right], \alpha=\left[\alpha_{1} ; \ldots ; \alpha_{N}\right]$. A solução pode ser obtida usando a Equação 30:

$$
\left[\begin{array}{c|c}
0 & -Y^{T} \\
\hline Y & Z Z^{T}+\gamma^{-1} I
\end{array}\right]\left[\begin{array}{l}
b \\
\hline \alpha
\end{array}\right]=\left[\begin{array}{l}
0 \\
\overrightarrow{1}
\end{array}\right]
$$

Outra alternativa é gerar a matriz $\Omega=Z Z^{T}$. Utilizando a função Kernel, temos que $\Omega_{k l}=y_{k} y_{l} \varphi\left(x_{k}\right)^{T} \varphi\left(x_{l}\right)=y_{k} y_{l} K\left(x_{k}, x_{l}\right)$, onde $K\left(x_{k}, x_{l}\right)$ representa o mapeamento realizado pela função de Kernel. Logo, a função decisão do classificador LS-SVM, Equação 24, pode ser definida através solução do sistema linear definido na Equação 30. Neste caso, a saída da LS-SVM pode ser obtida através do mesmo processo realizado pelas SVMs, porém ao contrário da SVM, nenhum ponto é desconsiderado na construção da fronteira de decisão.

\subsection{Comitês de máquinas}

Em vez de se fixar no estudo de preditores operando isoladamente, a subárea de pesquisa conhecida como Comitês de Máquinas (KUNCHEVA, 2004; TRESP, 2001) se ocupa do estudo de diferentes maneiras de se combinar vários estimadores, oriundos de distintos métodos de aprendizado (não-)supervisionado, em um só arranjo conceitual. Uma primeira motivação em se trabalhar com comitês de máquinas é a de eliminar a necessidade de se ter que configurar acertadamente parâmetros de cada estimador. Outra forte justificativa é que os módulos que compõem tais sistemas têm propensão a apresentar menor complexidade, facilitando o seu entendimento por parte do projetista, bem como uma possível modificação ou extensão a posteriori.

No contexto supervisionado, duas classes de abordagens complementares de comitês de máquinas podem ser discriminadas na literatura (SHARKEY, 1999). A primeira classe 
se baseia mais explicitamente no preceito de "dividir para conquistar", onde uma tarefa complexa passa a ser decomposta em certo número de subtarefas, cada uma delas alocada a um subgrupo de especialistas. Uma forma de se modularizar a arquitetura do sistema é a de se definir, dinamicamente, regiões do espaço de entradas a serem atribuídas aos especialistas, com isso tem-se que a decisão do grupo para uma certa amostra passa a ser tomada apenas por aquele(s) especialista(s) alocado(s) à região a que ela pertence. Essa estratégia de é conhecida como misturas de especialistas (MEs) (LIMA; COELHO; ZUBEN, 2004; JACOBS et al., 1991), que emprega um módulo de combinação especial, chamado de gating, que faz uso da informação de entrada de maneira a selecionar os especialistas mais aptos para tratarem a entrada corrente.

A outra classe de abordagens de comitês, conhecida por ensembles (coletâneas) de estimadores (HASHEM, 1997; KUNCHEVA, 2004; SHARKEY, 1999), segue a lógica de se fundir apropriadamente o conhecimento adquirido por vários módulos-especialistas para se chegar a uma decisão geral que seja, supostamente, superior àquela alcançável por qualquer um dos membros do grupo em separado. Neste caso, em vez de dividir a tarefa de predição em subtarefas, adota-se a redundância de diferentes módulos, os quais devem apresentar alta diversidade de generalização entre si. Os vários esquemas possíveis de combinação existentes na literatura diferem basicamente entre si com relação às suas arquiteturas, às características de seus módulos-combinadores e ao modo como produzem e selecionam seus componentes. Inclusas estão nesse contexto as proeminentes técnicas estatísticas de bagging e boosting (HASTIE; TIBSHIRANI; FRIEDMAN, 2009; KUNCHEVA, 2004), voltadas à geração de estimadores complementares mediante a reamostragem aleatória e adaptativa dos dados amostrais.

Costuma-se dividir o projeto efetivo de ensembles em três etapas sequenciais e interdependentes, destinadas à criação, seleção e combinação dos componentes, os quais, por sua vez, devem apresentar duas propriedades básicas: (1) elevados níveis de acuidade e (2) diferentes padrões de generalização. Nesse âmbito, ensembles heterogêneas de redes neurais feedforward, de máquinas de vetores-suporte e mesmo de diferentes indutores de aprendizado de máquina supervisionado são abordagens introduzidas na literatura pelo orientador desta dissertação (COELHO; LIMA; ZUBEN, 2003; LIMA; COELHO; ZUBEN, 2002b; LIMA; COELHO; ZUBEN, 2002a; SALGADO et al., 2006). Uma revisão sobre a teoria de ensembles será apresentada na Seção 4.3.1. 


\subsubsection{Ensembles}

Em (COELHO, 2004) tem-se que o termo ensemble representa diferentes métodos de construir, selecionar e combinar máquinas de aprendizados, que geram um conjunto de soluções redundantes para um determinado problema. Entretanto, cada máquina apresenta uma configuração diferente uma das outras. Na Figura 21 é apresentada a estrutura de um ensemble com $k$ componentes e um combinador, sendo que cada componente produz uma saída para a mesma entrada $x$.

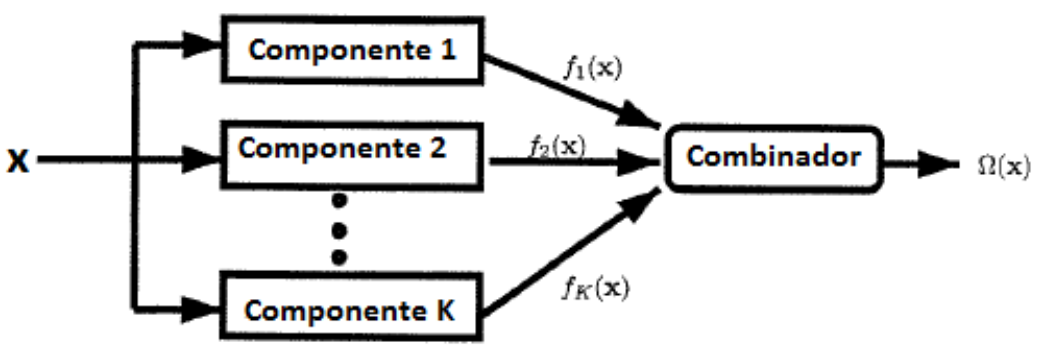

Figura 21 - Estrutura de um ensemble.

Para que um ensemble de classificadores possa obter um resultado superior aos componentes individuais é necessário que esses componentes, de forma individual, produzam resultados satisfatórios, porém devem ser diversos entre si (HANSEN; SALAMON, 1990). Em (LIMA, 2004) são apresentadas algumas motivações para o uso de ensembles, sendo que essas motivações nem sempre são verdadeiras, por isso podem acontecer casos no qual um ensemble apresente desempenho inferior ao obtido por alguns dos componentes isoladamente.

A primeira motivação para o uso de ensemble reside no fato que o treinamento de um classificador produz uma hipótese $f$ no espaço de hipóteses $H$. Entretanto, para realizar a construção de um classificador que consiga resolver um determinado problema no espaço de hipótese $H$ de forma perfeita é necessário ter um conjunto infinito de dados. Como geralmente tem-se um conjunto reduzido de dados, pode-se gerar um conjunto de hipóteses diferentes e através da combinação destas obter uma hipótese mais próxima da função desejada. Esse cenário é ilustrado na Figura 22(a) onde $f$ é a hipótese buscada e $f_{i}$ são as hipóteses geradas.

A segunda motivação proposta reside no fato que o projeto de classificadores envolve algum processo de otimização, o qual depende da inicialização adotada. Logo 
diferentes inicializações poderão produzir classificadores com desempenhos diferentes. Então a combinação de um conjunto de diferentes classificadores inicializados com diferentes configurações de parâmetros dentro de um mesmo espaço de hipóteses $H$ pode chegar a uma aproximação melhor para função esperada $f$. Esse cenário é apresentado na Figura $22(\mathrm{~b})$.

A terceira motivação diz respeito ao espaço de hipótese $H$, o qual pode não conseguir representar a função desejada $f$, o que é chamado de problema de representação. Logo pode-se selecionar e combinar um conjunto de classificadores $f_{i}$ de forma a obter uma melhor aproximação para a função desejada $f$. Esse cenário é ilustrado na Figura 22(c).

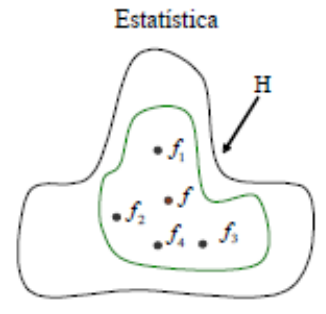

(a)

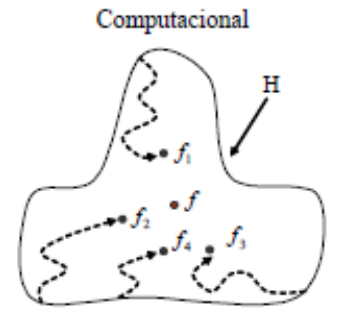

(b)

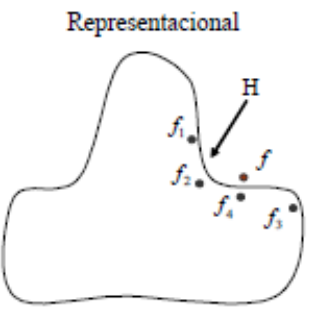

(c)

Figura 22 - Motivações para o uso de ensemble. Retirado de Lima(2004) (LIMA, 2004).

Conforme já mencionado, a construção de uma ensemble pode ser realizada em 3 passos distintos: geração de um conjunto de classificadores, seleção dos classificadores a serem utilizados e escolha do método de combinação a ser utilizado. Em Lima(2004) (LIMA, 2004) são apresentados diferentes métodos que podem ser utilizados para cada uma dessas etapas de construção de um ensemble. Nas próximas seções serão apresentadas algumas ideias para cada etapa.

\subsubsection{Geração de componentes}

Intuitivamente, a combinação de múltiplos classificadores é vantajosa, uma vez que classificadores diferentes podem implicitamente representar aspectos distintos e, ao mesmo tempo, relevantes para a solução de um dado problema. Basicamente, há duas formas de 
gerar esses componentes: i) emprego de arquiteturas diferentes para cada classificador, usando diferentes Máquinas de Kernel ou Máquinas de Kernel com diferentes funções de Kernel; ii) processamento dos dados de treinamento.

Como visto anteriormente para que um determinado ensemble apresente um desempenho satisfatório na resolução de um problema é necessário que os seus componentes apresentem desempenhos satisfatórios e sejam distintos entre si, pode-se definir duas maneiras de gerar esses componentes, sendo uma através da definição de diferentes arquiteturas para um mesmo classificador, neste caso de Máquinas de Kernel diferentes e com diferentes Kernel e a outra baseada em processamento sobre os dados de treinamento.

Na primeira categoria pode-se gerar os componentes do ensemble usando as seguintes estratégias:

- Diferentes Máquinas de Kernel: Essa abordagem consiste na utilização de diferentes máquinas de Kernel, por exemplo pode-se definir um conjunto de SVMs e LS-SVMs, onde cada uma delas é treinada com o mesmo conjunto de dados e ao final realiza-se uma combinação destes;

- Variação dos parâmetros: Essa abordagem emprega um conjunto de classificadores do mesmo tipo, mas com diferentes parâmetros, por exemplo, pode-se variar o tipo de função de Kernel, parâmetro da função Kernel e parâmetro de regularização.

Já em relação às estratégias que envolvem o processamento dos dados de treinamento, pode-se destacar os algoritmos de bagging (BREIMAN, 1996) e de boosting (SCHAPIRE, 1990). A primeira realiza uma re-amostragem dos dados e a segunda aplica uma abordagem adaptativa sobre a re-amostragem dos dados.

\subsubsection{Bagging}

O algoritmo bagging (BREIMAN, 1996) gera vários conjunto de treinamento a partir de amostragem uniforme do conjunto de dados, com reposição, e utiliza cada um desses conjuntos para treinar um classificador. A partir de um conjunto de dados $X$ contendo

$N$ elementos, a probabilidade de escolha de uma determinada instância é dada por $\frac{1}{N}$, gera-se $M$ subconjuntos de dados de treinamento, cada um contendo $N$ instâncias.

Em (LIMA, 2004) menciona-se que quanto maior o valor de $N$, maior é a possibilidade de que um subconjunto gerado apresente dados repetidos. Além disso, quando $N$ assume 
um valor suficientemente elevado, essa estratégia representa uma técnica eficaz para a construção de subconjuntos de treinamento, dado que mantém uma boa representação do conjunto original e mantém uma boa distinção entre cada subconjunto.

A construção de $M$ conjuntos de treinamento distintos, não garante que os $M$ componentes treinados apresentem capacidade de generalização distinta, para isso é necessário que os componentes sejam instáveis. Isto significa que os componentes devem responder de forma distinta para diferentes conjuntos de treinamento, porém é necessário que esta variação não seja muito alta.

\subsubsection{Boosting}

Neste método, os conjuntos de treinamento não são gerados via amostragem uniforme, como no algoritmo bagging. A probabilidade de uma dada amostra ser escolhida depende da contribuição desta para o erro dos classificadores já treinados. Uma instância que não seja corretamente classificada pelos classificadores já treinados terá uma maior probabilidade de ser selecionada que uma instância que seja corretamente classificada. Com isto, esta amostra terá uma chance maior de compor o conjunto de treinamento do próximo classificador a ser treinado. No bagging os classificadores podem ser treinados de forma paralela, visto que a probabilidade de escolha não depende do resultado da classificação, já no boosting cada classificador deve ser treinado de forma sequencial. O algoritmo boosting foi proposto por Schapire (SCHAPIRE, 1990).

Considere uma ensemble formada por 3 componentes, neste caso, dado um conjunto de dados contendo $N$ instâncias, inicialmente seleciona-se um conjunto $N_{1}$ contendo $N$ instâncias usando uma distribuição uniforme. Com base neste conjunto treina-se o componente $C_{1}$. O segundo componente $C_{2}$ é treinado sobre o conjunto $N_{2}$, onde metade das instâncias de $N_{2}$ foram classificadas corretamente por $C_{1}$. A última componente $C_{3}$ é treinada sobre um conjunto $N_{3}$, sendo que $N_{3}$ contém apenas os elementos que $C_{1}$ e $C_{2}$ discordaram sobre a sua classificação. A saída final do ensemble, para este exemplo, pode ser obtida com o voto majoritário.

A versão mais popular do algoritmo de boosting é chamada AdaBoost ((FREUND; SCHAPIRE, 1996)), na qual cada componente é treinado sequencialmente e a distribuição dos dados de treinamento é realizada levando-se em consideração os erros do componente treinado no passo imediatamente anterior. Neste, o conjunto de dados para o primeiro 
componente é selecionado baseado numa distribuição uniforme. Para o segundo componente, a distribuição dos dados é atualizada com base no erro cometido pelo componente anterior. Uma variante do AdaBoost foi proposta por (OZA, 2003) e, neste algoritmo, a distribuição das amostras se baseia no erro de todos os componentes treinados até o momento, e não apenas no erro do componente treinado no passo imediatamente anterior.

\subsubsection{Seleção de classificadores}

Após a geração dos componentes do ensemble, a etapa seguinte do processo é escolher, dentre estes candidatos gerados, aqueles que realmente contribuem para o desempenho do ensemble, uma vez que a inclusão de todos os candidatos no ensemble pode reduzir seu desempenho. Em (COELHO, 2004) duas abordagens para seleção de componente no ensemble foram discutidas, a saber, abordagem construtiva e poda. Essas técnicas serão descritas nas subseções a seguir.

\subsubsection{Abordagem construtiva}

Inicialmente os $M$ candidatos a comporem o ensemble são ordenados com base no desempenho individual obtido sobre o conjunto de dados de seleção. O candidato com melhor desempenho individual é inserido no ensemble. O próximo candidato (segundo melhor desempenho individual) é então adicionado ao ensemble. Se o desempenho do ensemble em relação ao conjunto de dados de seleção melhorar, o ensemble passa a ter dois componentes. Caso contrário, o elemento inserido é removido. Este processo se repete para todos os demais candidatos restantes na lista ordenada gerada inicialmente, um após o outro. Ao final da execução desta técnica de seleção, são testados $M-1$ ensembles ao todo.

\subsubsection{Abordagem de poda}

As técnicas de poda funcionam no sentido oposto ao adotado pelas técnicas construtivas. Neste caso, os $M$ candidatos são inicialmente ordenados a partir de seu desempenho individual em relação ao conjunto de dados de seleção ou treinamento. Todos os candidatos são inseridos no ensemble. Em seguida, o candidato com pior desempenho individual é 
removido e o ensemble tem seu desempenho avaliado em relação ao conjunto de dados de seleção. Se ocorreu uma melhora no seu desempenho em relação à configuração anterior, o ensemble passa a contar então com $M-1$ componentes. Caso contrário, o candidato retirado é re-inserido, e o processo então se repete para os demais candidatos, exceto o de melhor desempenho individual, que nunca é removido do ensemble.

\subsubsection{Combinação de Classificadores}

Outra questão na construção de ensembles diz respeito a forma como as saídas de cada componente serão combinadas para gerar uma única saída. Em (COELHO, 2004) e (LIMA, 2004) são apresentadas algumas formas de realizar a combinação de componentes de um ensemble de classificadores. A seguir será descrito dois métodos comumente utilizado:

Média e Média Ponderada: trata-se de um dos métodos mais comumente utilizados para a construção de ensembles. Este realiza uma combinação linear da saída dos classificadores usando a seguinte equação:

$$
\hat{f}(x)=\max _{k \in U} S_{k}
$$

onde $S_{k}=\frac{1}{M} \sum_{j=1}^{M} \mu_{j}^{k}(x), \mu_{j}^{k}$ é a saída do $j$-ésimo classificador para a $k$-ésima classe, $U$ é a quantidade de classes. Com isso a classe final será aquela que apresentar maior valor médio.

Voto Majoritário: dada uma instância do conjunto de dados, cada componente do ensemble apontará uma classe para esta amostra e a classe que receber o maior número de votos (for apontada pelo maior número de componentes), corresponderá ao rótulo atribuído a esta instância pelo ensemble. Neste caso, a classe final é aquela atribuída pela maioria dos componentes e pode ser definido como:

$$
\hat{f}=\arg \max _{k}\left(\sum_{j=1}^{M} G_{j}^{k}(x)\right)
$$

sendo que $G_{j}^{k}(x)=\left\{\begin{array}{l}1 \text { se } f_{j}(x)=k \\ 0 \text { se } f_{j}(x) \neq k\end{array}\right.$

Winner-takes-all : consiste em selecionar como rótulo da classe na saída do ensemble o rótulo gerado pelo componente que apresentar a saída de maior valor dentre todos os componentes do ensemble. 


\section{Abordagem proposta}

Neste capitulo serão descritas as diversas propostas de construção de sistemas biométricos unimodais e multimodais baseado em ensemble. Na Seção 5.1 serão apresentadas as propostas para construção de sistemas biométricos unimodais, enquanto que na Seção 5.2 serão apresentadas as propostas para a construção de sistemas biométricos multimodais.

\subsection{Construção dos sistemas biométricos unimodais}

A primeira etapa consiste na construção dos sistemas biométricos unimodais usando as estratégias de extração de característica apresentadas no Capítulo 3 juntamente com os classificadores, SVM e LS-SVM, com diferentes parâmetros. O objetivo desta etapa é verificar o desempenho dos modelos de forma individual para o problema estudado.

Após a construção dos sistemas individuais foi realizada a construção de diferentes ensembles, visando verificar se a combinação de diferentes classificadores pode produzir desempenho superior ao obtido pelos classificadores individuais. As estratégias utilizadas foram as seguintes:

- Variação dos parâmetros da técnica de extração de característica - neste caso os classificadores são do mesmo tipo (parâmetros e modelos iguais), somente os parâmetros das técnicas de extração sofrem variação. Dada uma técnica de extração de característica, para cada parâmetro é gerado um conjunto de característica e esses conjuntos são usados como entrada para um classificador. A saída dos classificadores é combinada por alguma das técnicas descrita no Capítulo 4. A Figura 23 ilustra este processo.

- Variação dos parâmetros da técnica de extração de característica e do parâmetro do classificador - neste caso os classificadores são do mesmo modelo (SVM ou LS-SVM), mas o parâmetro do função Kernel é selecionado dentro de um determinado intervalo. Na estratégia anterior, o valor do parâmetro da função Kernel é fixo. A Figura 24 ilustra este processo.

- Variação do modelo do classificador - neste caso, a técnica de extração de característica é mantida a mesma para todos os componentes, apenas o modelo do classificador que é alterado. O vetor de característica é usado como entrada para os classificadores 


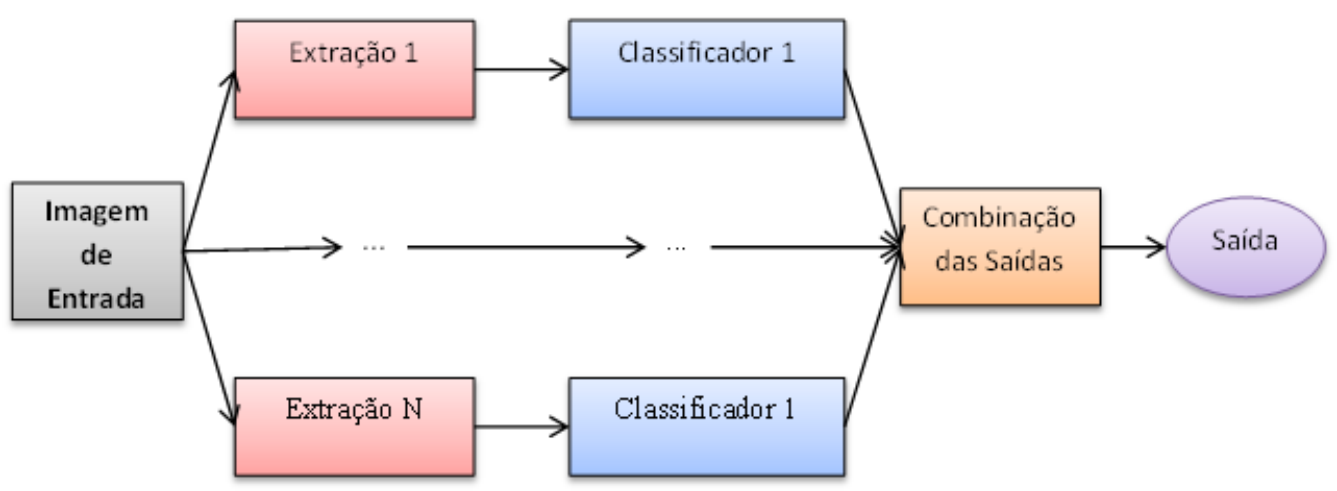

Figura 23 - Ensemble baseado na variação dos parâmetros da técnica de extração de características.

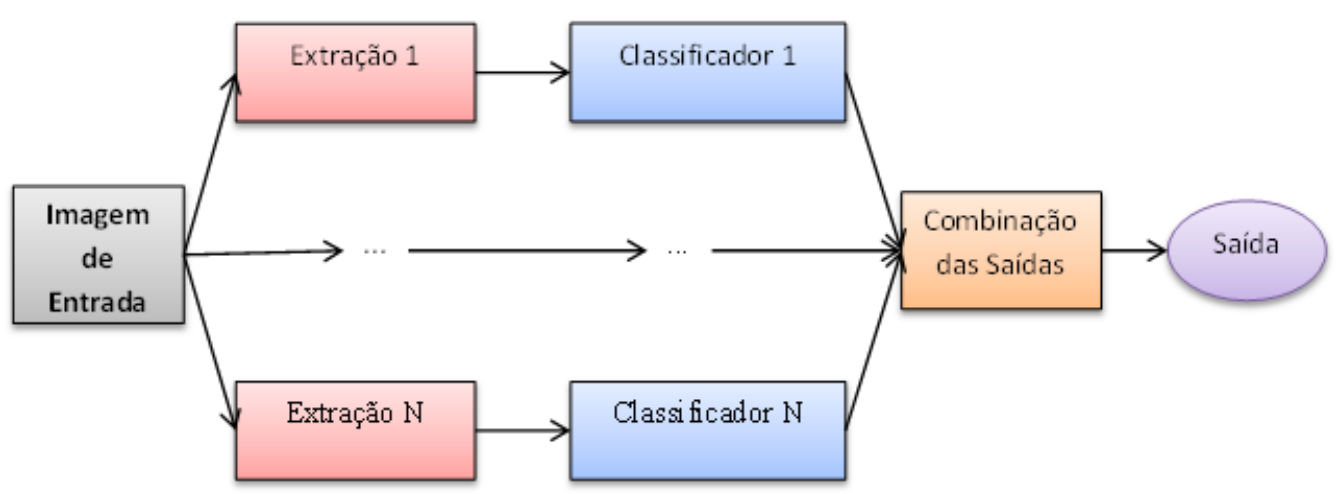

Figura 24 - Ensemble baseado na variação dos parâmetros da técnica de extração de características e do parâmetro do classificador.

SVM e LS-SVM, os quais possuem o mesmo valor de $\sigma$. Este processo é apresentado na Figura 25.

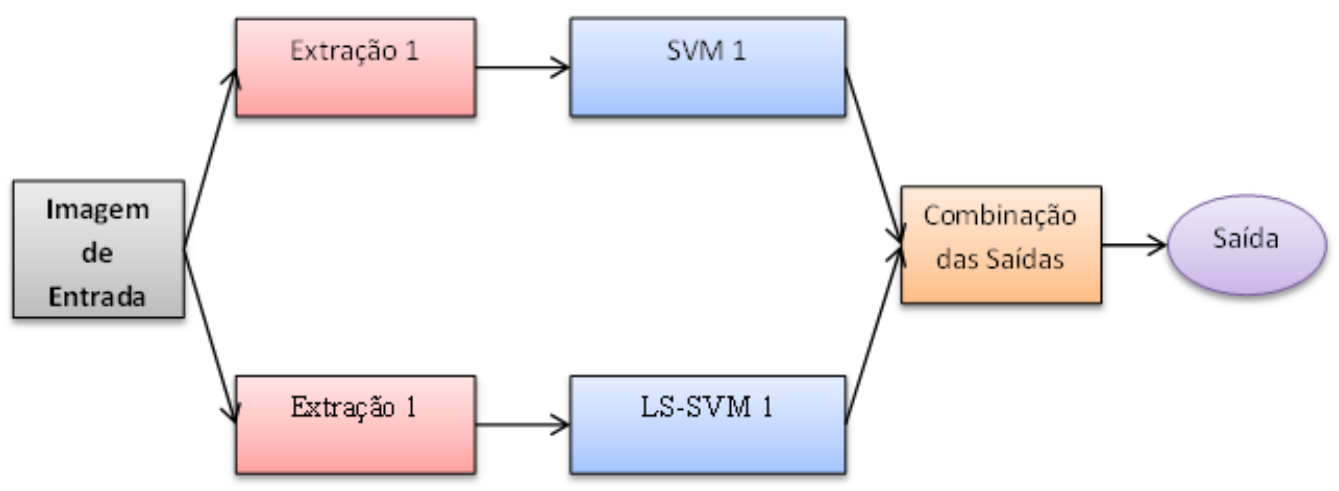

Figura 25 - Ensemble baseado na variação do modelo do classificador.

- Diferentes técnicas de extração de característica - neste caso, todos os componentes empregam o mesmo classificador (SVM ou LS-SVM). Cada componente emprega uma 
técnica de extração de característica diferente com os parâmetros que produziram melhor desempenho. A Figura 26 ilustra este processo.

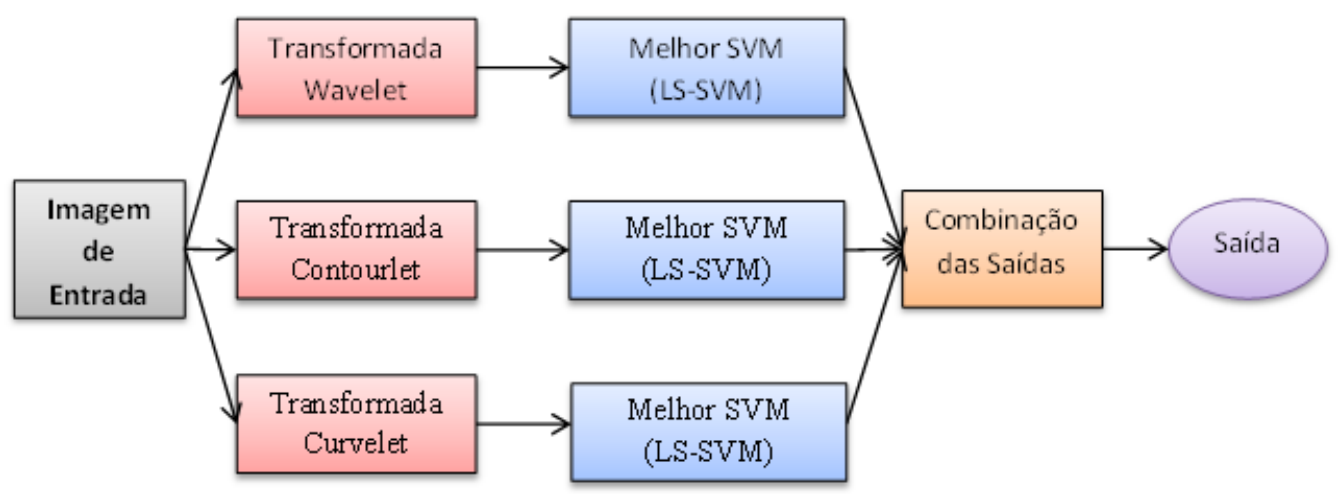

Figura 26 - Ensemble baseado em diferentes técnicas de extração de características.

- Diferentes técnicas de extração de característica com melhor Classificador - neste caso, cada componente emprega a melhor configuração obtida para cada técnica de extração de característica, isto é, dada uma técnica de extração de característica é escolhido os parâmetros e classificadores que produziram melhor desempenho. A Figura 27 ilustra este processo.

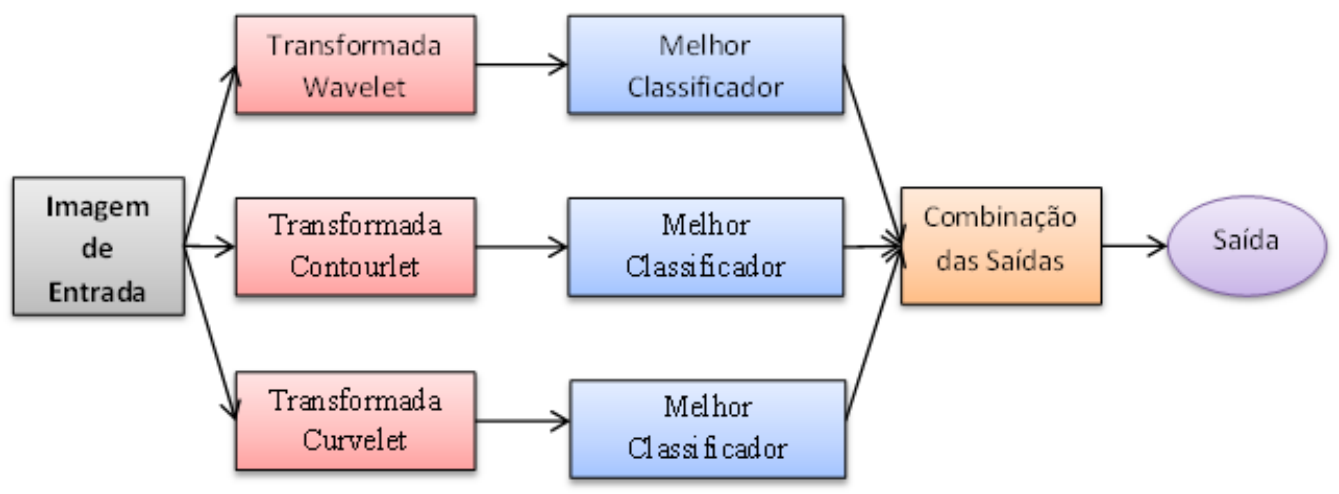

Figura 27 - Ensemble baseado em diferentes técnicas de extração de características usando o melhor classificador.

\subsection{Construção dos sistemas biométricos multimodais}

Como visto na Seção 2.2.1, o projeto de sistema biométrico multimodal envolve a determinação das modalidades biométricas, o nível de fusão das características biométricas e a estratégia de fusão a ser realizada. Com base nesses parâmetros várias arquiteturas serão propostas. 
A Figura 28 ilustra os diversos níveis de fusão no qual pode ser construído um sistema biométrico multimodal.

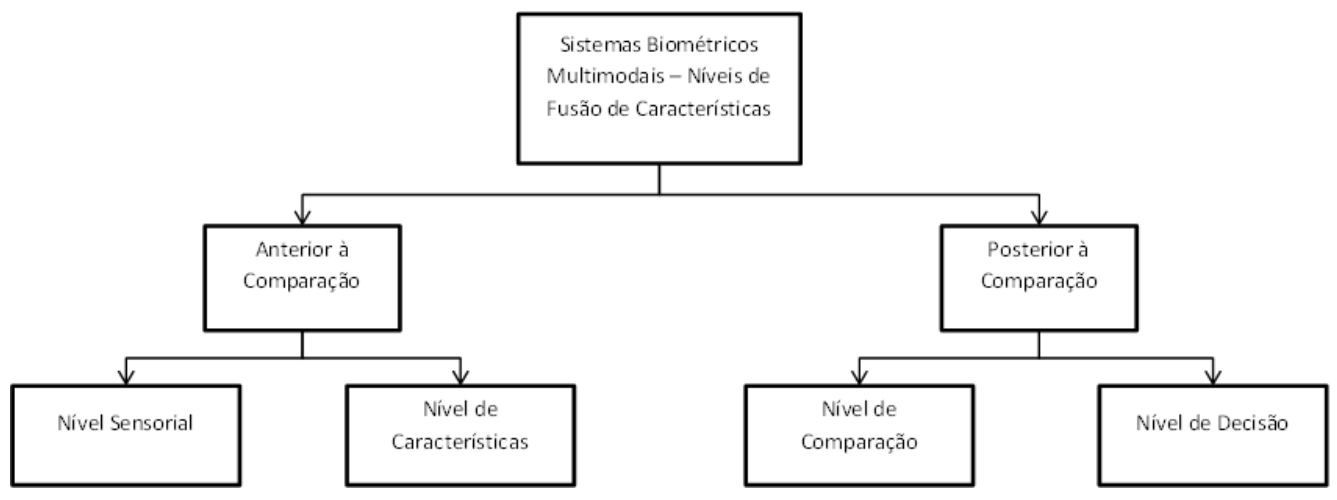

Figura 28 - Níveis de fusão em sistemas biométricos multimodais.

Para a construção dos sistemas biométricos multimodais foram utilizados somente dois níveis de fusão: fusão no nível de características e fusão no nível de decisão. A fusão no nível de decisão foi utilizada apenas para os melhores casos obtidos com os sistemas unimodais.

No caso da fusão no nível de característica, após a extração da informação relevante da imagem da face e da íris são aplicadas técnicas as extração de características descritas no Capítulo 3. Em seguida são aplicadas diferentes estratégias para a construção de um único vetor de características resultante da fusão de ambos os vetores individuais. No total foram selecionadas 7 estratégias diferentes de combinação das características, a saber: concatenação (RATTANI et al., 2006), coeficientes de aproximação da face e detalhes da íris (DIVYALOSHINI; SARASWATHI, 2014), coeficientes de aproximação da íris e detalhes da face (DIVYALOSHINI; SARASWATHI, 2014), preservação de contornos (KHARE; SRIVASTAVA; SINGH, 2012), mínimo dos coeficientes de aproximação e máximo dos coeficientes de detalhes (DIVYALOSHINI; SARASWATHI, 2014), média dos coeficientes de aproximação e máximo dos coeficientes de detalhes e soma (WANG et al., 2009).

Os métodos de fusão no nível de características que serão utilizadas respeitam os requisitos levantadas na Seção 2.2.1.1, isto é, i) mesmo intervalo de valores para os vetores de características a serem combinados; ii) vetores de característica de mesma dimensão para todos os usuários.

A estratégia de combinação de características baseados em concatenação, proposta por (RATTANI et al., 2006), realiza a fusão dos vetores de características $X=$ $x_{1}, x_{2}, \cdots, x_{n}$ e $Y=y_{1}, y_{2}, \cdots, y_{m}$ de forma a gerar o vetor de características $Z=$ 
$x_{1}, x_{2}, \cdots, x_{n}, y_{1}, y_{2}, \cdots, y_{m}$. A vantagem dessa abordagem é que cada característica biométrica pode passar por um processo de extração diferente, dado que não tem a necessidade de apresentarem a mesma dimensão para a sua combinação.

Como visto na Seção 2.2.1.1, para que a concatenação das características possa ser utilizada de forma efetiva é necessário que ambos os vetores estejam normalizadas no mesmo intervalo. O maior problema dessa abordagem é que o vetor resultante $Z$ terá a dimensão $n+m$, o que pode causar dificuldade para a construção dos classificadores. De modo a superar essa dificuldade pode ser aplicada técnicas de redução de dimensionalidade como PCA e LDA, esse processo pode ser realizado posterior (DESHMUKH; PAWAR; JOSHI, 2013) e anterior (AHMAD; WOO; DLAY, 2010) a concatenação.

A segunda e a terceira estratégia realiza a combinação das características através da substituição dos coeficientes de uma determinada banda, resultante do processo de decomposição das transformadas, de uma modalidade por outra. Estas estratégias foram propostas por (DIVYALOSHINI; SARASWATHI, 2014). No entanto, uma alteração foi realizada sobre o método original, ao invés de realizar a reconstrução da imagem após a substituição dos coeficientes, foram utilizados os coeficientes como vetor de característica. A transformada Curvelet, devido à natureza da sua decomposição, não apresenta essas estratégias no seu último nível. A Figura 29 mostra em detalhes o funcionamento dessas estratégias.

Estratégia 2

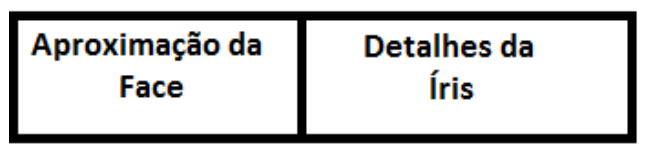

Estratégia 3

\begin{tabular}{|c|c|}
\hline $\begin{array}{c}\text { Aproximação da } \\
\text { Íris }\end{array}$ & $\begin{array}{c}\text { Detalhes da } \\
\text { Face }\end{array}$ \\
\hline
\end{tabular}

Figura 29 - Estratégias baseadas na troca de coeficientes extraídas da face e íris.

Com relação à estratégia de fusão de preservação de contornos proposta por (KHARE; SRIVASTAVA; SINGH, 2012), para que esta possa ser utilizada é necessário que as características biométricas sejam processadas pela mesma transformada. Os passos dessa abordagem podem ser descritos como:

- Decompor as imagens de entrada $I_{1}$ e $I_{2}$, gerando os coeficientes $C_{1}$ e $C_{2}$;

- Aplicação de uma técnica de detecção de contornos de forma a gerar as contornos das imagens $S_{1}$ e $S_{2}$. Em seguida aplica-se as seguintes condições:

$$
\text { - Se } S_{1}(x, y)=1 \text { e } S_{2}(x, y) \neq 1 \text { então } F(x, y)=C_{1}(x, y) \text {; }
$$


- Se $S_{2}(x, y)=1$ e $S_{1}(x, y) \neq 1$ então $F(x, y)=C_{2}(x, y)$;

- Se $S_{1}(x, y) /$ neq $1, S_{2}(x, y) \neq 1$ e $\left\|C_{1}(x, y)\right\| \geq\left\|C_{2}(x, y)\right\|$ então $F(x, y)=$ $C_{1}(x, y)$;

- Se $S_{1}(x, y) / n e q 1, S_{2}(x, y) \neq 1$ e $\left\|C_{1}(x, y)\right\|<\left\|C_{2}(x, y)\right\|$ então $F(x, y)=$ $C_{2}(x, y)$

- Esse processo é realizado para todas as possíveis subimagens e ao final o conjunto de coeficientes $F$ é utilizado como vetor de características a ser utilizado como entrada para um classificador.

A quinta e a sexta estratégia realiza a combinação das características através do cálculo de valores mínimos, médios e máximos em relação aos coeficientes de cada uma das bandas, resultantes das decomposições das transformadas. Estas também foram propostas em (DIVYALOSHINI; SARASWATHI, 2014). A Figura 30 apresenta o método de funcionamento dessas estratégias.

Estratégia 5

\begin{tabular}{|c|c|}
\hline Mínimo das & $\begin{array}{c}\text { Máximo dos } \\
\text { Detalhes }\end{array}$ \\
\hline
\end{tabular}

Estratégia 6

Média das Aproximações
Máximo dos Detalhes

Figura 30 - Estratégias baseadas nos coeficientes extraídos da face e íris.

A última estratégia realiza a soma de coeficientes de duas características biométricas. Esta foi proposta por (WANG et al., 2009). Dado duas característica biométrica representadas pelos vetores de características $X=x_{1}, x_{2}, \cdots, x_{n}$ e $Y=y_{1}, y_{2}, \cdots, y_{n}$, ambas apresentando a mesma quantidade de características $n$, então pode-se definir o vetor $Z$ como:

$$
Z=x_{1}+y_{1}, x_{2}+y_{2}, \cdots, x_{n}+y_{n}
$$

Após a construção dos sistemas multimodais baseados nas estratégias de combinação descritas acima, foram definidas as estratégias para construção de ensembles. As abordagens definidas seguiram o mesmo padrão dos ensembles projetados para os sistemas biométricos unimodais e podem ser descritas como:

- Variação dos parâmetros da técnica de extração de característica - neste caso, cada componente do ensemble emprega o mesmo classificador (parâmetro e modelos iguais) 
e mesma estratégia de fusão, somente os parâmetros das técnicas de extração de característica sofreram variação. A Figura 31 ilustra este processo.

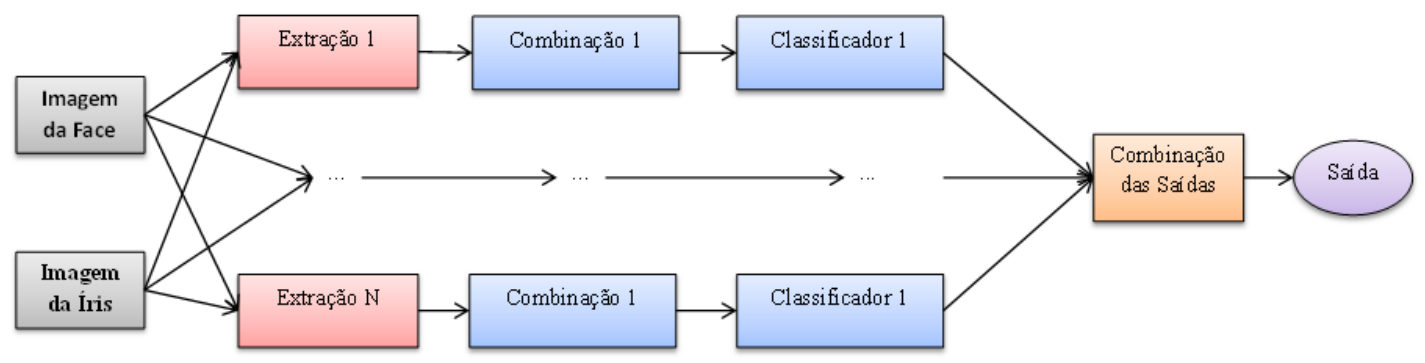

Figura 31 - Ensemble baseado na variação dos parâmetros da técnica de extração de características usando o mesmo classificador e mesma estratégia de fusão.

- Variação dos parâmetros da técnica de extração de característica e do parâmetro do classificador - neste caso, cada componente emprega a mesma estratégia de fusão, o mesmo classificado (SVM ou LS-SVM) com o parâmetro da função Kernel escolhido dentro de um determinado intervalo e os parâmetros das técnicas de extração de característica também sofreram variação. A Figura 32 ilustra este processo.

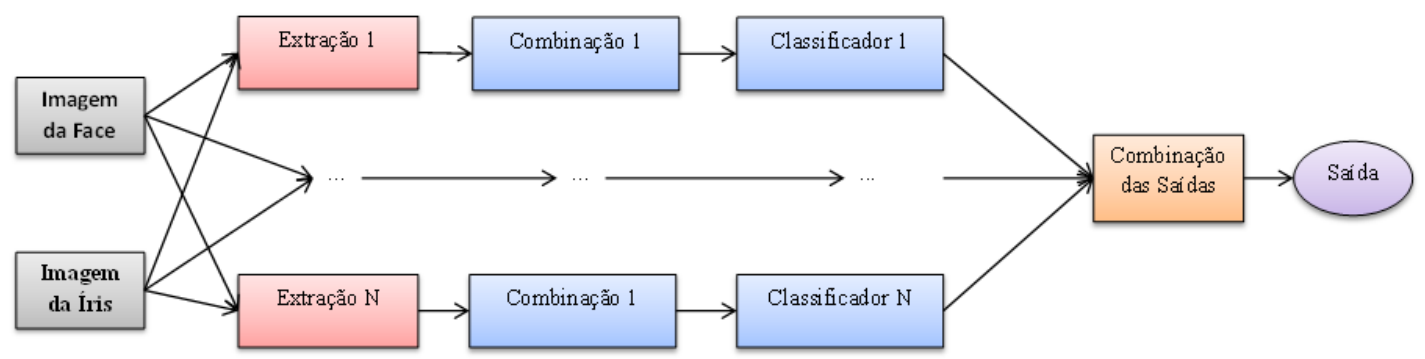

Figura 32 - Ensemble baseado na variação dos parâmetros da técnica de extração de característica e do parâmetro do classificador usando a mesma estratégia de fusão.

- Variação do modelo do classificador - neste caso, cada componente usa a mesma técnica de extração de característica, mesma estratégia de combinação, porém classificadores diferentes (SVM ou LS-SVM) construídos com o mesmo parâmetro de Kernel. A Figura 33 ilustra este processo.

- Diferentes técnicas de extração de característica usando o mesmo classificador - neste caso, cada componente emprega o mesmo classificador, mas com uma técnica de extração de característica diferente, cujos parâmetros foram aqueles que produziram melhor desempenho entre as estratégias de fusão. A Figura 34 ilustra este processo. 


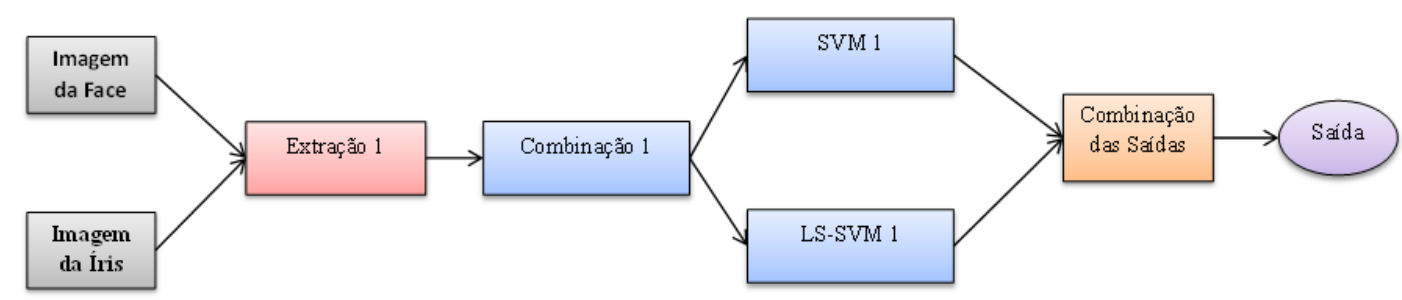

Figura 33 - Ensemble baseado na variação do modelo do classificador usando mesma configuração para as transformada e estratégia de fusão.

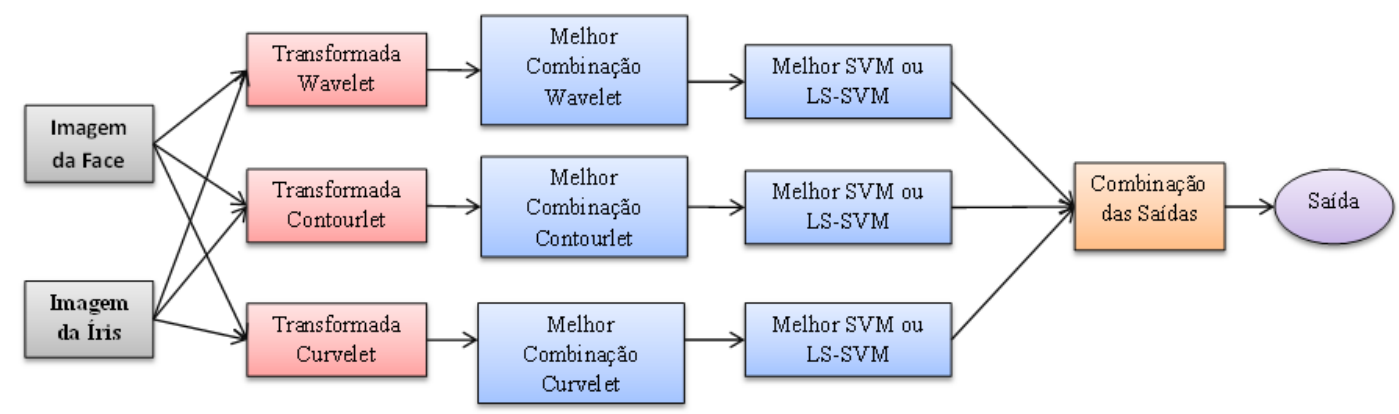

Figura 34 - Ensemble baseado em diferentes técnicas de extração de características usando o mesmo classificador.

- Diferentes técnicas de extração de característica usando melhor estratégia de fusão e classificador - neste caso, cada componente emprega uma técnica de extração de característica, cujos parâmetros, estratégia de fusão e classificador foram aquele que produziu melhor desempenho. A Figura 35 ilustra este processo.

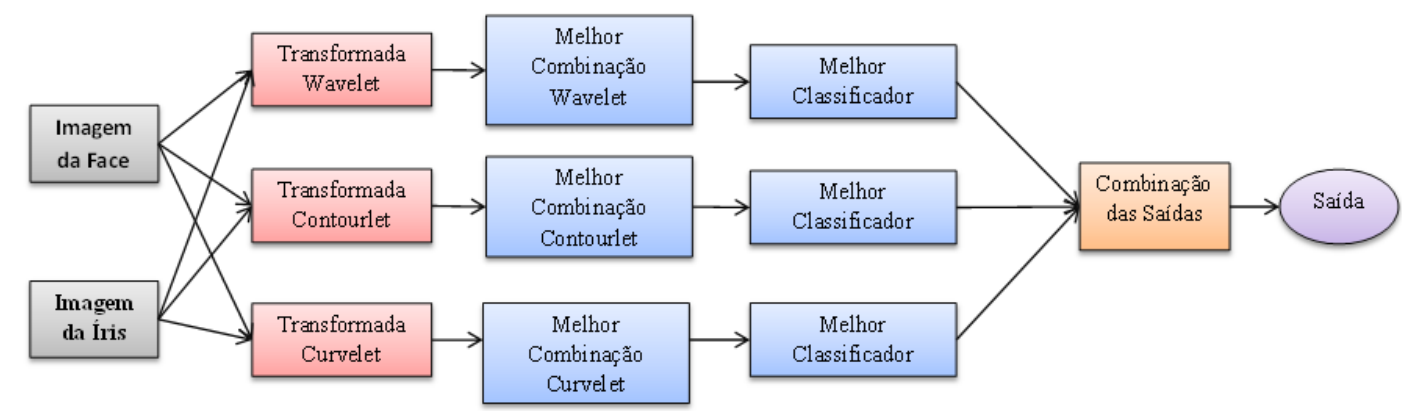

Figura 35 - Ensemble baseado em diferentes técnicas de extração de características usando melhor estratégia de fusão e classificador.

A próxima abordagem de construção de sistema biométrico multimodal baseado em ensemble, proposta nesta dissertação, foi realizada no nível de decisão, ou seja, combinando a saída dos sistemas biométricos unimodais de forma a tomar uma decisão final. As estratégias propostas são descritas a seguir: 
- Melhor SVM: realiza-se a combinação do melhor classificador SVM obtido para face e íris (Figura 36);

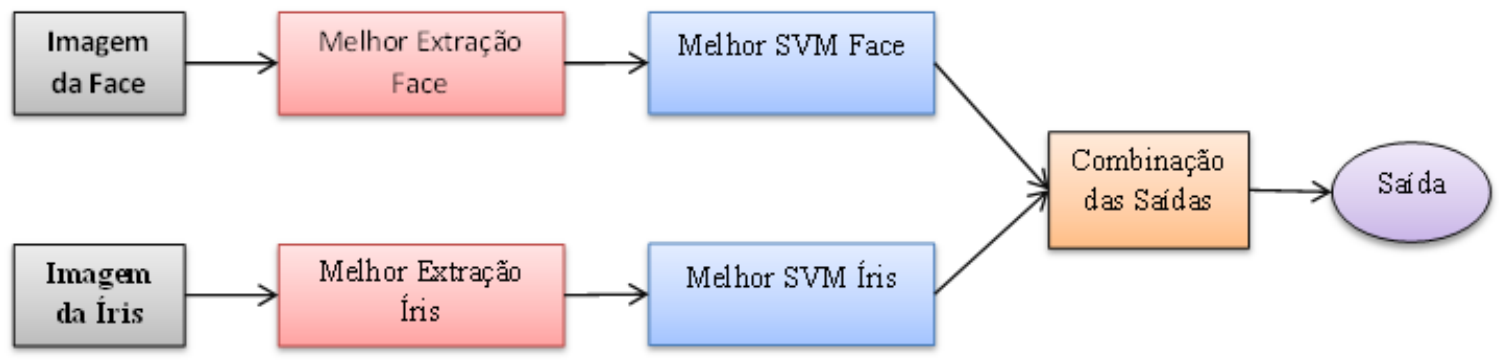

Figura 36 - Sistema multimodal usando fusão no nível de decisão baseado nas melhores SVMs construídas para face e íris.

- Melhor LS-SVM: Realiza-se a combinação do melhor classificador LS-SVM obtido para face e íris (Figura 37);

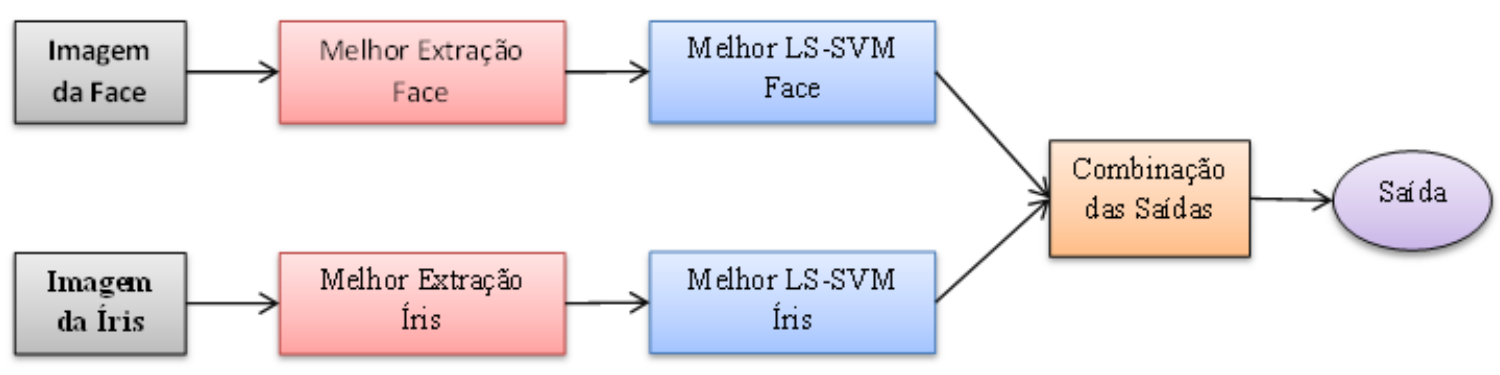

Figura 37 - Sistema multimodal usando fusão no nível de decisão baseado nas melhores LS-SVMs construídas para face e íris.

- Melhor classificador: Realiza-se a combinação do melhor classificador (SVM ou LS-SVM) para face e íris (Figura 38);

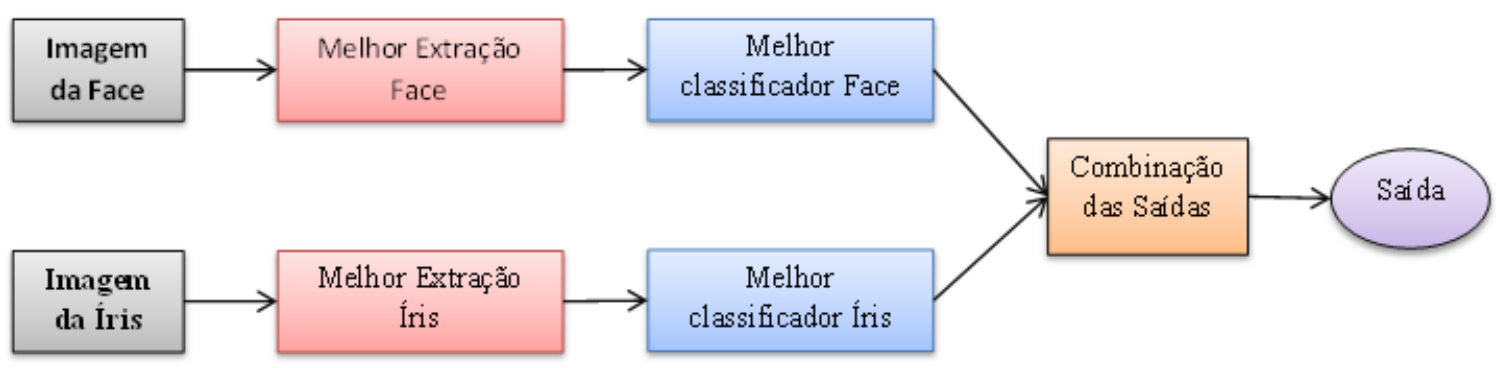

Figura 38 - Sistema multimodal usando fusão no nível de decisão baseado nos melhores classificadores obtidos para face e íris. 


\section{Resultados Experimentais}

Nessa seção, serão apresentados todos os resultados obtidos para as diversas propostas de construção de sistemas biométricos unimodais e multimodais.

\subsection{Experimentos Computacionais}

\subsubsection{Base de dados utilizada}

Visando validar os sistemas biométricos construídos foi utilizada a Base de Dados SDUMLA-HTM (YIN; LIU; SUN, 2011). Essa base é composta por imagens da face, íris, impressão digital, forma de caminhar e veias dos dedos de 106 usuários diferentes. As imagens de face foram obtidas sob 7 diferentes ângulos de visão e também com 12 variações nas condições do ambiente, totalizando 84 imagens por usuário. Essas imagens possuem resolução 480 × 640 e foram representadas no formato RGB. Exemplos de imagens da face podem ser vistos nas Figuras 39 e 40.
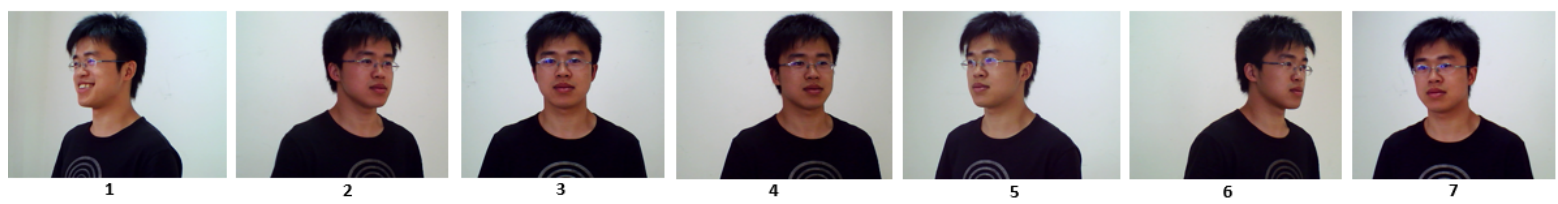

Figura 39 - Imagens da face obtidas sob diferentes ângulos de visão.
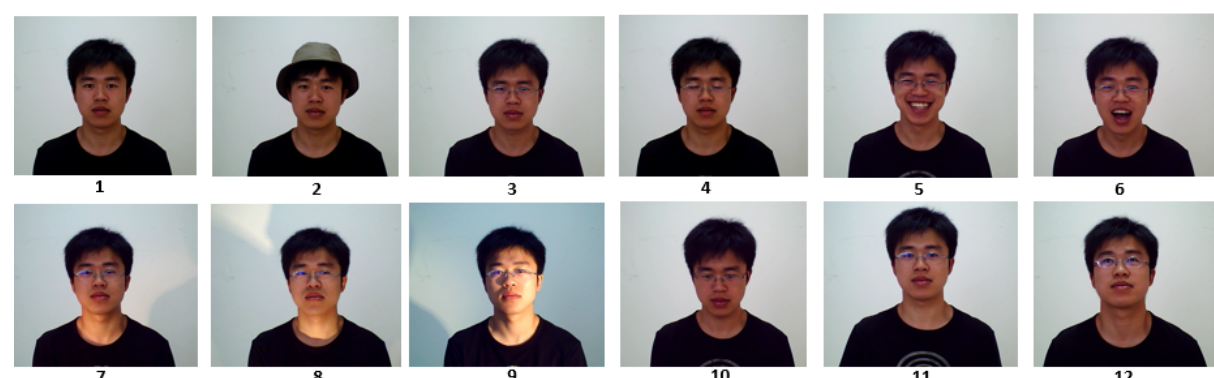

Figura 40 - Imagens da face obtidas sob variações nas condições do ambiente.

Na tentativa de evitar problemas de reflexo no caso da íris, as imagens foram obtidas dos usuários sem a utilização de óculos e com distância de 6 a $32 \mathrm{~cm}$ do sensor de captura. Para cada usuário foi obtido 5 imagens de cada uma das íris. Exemplos das imagens de íris podem ser vistos na Figura 41. 

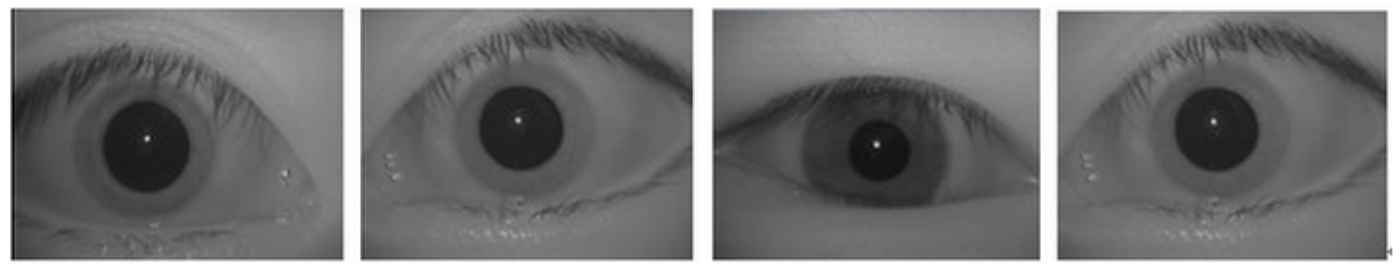

Figura 41 - Exemplo de imagens de íris obtidas da base de dados SDUMLA-HMT.

\subsubsection{Pré-processamento das imagens de face}

Antes de realizar a extração dos vetores de características que serão utilizados como entrada para os classificadores durante a fase de treinamento foi aplicado em cada uma das imagens o Algoritmo Viola-Jones (Seção 2.1.1.1). O objetivo desta etapa é segmentar a região de interesse dentro das imagens da face, diminuindo uma possível interferência causada pelo fundo das imagens.

Para algumas imagens não foi possível delimitar corretamente a face usando o Algoritmo de Viola-Jones. De forma a superar essa limitação foi utilizada uma heurística, que consiste em localizar uma posição média da face nas imagens onde ocorreu a segmentação correta. Usando esta posição como referência, foi realizada uma busca à esquerda, à direita, para cima e para baixo em todas as imagens, incluindo às que haviam sido segmentadas de forma correta, visando garantir que todas as imagens segmentadas fossem do mesmo tamanho.

Como as dimensões das imagens de face localizadas de cada usuário podem ser diferentes e como algumas das técnicas de extração características necessitam que as imagens tenham dimensão quadrada, foi realizada uma alteração da dimensão da imagem de entrada transformando-a para uma dimensão $128 \times 128$ pixels. Além disso, as imagens foram convertidas para escala de cinza. Após essa transformação, foi realizado o processo de extração de característica.

\subsubsection{Pré-processamento das imagens de íris}

Nos sistemas biométricos baseados em íris foi utilizado o método de Wildes e Camus, descrito na Seção 2.1.2.2, para detecção da íris. Após a segmentação da íris, esta foi convertida para coordenadas polares usando o Método de Daugman, apresentado na Seção 2.1.2.3. 
Após a conversão das imagens da íris para coordenadas polares, as técnicas de extração de características foram aplicadas usando diversas configurações. Algumas dessas técnicas de extração necessitam que as imagens de entrada tenham dimensão quadrada. De forma a atender esta exigência, foram geradas imagens polares da íris com a dimensão de $128 \times 128$ pixels. Esta transformação foi à mesma utilizada nas imagens de face. Após esta transformação, foram aplicadas as técnicas de extração de características sobre as imagens geradas.

\subsubsection{Extração de características}

Após a localização das regiões de interesse nas imagens de face e íris, foi realizado o processo de extração de características usando as diversas transformadas descritas no Capítulo 3. Para cada transformada foram utilizadas diferentes configurações, as quais são apresentadas na Tabela 2. Nesta tabela é apresentada a quantidade de características geradas por cada configuração de transformada.

\begin{tabular}{|c|c|c|c|c|c|}
\hline \multicolumn{2}{|c|}{ Wavelet } & \multicolumn{2}{c|}{ Contourlet } & \multicolumn{2}{c|}{ Curvelet } \\
\hline Função Mãe & Características & Pirâmide Laplaciana & Caracteristicas & Níveis & Caracteristicas \\
\hline Daubechies 2 & 1296 & Daubechies 2 & 5120 & 3 & 1024 \\
\hline Daubechies 4 & 1936 & Daubechies 4 & 5120 & $3+2$ & 7168 \\
\hline Symlet 3 & 1600 & Symlet 3 & 5120 & $3+2+1$ & 29696 \\
\hline Symlet 4 & 1936 & Symlet 4 & 5120 & & \\
\hline Symlet 5 & 2116 & Symlet 5 & 5120 & & \\
\hline
\end{tabular}

Tabela 2 - Configurações utilizadas por cada técnica de extração de características.

As estratégias de combinação de características mantém as mesmas dimensões descritas na Tabela 2, com exceção da estratégia baseada em concatenação, onde são gerados vetores de características com dimensão igual a $2 * n$, com $n$ sendo igual à quantidade de características da transformada que está sendo combinada.

\subsubsection{Configuração dos experimentos}

Visando validar os sistemas biométricos construídos, foi utilizado a abordagem validação cruzada 10-folds. De forma a aplicar os classificadores descritos no Capítulo 4 em problemas com múltiplas classes foi utilizada a estratégia um-contra-todos. Nesta estratégia, para $n c$ classes foram treinados $\frac{n c *(n c-1)}{2}$ classificadores, sendo que a saída final foi definida usando o voto majoritário. 
Para ambos os classificadores, SVM e LS-SVM, foi definido a função Kernel RBF como descrito na Tabela 1 , com $\sigma$ igual à $2^{i}$ e $i=[3,14]$ para os sistemas unimodais. Entretanto, para os sistemas multimodais, uma redução desse intervalo foi realizada com base no desempenho obtido pelos sistemas unimodais, isto é, o intervalo dos valores assumido por $i$ foi reduzido para $[4,8]$ nos sistemas multimodais usando transformada Wavelet e Contourlet e para [5,9] nos sistemas multimodais usando a transformada Curvelet.

Como a quantidade de imagens de face (84 imagens) é superior à de íris (10 imagens), nos sistema biométricos multimodais foi adotada uma estratégia de forma a garantir que todas as faces contidas em um fold fossem combinadas com apenas 1 íris daquele usuário, sendo essa íris selecionada de forma aleatória. Esse processo é ilustrado na Figura 42 e foi realizado para cada uma das classes independentemente, ou seja, as imagens de face do fold 1 do usuário 1 podem ter sido combinada com a sua íris de número 5, enquanto que para as imagens de face do fold 1 do usuário 2 podem ter sido combinadas com a sua íris de número 10. Veja que essa estratégia garante que a íris que foi utilizada no fold de teste não aparecerá nos folds de treinamento.

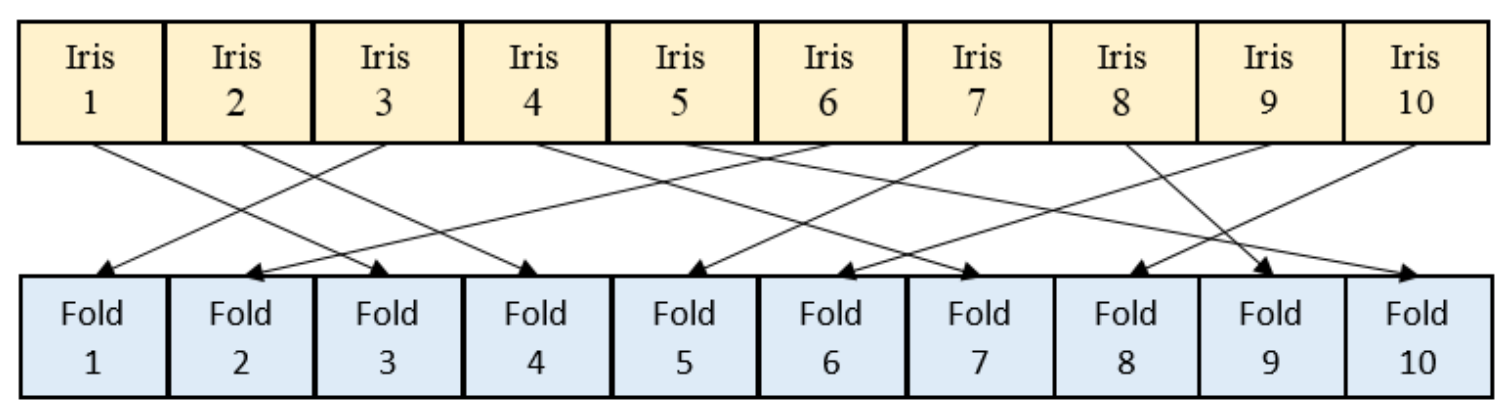

Figura 42 - Método utilizado para gerar o conjunto de dados nos sistemas multimodais.

A construção dos ensembles foi baseada nas estratégias propostas nas Seções 5.1 e 5.2. Sendo que para a construção dos sistemas multimodais foram selecionadas a melhor e a pior estratégia de combinação por transformada. O objetivo foi verificar se com soluções ruins é possível obter resultados melhores ou próximos dos obtidos pelos sistemas biométricos unimodais.

Durante os experimentos envolvendo sistemas biométricos com ensemble é possível que ocorra empate na tomada de decisão, caso a maioria dos classificadores não apontarem para uma mesma classe de saída. Neste caso, foi utilizada a taxa de semelhança da instância a ser analisada para todas as classes que foram votadas. A saída é decidida de acordo 
com a classe que apresenta maior semelhança com aquela instância de teste. O cálculo de semelhança de uma instância a uma classe foi realizada usando a equação:

$$
\operatorname{Sem}(x, c)=1-\frac{\operatorname{dist}\left(x, y_{n}\right)}{\operatorname{dist}\left(x, y_{d}\right)},
$$

na qual $x$ representa a instância a ser testada, $y_{n}$ é a instância da classe $c$ mais próxima de $x, y_{d}$ é a instância da classe $c$ mais distante da amostra $x$ e dist $(x, y)$ é a distância

euclidiana entre dois pontos. É esperado que caso uma instância fosse classificada na classe correta o valor de $\operatorname{Sem}(x, c)$ seja próximo de 1.

\subsection{Resultado para os sistemas biométricos unimodais}

O primeiro conjunto de testes envolveu a construção dos sistemas biométricos baseados em face ou íris. Cada conjunto de teste foi realizado com ambos os classificadores, SVM e LS-SVM, com Kernel RBF e com o parâmetro de $\sigma$ igual a $2^{i}$ e $i=[3,14]$. Além disso, foi utilizada a estratégia de validação cruzada 10-folds. Os resultados foram apresentados de acordo com a taxa de erro obtida em cada uma das execuções.

\subsubsection{Sistemas biométricos baseados em face}

Os primeiros sistemas criados utilizaram apenas a imagem da face dos usuários para realizar a sua identificação. Na Tabela 3 são apresentados os resultados obtidos usando a transformada Wavelet como técnica de extração de característica.

\begin{tabular}{|c|c|c|c|c|}
\hline \multirow{2}{*}{ Wavelet } & \multicolumn{2}{|r|}{$\overline{\text { SVM }}$} & \multicolumn{2}{|r|}{ LS-SVM } \\
\hline & 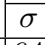 & rro \pm Desvio Padrão & 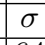 & ro \pm Desvio Padr \\
\hline 2 & 64 & $15,01 \% \pm 1,27$ & 64 & $14,70 \% \pm 1,38 \%$ \\
\hline & 64 & $17,22 \% \pm 2,36$ & 64 & $17,42 \% \pm 1,14 \%$ \\
\hline & 64 & & 64 & $\pm 1,76 \%$ \\
\hline & 64 & 17,2 & 64 & $\pm 1,24 \%$ \\
\hline Symlet 5 & 64 & $16,56 \% \pm 1,37$ & 64 & $15,95 \% \pm 1,28 \%$ \\
\hline
\end{tabular}

Tabela 3 - Resultados obtidos usando a transformada Wavelet para a face.

Pode-se verificar que dentre as diversas funções Wavelets utilizadas, a função Daubechies de ordem 2 foi a que gerou um conjunto de características mais discriminantes, visto que para ambos os classificadores foi possível obter os melhores desempenhos com essa função. Os melhores resultados para ambos os classificadores foram encontrados com parâmetro $\sigma$ no intervalo $[16,256]$, sendo que o melhor parâmetro encontrado foi igual a 
64. O sistema de reconhecimento que obteve melhor desempenho com a face usando a transformada Wavelet e classificador LS-SVM gerou uma taxa de erro igual a 14,70\%, enquanto que para a SVM foi gerado uma taxa de erro igual a 15,01\%.

Na Tabela 4 são apresentados os resultados usando a transformada Contourlet para a extração de características envolvendo a face. Para a construção do banco de filtros direcionais foi utilizado o filtro PKVA, já para a construção da Pirâmide Laplaciana foram utilizadas as mesmas funções Wavelets aplicadas na transformada Wavelet.

\begin{tabular}{|c|c|c|c|c|}
\hline \multirow{2}{*}{ Contourlet } & \multicolumn{2}{|c|}{ SVM } & \multicolumn{2}{c|}{ LS-SVM } \\
\cline { 2 - 5 } & $\sigma$ & Erro \pm Desvio Padrão & $\sigma$ & Erro \pm Desvio Padrão \\
\hline Daubechies 2 & 128 & $21,54 \% \pm 1,59$ & 128 & $21,26 \% \pm 1,71 \%$ \\
\hline Daubechies 4 & 128 & $24,41 \% \pm 2,99$ & 128 & $25,42 \% \pm 1,35 \%$ \\
\hline Symlet 3 & 128 & $26,03 \% \pm 1,51$ & 128 & $25,98 \% \pm 1,51 \%$ \\
\hline Symlet 4 & 128 & $25,97 \% \pm 1,55$ & 128 & $25,36 \% \pm 1,36 \%$ \\
\hline Symlet 5 & 128 & $25,99 \% \pm 1,54$ & 128 & $25,36 \% \pm 1,36 \%$ \\
\hline
\end{tabular}

Tabela 4 - Resultados obtidos usando a transformada Contourlet para a face.

Analisando os resultados obtidos com a transformada Contourlet, pode-se observar que essa transformada não gerou um conjunto de características com alto poder discriminatório. A utilização da função Wavelet Daubechies de ordem 2 para a construção dos filtros da Pirâmide Laplaciana produziu os melhores resultados. No caso da transformada Wavelet, esta função Wavelet também produziu os melhores resultados. O melhor resultado usando a transformada Contourlet foi obtido com o classificador LS-SVM. Neste caso, foi obtida uma taxa de erro igual a $21,26 \%$.

O valor do parâmetro $\sigma$, que produziu melhor desempenho seguiu o mesmo comportamento dos experimentos envolvendo a transformada Wavelet, no qual os melhores resultados foram obtidos no intervalo [16, 256], sendo que o melhor resultado foi obtido com o valor igual a 128. O melhor resultado para o classificador SVM foi alcançado com uma de taxa de erro igual a 21,54\%, enquanto para a LS-SVM foi obtido uma taxa de igual a $21,26 \%$.

A Tabela 5 apresenta os resultados obtidos para reconhecimento facial usando a transformada Curvelet como técnica de extração de características. Neste caso, os melhores resultados, independente do classificador, foram alcançados usando somente os coeficientes do nível 3, que contém apenas uma aproximação da imagem original.

O valor do melhor parâmetro $\sigma$ para essa transformada ficou no intervalo [32, 512], sendo que o melhor resultado foi obtido usando o valor igual a 64. Este é mesmo valor obtido para transformada Wavelet e próximo do valor obtido para a transformada Contourlet. O 
melhor resultado foi obtido usando o classificador LS-SVM, neste caso, foi obtida uma taxa de erro igual a 6,36\%. Já o classificador SVM alcançou uma taxa de erro igual a $8,04 \%$.

\begin{tabular}{|c|c|c|c|c|}
\hline \multirow{2}{*}{ Curvelet } & \multicolumn{2}{|c|}{ SVM } & \multicolumn{2}{c|}{ LS-SVM } \\
\cline { 2 - 5 } & $\sigma$ & Erro \pm Desvio Padrão & $\sigma$ & Erro \pm Desvio Padrão \\
\hline Level 3 & 32 & $8,04 \% \pm 0,84$ & 64 & $6,36 \% \pm 1,01 \%$ \\
\hline Level $3+2$ & 64 & $10,15 \% \pm 4,46$ & 128 & $17,74 \% \pm 1,52 \%$ \\
\hline Level $3+2+1$ & 256 & $27,83 \% \pm 1,30$ & 256 & $21,42 \% \pm 4,56$ \\
\hline
\end{tabular}

Tabela 5 - Resultados obtidos usando a transformada Curvelet para a face.

Analisando os resultados de forma geral, pode-se notar que dentre as três abordagens empregadas para representar a face dos usuários, a transformada Curvelet foi a que produziu o conjunto de característica com maior poder discriminante, visto que o desempenho alcançado foi superior às outras transformadas. A utilização dos coeficientes do nível 3, o qual contém apenas uma aproximação da imagem original, gerou sistemas de reconhecimento com taxa de erro menores que $10 \%$, enquanto que a utilização do nível 2 com o classificador SVM foi possível obter uma taxa de erro igual a 10,15\%. Esse desempenho foi superior ao melhor desempenho alcançado pelas outras transformadas.

Analisando o desempenho dos classificadores, independente da técnica de extração de característica utilizada, pode-se verificar que ambos os classificadores apresentaram desempenhos muito próximos e com valor de $\sigma$ também muito próximos. Logo, pode-se dizer que o valor de $\sigma$ ótimo, para estas estratégias utilizadas e para a dimensão dos dados de entrada utilizada, está dentro do intervalo [16,512].

\subsubsection{Sistemas biométricos baseados em íris}

O segundo modelo de sistema biométrico unimodal projetado emprega apenas a íris do usuário para realizar a sua identificação. A Tabela 6 apresenta os resultados obtidos usando a transformada Wavelet para extrair os coeficientes das imagens de entrada do usuário.

\begin{tabular}{|c|c|c|c|c|}
\hline \multirow{2}{*}{ Wavelet } & \multicolumn{2}{|c|}{ SVM } & \multicolumn{2}{c|}{ LS-SVM } \\
\cline { 2 - 5 } & $\sigma$ & Erro \pm Desvio Padrão & $\sigma$ & Erro \pm Desvio Padrão \\
\hline Daubechies 2 & 64 & $9,71 \% \pm 2,43$ & 64 & $9,81 \% \pm 2,40 \%$ \\
\hline Daubechies 4 & 64 & $12,45 \% \pm 2,42$ & 64 & $12,45 \% \pm 2,42 \%$ \\
\hline Symlet 3 & 64 & $10,66 \% \pm 2,88$ & 64 & $10,56 \% \pm 2,94 \%$ \\
\hline Symlet 4 & 64 & $13,01 \% \pm 2,54$ & 64 & $13,01 \% \pm 2,54 \%$ \\
\hline Symlet 5 & 64 & $13,67 \% \pm 3,56$ & 64 & $13,67 \% \pm 3,64 \%$ \\
\hline
\end{tabular}

Tabela 6 - Resultados obtidos usando a transformada Wavelet para a íris. 
Analisando os resultados, pode-se observar que a transformada Wavelet foi capaz de gerar um conjunto de característica com alto poder discriminante para a representação da íris. O melhor desempenho foi obtido com uma taxa de erro inferior a 10\%. Em relação às funções Wavelets utilizadas, o melhor resultado obtido foi usando a função Daubechies de ordem 2, resultado semelhante foi obtido para os sistemas envolvendo a face. Já o valor do parâmetro $\sigma$ ficou no intervalo $[16,256]$, com valor ótimo igual a 64 . O melhor resultado obtido foi usando o classificador SVM, o qual apresentou uma taxa de erro igual a 9,71\%, enquanto que o classificador LS-SVM obteve uma taxa de erro igual a 9,81\%.

Na Tabela 7 são apresentados os resultados obtidos usando a transformada Contourlet como técnica extração de características.

\begin{tabular}{|c|c|c|c|c|}
\hline \multirow{2}{*}{ Contourlet } & \multicolumn{2}{|c|}{ SVM } & \multicolumn{2}{c|}{ LS-SVM } \\
\cline { 2 - 5 } & $\sigma$ & Erro \pm Desvio Padrão & $\sigma$ & Erro \pm Desvio Padrão \\
\hline Daubechies 2 & 128 & $11,50 \% \pm 2,54$ & 128 & $11,50 \% \pm 2,54 \%$ \\
\hline Daubechies 4 & 128 & $12,07 \% \pm 2,54$ & 128 & $12,16 \% \pm 2,53 \%$ \\
\hline Symlet 3 & 128 & $12,92 \% \pm 3,32$ & 128 & $12,92 \% \pm 3,32 \%$ \\
\hline Symlet 4 & 128 & $12,54 \% \pm 2,43$ & 128 & $12,54 \% \pm 2,43 \%$ \\
\hline Symlet 5 & 64 & $12,64 \% \pm 2,60$ & 64 & $12,64 \% \pm 2,60 \%$ \\
\hline
\end{tabular}

Tabela 7 - Resultados obtidos usando a transformada Contourlet para a íris.

Pode-se notar que o conjunto de características extraídas usando a transformada Contourlet para as imagens da íris tem um poder discriminante superior ao obtido com as mesmas abordagens para as imagens de face, dado que a taxa de erro obtida com essa abordagem, no melhor caso, ficou abaixo dos $12 \%$. Em relação ao valor do parâmetro $\sigma$ observou-se o mesmo comportamento em relação a face, onde os melhores resultados ficaram no intervalo de $[16,256]$. A melhor taxa de erro foi obtida com $\sigma=128$ e seu valor foi igual a 11,50\% para ambos os classificadores usando a função Daubechies de ordem 2 como Filtro da Pirâmide Laplaciana .

A Tabela 8 apresenta os resultados obtidos usando a transformada Curvelet como técnica extração de característica para as imagens da íris.

\begin{tabular}{|c|c|c|c|c|}
\hline \multirow{2}{*}{ Curvelet } & \multicolumn{2}{|c|}{ SVM } & \multicolumn{2}{c|}{ LS-SVM } \\
\cline { 2 - 5 } & $\sigma$ & Erro \pm Desvio Padrão & $\sigma$ & Erro \pm Desvio Padrão \\
\hline Level 3 & 128 & $11,50 \% \pm 2,54$ & 128 & $11,50 \% \pm 2,54 \%$ \\
\hline Level $3+2$ & 128 & $24,24 \% \pm 3,90$ & 128 & $24,24 \% \pm 3,95 \%$ \\
\hline Level $3+2+1$ & 256 & $26,13 \% \pm 4,10$ & 256 & $26,13 \% \pm 4,10$ \\
\hline
\end{tabular}

Tabela 8 - Resultados obtidos usando a transformada Curvelet para a íris.

Ao contrário do desempenho exibido nos sistemas envolvendo a face, a transformada Curvelet não conseguiu extrair o melhor conjunto de características da íris. O melhor 
resultado é similar ao alcançado pela transformada Contourlet. A menor taxa de erro obtida com essa transformada foi igual a 11,50\% usando os coeficientes do nível 3, sendo esse resultado independente do classificador utilizado. Os melhores resultados foram obtidos com $\sigma$ no intervalo de $[32,512]$, sendo que o melhor resultado foi obtido com o valor igual 128. Este valor é muito próximo do intervalo obtido pelas outras transformadas. Uma característica interessante desses resultados é que eles foram os mesmos, independente do classificador.

Em relação a todos os sistemas unimodais aqui propostos, baseados em face ou íris, pode-se notar que os valores de $\sigma$ que produziram os melhores resultados ficaram muito próximos. Para transformada Wavelet e Contourlet os valores de $\sigma$ ficaram no intervalo [16,256], já para transformada Curvelet ficaram no intervalo [32,512]. Estes intervalos foram os mesmos para ambas as modalidades biométricas, face e íris. Logo, pode-se mencionar que para a construção de sistemas biométricos multimodais, estes intervalos correspondem a um ponto de partida importante. Neste caso, não é necessário fazer uma busca em um espaço maior.

O melhor resultado para face foi obtido a uma taxa de erro igual a $6,36 \%$. Isto significa que 566 imagens das 8904 imagens foram classificadas incorretamente, usando os coeficientes do nível 3 da transformada Curvelet e classificador LS-SVM com $\sigma=64$. Para a íris, o melhor resultado foi alcançado a uma taxa de erro igual a 9,71\%. Isto significa que 102 imagens das 1060 imagens da íris foram classificadas incorretamente, usando a transformada Wavelet com função Daubechies de ordem 2 e classificador SVM com $\sigma=64$. Estes resultados serão analisados mais detalhadamente na Seção 6.5.

Analisando os resultados alcançados para os sistemas unimodais, pode-se dizer que a transformada Curvelet conseguiu gerar uma boa representação para as imagens da face, o que já era esperado devido à natureza da transformada. Em relação às imagens da íris, possivelmente por não apresentarem contornos muito bem definidos, a transformada Wavelet conseguiu extrair as melhores características. Já a transformada Contourlet não conseguiu produzir bons resultados para nenhuma das modalidades biométricas (face e íris). Isto mostra que principalmente para as imagens de face aqui utilizadas a representação baseada em contornos não conseguiu produzir um vetor de características discriminante. 


\subsection{Resultado para os sistemas biométricos multimodais}

Com base no desempenho alcançado pelos sistemas biométricos unimodais foram construídos os sistemas multimodais, os quais realizam a fusão das características extraídas da face e íris para realizar a identificação do usuário. Os sistemas multimodais foram construídos utilizando um intervalo de valores de $\sigma$ menor que o adotado nos sistemas unimodais. Este subintervalo foi escolhido de acordo com o desempenho alcançado pelas técnicas de extração de característica. O intervalo para a transformada Wavelet e Contourlet foi definido como sendo $[16,256]$ e $[32,512]$ para a transformada Curvelet.

\subsubsection{Transformada Wavelet}

A primeira técnica de extração de característica a ser analisada foi à transformada Wavelet. As estratégias de fusão utilizadas foram descritas na Seção 6.1. Os resultados obtidos com estas estratégias são apresentados nas Tabelas 9-15.

A Tabela 9 apresenta os resultados obtidos usando a primeira estratégia de combinação, isto é, concatenação dos coeficientes de face e íris. Essa estratégia conseguiu gerar os melhores desempenhos em relação à transformada Wavelet. Nesta foi possível obter uma taxa de erro igual a 5,10\% no melhor caso, usando o classificador SVM e a função Wavelet Daubechies de ordem 2. Observe-se que esse resultado é superior aos melhores resultados obtido pelos sistemas unimodais.

\begin{tabular}{|c|c|c|c|c|}
\hline \multirow{2}{*}{ Wavelet } & \multicolumn{2}{|c|}{ SVM } & \multicolumn{2}{c|}{ LS-SVM } \\
\cline { 2 - 5 } & $\sigma$ & Erro \pm Desvio Padrão & $\sigma$ & Erro \pm Desvio Padrão \\
\hline Daubechies 2 & 128 & $5,10 \% \pm 2,13$ & 128 & $5,38 \% \pm 1,93 \%$ \\
\hline Daubechies 4 & 128 & $6,69 \% \pm 2,13$ & 128 & $6,96 \% \pm 2,18 \%$ \\
\hline Symlet 3 & 128 & $5,74 \% \pm 2,40$ & 128 & $5,77 \% \pm 2,47 \%$ \\
\hline Symlet 4 & 128 & $6,43 \% \pm 2,84$ & 128 & $6,68 \% \pm 2,99 \%$ \\
\hline Symlet 5 & 256 & $6,41 \% \pm 2,87$ & 256 & $6,70 \% \pm 2,86 \%$ \\
\hline
\end{tabular}

Tabela 9 - Resultados obtidos usando a concatenação dos coeficientes extraídos da face e íris via transformada Wavelet.

Analisando a Tabela 9, pode-se notar que essa estratégia gerou vetores de características com alto poder discriminante, visto que, no pior caso, foi alcançado uma taxa de erro igual a 6,96\%. Este desempenho foi superior à quase todos os resultados obtidos com os sistemas unimodais, com exceção dos resultados de face usando transformada Curvelet. Já em relação ao parâmetro $\sigma$, o melhor resultado foi obtido com valor igual a 128 para 
todos os casos, com exceção dos sistemas que envolveram a concatenação dos coeficientes da função Symlet de ordem 5 .

A segunda estratégia de combinação emprega os coeficientes de aproximação da face e coeficientes de detalhes da íris. A Tabela 10 apresenta os resultados obtidos. Essa estratégia também foi capaz de gerar sistemas biométricos com bons desempenhos. O desempenho alcançado foi superior aos obtidos com os sistemas biométricos baseados apenas na íris. O melhor resultado obtido com essa estratégia foi usando a função Wavelet Daubechies de ordem 2, com classificador SVM e parâmetro $\sigma$ igual 64. Neste caso, foi obtida uma taxa de erro igual a $8,85 \%$.

\begin{tabular}{|c|c|c|c|c|}
\hline \multirow{2}{*}{ Wavelet } & \multicolumn{2}{|c|}{ SVM } & \multicolumn{2}{c|}{ LS-SVM } \\
\cline { 2 - 5 } & $\sigma$ & Erro \pm Desvio Padrão & $\sigma$ & Erro \pm Desvio Padrão \\
\hline Daubechies 2 & 64 & $8,85 \% \pm 3,05$ & 32 & $9,94 \% \pm 3,32 \%$ \\
\hline Daubechies 4 & 64 & $11,10 \% \pm 3,87$ & 64 & $13,38 \% \pm 4,82 \%$ \\
\hline Symlet 3 & 64 & $9,47 \% \pm 3,30$ & 32 & $11,41 \% \pm 3,03 \%$ \\
\hline Symlet 4 & 64 & $10,68 \% \pm 3,45$ & 64 & $13,03 \% \pm 3,81 \%$ \\
\hline Symlet 5 & 64 & $12,17 \% \pm 3,96$ & 64 & $14,26 \% \pm 4,45 \%$ \\
\hline
\end{tabular}

Tabela 10 - Resultados obtidos usando os coeficientes de aproximação da face e detalhes da íris extraídos via transformada Wavelet.

Essa segunda estratégia também foi capaz de gerar vetores de características com alto poder discriminante. Os melhores resultado foram alcançados usando funções Daubechies de ordem 2, independente dos classificadores, e Symlet de ordem 3 com o classificador SVM. Em relação ao valor do parâmetro $\sigma$, os melhores resultados foram obtidos com valores próximos de 64 .

A terceira estratégia de combinação emprega os coeficientes de aproximação da íris e coeficientes de detalhes da face. Os resultados obtidos com esta estratégia são apresentados na Tabela 11. Com essa estratégia foi possível alcançar um desempenho superior aos obtidos pelos sistemas unimodais baseados em íris. No melhor caso, foi obtido uma taxa de erro igual a 7,36\% usando a função Wavelet Daubechies de ordem 2, classificador LS-SVM e parâmetro $\sigma$ igual a 256 .

\begin{tabular}{|c|c|c|c|c|}
\hline \multirow{2}{*}{ Wavelet } & \multicolumn{2}{|c|}{ SVM } & \multicolumn{2}{c|}{ LS-SVM } \\
\cline { 2 - 5 } & $\sigma$ & Erro \pm Desvio Padrão & $\sigma$ & Erro \pm Desvio Padrão \\
\hline Daubechies 2 & 256 & $8,88 \% \pm 2,64$ & 256 & $7,36 \% \pm 2,39 \%$ \\
\hline Daubechies 4 & 256 & $10,93 \% \pm 3,57$ & 128 & $9,17 \% \pm 2,81 \%$ \\
\hline Symlet 3 & 64 & $10,62 \% \pm 3,56$ & 64 & $9,01 \% \pm 2,67 \%$ \\
\hline Symlet 4 & 128 & $10,47 \% \pm 4,00$ & 128 & $8,77 \% \pm 2,88 \%$ \\
\hline Symlet 5 & 128 & $10,97 \% \pm 3,81$ & 128 & $9,06 \% \pm 2,99 \%$ \\
\hline
\end{tabular}

Tabela 11 - Resultados obtidos usando os coeficientes de aproximação da íris e os detalhes da face extraídos via transformada Wavelet. 
Os resultados obtidos com esta estratégia usando o classificador LS-SVM foram superiores àqueles obtidos pelos sistemas unimodais baseados em íris. Entretanto, estes não superaram os resultados obtidos com face usando a transformada Curvelet. Ao contrário das outras estratégias, os valores de $\sigma$ para melhores soluções sofreram uma maior variação, com os valores obtidos dentro do intervalo $[64,256]$.

A quarta estratégia realiza a combinação baseada em contornos. Na Tabela 12 são apresentados os resultados obtidos. Essa estratégia não foi capaz de fornecer nenhum resultado que superasse os sistemas unimodais, mostrando não ser capaz de melhorar o poder discriminante dos vetores de características iniciais. O melhor resultado obtido com essa estratégia foi usando a função Wavelet Daubechies de ordem 2, classificador LS-SVM e parâmetro $\sigma$ igual a 64 . Neste caso, foi obtida uma taxa de erro igual a $12,22 \%$.

\begin{tabular}{|c|c|c|c|c|}
\hline \multirow{2}{*}{ Wavelet } & \multicolumn{2}{|c|}{ SVM } & \multicolumn{2}{c|}{ LS-SVM } \\
\cline { 2 - 5 } & $\sigma$ & Erro \pm Desvio Padrão & $\sigma$ & Erro \pm Desvio Padrão \\
\hline Daubechies 2 & 64 & $12,51 \% \pm 1,56$ & 64 & $12,22 \% \pm 1,34 \%$ \\
\hline Daubechies 4 & 64 & $15,56 \% \pm 1,03$ & 64 & $15,10 \% \pm 1,16 \%$ \\
\hline Symlet 3 & 64 & $14,49 \% \pm 1,51$ & 64 & $13,81 \% \pm 1,23 \%$ \\
\hline Symlet 4 & 64 & $13,03 \% \pm 1,48$ & 64 & $12,68 \% \pm 1,27 \%$ \\
\hline Symlet 5 & 64 & $13,16 \% \pm 1,51$ & 64 & $12,62 \% \pm 1,24 \%$ \\
\hline
\end{tabular}

Tabela 12 - Resultados obtidos usando a estratégia de fusão baseada na detecção de contornos e a transformada Wavelet.

A quinta estratégia emprega o mínimo dos coeficientes de aproximação e o máximo dos coeficientes de detalhes para gerar o vetor de característica. Os resultados obtidos são apresentados na Tabela 13. Essa abordagem produziu sistemas biométricos que superaram o desempenho dos sistemas unimodais para mais de uma função Wavelet. O melhor resultado obtido foi usando função Wavelet Daubechies de ordem 2, classificador LS-SVM e parâmetro $\sigma$ com valor igual 128. Neste caso, foi obtido uma taxa de erro igual a $6,04 \%$.

\begin{tabular}{|c|c|c|c|c|}
\hline \multirow{2}{*}{ Wavelet } & \multicolumn{2}{|c|}{ SVM } & \multicolumn{2}{c|}{ LS-SVM } \\
\cline { 2 - 5 } & $\sigma$ & Erro \pm Desvio Padrão & $\sigma$ & Erro \pm Desvio Padrão \\
\hline Daubechies 2 & 256 & $7,06 \% \pm 1,85$ & 128 & $6,04 \% \pm 1,58 \%$ \\
\hline Daubechies 4 & 256 & $8,90 \% \pm 2,06$ & 128 & $7,71 \% \pm 1,35 \%$ \\
\hline Symlet 3 & 256 & $7,84 \% \pm 1,96$ & 64 & $7,32 \% \pm 1,47 \%$ \\
\hline Symlet 4 & 256 & $7,28 \% \pm 1,91$ & 128 & $6,18 \% \pm 1,27 \%$ \\
\hline Symlet 5 & 128 & $8,89 \% \pm 1,23$ & 128 & $7,79 \% \pm 0,98 \%$ \\
\hline
\end{tabular}

Tabela 13 - Resultados obtidos usando o mínimo dos coeficientes de aproximação e o máximo dos coeficientes de detalhes extraídos via transformada Wavelet.

Pode-se verificar que essa estratégia produziu vetores de características com boa capacidade de discriminação. Neste caso, todos os resultados obtidos produziram uma taxa de erro abaixo de $9 \%$. Os sistemas biométricos compostos por um classificador LS-SVM 
forneceram as menores taxa de erro para essa estratégia. Os valores de $\sigma$ dessa estratégia sofreram grande varação e ficou dentro do intervalo [64,256]. Neste casso, a maioria dos melhores valores de $\sigma$ ficaram em torno de 128 .

A sexta estratégia produziu um vetor de característica usando a média dos coeficientes de aproximação e o máximo dos coeficientes de detalhes. Os resultados obtidos são apresentados na Tabela 14. Essa estratégia conseguiu realizar uma melhora em relação aos resultados obtidos com a íris, porém não superou o desempenho obtido usando transformada Curvelet nas imagens de face. O melhor resultado obtido com a função Wavelet Symlet de ordem 4, classificador LS-SVM e valor de $\sigma$ igual a 64. Neste caso, foi obtida uma taxa de erro igual a $9,15 \%$.

\begin{tabular}{|c|c|c|c|c|}
\hline \multirow{2}{*}{ Wavelet } & \multicolumn{2}{|c|}{ SVM } & \multicolumn{2}{c|}{ LS-SVM } \\
\cline { 2 - 5 } & $\sigma$ & Erro \pm Desvio Padrão & $\sigma$ & Erro \pm Desvio Padrão \\
\hline Daubechies 2 & 64 & $10,49 \% \pm 1,21$ & 64 & $9,92 \% \pm 1,27 \%$ \\
\hline Daubechies 4 & 128 & $10,72 \% \pm 0,86$ & 128 & $10,26 \% \pm 0,90 \%$ \\
\hline Symlet 3 & 64 & $9,92 \% \pm 1,27$ & 128 & $9,62 \% \pm 1,36 \%$ \\
\hline Symlet 4 & 64 & $9,92 \% \pm 1,27$ & 64 & $9,15 \% \pm 0,89 \%$ \\
\hline Symlet 5 & 128 & $9,75 \% \pm 1,14$ & 128 & $9,41 \% \pm 0,86 \%$ \\
\hline
\end{tabular}

Tabela 14 - Resultados obtidos usando a média dos coeficientes de aproximação e o máximo dos coeficientes de detalhes extraídos via transformada Wavelet.

Nota-se que essa estratégia foi capaz de gerar vetores de características com bom poder discriminante, porém não o suficiente para superar o desempenho alcançado pelos melhores sistemas unimodais. Com essa estratégia, a maioria dos sistemas biométricos apresentou uma taxa de erro menor que 10\%, sendo que alguns destes apresentaram o mesmo desempenho para diferentes funções Wavelets. O valor do parâmetro $\sigma$ para essa estratégia ficou dentro do intervalo $[64,128]$. Um fato importante que não houve a predominância de nenhum valor dentro deste intervalo nos melhores resultados.

A última estratégia realiza a soma dos vetores de características, ou seja, o vetor de característica da íris é somado ao vetor de característica da face. O vetor resultante foi usado como entrada para o classificador. Os resultados obtidos são apresentados na Tabela 15. Essa estratégia também não foi capaz de gerar nenhum sistema biométrico com desempenho melhor que os sistemas unimodais. O melhor desempenho foi obtido usando a função Wavelet Daubechies de ordem 2, classificador LS-SVM e valor de $\sigma$ igual a 64 . Neste caso, foi obtida uma taxa de erro igual a $14,64 \%$. 


\begin{tabular}{|c|c|c|c|c|}
\hline \multirow{2}{*}{ Wavelet } & \multicolumn{2}{|c|}{ SVM } & \multicolumn{2}{c|}{ LS-SVM } \\
\cline { 2 - 5 } & $\sigma$ & Erro \pm Desvio Padrão & $\sigma$ & Erro \pm Desvio Padrão \\
\hline Daubechies 2 & 64 & $14,93 \% \pm 1,26$ & 64 & $14,64 \% \pm 1,37 \%$ \\
\hline Daubechies 4 & 64 & $18,16 \% \pm 1,27$ & 64 & $17,35 \% \pm 1,11 \%$ \\
\hline Symlet 3 & 64 & $17,21 \% \pm 1,99$ & 64 & $16,74 \% \pm 1,81 \%$ \\
\hline Symlet 4 & 64 & $16,08 \% \pm 1,45$ & 64 & $15,66 \% \pm 1,26 \%$ \\
\hline Symlet 5 & 64 & $16,47 \% \pm 1,40$ & 64 & $15,94 \% \pm 1,36 \%$ \\
\hline
\end{tabular}

Tabela 15 - Resultados obtidos usando a soma dos coeficientes extraídos das imagens de face e íris via transformada Wavelet.

Dentre todos os sistemas que utilizaram a transformada Wavelet para a construção dos sistemas multimodais, o melhor resultado global produziu uma taxa de erro igual a 5,10\% usando o classificador SVM, função Wavelet Daubechies de ordem 2 e $\sigma$ igual a 128. Esse resultado é superior ao desempenho alcançado pelos sistemas biométricos unimodais usando face ou íris. O pior resultado obtido foi usando a soma dos coeficientes extraídos das imagens de face, o qual não conseguiu realizar uma melhora em relação aos sistemas unimodais, no melhor caso, foi obtida uma taxa de erro igual a 14,64\%. De forma geral, pode-se notar que se a estratégia de fusão no nível de característica for escolhida adequadamente o desempenho pode ser melhorado.

\subsubsection{Transformada Contourlet}

A segunda técnica de extração de características utilizada foi à transformada Contourlet. As estratégias de fusão foram às mesmas empregadas com a transformada Wavelet. Os resultados obtidos são apresentados nas Tabelas 16-22.

Analisando a Tabela 16 é possível observar que a primeira estratégia conseguiu obter resultados superiores aos obtidos com os sistemas biométricos unimodais baseados em íris. Entretanto, esta estratégia não produziu nenhuma melhora em relação aos sistemas unimodais baseado em face usando transformada Wavelet. O melhor resultado foi obtido usando a Pirâmide Laplaciana com função Daubechies de ordem 2, classificador SVM e parâmetro $\sigma$ igual a 256. Neste caso, foi obtida uma taxa de erro igual a $6,68 \%$.

\begin{tabular}{|c|c|c|c|c|}
\hline \multirow{2}{*}{ Contourlet } & \multicolumn{2}{|c|}{ SVM } & \multicolumn{2}{c|}{ LS-SVM } \\
\cline { 2 - 5 } & $\sigma$ & Erro \pm Desvio Padrão & $\sigma$ & Erro \pm Desvio Padrão \\
\hline Daubechies 2 & 256 & $6,68 \% \pm 2,55$ & 256 & $6,83 \% \pm 2,61 \%$ \\
\hline Daubechies 4 & 128 & $7,83 \% \pm 2,60$ & 256 & $7,26 \% \pm 2,65 \%$ \\
\hline Symlet 3 & 128 & $9,03 \% \pm 2,90$ & 128 & $9,03 \% \pm 2,90 \%$ \\
\hline Symlet 4 & 256 & $8,24 \% \pm 2,41$ & 256 & $8,34 \% \pm 2,40 \%$ \\
\hline Symlet 5 & 256 & $8,41 \% \pm 2,95$ & 256 & $8,50 \% \pm 3,03 \%$ \\
\hline
\end{tabular}

Tabela 16 - Resultados obtidos usando a concatenação dos coeficientes extraídos da face e íris via transformada Contourlet. 
Pode-se notar que os resultados obtidos com essa estratégia conseguiu uma melhora considerável em relação aos obtidos com os sistemas unimodais baseados na transformada Contourlet. Anteriormente, o melhor resultado obtido, em termos de taxa de erro, para os sistemas unimodais tinha sido igual a $11,50 \%$ para íris e $21,26 \%$ para face. Com a estratégia de fusão, o melhor resultado foi igual a 6,68\%. Isto mostra que essa estratégia pode melhorar o poder discriminativo das características. Os melhores resultados foram obtidos com parâmetro $\sigma$ no intervalo $[128,256]$. Sendo que a maioria dos resultados foi obtida com $\sigma$ igual a 256 .

Os resultados obtidos com a segunda estratégia de fusão são apresentados na Tabela 17. Similar à estratégia anterior, esta estratégia não conseguiu melhorar os resultados obtidos pelos sistemas unimodais usando transformada Wavelet, porém conseguiu apresentar uma melhora em relação aos sistemas unimodais baseados em face usando transformada Contourlet. O melhor resultado obtido com essa estratégia foi usando a Pirâmide Laplaciana com função Daubechies de ordem 2, classificador SVM e parâmetro $\sigma$ igual a 64 .Neste caso, onde foi obtida uma taxa de erro igual a $11,50 \%$.

\begin{tabular}{|c|c|c|c|c|}
\hline \multirow{2}{*}{ Contourlet } & SVM & \multicolumn{2}{c|}{ LS-SVM } \\
\cline { 2 - 5 } & $\sigma$ & Erro \pm Desvio Padrão & $\sigma$ & Erro \pm Desvio Padrão \\
\hline Daubechies 2 & 64 & $11,50 \% \pm 4,17$ & 64 & $11,94 \% \pm 4,04 \%$ \\
\hline Daubechies 4 & 64 & $12,59 \% \pm 4,47$ & 64 & $13,24 \% \pm 4,81 \%$ \\
\hline Symlet 3 & 64 & $14,32 \% \pm 3,88$ & 64 & $15,28 \% \pm 4,10 \%$ \\
\hline Symlet 4 & 64 & $13,60 \% \pm 4,27$ & 64 & $14,36 \% \pm 4,23 \%$ \\
\hline Symlet 5 & 64 & $12,84 \% \pm 3,94$ & 64 & $13,30 \% \pm 4,34 \%$ \\
\hline
\end{tabular}

Tabela 17 - Resultados obtidos usando os coeficientes de aproximação da face e os coeficientes de detalhes da íris extraídos via transformada Contourlet.

Analisando a Tabela 17 pode-se notar que foi possível alcançar uma melhora no desempenho dos sistemas baseados em face usando transformada Contourlet. Entretanto, no melhor caso, foi possível obter o mesmo desempenho obtido com os sistemas baseados em íris usando a transformada Contourlet. Os melhores resultados foram obtidos com parâmetro $\sigma$ igual a 64 para todas as soluções.

Os resultados obtidos com a terceira estratégia de fusão são apresentados na Tabela 18. Observe que estes foram superiores apenas aos sistemas biométricos unimodais baseados em face envolvendo transformada Contourlet, porém os resultados obtidos foram inferiores a segunda estratégia. O melhor resultado obtido com essa estratégia foi usando a Pirâmide Laplaciana com função Daubechies de ordem 2, classificador LS-SVM e parâmetro $\sigma$ igual a 128 . Neste caso, foi obtida uma taxa de erro igual a $12,81 \%$. 


\begin{tabular}{|c|c|c|c|c|}
\hline \multirow{2}{*}{ Contourlet } & \multicolumn{2}{|c|}{ SVM } & \multicolumn{2}{c|}{ LS-SVM } \\
\cline { 2 - 5 } & $\sigma$ & Erro \pm Desvio Padrão & $\sigma$ & Erro \pm Desvio Padrão \\
\hline Daubechies 2 & 128 & $13,18 \% \pm 1,79$ & 128 & $12,81 \% \pm 1,84 \%$ \\
\hline Daubechies 4 & 256 & $16,71 \% \pm 1,83$ & 128 & $16,85 \% \pm 1,86 \%$ \\
\hline Symlet 3 & 128 & $16,87 \% \pm 1,61$ & 128 & $16,58 \% \pm 1,64 \%$ \\
\hline Symlet 4 & 128 & $17,00 \% \pm 1,65$ & 128 & $16,72 \% \pm 1,74 \%$ \\
\hline Symlet 5 & 128 & $17,00 \% \pm 1,65$ & 128 & $16,72 \% \pm 1,74 \%$ \\
\hline
\end{tabular}

Tabela 18 - Resultados obtidos usando os coeficientes de aproximação da íris e os coeficientes detalhes da face extraídos via transformada Contourlet.

Pode-se notar que essa estratégia conseguiu melhorar o desempenho em relação aos sistemas unimodais que envolveram a transformada Contourlet e face, porém não foi possível chegar ao mesmo nível de desempenho dos sistemas baseados em íris. Portanto, com essa estratégia não foi possível produzir uma melhora no poder discriminante dos vetores de características originais. Os melhores valores de $\sigma$ para essa estratégia ficaram no intervalo $[128,256]$, sendo que o valor igual a 256 foi utilizado apenas em um dos melhores casos.

A Tabela 19 apresenta os resultados obtidos para a quarta estratégia de fusão. Esta apresentou um dos piores desempenhos com essa transformada, ficando muito próxima dos resultados obtidos pelos sistemas unimodais usando apenas face e a transformada Contourlet. O melhor resultado obtido com essa estratégia foi usando Pirâmide Laplaciana com função Daubechies de ordem 2, classificador LS-SVM e parâmetro $\sigma$ igual a 128. Neste caso, foi obtida uma taxa de erro igual a 19,09\%.

\begin{tabular}{|c|c|c|c|c|}
\hline \multirow{2}{*}{ Contourlet } & \multicolumn{2}{|c|}{ SVM } & \multicolumn{2}{c|}{ LS-SVM } \\
\cline { 2 - 5 } & $\sigma$ & Erro \pm Desvio Padrão & $\sigma$ & Erro \pm Desvio Padrão \\
\hline Daubechies 2 & 128 & $19,32 \% \pm 1,28$ & 128 & $19,09 \% \pm 1,28 \%$ \\
\hline Daubechies 4 & 128 & $22,37 \% \pm 1,87$ & 128 & $22,16 \% \pm 1,62 \%$ \\
\hline Symlet 3 & 128 & $22,87 \% \pm 1,85$ & 128 & $22,83 \% \pm 1,82 \%$ \\
\hline Symlet 4 & 128 & $22,59 \% \pm 1,71$ & 128 & $22,37 \% \pm 1,60 \%$ \\
\hline Symlet 5 & 128 & $23,19 \% \pm 1,60$ & 128 & $23,03 \% \pm 1,53 \%$ \\
\hline
\end{tabular}

Tabela 19 - Resultados obtidos usando a estratégia de fusão baseada na detecção de contornos e a transformada Contourlet.

Analisando os resultados apresentados na Tabela 19, pode-se verificar que a quarta estratégia não conseguiu produzir nenhuma melhora no desempenho, visto que não foi possível obter resultados próximos dos sistemas unimodais baseados em íris usando essa mesma transformada. Em relação ao parâmetro $\sigma$, os melhores resultados foram obtidos com o valor igual a 128 .

Os resultados obtidos com a quinta estratégia de fusão são apresentados na Tabela 20. Ao contrário da estratégia anterior, esta estratégia conseguiu gerar uma melhora no 
desempenho em relação aos sistemas biométricos unimodais baseados em íris usando essa transformada. Entretanto, não foi capaz de superar o melhor sistema unimodal baseado em face. O melhor resultado dessa abordagem foi obtido usando Pirâmide Laplaciana com função Symlet de ordem 4, classificador LS-SVM e valor de $\sigma$ igual a 256, neste caso, foi obtida a taxa de erro igual a $6,87 \%$.

\begin{tabular}{|c|c|c|c|c|}
\hline \multirow{2}{*}{ Contourlet } & \multicolumn{2}{|c|}{ SVM } & \multicolumn{2}{c|}{ LS-SVM } \\
\cline { 2 - 5 } & $\sigma$ & Erro \pm Desvio Padrão & $\sigma$ & Erro \pm Desvio Padrão \\
\hline Daubechies 2 & 256 & $7,05 \% \pm 1,00$ & 256 & $7,05 \% \pm 0,93 \%$ \\
\hline Daubechies 4 & 256 & $7,07 \% \pm 1,02$ & 256 & $7,41 \% \pm 0,82 \%$ \\
\hline Symlet 3 & 256 & $7,78 \% \pm 0,92$ & 256 & $7,88 \% \pm 0,92 \%$ \\
\hline Symlet 4 & 256 & $6,98 \% \pm 1,02$ & 256 & $6,87 \% \pm 0,90 \%$ \\
\hline Symlet 5 & 256 & $6,98 \% \pm 1,02$ & 256 & $8,32 \% \pm 1,02 \%$ \\
\hline
\end{tabular}

Tabela 20 - Resultados obtidos usando o mínimo dos coeficientes de aproximação e o máximo dos coeficientes de detalhes extraídos via transformada Contourlet.

Apesar dessa estratégia não ter conseguido gerar um sistema biométrico que alcançasse uma taxa de erro menor que a obtida pelo melhor sistema biométrico unimodal baseado em face, sua taxa de erro ficou em torno de 1\% acima do melhor resultado. Essa estratégia conseguiu aumentar o poder discriminante dos vetores de características baseados na transformada Contourlet. Isto demonstra que é possível melhorar o desempenho das características originais. Os sistemas unimodais baseado em face ou íris construídos via coeficientes extraídos pela transformada Contourlet não conseguiram obter uma taxa de erro menor que 10\%, já os sistemas multimodais usando esta estratégia de combinação conseguiram obter uma taxa de erro mais baixa. O valor do parâmetro $\sigma$ foi igual a 256 para todos os melhores resultados obtidos.

A Tabela 21 apresenta os resultados para sexta estratégia de combinação. Com esta estratégia também foi possível gerar sistemas biométricos com desempenho superior ao melhor sistema biométrico unimodal baseado em íris, porém não foi possível superar o melhor sistema biométrico unimodal baseado em face. O melhor resultado obtido por essa estratégia foi usando a Pirâmide Laplaciana com função Daubechies de ordem 4, classificador SVM e parâmetro $\sigma$ igual a 256. Neste caso, foi obtida uma taxa de erro igual a $9,46 \%$. 


\begin{tabular}{|c|c|c|c|c|}
\hline \multirow{2}{*}{ Contourlet } & \multicolumn{2}{|c|}{ SVM } & \multicolumn{2}{c|}{ LS-SVM } \\
\cline { 2 - 5 } & $\sigma$ & Erro \pm Desvio Padrão & $\sigma$ & Erro \pm Desvio Padrão \\
\hline Daubechies 2 & 256 & $10,35 \% \pm 1,12$ & 256 & $10,40 \% \pm 1,08 \%$ \\
\hline Daubechies 4 & 256 & $9,46 \% \pm 1,02$ & 256 & $10,10 \% \pm 1,20 \%$ \\
\hline Symlet 3 & 256 & $10,41 \% \pm 1,02$ & 256 & $10,37 \% \pm 1,02 \%$ \\
\hline Symlet 4 & 256 & $9,79 \% \pm 1,40$ & 256 & $10,27 \% \pm 1,08 \%$ \\
\hline Symlet 5 & 256 & $9,71 \% \pm 1,35$ & 256 & $9,92 \% \pm 1,33 \%$ \\
\hline
\end{tabular}

Tabela 21 - Resultados obtidos usando a média dos coeficientes de aproximação e o máximo dos coeficientes de detalhes extraídos via transformada Contourlet.

Conforme já mencionado acima, essa estratégia foi capaz de gerar um vetor de características com maior poder discriminante, porém não conseguiu superar o melhor resultado global obtido pelos sistemas unimodais. Apesar disso, a taxa de erro obtida com essa estratégia ficou abaixo de 10\%, superando o desempenho alcançado pelos sistemas unimodais obtidos com essa mesma transformada. Em relação ao parâmetro $\sigma$ todos os resultados foram obtidos com o valor igual a 256 .

Na Tabela 22 são apresentados os resultados obtidos para estratégia baseada na soma dos vetores de característica extraído da face e da íris. Essa estratégia gerou os sistemas biométricos com os piores desempenhos em relação às outras abordagens de fusão. Os resultados ficaram próximos daqueles obtidos com os sistemas biométricos unimodais baseados em face usando a transformada Contourlet (Tabela 4), os quais foram os piores resultados alcançados pelos sistemas unimodais. O melhor resultado obtido com essa estratégia foi usando a Pirâmide Laplaciana com função Daubechies de ordem 2, classificador LS-SVM e parâmetro $\sigma$ igual a 128. Neste caso, foi obtida uma taxa de erro igual a $21,27 \%$.

\begin{tabular}{|c|c|c|c|c|}
\hline \multirow{2}{*}{ Contourlet } & \multicolumn{2}{|c|}{ SVM } & \multicolumn{2}{c|}{ LS-SVM } \\
\cline { 2 - 5 } & $\sigma$ & Erro \pm Desvio Padrão & $\sigma$ & Erro \pm Desvio Padrão \\
\hline Daubechies 2 & 128 & $21,55 \% \pm 1,62$ & 128 & $21,27 \% \pm 1,73 \%$ \\
\hline Daubechies 4 & 128 & $25,66 \% \pm 1,27$ & 128 & $25,39 \% \pm 1,36 \%$ \\
\hline Symlet 3 & 128 & $26,01 \% \pm 1,55$ & 128 & $25,94 \% \pm 1,49 \%$ \\
\hline Symlet 4 & 128 & $25,73 \% \pm 1,45$ & 128 & $25,37 \% \pm 1,38 \%$ \\
\hline Symlet 5 & 128 & $26,30 \% \pm 1,71$ & 128 & $25,95 \% \pm 1,70 \%$ \\
\hline
\end{tabular}

Tabela 22 - Resultados obtidos usando a soma dos coeficientes extraídos das imagens de face e íris pela transformada Contourlet.

De forma geral, a transformada Contourlet com as estratégias de fusão conseguiram produzir sistemas que superaram o desempenho do melhor sistema baseado em íris (taxa de erro de $9,71 \%$ ), porém não conseguiram superar o desempenho do melhor sistema unimodal baseado em face (taxa de erro de 6,36\%). Os melhores resultados foram alcançados usando as estratégias \#1 e \#4, as quais produziram uma taxa de erro igual a 6,68\% e 6,87\%, 
respectivamente. Observe que este resultado é próximo daqueles obtidos pelos sistemas unimodais baseado em face.

Apesar dos resultados descritos nesta seção não superarem aqueles obtidos pelo melhor sistema unimodal, em relação aos sistemas unimodais construídos via os coeficientes extraídos pela transformada Contourlet foi possível obter um ganho considerável no desempenho para algumas estratégias. Isto mostra que os sistemas multimodais podem vir a superar os sistemas unimodais ou aliviar o problema de escolha de parâmetros.

\subsubsection{Transformada Curvelet}

Nesta seção é investigado o emprego das estratégias de combinação para os coeficientes da transformada Curvelet extraídos das imagens de face e íris visando reconhecimento biométrico. Os resultados obtidos com essa transformada e as estratégias de fusão são apresentados nas Tabelas 23-29.

Os resultados obtidos com a primeira estratégia de fusão são apresentados na Tabela 23. Essa estratégia conseguiu obter os melhores resultados quando comparado com os alcançados pelos melhores sistemas biométricos unimodais baseados em face ou íris e pelos sistemas multimodais aqui propostos. O melhor resultado foi obtido usando os coeficientes do nível 3, classificador LS-SVM e parâmetro de $\sigma$ igual a 512. Neste caso, foi obtida uma taxa de erro igual a $4,70 \%$.

\begin{tabular}{|c|c|c|c|c|}
\hline \multirow{2}{*}{ Curvelet } & \multicolumn{2}{|c|}{ SVM } & \multicolumn{2}{c|}{ LS-SVM } \\
\cline { 2 - 5 } & $\sigma$ & Erro \pm Desvio Padrão & $\sigma$ & Erro \pm Desvio Padrão \\
\hline Level 3 & 64 & $8,09 \% \pm 2,23$ & 512 & $4,70 \% \pm 2,00 \%$ \\
\hline Level $3+2$ & 128 & $8,03 \% \pm 2,38$ & 512 & $7,05 \% \pm 4,49 \%$ \\
\hline Level $3+2+1$ & 256 & $12,92 \% \pm 5,18$ & 512 & $11,55 \% \pm 6,19$ \\
\hline
\end{tabular}

Tabela 23 - Resultados obtidos usando a concatenação dos coeficientes extraídos da face e íris via transformada Curvelet

A maioria dos resultados obtidos com essa estratégia obteve uma taxa de erro abaixo de 10\%, superando o desempenho obtido pelos sistemas baseados em íris com essa transformada, o qual é próximo do melhor resultado global. Em relação ao parâmetro $\sigma$, os valores sofreram uma grande variação e ficaram dentro do intervalo [64,512]. Neste caso, o melhor resultado foi obtido com $\sigma$ igual a 512 .

Os resultados obtidos com a segunda estratégia são apresentados na Tabela 24. Observe que essa estratégia produziu resultados muito ruins, os quais ficaram abaixo inclusive 
dos piores resultados obtidos com os sistemas unimodais. Isto mostra que essa estratégia de fusão não conseguiu gerar vetores de características com bom poder discriminante. $\mathrm{O}$ melhor resultado obtido com essa abordagem foi usando os coeficientes do nível 2, para ambos os classificadores e com valor $\sigma$ igual a 64 . Neste caso, foi obtida uma taxa de erro igual a $26,61 \%$, que foi um dos piores resultados.

\begin{tabular}{|c|c|c|c|c|}
\hline \multirow{2}{*}{ Curvelet } & \multicolumn{2}{|c|}{ SVM } & \multicolumn{2}{c|}{ LS-SVM } \\
\cline { 2 - 5 } & $\sigma$ & Erro \pm Desvio Padrão & $\sigma$ & Erro \pm Desvio Padrão \\
\hline Level $3+2$ & 64 & $26,61 \% \pm 2,88$ & 64 & $26,61 \% \pm 2,88 \%$ \\
\hline Level $3+2+1$ & 128 & $29,25 \% \pm 6,74$ & 256 & $30,30 \% \pm 6,15$ \\
\hline
\end{tabular}

Tabela 24 - Resultados obtidos usando os coeficientes de aproximação da face e os coeficientes de detalhes da íris extraídos via transformada Curvelet.

Na Tabela 25 são apresentados os resultados alcançados com a terceira estratégia. Essa estratégia não conseguiu fornecer resultados superiores aos melhores sistemas unimodais, porém conseguiu fornecer uma melhora em relação aos sistemas unimodais baseados em íris com essa mesma transformada. O melhor resultado obtido com essa abordagem foi usando os coeficientes do nível 3+2, classificador LS-SVM, e parâmetro $\sigma$ igual a 128 . Neste caso, foi obtida uma taxa de erro igual a 10,53\%.

\begin{tabular}{|c|c|c|c|c|}
\hline \multirow{2}{*}{ Curvelet } & \multicolumn{2}{|c|}{ SVM } & \multicolumn{2}{c|}{ LS-SVM } \\
\cline { 2 - 5 } & $\sigma$ & Erro \pm Desvio Padrão & $\sigma$ & Erro \pm Desvio Padrão \\
\hline Level $3+2$ & 128 & $11,91 \% \pm 2,10$ & 128 & $10,53 \% \pm 1,97 \%$ \\
\hline Level $3+2+1$ & 256 & $20,22 \% \pm 1,83$ & 256 & $19,93 \% \pm 1,77$ \\
\hline
\end{tabular}

Tabela 25 - Resultados obtidos usando os coeficientes de aproximação da íris e os coeficientes de detalhes da face extraídos via transformada Curvelet.

Os resultados obtidos com a quarta estratégia são apresentados na Tabela 26. Essa estratégia também não foi capaz de fornecer resultados superiores aos melhores sistemas unimodais, porém obteve uma melhora em relação aos resultados obtidos baseado em íris com essa mesma transformada. O melhor resultado obtido com essa abordagem foi usando os coeficientes do nível 3, classificador SVM e parâmetro $\sigma$ igual a 32. Neste caso, foi obtida uma taxa de erro igual a $11,09 \%$.

\begin{tabular}{|c|c|c|c|c|}
\hline \multirow{2}{*}{ Curvelet } & \multicolumn{2}{|c|}{ SVM } & \multicolumn{2}{c|}{ LS-SVM } \\
\cline { 2 - 5 } & $\sigma$ & Erro \pm Desvio Padrão & $\sigma$ & Erro \pm Desvio Padrão \\
\hline Level 3 & 32 & $11,09 \% \pm 2,27$ & 32 & $12,10 \% \pm 2,59 \%$ \\
\hline Level $3+2$ & 128 & $15,53 \% \pm 1,32$ & 128 & $15,06 \% \pm 1,31 \%$ \\
\hline Level $3+2+1$ & 256 & $25,74 \% \pm 1,28$ & 256 & $21,58 \% \pm 5,59$ \\
\hline
\end{tabular}

Tabela 26 - Resultados obtidos usando a estratégia de fusão baseada na detecção de contornos e a transformada Curvelet. 
Na Tabela 27 são apresentado os resultados obtidos com a quinta estratégia de fusão. Esta conseguiu gerar resultados superiores aos obtidos pelos melhores sistemas unimodais baseados em face e íris. O melhor resultado obtido foi usando os coeficientes dos níveis $3+2+1$, classificador SVM e parâmetro $\sigma$ igual a 512. Neste caso, foi obtida uma taxa de erro igual a 5,98\%.

\begin{tabular}{|c|c|c|c|c|}
\hline \multirow{2}{*}{ Curvelet } & \multicolumn{2}{|c|}{ SVM } & \multicolumn{2}{c|}{ LS-SVM } \\
\cline { 2 - 5 } & $\sigma$ & Erro \pm Desvio Padrão & $\sigma$ & Erro \pm Desvio Padrão \\
\hline Level 3 & 64 & $13,87 \% \pm 3,86$ & 32 & $11,87 \% \pm 3,03 \%$ \\
\hline Level $3+2$ & 256 & $7,13 \% \pm 0,99$ & 128 & $10,75 \% \pm 4,16 \%$ \\
\hline Level $3+2+1$ & 512 & $5,98 \% \pm 0,96$ & 128 & $10,75 \% \pm 4,16$ \\
\hline
\end{tabular}

Tabela 27 - Resultados obtidos usando o mínimo dos coeficientes de aproximação e o máximo dos coeficientes de detalhes extraídos via transformada Curvelet.

Somente um dos resultados obtidos com essa estratégia superou o desempenho obtido com os melhores sistemas unimodais. O segundo melhor resultado obteve uma taxa de erro igual a 7,13\%, o qual é muito próximo do melhor resultado global. Vale lembrar que o segundo melhor resultado supera o desempenho do melhor sistema baseado em íris. Outro detalhe importante é que a maioria dos sistemas baseados em face construídos com essa estratégia teve um desempenho superior aos sistemas baseados em íris usando essa transformada. Os melhores resultados de $\sigma$ ficaram dentro do intervalo [32,512], sendo que a maioria foi obtida com valor igual a 128.

Os resultados alcançados com a sexta estratégia são apresentados na Tabela 28. Essa estratégia foi capaz de gerar resultados superiores aos obtidos com os sistemas unimodais. O melhor resultado obtido com essa estratégia foi usando os coeficientes do nível 3, classificador LS-SVM e parâmetro $\sigma$ igual a 64. Neste caso, foi obtida uma taxa de erro igual a $6,41 \%$.

\begin{tabular}{|c|c|c|c|c|}
\hline \multirow{2}{*}{ Curvelet } & \multicolumn{2}{|c|}{ SVM } & \multicolumn{2}{c|}{ LS-SVM } \\
\cline { 2 - 5 } & $\sigma$ & Erro \pm Desvio Padrão & $\sigma$ & Erro \pm Desvio Padrão \\
\hline Level 3 & 32 & $7,99 \% \pm 0,79$ & 64 & $6,41 \% \pm 1,04 \%$ \\
\hline Level $3+2$ & 128 & $9,26 \% \pm 1,03$ & 128 & $8,93 \% \pm 1,07 \%$ \\
\hline Level $3+2+1$ & 512 & $7,33 \% \pm 0,81$ & 512 & $7,25 \% \pm 0,80$ \\
\hline
\end{tabular}

Tabela 28 - Resultados obtidos usando a média dos coeficientes de aproximação e o máximo dos coeficientes de detalhes extraídos via transformada Curvelet.

Pode-se notar que essa estratégia de fusão conseguiu melhorar o desempenho alcançado pelos sistemas unimodais. Apesar de apenas um dos sistemas construídos terem alcançado desempenho superior ao melhor sistema unimodal, os outros sistemas obtiveram desempenho superior aos sistemas baseados em íris. Estes apresentaram, em sua maioria, 
uma taxa de erro inferior a 9\%. Isto demonstra que os vetores de características gerados com essa estratégia apresentaram um alto poder discriminativo. Em relação ao parâmetro $\sigma$, os melhores resultados foram alcançados com valores dentro do intervalo $[32,512]$. De forma geral, essa estratégia teve um comportamento similar à estratégia anterior.

Na Tabela 29 são apresentados os resultados obtidos com a sétima estratégia de fusão. Essa estratégia também foi capaz de superar os melhores sistemas unimodais, o qual foi alcançado quando foram somados os coeficientes do nível 3 de decomposição de face e íris. O melhor desempenho obtido foi usando o coeficiente do nível 3, classificador LS-SVM e parâmetro $\sigma$ igual a 64 . Neste caso, foi obtida uma taxa de erro igual a 6,41\%. Resultado similar ao obtido pela sexta estratégia.

\begin{tabular}{|c|c|c|c|c|}
\hline \multirow{2}{*}{ Curvelet } & \multicolumn{2}{|c|}{ SVM } & \multicolumn{2}{c|}{ LS-SVM } \\
\cline { 2 - 5 } & $\sigma$ & Erro \pm Desvio Padrão & $\sigma$ & Erro \pm Desvio Padrão \\
\hline Level 3 & 32 & $7,99 \% \pm 0,79$ & 64 & $6,41 \% \pm 1,04 \%$ \\
\hline Level $3+2$ & 128 & $18,36 \% \pm 1,67$ & 128 & $17,73 \% \pm 1,52 \%$ \\
\hline Level $3+2+1$ & 512 & $27,54 \% \pm 3,34$ & 256 & $27,57 \% \pm 1,32$ \\
\hline
\end{tabular}

Tabela 29 - Resultados obtidos usando a soma dos coeficientes extraídos das imagens de face e íris via transformada Curvelet.

Com exceção da sexta estratégia, a fusão dos coeficientes dos níveis $3+2$ e $3+2+1$ não foram capazes de melhorar o desempenho dos sistemas. Neste caso, os resultados ficaram piores que os obtidos pelos sistemas unimodais usando a mesma transformada. Isso mostra que possivelmente a soma dos coeficientes dos outros níveis, ao invés de auxiliar na separação das classes, dificulta a discriminação. Em relação ao valor do parâmetro $\sigma$, os melhores resultados foram obtidos com $\sigma$ no intervalo $[32,512]$.

\subsubsection{Melhores sistemas multimodais}

Na Tabela 30 são apresentados os resultados alcançados pelos sistemas multimodais, os quais foram superiores ou muito próximo dos melhores resultados obtidos pelos sistemas unimodais. Os melhores resultados obtidos estão destacados em negrito. Vale lembrar que os melhores resultados obtidos pelos sistemas unimodais atingiram uma taxa de erro igual a $6,36 \%$ para face e igual a $9,71 \%$ para íris. 


\begin{tabular}{|c|c|c|c|c|c|}
\hline \multicolumn{7}{|c|}{ Melhores Sistemas Multimodais } \\
\hline Transformada & Configuração & Estratégia & Classificador & $\sigma$ & Erro \pm Desvio padrão \\
\hline Wavelet & Daubechies 2 & Concatenação & SVM & $\mathbf{1 2 8}$ & $5,10 \% \pm 2,13$ \\
\hline Wavelet & Daubechies 2 & Min. A. Max. D. & LS-SVM & 128 & $6,04 \% \pm 1,58$ \\
\hline Contourlet & Daubechies 2 & Concatenação & SVM & $\mathbf{2 5 6}$ & $6,68 \% \pm 2,55$ \\
\hline Contourlet & Symlet 4 & Min. A. Max. D. & LS-SVM & 128 & $6,87 \% \pm 0,90$ \\
\hline Curvelet & Nível 3 & Concatenação & LS-SVM & $\mathbf{5 1 2}$ & $4,70 \% \pm 2,00$ \\
\hline Curvelet & Nível 3+2+1 & Min. A. Max. D. & SVM & 512 & $5,98 \% \pm 0,96$ \\
\hline Curvelet & Nível 3 & Média A. Max D. & LS-SVM & 64 & $6,41 \% \pm 1,04$ \\
\hline Curvelet & Nível 3 & Soma & LS-SVM & 64 & $6,41 \% \pm 1,04$ \\
\hline
\end{tabular}

Tabela 30 - Melhores resultados obtidos pelos sistemas biométricos multimodais.

Pode-se verificar que as transformadas de Wavelet e Curvelet conseguiram produzir sistemas biométricos superiores aos sistemas unimodais baseados em face e íris. Esse resultado foi obtido por algumas estratégias de fusão. É importante destacar que as estratégias de fusão por concatenação e por mínimo dos coeficientes de aproximação e máximo dos coeficientes de detalhes foram as duas estratégias que produziram os melhores resultados, independente da técnica de extração de característica utilizada.

A transformada Contourlet não conseguiu produzir sistemas biométricos que superasse o desempenho dos melhores sistemas unimodais. No entanto, com o emprego das estratégias de fusão dos coeficientes extraídos via transformada Contourlet foi obtida uma melhora significativa no desempenho em relação aos sistemas unimodais. Com o emprego da transformada Contourlet, as menores taxas de erro alcançadas pelos sistemas unimodais baseado em face foi igual a 11,50\% e pelos sistemas baseado em íris foi igual a 21, 26\%. Com o emprego das estratégias de fusão estes erros caíram para faixa de $6 \%$. Isto demonstra que realmente é possível, com uma escolha adequada das estratégias de fusão, obter uma melhora significativa no desempenho em relação aos sistemas unimodais.

\subsection{Resultado obtido usando Ensemble}

Essa seção apresenta os resultados obtidos com as estratégias de construção de ensemble descritas nas Seções 5.1 e 5.2. Os primeiros ensembles construídos foram baseados na combinação dos sistemas unimodais.

\subsubsection{Ensemble envolvendo sistemas unimodais baseados em face}

Nessa seção, serão apresentados os resultados alcançados com os ensembles construídos usando a fusão dos sistemas biométricos baseado em face para reconhecimento 
do usuário. As estratégias de construção do ensemble foram descritas na Seção 5.1. A combinação baseada no intervalo $\sigma$ foi realizada usando classificadores com diferentes valores de $\sigma$ selecionados no intervalo $[32,128]$. Esse intervalo foi escolhido de forma a garantir que os classificadores tenham alcançado um bom desempenho. Os resultados obtidos são apresentados nas Tabelas 31-34.

O primeiro conjunto de ensemble foi baseado na combinação dos classificadores construídos com base nos coeficientes extraídos via transformada Wavelet. Os resultados obtidos com essa abordagem são apresentados na Tabela 31.

\begin{tabular}{|c|c|c|c|c|}
\hline Wavelet & Classificador & Estratégia & Valor de $\sigma$ & Taxa de Erro \pm Desvio Padrão \\
\hline Todas & SVM & Combinação por $\sigma$ & 64 & $15,33 \% \pm 1,55$ \\
\hline Todas & LS-SVM & Combinação por $\sigma$ & 64 & $14,15 \% \pm 1,14$ \\
\hline Todas & SVM & Intervalo de $\sigma$ & {$[32,128]$} & $14,82 \% \pm 1,41$ \\
\hline Todas & LS-SVM & Intervalo de $\sigma$ & {$[32,128]$} & $13,63 \% \pm 1,16$ \\
\hline DB2 & Ambos & Combinação por $\sigma$ & 64 & $14,47 \% \pm 1,32$ \\
\hline DB4 & Ambos & Combinação por $\sigma$ & 64 & $16,82 \% \pm 1,71$ \\
\hline SYM3 & Ambos & Combinação por $\sigma$ & 64 & $16,62 \% \pm 1,93$ \\
\hline SYM4 & Ambos & Combinação por $\sigma$ & 64 & $15,21 \% \pm 1,89$ \\
\hline SYM5 & Ambos & Combinação por $\sigma$ & 64 & $15,89 \% \pm 1,21$ \\
\hline
\end{tabular}

Tabela 31 - Resultados obtidos pelos ensembles usando classificadores construídos com base nos coeficientes da transformada Wavelet extraídos da face.

Pode-se verificar que os ensembles envolvendo a transformada Wavelet conseguiram superar o desempenho obtido pelos sistemas unimodais (taxa de erro igual a 14,70\%) usando três estratégias diferentes: combinação por $\sigma$ usando o classificador LS-SVM (taxa de erro igual a 14,15\%), combinação por intervalo de $\sigma$ usando classificador LS-SVM (taxa de erro igual a 13,63\%) e combinação por $\sigma$ considerando a função Wavelet Daubechies de Ordem 2 (taxa de erro igual a 14,47\%).

O segundo conjunto de ensembles foi baseado na combinação dos classificadores construídos com base nos coeficientes extraídos via transformada Contourlet. Os resultados obtidos com essa abordagem estão descritos na Tabela 32.

\begin{tabular}{|c|c|c|c|c|}
\hline Contourlet & Classificador & Estratégia & Valor de $\sigma$ & Taxa de Erro \pm Desvio Padrão \\
\hline Todas & SVM & Combinação por $\sigma$ & 128 & $25,82 \% \pm 1,77$ \\
\hline Todas & LS-SVM & Combinação por $\sigma$ & 128 & $24,10 \% \pm 1,42$ \\
\hline Todas & SVM & Intervalo de $\sigma$ & {$[32,128]$} & $24,87 \% \pm 1,54$ \\
\hline Todas & LS-SVM & Intervalo de $\sigma$ & {$[32,128]$} & $24,24 \% \pm 1,80$ \\
\hline DB2 & Ambos & Combinação por $\sigma$ & 128 & $21,24 \% \pm 1,65$ \\
\hline DB4 & Ambos & Combinação por $\sigma$ & 128 & $24,33 \% \pm 2,61$ \\
\hline SYM3 & Ambos & Combinação por $\sigma$ & 128 & $25,76 \% \pm 1,51$ \\
\hline SYM4 & Ambos & Combinação por $\sigma$ & 128 & $24,41 \% \pm 1,43$ \\
\hline SYM5 & Ambos & Combinação por $\sigma$ & 128 & $24,22 \% \pm 1,57$ \\
\hline
\end{tabular}

Tabela 32 - Resultados obtidos pelos ensembles usando classificadores construídos com base nos coeficientes da transformada Contourlet extraídos da face. 
Ao contrário da abordagem anterior, os ensembles envolvendo a transformada Contourlet não conseguiram superar o melhor desempenho alcançado pelos sistemas unimodais. Uma das possíveis causas esta relacionado ao desempenho dos sistemas individuais, os quais não apresentaram um bom desempenho. No melhor caso foi obtido uma taxa de erro igual a 21,24\% usando os coeficientes baseados na Pirâmide Laplaciana com função Wavelet Daubechies de ordem 2 e ambos os classificadores com valor de $\sigma$ igual a 128. Esse resultado representa numa melhora de 0,02\% em relação ao sistema unimodal baseado em face, que corresponde a um acerto adicional de apenas duas imagens. Neste caso, o melhor sistema unimodal envolvendo a mesma transformada alcançou uma taxa de erro igual a 21,26\%. Isto demonstra que a combinação de diferentes classificadores produz bom resultado se estes apresentarem um desempenho satisfatório.

O terceiro conjunto de ensembles foi baseado na combinação dos classificadores gerados com base nos coeficientes extraídos via transformada Curvelet. Essa transformada foi a responsável por extrair um conjunto de coeficientes da face com alto poder discriminatório produzindo o melhor resultado alcançado pelos sistemas unimodais. Neste caso, foi obtida uma taxa de erro igual a 6,36\%. Na Tabela 33 são apresentados os resultados obtidos com essa abordagem.

\begin{tabular}{|c|c|c|c|c|}
\hline Curvelet & Classificador & Estratégia & Valor de $\sigma$ & Taxa de Erro \pm Desvio Padrão \\
\hline Todos & SVM & Combinação por $\sigma$ & 32 & $8,68 \% \pm 1,64$ \\
\hline Todos & LS-SVM & Combinação por $\sigma$ & 128 & $16,00 \% \pm 3,03$ \\
\hline Todos & SVM & Intervalo de $\sigma$ & {$[32,128]$} & $8,25 \% \pm 1,19$ \\
\hline Todos & LS-SVM & Intervalo de $\sigma$ & {$[32,128]$} & $11,73 \% \pm 2,28$ \\
\hline 3 & Ambos & Combinação por $\sigma$ & 64 & $7,41 \% \pm 1,00$ \\
\hline $3+2$ & Ambos & Combinação por $\sigma$ & 128 & $12,28 \% \pm 2,95 \%$ \\
\hline $3+2+1$ & Ambos & Combinação por $\sigma$ & 256 & $23,59 \% \pm 3,13$ \\
\hline
\end{tabular}

Tabela 33 - Resultados obtidos pelos ensembles usando classificadores construídos com base nos coeficientes da transformada Curvelet extraídos da face.

Analisando os resultados descritos na Tabela 33 é possível notar que o ensemble envolvendo a transformada Curvelet não conseguiu superar o desempenho do melhor sistema biométrico unimodal. Uma das possíveis causas é a variação de desempenho dos classificadores construídos com base nos coeficientes do nível 3 em relação aos classificadores construídos usando os outros níveis. O melhor resultado com essa transformada foi obtido usando a combinação dos classificadores gerados com os coeficientes do nível 3 e valor de $\sigma$ igual a 64 para ambos os classificadores. Neste caso, foi alcançada uma taxa de erro igual a $7,41 \%$. 
O quarto conjunto de ensemble foi baseado na combinação dos melhores classificadores gerados por cada transformada. Os resultados obtidos com esta abordagem são apresentados na Tabela 34 .

\begin{tabular}{|c|c|c|}
\hline Classificador & Configuração(Valor de $\sigma$ ) & Taxa de Erro \pm Desvio Padrão \\
\hline SVM & $\begin{array}{c}\text { Wavelet - DB2 (64) } \\
\text { Contourlet - DB2 (128) } \\
\text { Curvelet - 3 (32) }\end{array}$ & $11,08 \% \pm 1,07$ \\
\hline LS-SVM & $\begin{array}{c}\text { Wavelet - DB2 (64) } \\
\text { Contourlet - DB2 (128) } \\
\text { Curvelet - 3 (64) }\end{array}$ & $10,79 \% \pm 1,41$ \\
\hline LS-SVM & $\begin{array}{c}\text { Wavelet - DB2 (64) } \\
\text { LS-SVM }\end{array}$ & $\begin{array}{c}\text { Contourlet - DB2 (128) } \\
\text { Curvelet - 3 (64) }\end{array}$ \\
LS-SVM &
\end{tabular}

Tabela 34 - Resultados obtidos pelos ensembles usando classificadores construídos com base nos coeficientes de diferentes transformadas extraídos da face.

Como houve uma grande variação do desempenho obtido pelos classificadores gerados pelas diferentes transformadas, a combinação destes não conseguiu superar o melhor desempenho global alcançado pelo sistema unimodal (taxa de erro igual 6,36\%). Entretanto, analisando as três estratégias de construção de ensemble (combinação por $\sigma$, combinação por intervalo de $\sigma$ e combinação por $\sigma$ considerando uma função Wavelet específica), pode-se observar que foi possível melhorar o desempenho em relação aos sistemas unimodais baseado em transformadas Wavelet e Contourlet, que no melhor caso obtiveram uma taxa de erro igual a 14,70\% e 21,26\% respectivamente. Isto mostra que o ensemble de um conjunto de classificadores pode não superar o desempenho do melhor classificador, porém o ensemble gerado terá um desempenho razoável.

\subsubsection{Ensemble envolvendo sistemas unimodais baseados em íris}

Nessa seção, serão apresentados os resultados alcançados com os ensembles construídos usando a fusão dos sistemas biométricos baseado em íris para reconhecimento do usuário. As estratégias de construção ensemble foram descritas na Seção 5.1. A combinação baseada no intervalo $\sigma$ foi realizada usando classificadores com diferentes valores de $\sigma$ selecionados no intervalo $[32,128]$. Esse intervalo foi escolhido de forma a garantir que os classificadores tenham alcançado bom desempenho. Os resultados obtidos são apresentados nas Tabelas 35-38. 
O primeiro conjunto de ensemble foi baseado na combinação dos classificadores construídos com base nos coeficientes extraídos da íris através da transformada Wavelet. Os resultados obtidos com essa abordagem estão descritos na Tabela 35.

\begin{tabular}{|c|c|c|c|c|}
\hline Wavelet & Classificador & Estratégia & Valor de $\sigma$ & Taxa de Erro \pm Desvio Padrão \\
\hline Todas & SVM & Combinação por $\sigma$ & 64 & $10,94 \% \pm 3,15$ \\
\hline Todas & LS-SVM & Combinação por $\sigma$ & 64 & $10,84 \% \pm 3,12$ \\
\hline Todas & SVM & Intervalo de $\sigma$ & {$[32,128]$} & $10,47 \% \pm 2,93$ \\
\hline Todas & LS-SVM & Intervalo de $\sigma$ & {$[32,128]$} & $10,37 \% \pm 2,77$ \\
\hline DB2 & Ambos & Combinação por $\sigma$ & 64 & $9,71 \% \pm 2,43$ \\
\hline DB4 & Ambos & Combinação por $\sigma$ & 64 & $12,45 \% \pm 2,42$ \\
\hline SYM3 & Ambos & Combinação por $\sigma$ & 64 & $10,66 \% \pm 2,88$ \\
\hline SYM4 & Ambos & Combinação por $\sigma$ & 64 & $13,01 \% \pm 2,54$ \\
\hline SYM5 & Ambos & Combinação por $\sigma$ & 64 & $13,77 \% \pm 3,47$ \\
\hline
\end{tabular}

Tabela 35 - Resultados obtidos pelos ensembles usando classificadores construídos com base nos coeficientes da transformada Wavelet extraídos da íris.

Os ensembles envolvendo a transformada Wavelet não conseguiram superar o melhor desempenho obtido pelos sistemas unimodais. O melhor resultado com ensemble foi obtido usando a função Wavelet Daubechies de ordem 2 e ambos os classificadores com valor de $\sigma$ igual a 64 . Neste caso, foi obtida a taxa de erro igual a 9,71\%. Esse resultado é igual ao obtido pelo melhor sistema unimodal baseado em íris (Tabela 6).

O segundo conjunto de ensembles foi baseado na combinação dos classificadores construídos com base nos coeficientes extraídos da íris via transformada Contourlet. Os resultados obtidos com essa abordagem estão descritos na Tabela 36.

\begin{tabular}{|c|c|c|c|c|}
\hline Contourlet & Classificador & Estratégia & Valor de $\sigma$ & Taxa de Erro \pm Desvio Padrão \\
\hline Todas & SVM & Combinação por $\sigma$ & 64 & $11,98 \% \pm 1,99$ \\
\hline Todas & LS-SVM & Combinação por $\sigma$ & 64 & $12,07 \% \pm 1,92$ \\
\hline Todas & SVM & Intervalo de $\sigma$ & {$[32,128]$} & $11,32 \% \pm 2,08$ \\
\hline Todas & LS-SVM & Intervalo de $\sigma$ & {$[32,128]$} & $11,41 \% \pm 1,91$ \\
\hline DB2 & Ambos & Combinação por $\sigma$ & 128 & $11,50 \% \pm 2,54$ \\
\hline DB4 & Ambos & Combinação por $\sigma$ & 128 & $12,16 \% \pm 2,53$ \\
\hline SYM3 & Ambos & Combinação por $\sigma$ & 128 & $12,92 \% \pm 3,32$ \\
\hline SYM4 & Ambos & Combinação por $\sigma$ & 128 & $12,54 \% \pm 2,43$ \\
\hline SYM5 & Ambos & Combinação por $\sigma$ & 64 & $12,64 \% \pm 2,60$ \\
\hline
\end{tabular}

Tabela 36 - Resultados obtidos pelos ensembles usando classificadores construídos com base nos coeficientes da transformada Contourlet extraídos da íris.

Os ensembles envolvendo a transformada Contourlet conseguiram obter uma melhora em relação aos sistemas unimodais baseados em íris, os quais utilizaram essa mesma transformada. No entanto, o ensemble não foi capaz de superar o desempenho do melhor sistema baseado em íris. As estratégias de construção de ensemble que produziram os melhores resultados em relação ao melhor sistema unimodal baseado em íris construídos via coeficientes extraídos pela transformada Contourlet, o qual obteve uma taxa de erro igual 
a 11,50\%, foram as seguintes: usando todas as funções Wavelet e classificador SVM com os valores de $\sigma$ dentro do intervalo $[32,128]$ foi obtido uma taxa de erro igual a 11,32\%; usando todas as funções Wavelet, classificador LS-SVM com os valores de $\sigma$ dentro do intervalo $[32,128]$ foi obtido uma taxa de erro igual a $(11,41 \%)$.

O terceiro conjunto de ensembles foi baseado na combinação dos classificadores gerados com base nos coeficientes extraídos via transformada Curvelet. Na Tabela 37 são apresentados os resultados obtidos com essa abordagem.

\begin{tabular}{|c|c|c|c|c|}
\hline Curvelet & Classificador & Estratégia & Valor de $\sigma$ & Taxa de Erro \pm Desvio Padrão \\
\hline Todos & SVM & Combinação por $\sigma$ & 128 & $15,66 \% \pm 3,61$ \\
\hline Todos & LS-SVM & Combinação por $\sigma$ & 128 & $13,58 \% \pm 2,85$ \\
\hline Todos & SVM & Intervalo de $\sigma$ & {$[32,128]$} & $13,86 \% \pm 3,32$ \\
\hline Todos & LS-SVM & Intervalo de $\sigma$ & {$[32,128]$} & $12,16 \% \pm 3,18$ \\
\hline 3 & Ambos & Combinação por $\sigma$ & 64 & $11,60 \% \pm 4,17$ \\
\hline $3+2$ & Ambos & Combinação por $\sigma$ & 128 & $24,15 \% \pm 3,95$ \\
\hline $3+2+1$ & Ambos & Combinação por $\sigma$ & 256 & $26,13 \% \pm 4,10$ \\
\hline
\end{tabular}

Tabela 37 - Resultados obtidos pelos ensembles usando classificadores construídos com base nos coeficientes da transformada Curvelet extraídos da íris.

Os resultados obtidos com os ensembles envolvendo a transformada Curvelet não conseguiram superar o melhor desempenho global. Além disso, não conseguiu superar o melhor desempenho obtido pelos sistemas unimodais usando a mesma transformada. $\mathrm{O}$ melhor resultado obtido com ensemble foi usando os coeficientes do nível 3 e ambos os classificadores com parâmetro $\sigma$ igual a 64. Neste caso, foi obtida uma taxa de erro igual a $11,60 \%$. Esse resultado corresponde a $0,10 \%$ acima do melhor resultado obtido pelo sistema unimodal usando essa mesma transformada (Tabela 8).

O quarto conjunto de ensemble foi baseado na combinação dos melhores sistemas unimodais baseado em íris gerados por cada transformada. Os resultados obtidos com esta abordagem são apresentados na Tabela 38.

\begin{tabular}{|c|c|c|}
\hline Classificador & Configuração(Valor de $\sigma$ ) & Taxa de Erro \pm Desvio Padrão \\
\hline SVM & $\begin{array}{c}\text { Wavelet - DB2 (64) } \\
\text { Contourlet - DB2 (128) } \\
\text { Curvelet - 3 (128) }\end{array}$ & $8,67 \% \pm 2,38$ \\
\hline LS-SVM & $\begin{array}{c}\text { Wavelet - DB2 (64) } \\
\text { Contourlet - DB2 (128) } \\
\text { Curvelet - 3 (128) }\end{array}$ & $8,49 \% \pm 2,39$ \\
\hline SVM & $\begin{array}{c}\text { Wavelet - DB2 (64) } \\
\text { SVM }\end{array}$ & $\begin{array}{c}\text { Contourlet - DB2 (128) } \\
\text { Curvelet - 3 (128) }\end{array}$ \\
SVM & \multicolumn{2}{|c|}{$8,67 \% \pm 2,38$} \\
\hline
\end{tabular}

Tabela 38 - Resultados obtidos pelos ensembles usando classificadores construídos com base nos coeficientes de diferentes transformadas extraídos da íris. 
Com a combinação dos melhores sistemas unimodais baseado em íris gerados por cada transformada foi possível obter uma melhora em relação ao melhor sistema unimodal baseado em íris. O melhor resultado obtido foi usando a combinação dos melhores resultados obtido com o classificador LS-SVM. Neste caso, foi obtida uma taxa de erro igual a 8,49\%, sendo que o melhor resultado global alcançado pelos sistemas unimodais baseado em íris foi igual a 9,71\% usando a transformada Wavelet. Isso demonstra que, apesar das transformadas Contourlet e Curvelet não terem conseguido obter uma taxa de erro abaixo de $10 \%$, ao combinarmos a saída dos sistemas gerados por essas transformadas com o sistema gerado pela transformada Wavelet foi possível melhorar o resultado global. Neste caso, os coeficientes extraídos pela transformada Contourlet e Curvelet conseguiram discriminar corretamente algumas instâncias que eram classificadas incorretamente pelos coeficientes da transformada Wavelet.

\subsubsection{Ensemble envolvendo sistemas multimodais}

Nessa seção, são apresentados os resultados alcançados pelo ensemble baseados na combinação dos sistemas multimodais. Para a construção dos ensembles foram selecionadas as estratégias de fusão que obtiveram pior e melhor desempenho por transformada, isto é, para cada transformada foi construído dois ensembles, um tendo como base sistemas multimodais construídos usando a pior estratégia de fusão e outro tendo como base sistemas multimodais construídos usando a melhor estratégia de fusão. As estratégias selecionadas são apresentadas na Tabela 39.

\begin{tabular}{|c|c|c|}
\hline Transformada & Melhor Abordagem & Pior Abordagem \\
\hline Wavelet & Concatenação & Soma \\
\hline Contourlet & Mínimo A. Máximo D. & Soma \\
\hline Curvelet & Concatenação & Contornos \\
\hline
\end{tabular}

Tabela 39 - Estratégias de fusão usadas nos sistemas multimodais que produziram melhor e pior desempenho.

\subsubsection{Transformada Wavelet}

Foram gerados dois ensembles, um envolvendo sistemas multimodais baseado na soma dos coeficientes extraídos via transformada Wavelet e outro envolvendo sistemas multimodais baseado na concatenação destes coeficientes. Na Tabela 40 são apresentados 
os resultados obtidos com ensemble envolvendo sistemas multimodais, os quais foram construídos usando a soma dos coeficientes de Wavelet.

\begin{tabular}{|c|c|c|c|c|}
\hline \multicolumn{5}{|c|}{ Estratégia de fusão - soma dos coeficientes } \\
\hline Wavelet & Classificador & Estratégia & Valor de $\sigma$ & Taxa de Erro \pm Desvio Padrão \\
\hline Todas & SVM & Combinação por $\sigma$ & 64 & $14,90 \% \pm 1,25$ \\
\hline Todas & LS-SVM & Combinação por $\sigma$ & 64 & $14,42 \% \pm 1,06$ \\
\hline Todas & SVM & Intervalo de $\sigma$ & {$[32,128]$} & $14,22 \% \pm 1,31$ \\
\hline Todas & LS-SVM & Intervalo de $\sigma$ & {$[32,128]$} & $13,78 \% \pm 1,26$ \\
\hline DB2 & Ambos & Combinação por $\sigma$ & 64 & $14,40 \% \pm 1,36$ \\
\hline DB4 & Ambos & Combinação por $\sigma$ & 64 & $17,31 \% \pm 1,20$ \\
\hline SYM3 & Ambos & Combinação por $\sigma$ & 64 & $16,63 \% \pm 1,94$ \\
\hline SYM4 & Ambos & Combinação por $\sigma$ & 64 & $15,61 \% \pm 1,36$ \\
\hline SYM5 & Ambos & Combinação por $\sigma$ & 64 & $15,82 \% \pm 1,29$ \\
\hline
\end{tabular}

Tabela 40 - Resultados obtidos pelos ensembles envolvendo sistemas multimodais construídos usando a soma dos coeficientes da transformada de Wavelet.

O melhor sistema multimodal usando a estratégia de fusão baseada na soma dos coeficientes alcançou uma taxa de erro igual a 14,64\%. Neste caso, cada função Wavelet produziu um sistema multimodal. Ao combinarmos todos os sistemas multimodais gerados usando a soma dos coeficientes de Wavelet extraídos das imagens de face e íris e classificador LS-SVM com valor de $\sigma$ dentro do intervalo $[32,128]$ foi obtido uma taxa de erro igual a $13,78 \%$. Isto significa que foi possível classificar corretamente cerca de 90 imagens adicionais em relação ao melhor sistema multimodal usando a estratégia de fusão baseada em soma. Entretanto, não foi possível superar o desempenho obtido pelo melhor sistema multimodal.

Na Tabela 41 são apresentados os resultados obtidos com o ensemble envolvendo sistemas multimodais baseados na estratégia de concatenação das características extraídas das imagens de face e íris. Essa estratégia de fusão foi responsável por gerar os melhores resultados obtidos pelos sistemas multimodais usando a transformada Wavelet. No melhor caso, foi obtido uma taxa de erro igual a $5,10 \%$.

\begin{tabular}{|c|c|c|c|c|}
\hline \multicolumn{5}{c}{ Estratégia de Concatenação } \\
\hline Wavelet & Classificador & Estratégia & Valor de $\sigma$ & Taxa de Erro \pm Desvio Padrão \\
\hline Todas & SVM & Combinação por $\sigma$ & 128 & $5,17 \% \pm 2,20$ \\
\hline Todas & LS-SVM & Combinação por $\sigma$ & 256 & $5,43 \% \pm 2,36$ \\
\hline Todas & SVM & Intervalo de $\sigma$ & {$[32,128]$} & $5,34 \% \pm 2,17$ \\
\hline Todas & LS-SVM & Intervalo de $\sigma$ & {$[32,128]$} & $5,18 \% \pm 2,18$ \\
\hline DB2 & Ambos & Combinação por $\sigma$ & 128 & $5,02 \% \pm 2,07$ \\
\hline DB4 & Ambos & Combinação por $\sigma$ & 256 & $6,45 \% \pm 2,18$ \\
\hline SYM3 & Ambos & Combinação por $\sigma$ & 128 & $5,57 \% \pm 2,39$ \\
\hline SYM4 & Ambos & Combinação por $\sigma$ & 128 & $6,31 \% \pm 2,79$ \\
\hline SYM5 & Ambos & Combinação por $\sigma$ & 256 & $6,23 \% \pm 2,88$ \\
\hline
\end{tabular}

Tabela 41 - Resultados obtidos pelos ensembles envolvendo sistemas multimodais construídos usando a concatenação dos coeficientes da transformada de Wavelet. 
Analisando a Tabela 41, pode-se notar que apenas uma das estratégias de combinação conseguiu superar o desempenho do melhor sistema multimodal, o qual foi obtido usando função Wavelet Daubechies de ordem 2, classificador com parâmetro $\sigma$ igual a 128 . Neste caso, foi obtida uma taxa de erro igual a 5,02\%. Apesar das outras estratégias de combinação não terem superado o desempenho do melhor componente (sistema multimodal) do ensemble, estas alcançaram um desempenho muito próximo do melhor resultado global. No pior caso, foi obtido uma taxa de erro igual a 6,45\%. Isto demonstra que o emprego do ensemble pode aliviar a escolha de alguns parâmetros do classificador, como por exemplo, parâmetro $\sigma$. Neste caso, não é necessário se preocupar com um ajuste fino deste parâmetro, a combinação de vários sistemas multimodais pode alcançar um desempenho bastante próximo do melhor resultado global.

\subsubsection{Transformada Contourlet}

Dois ensembles foram gerados, um envolvendo sistemas multimodais baseado na soma dos coeficientes extraídos via transformada Contourlet e outro envolvendo sistemas multimodais baseado no mínimo dos coeficientes de aproximação e máximo dos coeficientes de detalhes extraídos por meio da transformada Contourlet. Na Tabela 42 são apresentados os resultados obtidos com o ensemble gerado a partir de sistemas multimodais construídos usando a estratégia baseada na soma.

\begin{tabular}{|c|c|c|c|c|}
\hline \multicolumn{5}{c|}{ Estratégia de Soma } \\
\hline Contourlet & Classificador & Estratégia & Valor de $\sigma$ & Taxa de Erro \pm Desvio Padrão \\
\hline Todas & SVM & Combinação por $\sigma$ & 128 & $24,25 \% \pm 1,37$ \\
\hline Todas & LS-SVM & Combinação por $\sigma$ & 128 & $23,46 \% \pm 1,13$ \\
\hline Todas & SVM & Intervalo de $\sigma$ & {$[32,128]$} & $24,59 \% \pm 1,57$ \\
\hline Todas & LS-SVM & Intervalo de $\sigma$ & {$[32,128]$} & $24,22 \% \pm 1,57$ \\
\hline DB2 & Ambos & Combinação por $\sigma$ & 128 & $21,28 \% \pm 1,65$ \\
\hline DB4 & Ambos & Combinação por $\sigma$ & 128 & $25,35 \% \pm 1,30$ \\
\hline SYM3 & Ambos & Combinação por $\sigma$ & 128 & $25,74 \% \pm 1,51$ \\
\hline SYM4 & Ambos & Combinação por $\sigma$ & 128 & $24,66 \% \pm 1,30$ \\
\hline SYM5 & Ambos & Combinação por $\sigma$ & 128 & $25,89 \% \pm 1,69$ \\
\hline
\end{tabular}

Tabela 42 - Resultados obtidos pelos ensembles envolvendo sistemas multimodais construídos usando a soma dos coeficientes da transformada de Contourlet.

Ensemble envolvendo sistemas multimodais baseado na soma dos coeficientes extraídos via transformada Contourlet gerou os piores resultados em relação a todos os sistemas multimodais. No melhor caso, os sistemas multimodais construídos usando coeficientes da transformada Contourlet alcançaram uma taxa de erro igual a $21,28 \%$. A combinação dos sistemas multimodais não conseguiu gerar nenhum resultado superior a 
essa taxa de erro. Em apenas um dos cenários foi possível obter uma taxa de erro próxima desse valor. O melhor cenário foi alcançado usando a Pirâmide Laplaciana com função Wavelet Daubechies de ordem 2 e os classificadores SVM e LS-SVM com valor de $\sigma$ igual 128. Neste caso, foi obtida uma taxa de erro igual a 21,28\%. Isto mostra que apesar do resultado obtido com ensemble não ter sido bom, para algumas configurações foi possível chegar a um resultado próximo do melhor sistema multimodal baseado na transformada Contourlet com a combinação de diferentes classificadores.

Na Tabela 43 são apresentados os resultados obtidos com o ensemble envolvendo sistemas multimodais baseados na fusão do mínimo dos coeficientes de aproximação e máximo dos coeficientes de detalhes extraídos das imagens de face e íris.

\begin{tabular}{|c|c|c|c|c|}
\hline \multicolumn{5}{|c|}{ Estratégia de Mínimo Aproximação e Máximo dos Detalhes } \\
\hline Contourlet & Classificador & Estratégia & Valor de $\sigma$ & Taxa de Erro \pm Desvio Padrão \\
\hline Todas & SVM & Combinação por $\sigma$ & 256 & $6,63 \% \pm 0,93$ \\
\hline Todas & LS-SVM & Combinação por $\sigma$ & 256 & $6,53 \% \pm 0,69$ \\
\hline Todas & SVM & Intervalo de $\sigma$ & {$[32,128]$} & $8,62 \% \pm 0,78$ \\
\hline Todas & LS-SVM & Intervalo de $\sigma$ & {$[32,128]$} & $8,56 \% \pm 0,84$ \\
\hline DB2 & Ambos & Combinação por $\sigma$ & 256 & $7,08 \% \pm 0,91$ \\
\hline DB4 & Ambos & Combinação por $\sigma$ & 256 & $7,01 \% \pm 0,63$ \\
\hline SYM3 & Ambos & Combinação por $\sigma$ & 256 & $7,77 \% \pm 0,94$ \\
\hline SYM4 & Ambos & Combinação por $\sigma$ & 256 & $6,85 \% \pm 0,97$ \\
\hline SYM5 & Ambos & Combinação por $\sigma$ & 256 & $7,47 \% \pm 1,02$ \\
\hline
\end{tabular}

Tabela 43 - Resultados obtidos pelos ensembles envolvendo sistemas multimodais construídos usando o mínimo dos coeficientes de aproximação e máximo dos coeficientes de detalhes da transformada de Contourlet.

Com o emprego de ensemble envolvendo sistemas multimodais baseados na tranformada Contourlet foi possível gerar resultados que superassem o desempenho obtido pelos sistemas multimodais, construídos usando os coeficientes da transformada Contourlet, em dois casos diferentes: uso de classificadores SVM com valor de $\sigma$ igual a 256 e com todas as pirâmides Laplacianas foi obtido taxa de erro igual a 6,63\%; uso de classificadores SVM e LS-SVM com valor de $\sigma$ igual a 256 e com todas as Pirâmides Laplacianas foi obtido taxa de erro igual a 6,53\%. O melhor sistema multimodal usando os coeficientes dessa transformada obteve uma taxa de erro igual a 6,87\% (veja Tabela 20). Apesar das outras estratégias de construção de ensemble não terem alcançado desempenho superior ao obtido pelos sistemas multimodais, essas obtiveram uma taxa de erro muito próxima do melhor caso. Isto demonstra a vantagem do emprego de ensemble, o qual pode aliviar a escolha dos parâmetros do classificador, produzindo um desempenho muito próximo do melhor caso. 


\subsubsection{Transformada Curvelet}

Novamente, dois ensembles foram gerados, um envolvendo sistemas multimodais baseado em contornos e outro envolvendo sistemas multimodais baseado na concatenação dos coeficientes da transformada Curvelet. Na Tabela 44 são apresentados os resultados obtidos com ensemble envolvendo sistemas multimodais, os quais foram construídos usando contornos e coeficientes da transformada de Curvelet.

\begin{tabular}{|c|c|c|c|c|}
\hline \multicolumn{5}{|c|}{ Estratégia de Combinação de Contornos } \\
\hline Curvelet & Classificador & Estratégia & Valor de $\sigma$ & Taxa de Erro \pm Desvio Padrão \\
\hline Todas & SVM & Combinação por $\sigma$ & 128 & $10,34 \% \pm 1,19$ \\
\hline Todas & LS-SVM & Combinação por $\sigma$ & 128 & $12,68 \% \pm 1,81$ \\
\hline Todas & SVM & Intervalo de $\sigma$ & {$[32,128]$} & $9,53 \% \pm 2,52$ \\
\hline Todas & LS-SVM & Intervalo de $\sigma$ & {$[32,128]$} & $9,72 \% \pm 1,48$ \\
\hline 3 & Ambos & Combinação por $\sigma$ & 32 & $10,72 \% \pm 2,12$ \\
\hline $3+2$ & Ambos & Combinação por $\sigma$ & 128 & $14,90 \% \pm 1,22$ \\
\hline $3+2+1$ & Ambos & Combinação por $\sigma$ & 256 & $23,46 \% \pm 3,39$ \\
\hline
\end{tabular}

Tabela 44 - Resultados obtidos pelos ensembles envolvendo sistemas multimodais construídos usando a detecção de contornos e a transformada de Curvelet.

Sistemas multimodais com fusão baseada em contornos alcançaram os piores desempenhos. No melhor caso, foi obtido uma taxa de erro igual a 11,09\%. Já os ensembles envolvendo estes sistemas obtiveram, no melhor caso, uma taxa de erro igual a 9,53\%, o que representa uma melhora no desempenho de 1,56\%. Neste caso, esse resultado foi obtido usando classificador LS-SVM com $\sigma$ dentro do intervalo [32, 128] e com todos os coeficientes de Curvelet.

Na Tabela 45 são apresentados os resultados obtidos com ensemble envolvendo sistemas multimodais baseados na concatenação dos coeficientes de Curvelet.

\begin{tabular}{|c|c|c|c|c|}
\hline \multicolumn{5}{|c|}{ Estratégia de Concatenação } \\
\hline Curvelet & Classificador & Estratégia & Valor de $\sigma$ & Taxa de Erro \pm Desvio Padrão \\
\hline Todas & SVM & Combinação por $\sigma$ & 128 & $6,72 \% \pm 2,03$ \\
\hline Todas & LS-SVM & Combinação por $\sigma$ & 512 & $7,05 \% \pm 4,49$ \\
\hline Todas & SVM & Intervalo de $\sigma$ & {$[32,128]$} & $6,82 \% \pm 2,22$ \\
\hline Todas & LS-SVM & Intervalo de $\sigma$ & {$[32,128]$} & $5,19 \% \pm 1,80$ \\
\hline 3 & Ambos & Combinação por $\sigma$ & 64 & $4,36 \% \pm 1,66$ \\
\hline $3+2$ & Ambos & Combinação por $\sigma$ & 128 & $5,27 \% \pm 2,12$ \\
\hline $3+2+1$ & Ambos & Combinação por $\sigma$ & 512 & $6,46 \% \pm 4,28$ \\
\hline
\end{tabular}

Tabela 45 - Resultados obtidos pelos ensembles envolvendo sistemas multimodais construídos usando a concatenação dos coeficientes da transformada de Curvelet.

No melhor caso, sistemas multimodais baseados na concatenação dos coeficientes de Curvelet obtiveram uma taxa de erro igual a 4,70\% (veja Tabela 23). Esta taxa corresponde ao melhor resultado global alcançado pelos sistemas multimodais. Por outro lado, ensemble 
envolvendo tais sistemas conseguiu produzir uma melhora nesse desempenho. No melhor caso, foi obtido uma taxa de erro igual a 4,36\%. Este resultado foi alcançado usando classificadores SVM e LS-SVM com parâmetro $\sigma$ igual a 64 e com os coeficientes de Curvelet do nível 3.

\subsubsection{Diferentes transformadas}

Nesta seção, foi investigado o desempenho alcançado pelos ensembles envolvendo os melhores sistemas multimodais construídos por cada transformada. Nesse caso, foi analisado dois cenários, um no qual os sistemas multimodais eram compostos apenas por classificadores SVMs ou LS-SVMs e outro na qual eram compostos pelo classificador que alcançou melhor desempenho. Os resultados obtidos com ensembles para estes dois cenários são apresentados na Tabela 46.

\begin{tabular}{|c|c|c|c|}
\hline Classificador & Configuração(Valor de $\sigma$ ) & Estratégia de Fusão & Taxa de Erro \pm Desvio Padrão \\
\hline SVM & $\begin{array}{c}\text { Wavelet - DB2 (128) } \\
\text { Contourlet - DB2 }(256) \\
\text { Curvelet - 3+2+1 }(512)\end{array}$ & $\begin{array}{c}\text { Concatenação } \\
\text { Concatenação } \\
\text { Min. Apr. - Max. Det }\end{array}$ & $2,09 \% \pm 1,16$ \\
\hline LS-SVM & $\begin{array}{c}\text { Wavelet - DB2 (128) } \\
\text { Contourlet - DB2 }(256) \\
\text { Curvelet - } 3(512)\end{array}$ & $\begin{array}{l}\text { Concatenação } \\
\text { Concatenação } \\
\text { Concatenação }\end{array}$ & $3,52 \% \pm 2,10$ \\
\hline $\begin{array}{c}\text { SVM } \\
\text { SVM } \\
\text { LS-SVM }\end{array}$ & $\begin{array}{c}\text { Wavelet - DB2 (128) } \\
\text { Contourlet - DB2 }(256) \\
\text { Curvelet - } 3(512)\end{array}$ & $\begin{array}{l}\text { Concatenação } \\
\text { Concatenação } \\
\text { Concatenação }\end{array}$ & $3,44 \% \pm 1,75$ \\
\hline
\end{tabular}

Tabela 46 - Resultados obtidos pelos ensembles envolvendo os melhores sistemas multimodais construídos por cada transformada.

No melhor caso, os sistemas multimodais alcançaram uma taxa de erro igual a 4,70\%. Este desempenho foi superado pelos ensembles envolvendo os melhores sistemas multimodais construídos por cada transformada usando classificadores do mesmo tipo (SVMs ou LS-SVM) ou diferentes. No melhor caso, foi obtido uma taxa de erro igual a 2,09\%. Esse resultado foi alcançado usando sistemas multimodais com classificadores SVMs. Isto mostra que o ensemble pode superar o melhor o resultado alcançado por um sistema multimodal, desde que seus componentes sejam selecionados adequadamente.

Analisando os resultados apresentados na Tabela 46 é possível verificar que todos os ensembles gerados obtiveram os melhores resultados em relação aos sistemas multimodais e unimodais, com exceção dos sistemas unimodais envolvendo face. Além de poder produzir uma melhora no desempenho, o emprego de ensemble pode aliviar o problema de seleção de parâmetros na construção de um sistema biométrico, ou seja, não é necessário realizar 
um ajuste fino nos parâmetros do classificador, buscar a melhor técnica de extração de característica e estratégia de fusão.

\subsubsection{Fusão no Nível de decisão}

Anteriormente, sistemas multimodais com fusão no nível de característica e ensemble baseado nesses sistemas foram investigados. Nesta seção, os resultados alcançados com sistemas multimodais com fusão no nível de decisão. Na fusão no nível de decisão, as saída dos classificadores baseado em face ou íris são combinadas usando voto majoritário. $\mathrm{Na}$ Tabela 47 são apresentados esses resultados.

\begin{tabular}{|c|c|c|c|}
\hline \multicolumn{4}{|c|}{ Fusão no Nível de Decisão } \\
\hline Característica & Transformada (Configuração) & Classificador $(\sigma)$ & Taxa de Erro \pm Desvio Padrão \\
\hline Face & Curvelet - 3 & SVM $(32)$ & $6,39 \% \pm 0,99$ \\
Íris & Wavelet - Daubechies 2 & SVM $(64)$ & $4,85 \% \pm 1,10$ \\
\hline Face & Curvelet - 3 & LS-SVM(64) \\
Íris & Wavelet - Daubechies 2 & Curvelet - 3 & \multirow{2}{*}{ LS-SVM(64) } \\
\hline Face & Wavelet - Daubechies 2 & SVM $(64)$ & $4,85 \% \pm 1,10$ \\
Íris &
\end{tabular}

Tabela 47 - Resultados obtidos com sistemas multimodais com fusão no nível de decisão.

Sistemas multimodais com fusão no nível de decisão conseguiram superar o melhor desempenho obtido pelos sistemas unimodais e seus respectivos ensembles, porém não foram capazes de superar o desempenho obtido pelos melhores sistemas multimodais e seus respectivos ensembles. No melhor caso, foi obtido uma taxa de erro igual a 4,85\%. Observe que esta taxa de erro é muito próxima da taxa obtida pelos melhores sistemas multimodais $(4,70 \%)$. Logo pode se destacar que a combinação de dois sistemas unimodais distintos, uma para cada modalidade biometria, pode gerar sistemas com desempenho superior ao alcançado individualmente.

\subsection{Estudo comparativo envolvendo os melhores resultados}

A Tabela 48 apresenta os melhores resultados alcançados pelos sistemas unimodais, multimodais e seus respectivos ensembles. Pode-se notar que os melhores sistemas biométricos, independente da abordagem utilizada, conseguiram chegar a uma taxa de erro menor que 10\%. O que demonstra a viabilidade das diversas configurações de sistemas multimodais e ensemble propostas nesta dissertação. 


\begin{tabular}{|c|c|c|c|c|}
\hline \multicolumn{4}{|c|}{ Melhores Resultados } \\
\hline Abordagem & Transformada & Classificador & $\sigma$ & Taxa de Erro \\
\hline Face & Curvelet - 3 & LS-SVM & 64 & $6,36 \%$ \\
\hline İris & Wavelet - DB2 & SVM & 64 & $9,71 \%$ \\
\hline Face + Ensemble & Curvelet - 3 & Ambos & 64 & $7,41 \%$ \\
\hline Íris + Ensemble & $\begin{array}{c}\text { Wavelet - DB2 } \\
\text { Contourlet - DB2 } \\
\text { Curvelet - 3 }\end{array}$ & LS-SVM & $\begin{array}{c}64 \\
128\end{array}$ & $8,49 \%$ \\
\hline Multimodal & Curvelet - 3 - Concatenação & LS-SVM & 512 & $4,70 \%$ \\
\hline Multimodal + Ensemble & $\begin{array}{c}\text { Wavelet - DB2 - Concatenação } \\
\text { Contourlet - DB2 - Concatenação } \\
\text { Curvelet - 3 - Min. Apr. - Max. Det. }\end{array}$ & SVM & $\begin{array}{c}128 \\
256\end{array}$ & $2,09 \%$ \\
\hline
\end{tabular}

Tabela 48 - Melhores resultados obtidos com sistemas unimodais, multimodais e seus respectivos ensembles.

De forma geral, os ensembles conseguiram gerar os melhores resultados em relação aos seus componentes para quase todos cenários, com exceção dos sistemas unimodais envolvendo face. Neste caso, ensemble envolvendo tais sistemas não foi capaz de superar o desempenho alcançado pelo melhor sistema unimodal baseado em face. O melhor resultado global foi obtido com ensemble envolvendo os melhores sistemas multimodais por cada transformada. No melhor caso, foi obtida uma taxa de erro igual a 2,09\%.

Originalmente, as SVMs e LS-SVMs foram propostas para problema de classificação binária. A aplicação das SVMS e LS-SVMs em problema de classificação envolvendo múltiplas classes pode ser realizada usando a estratégia um-contra-um ou um contracontra-todos. Conforme já mencionado, nesta dissertação foi utilizado à estratégia umcontra-todos. Nessa estratégia a decisão final é tomada via voto majoritário. Logo, não é possível obter com esta estratégia o grau de semelhança de uma instância para uma determinada classe. Este grau de semelhança é muito utilizado para definir limiar de aceitação e rejeição, consequentemente analisar o desempenho do sistema biométrico em termos de Taxa de Falsa Aceitação (FAR) e Falsa Rejeição (FRR). Nesta dissertação foi utilizado a Equação 34 para cálculo do grau de semelhança. Para uma determinada instância, após a definição da classe via voto majoritário, o grau de semelhança é calculado para classe de saída.

\subsubsection{Melhor sistema biométrico unimodal baseado em face}

A Figura 43 apresenta as taxas FAR e FRR do melhor sistema baseado em face. Com limiar de semelhança igual a 0,752, as taxas de FAR e FRR se igualam. Neste ponto, ambas as taxas apresentam valor próximo de 0,25. Se usarmos um limiar de semelhança 
menor que 0,752 temos uma taxa de falsa aceitação maior, ou seja, estaremos aceitando uma maior quantidade de pessoas que deveriam ser rejeitadas pelo sistema. Por outro lado, se usarmos um limiar de semelhança acima de 0,752, estaremos rejeitando uma maior quantidade de pessoas que deveriam ser aceitas pelo sistema.

Vale a pena destacar que um limiar de semelhança alto (no caso 0,752 ) indica que as instâncias, independente da classe, estão muito próximas. Apesar disso, o classificador LS-SVM conseguiu obter uma taxa de erro igual a 6,36\%.

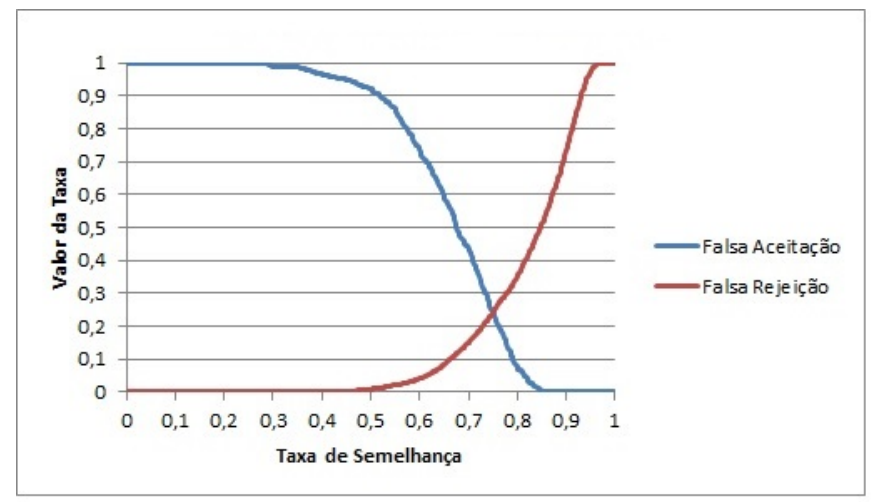

Figura 43 - Curva com a Taxa de Falsa Aceitação versus Taxa de Falsa Rejeição alcançada pelo melhor sistema unimodal baseado em face.

Na Figura 44 é apresentada a taxa de erro obtida pelo melhor sistema unimodal baseado em face para cada classe. Observe que o sistema apresentou o pior desempenho para a classe referente ao usuário \#53. Neste caso, foi obtida uma taxa de erro igual a 19,05\%. A distribuição das saídas geradas pelo sistema para o usuário \#53 é apresentada na Figura 45. Observe que das 84 imagens referentes ao usuário \#53, 16 imagens foram classificadas de forma incorreta. A grande maioria dessas imagens foi classificada como pertencente ao usuário \#50.

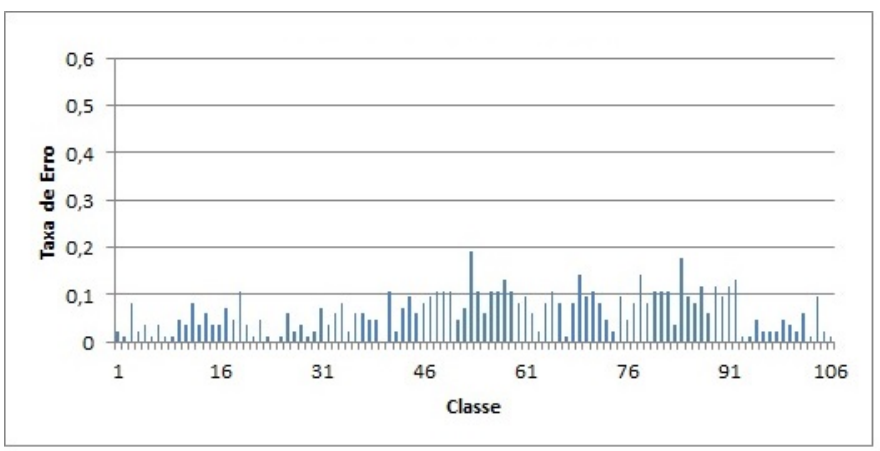

Figura 44 - Distribuição das taxas de erro geradas pelo melhor sistema baseado em face para cada classe. 


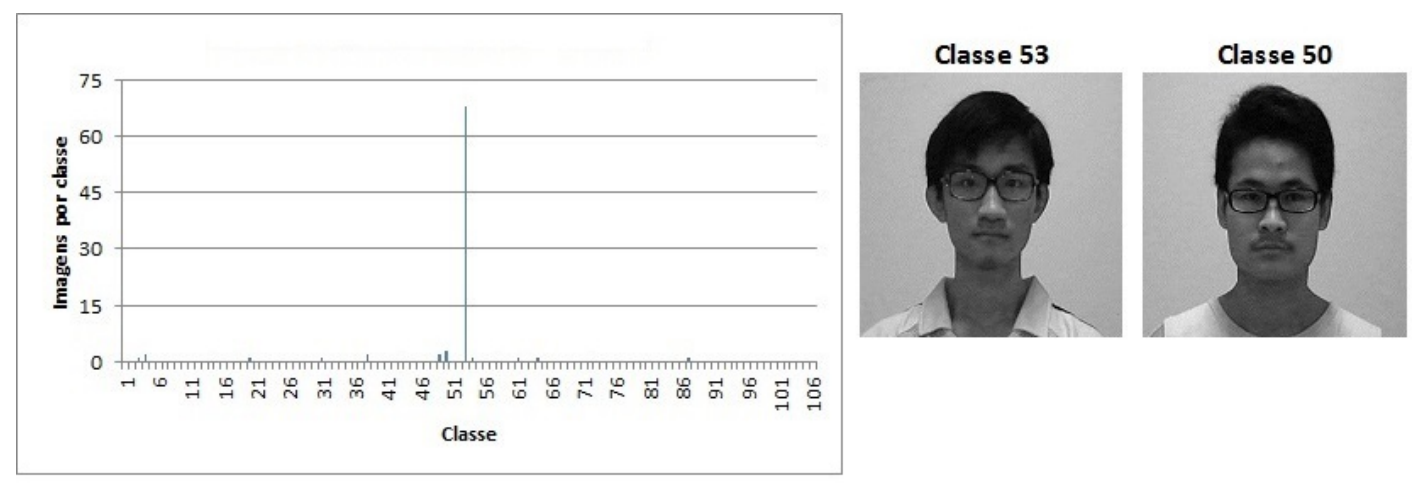

Figura 45 - Distribuição das saídas geradas pelo melhor sistema unimodal baseado em face para a classe \#53.

Na Figura 46 é apresentada a taxa de erro obtida pelo melhor sistema unimodal baseado em face para cada pose (a Figura 39 apresenta as diferentes poses). Observe que o pior desempenho foi obtido para a pose \#1. Neste caso, foi obtida uma taxa de erro igual a 10,69\%, ou seja, das 1272 imagens da pose \#1, 136 imagens foram classificadas incorretamente. O segundo pior desempenho foi obtido para a pose \#6. Neste caso, a taxa de erro foi igual a 10,14\%. Isto demonstra a dificuldade de classificação para imagens com grande variação na orientação.

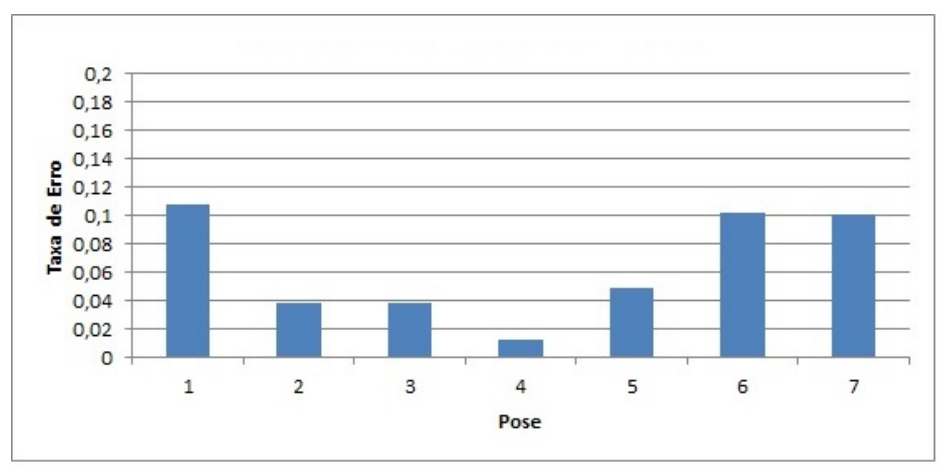

Figura 46 - Distribuição das taxas de erro geradas pelo melhor sistema unimodal baseado em face para cada pose.

A Figura 47 apresenta a distribuição das imagens classificadas incorretamente por classe geradas pelo melhor sistema baseado em face para a pose \#1. O pior desempenho foi obtido para o usuário \#69. Neste caso, 6 das 12 imagens foram classificadas incorretamente. Apesar da pose \#1 apresentar uma grande inclinação da face, 65 usuários tiveram uma, ou nenhuma, imagem desta pose classificada incorretamente considerando as 12 imagens possíveis. Isto mostra que a transformada Curvelet conseguiu gerar uma boa representação para imagens com grande variação na orientação da face. 


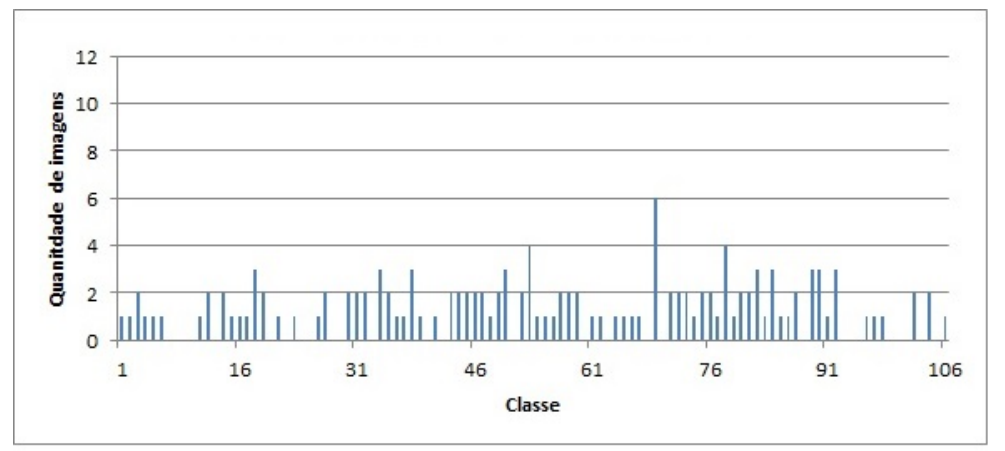

Figura 47 - Distribuição das imagens classificadas incorretamente por classe geradas pelo melhor sistema unimodal baseado em face para a pose \#1.

Na Figura 48 é apresentado a distribuição da taxa de erro para diferentes variações nas condições do ambiente (a Figura 40 apresenta as diferentes variações do ambiente) geradas pelo melhor sistema unimodal baseado em face. Observe que o pior desempenho foi obtido para a variação no ambiente \#9. Neste caso, foram classificadas incorretamente 178 imagens das 742 possíveis. As variações no ambiente \#7, \#8 e \#9 referem-se à grande variação na iluminação do ambiente. Isto demonstra que mesmo sobre condições adversas no ambiente, a transformada Curvelet conseguiu obter uma boa representação para essas imagens.

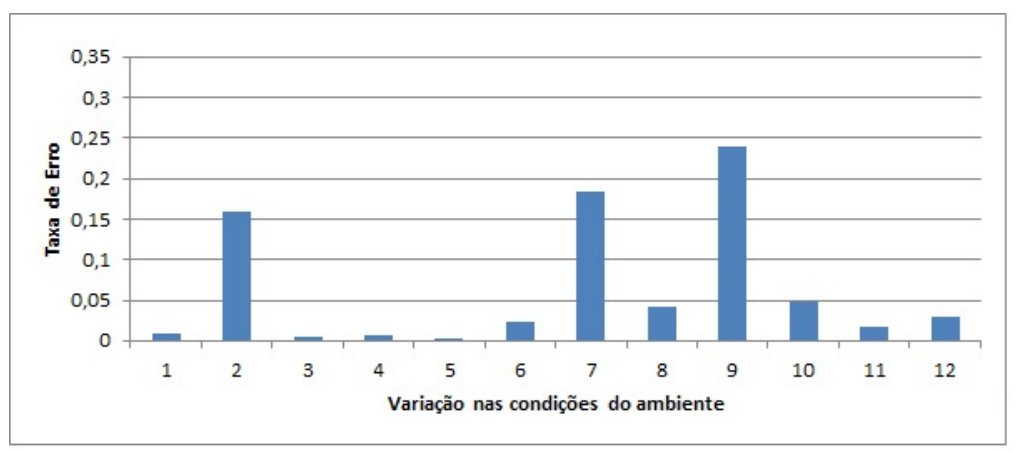

Figura 48 - Distribuição das taxas de erro geradas pelo melhor sistema unimodal baseado em face para diferentes variações nas condições do ambiente.

A Figura 49 apresenta a distribuição das imagens classificadas incorretamente por classe geradas pelo sistema unimodal baseado em face para a variação no ambiente \#9. Observe que para as classes (usuários) \#14, \#49, \#53, \#84, \#89, \#90 e \#91 o sistema classificou incorretamente 4 imagens das 7 imagens possíveis. Vale a pena ressaltar que para 53 classes, o sistema não apresentou nenhum erro de classificação. 


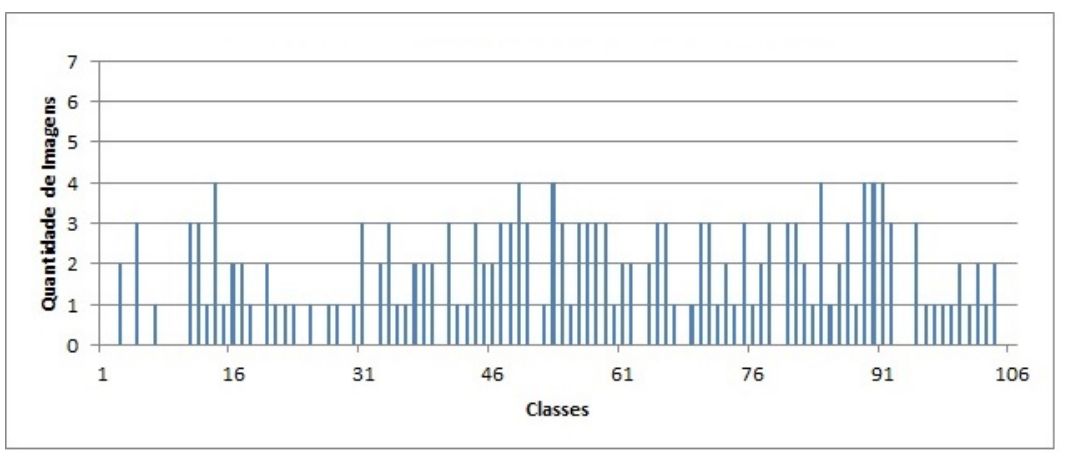

Figura 49 - Distribuição das imagens classificadas incorretamente por classe geradas pelo melhor sistema unimodal baseado em face para a variação no ambiente \#9.

\subsubsection{Melhor ensemble envolvendo sistemas biométricos unimodais baseado em face}

Na Figura 50 são apresentadas as taxas de FAR e FRR para ensemble envolvendo sistemas unimodais baseado em face. Para limiar de semelhança igual a 0,762 as taxas de FAR e FRR se igualam. Neste ponto, ambas as taxas apresentam valor próximo de 0,25 . Observe que este resultado é semelhante ao obtido pelo melhor sistema unimodal baseado em face. No entanto, o ensemble obteve uma taxa de erro um pouco maior quando comparado para o melhor sistema unimodal baseado em face.

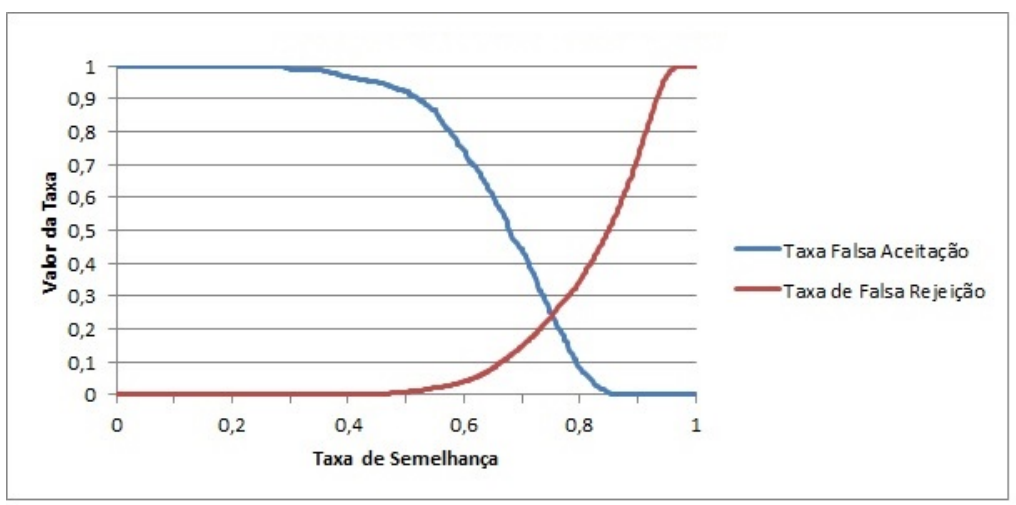

Figura 50 - Curva com a Taxa de Falsa Aceitação versus Taxa de Falsa Rejeição alcançada pelo melhor ensemble envolvendo sistemas unimodais baseado em face.

A Figura 51 apresenta a taxa de erro obtida pelo ensemble para cada classe. Observe que o sistema apresentou o pior desempenho para a classe referente ao usuário \#78. Neste caso, foi obtida uma taxa de erro igual a 21,43\%. A distribuição das saídas geradas pelo sistema para o usuário \#78 é apresentada na Figura 52. Observe que das 84 imagens referentes ao usuário \#78, 18 imagens foram classificadas de forma incorreta. 
Dessas imagens classificadas incorretamente, cerca de 5 imagens foram classificadas como pertencente ao usuário \#9.

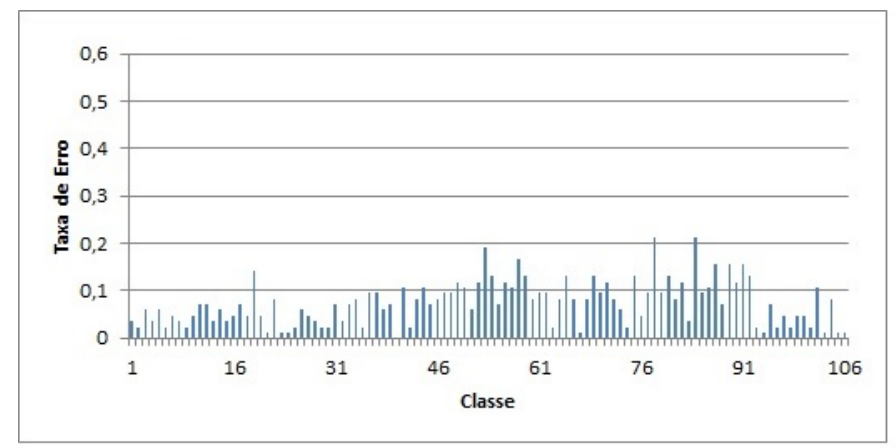

Figura 51 - Distribuição das taxas de erro geradas pelo melhor ensemble envolvendo sistemas unimodais baseado em face para cada classe.
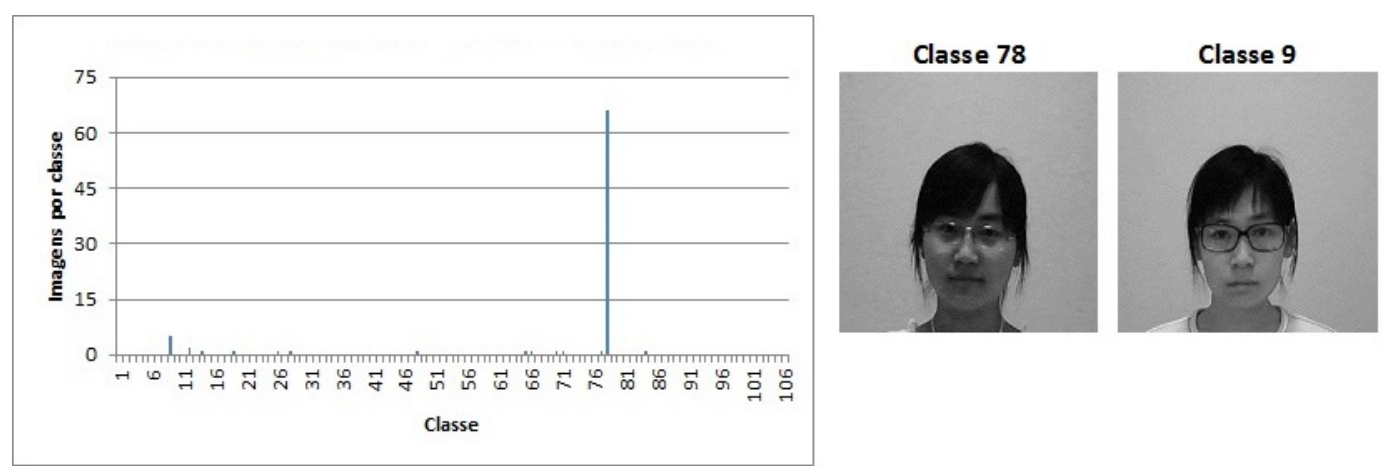

Figura 52 - Distribuição das saídas geradas pelo melhor ensemble envolvendo sistemas unimodais baseado em face para a classe \#78.

Na Figura 53 é apresentada a taxa de erro obtida pelo ensemble envolvendo sistemas unimodais baseado em face para cada pose (a Figura 39 apresenta as diferentes poses). Note que o pior desempenho foi obtido para a pose \#7. Neste caso, foi obtida uma taxa de erro igual a 11,64\%. O segundo pior desempenho foi obtido para a pose \#1. Neste caso, a taxa de erro foi igual a 11,14\%. Isto demonstra que o ensemble teve dificuldade de classificar imagens com grande variação na orientação.

A Figura 54 apresenta a distribuição das imagens classificadas incorretamente por classe geradas pelo melhor ensemble envolvendo sistemas unimodais baseado em face para a pose \#1. O pior desempenho foi obtido para o usuário \#58, \#80 e \#84. Neste caso, 4 das 12 imagens foram classificadas incorretamente. 58 usuários tiveram uma, ou nenhuma, imagem desta pose classificada incorretamente considerando as 12 imagens possíveis.

Na Figura 55 é apresentado a distribuição da taxa de erro para diferentes variações nas condições do ambiente (a Figura 40 apresenta as diferentes variações do ambiente) 


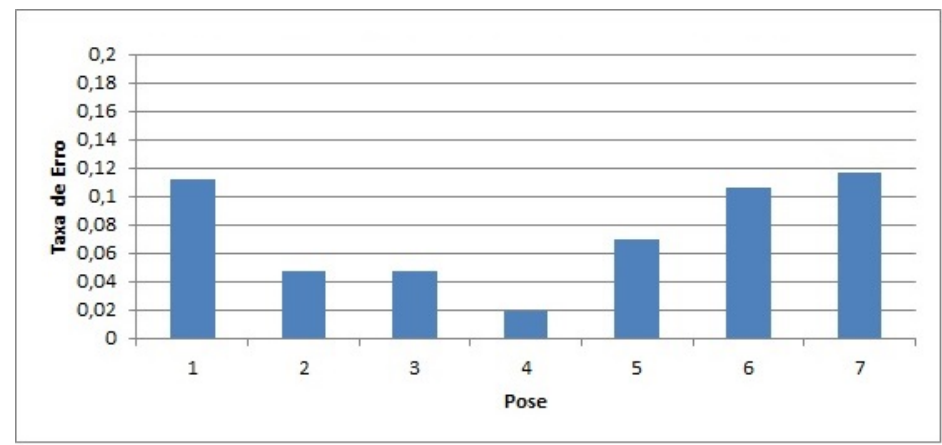

Figura 53 - Distribuição das taxas de erro geradas pelo melhor ensemble envolvendo sistemas unimodais baseado em face para cada pose.

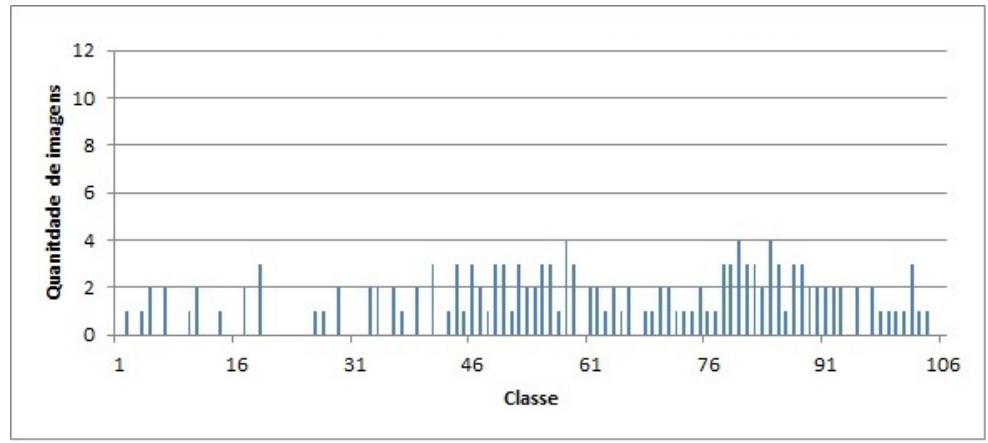

Figura 54 - Distribuição das imagens classificadas incorretamente por classe geradas pelo melhor ensemble envolvendo sistemas unimodais baseado em face para a pose $\# 7$.

geradas pelo melhor ensemble envolvendo sistemas unimodais baseado em face. Observe que o pior desempenho foi obtido para a variação no ambiente \#9. Neste caso, foram classificadas incorretamente 230 imagens das 742 imagens possíveis. Neste caso, o ensemble não conseguiu melhorar o resultado obtido pelo melhor sistema unimodal baseado em face. Inclusive, neste caso, ocorreu uma piora no desempenho.

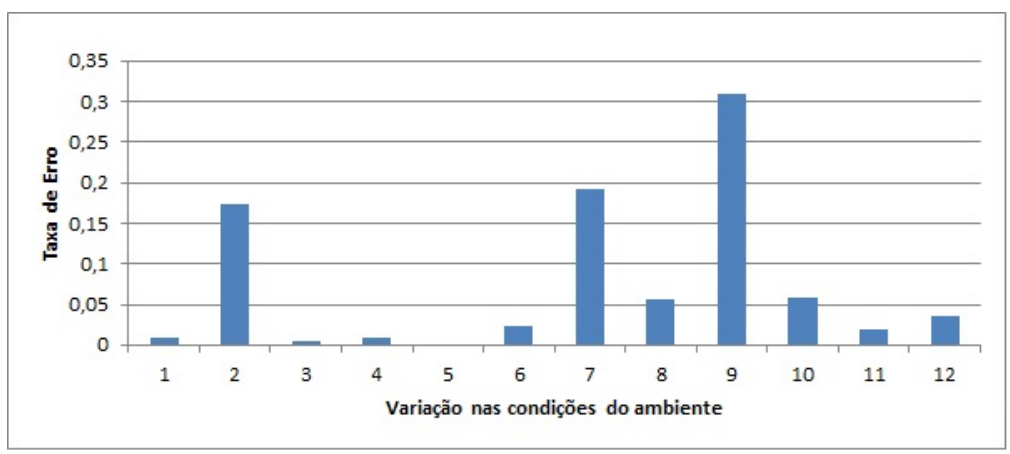

Figura 55 - Distribuição das taxas de erro geradas pelo melhor ensemble envolvendo sistemas unimodais baseado em face para diferentes variações nas condições do ambiente. 
A Figura 56 a distribuição das imagens classificadas incorretamente pelo melhor ensemble envolvendo sistemas unimodais baseado em face para a variação no ambiente \#9. Observe que para as classes (usuários) \#49, \#56, \#71, \#78, \#80, \#84, \#89 e \#91 o sistema classificou incorretamente 5 imagens das 7 imagens possíveis. Vale a pena ressaltar que para 13 classes, o sistema não apresentou nenhum erro.

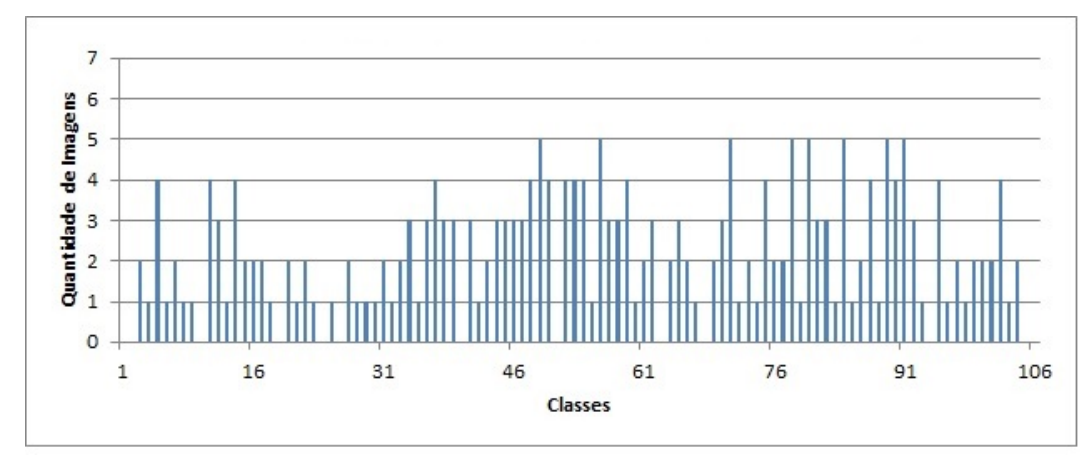

Figura 56 - Distribuição das imagens classificadas incorretamente por classe pelo ensemble envolvendo sistemas unimodais baseado em face para a variação no ambiente $\# 9$.

\subsubsection{Melhor sistema biométrico unimodal baseado em íris}

A Figura 57 apresenta as taxas de FAR e FRR para o melhor sistema unimodal envolvendo íris. Com o limiar de semelhança igual a 0,292 as taxas de FAR e FRR se igualam. Neste ponto, ambas as taxas apresentam valor próximo de 0,3. Este limiar de semelhança baixo significa que as imagens da íris apresentam grande variação. Apesar disso, as SVMs e LS-SVMs conseguiram obter uma alta taxa de acerto. Logo pode se que o mapeamento realizado pela função Kernel conseguiu aumentar a separação entre as classes.

Na Figura 58 é apresentada a taxa de erro obtida pelo melhor sistema unimodal baseado em íris para cada classe. Observe que o sistema apresentou o pior desempenho para a classe referente ao usuário \#89. Neste caso, foi obtida uma taxa de erro igual a 50\%.Vale a pena destacar que para 49 das 106 classes, o melhor sistema unimodal baseado em íris obteve uma taxa de acerto igual a 100\%. A distribuição das saídas geradas pelo sistema para o usuário \#89 é apresentada na Figura 59. Observe que das 10 imagens referentes ao usuário \#89, 5 imagens foram classificadas de forma incorreta, sendo essas imagens foram classificadas como pertencente as classes \#24, \#76, \#104, \#105 e \#106. 


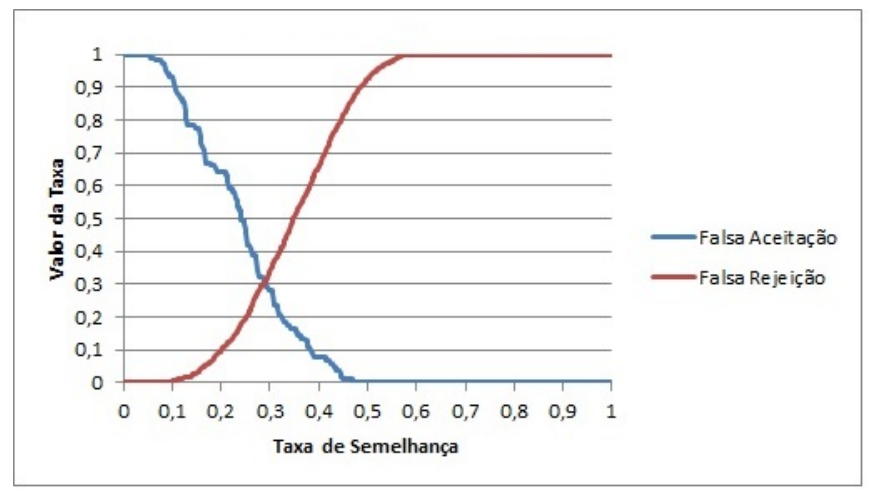

Figura 57 - Curva com a Taxa de Falsa Aceitação versus Taxa de Falsa Rejeição alcançada pelo melhor sistema unimodal baseado em íris.

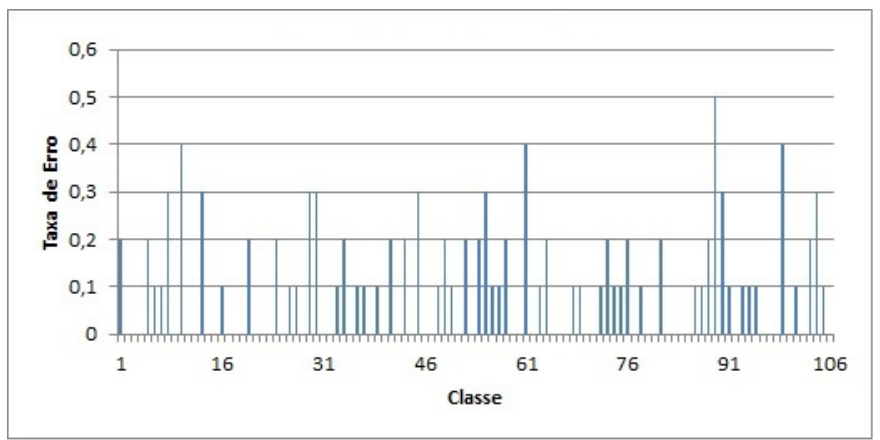

Figura 58 - Distribuição das taxas de erro geradas pelo melhor sistema unimodal baseado em íris para cada classe.

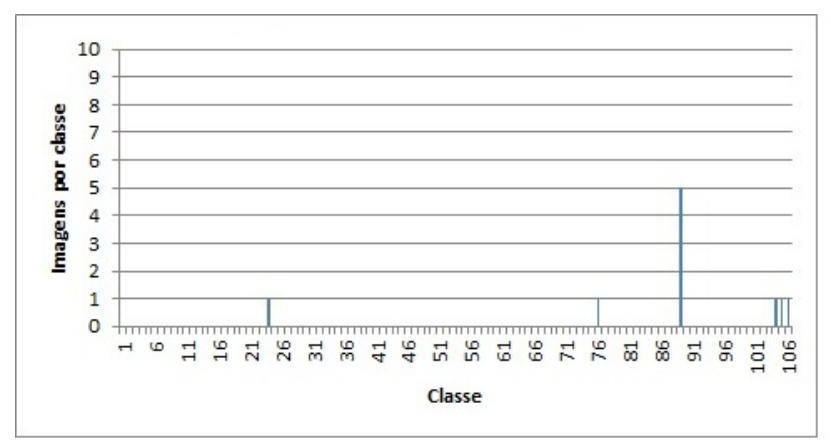

Figura 59 - Distribuição das saídas geradas pelo melhor sistema unimodal baseado em íris para a classe \#89.

Os resultados obtidos pelo sistema unimodal baseado na íris do olho esquerdo e direito são apresentados na Figura 60. Analisando o desempenho alcançado por cada uma das íris, pode se dizer que estes são muito próximos. Neste caso, os sistemas baseado na íris do olho esquerdo obtiveram uma taxa de erro igual a $9,43 \%$, que corresponde a 50 imagens classificadas incorretamente. Já os sistemas baseados na íris do olho direito 
alcançaram uma taxa de erro igual a 10,00\%, que corresponde a 53 imagens classificadas incorretamente.

A Figura 61 apresenta a distribuição dos erros alcançados pelo melhor sistema unimodal baseado na íris direita para cada classe. Neste caso, a classe \#10 apresentou a maior taxa de erro, isto é, 4 em 5 das imagens possiveis foram classificadas incorretamente.

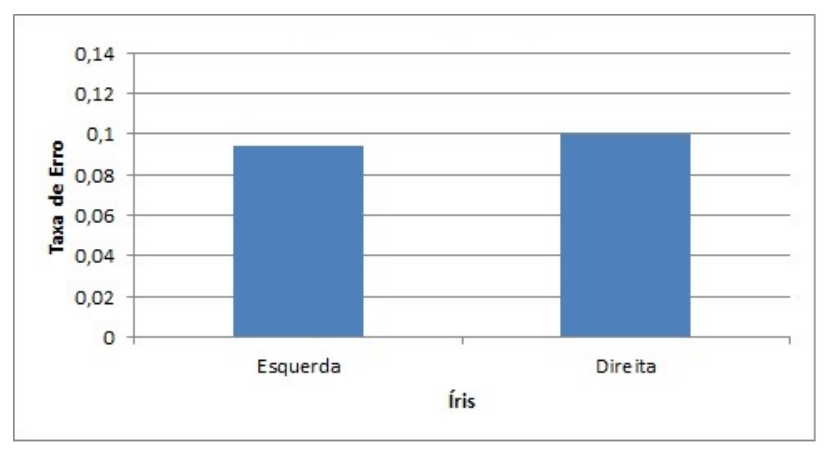

Figura 60 - Distribuição das taxas de erro obtida pelo melhor sistema unimodal baseado em íris para íris esquerda e direita.

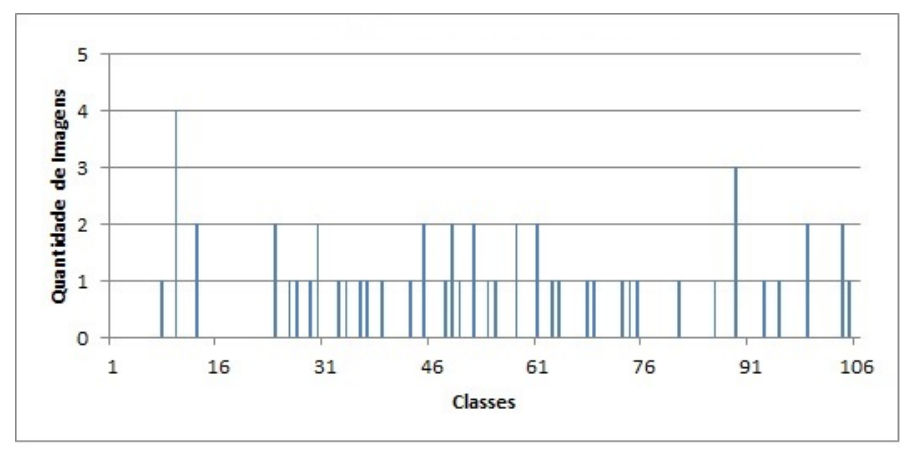

Figura 61 - Distribuição das taxas de erro obtida pelo melhor sistema unimodal baseado na íris direita para cada classe.

\subsubsection{Melhor ensemble envolvendo sistemas biométricos unimodais
baseado em ír}

Na Figura 62 são apresentadas as taxas de FAR e FRR para ensemble envolvendo sistemas unimodais baseado em íris. Para limiar de semelhança igual a 0,292 as taxas de FAR e FRR se igualam. Nesse ponto, ambas as taxas apresentam valor próximo de 0,3. Este valor foi superior ao obtido pelo melhor sistema unimodal baseado em íris. Isto justifica o fato do ensemble ter alcançado desempenho superior em relação aos sistemas unimodais baseado em íris. 


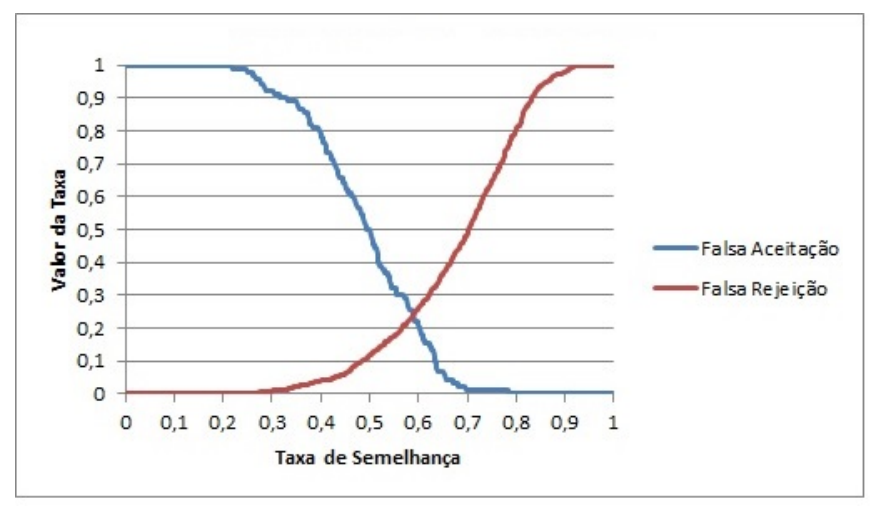

Figura 62 - Curva com a Taxa de Falsa Aceitação versus Taxa de Falsa Rejeição alcançada pelo melhor ensemble envolvendo sistemas unimodais baseado em íris.

A Figura 63 apresenta a taxa de erro obtida pelo ensemble para cada classe. Observe que o sistema apresentou os piores desempenhos para as classes \#10, \#61 e \#104. Para essas classes foi obtida uma taxa de erro igual a 40,00\%. Por outro, em 53 das 106 classes foi alcançado uma taxa de acerto igual a 100\%. A distribuição das saídas geradas pelo melhor ensemble para classe \#10 é apresentada na Figura 64. Note que 4 das imagens 10 da íris da classe \#10 foram classificadas como pertencente as classes \#3, \#32, \#45 e \#58.

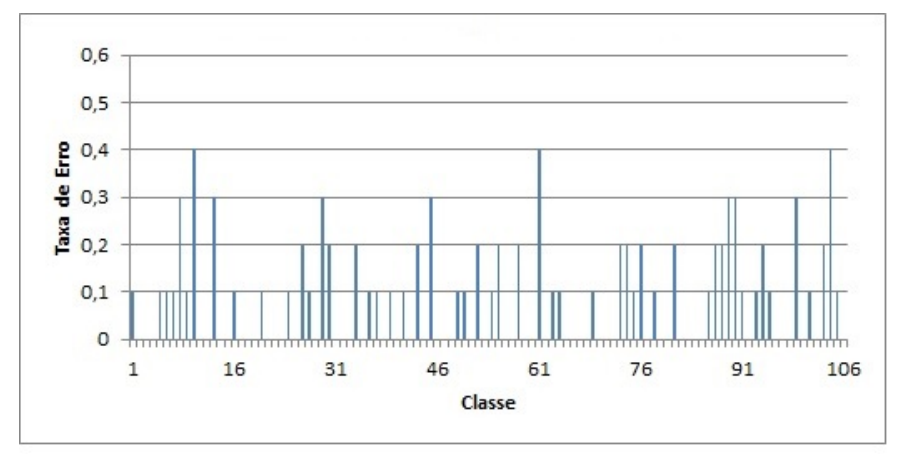

Figura 63 - Distribuição das taxas de erro obtida pelo melhor ensemble envolvendo sistemas unimodais baseado em íris para cada classe.

Os resultados obtidos pelo ensemble envolvendo sistemas unimodais baseado em íris para íris esquerda e direita são apresentados na Figura 65. Observe que a taxa de erro obtida pelo ensemble é a mesma para a íris esquerda e direita. Neste caso, foi obtida uma taxa de erro igual a 8,49\%, que corresponde a 45 imagens classificadas incorretamente. Este resultado é superior ao obtido pelo melhor sistema unimodal baseado em íris.

A Figura 66 apresenta a distribuição dos erros alcançados pelo melhor ensemble envolvendo sistemas unimodais baseado na íris do olho direito para cada classe. Neste 


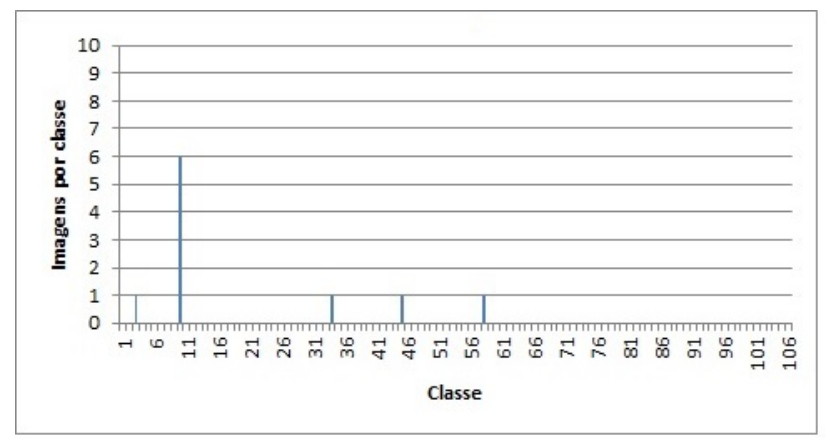

Figura 64 - Distribuição das saídas geradas pelo melhor ensemble envolvendo sistemas unimodais baseado em íris para a classe \#10.

caso, a classe \#10 apresentou a maior taxa de erro, isto é, 4 em 5 das imagens possíveis foram classificadas incorretamente.

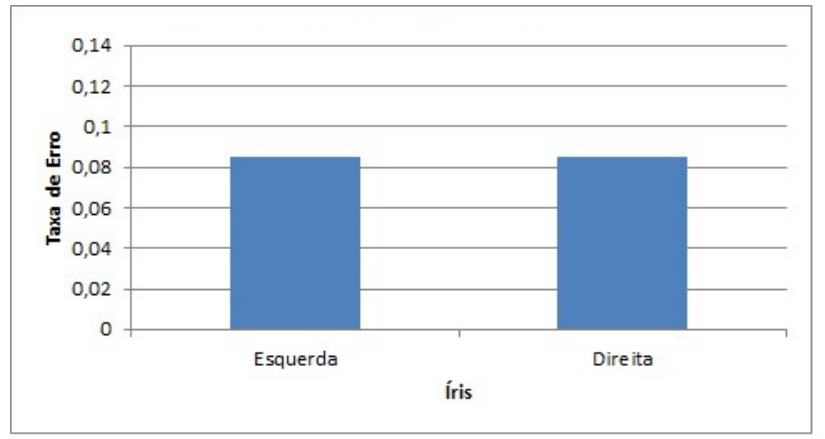

Figura 65 - Distribuição das taxas de erro geradas pelo melhor ensemble envolvendo sistemas unimodais baseado em íris para íris esquerda e direita.

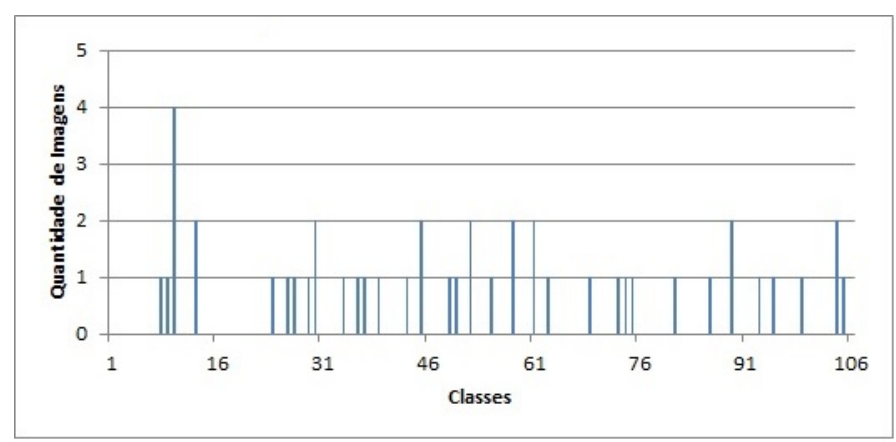

Figura 66 - Distribuição das taxas de erro geradas pelo melhor ensemble envolvendo sistemas unimodais baseado na íris direita para cada classe. 


\subsubsection{Melhor sistema biométrico multimodal}

A Figura 67 apresenta as taxas FAR e FRR para o melhor sistema multimodal. Com limiar de semelhança igual a 0,65, as taxas de FAR e FRR se igualam. Neste ponto, ambas as taxas apresentam valor próximo de 0,2 . Isto mostra que o sistema multimodal pode superar o desempenho alcançado pelos sistemas unimodais, apesar do conjunto de dados apresentar um alto grau de semelhança.

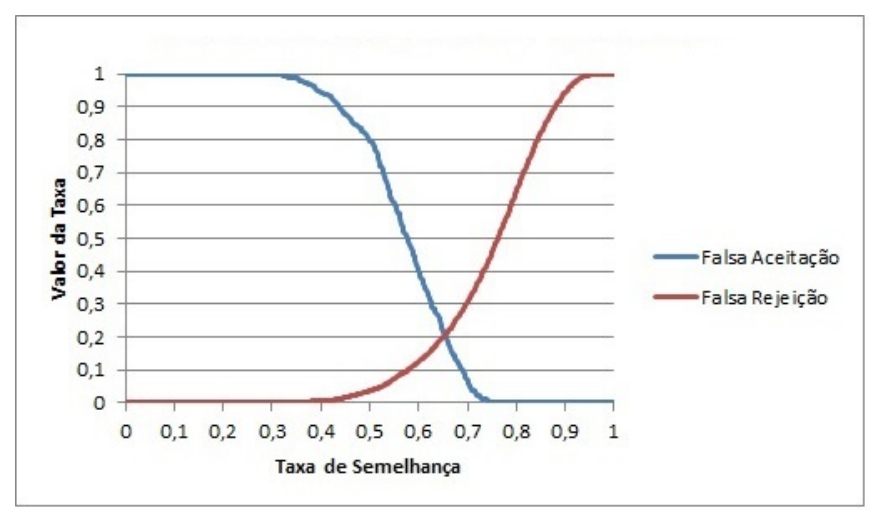

Figura 67 - Curva com a Taxa de Falsa Aceitação versus Taxa de Falsa Rejeição alcançada pelo melhor sistema multimodal.

Na Figura 68 é apresentada a taxa de erro obtida pelo melhor sistema multimodal para cada classe. Observe que o sistema apresentou o pior desempenho para a classe \#13. Neste caso, foi obtida a taxa de erro igual a 30,95\%. A distribuição das saídas geradas pelo sistema para a classe \#13 é apresentada na Figura 69. Note que das 84 imagens referentes ao usuário \#13, 26 imagens foram classificadas incorretamente. Dessas 26 imagens, 9 imagens foram classificadas como pertencentes a classe \#68.

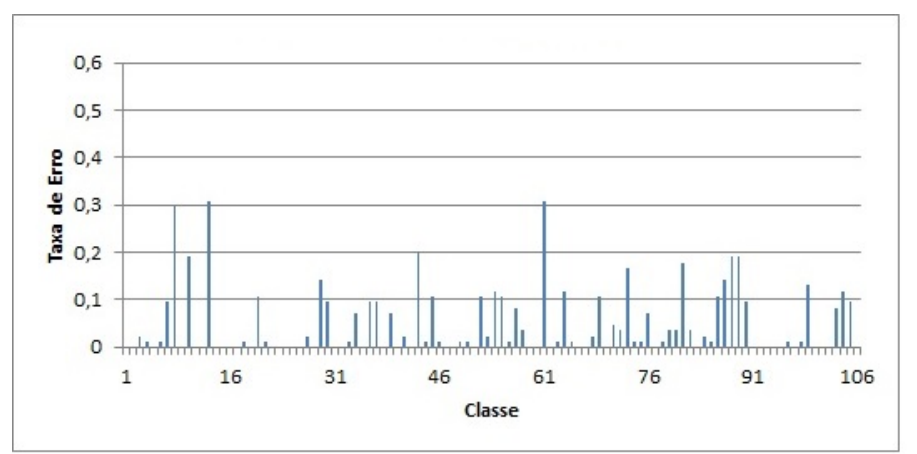

Figura 68 - Distribuição das taxas de erro geradas pelo melhor sistema multimodal para cada classe. 


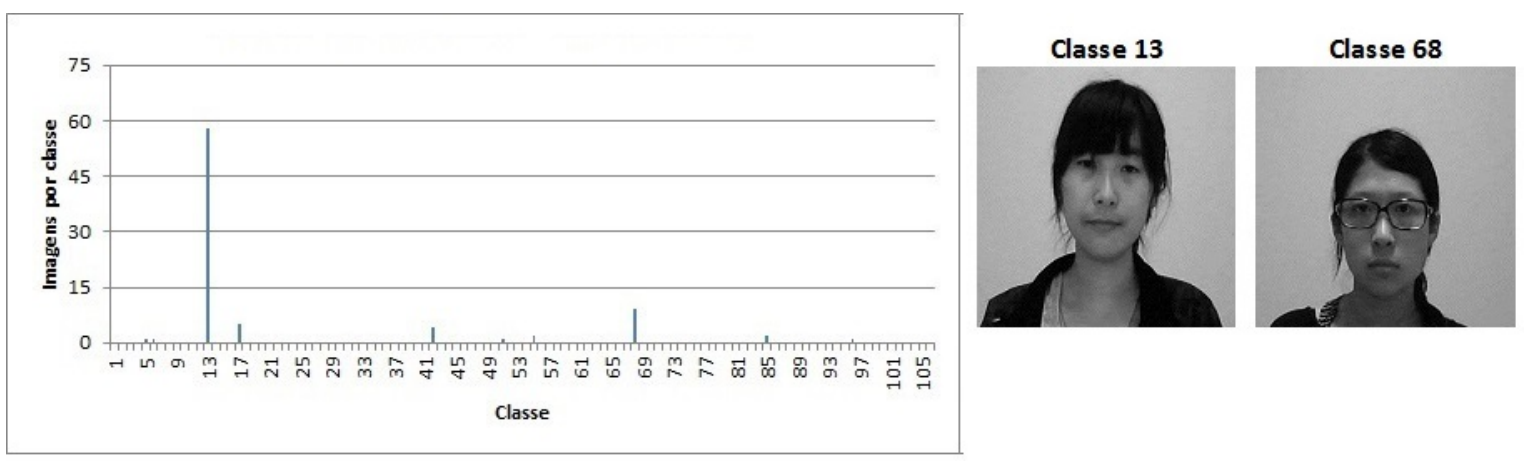

Figura 69 - Distribuição das saídas geradas pelo melhor sistema multimodal para a classe \#13.

Na Figura 70 é apresentada a taxa de erro obtida pelo melhor sistema multimodal para cada pose (a Figura 39 apresenta as diferentes poses). Observe que o pior desempenho foi obtido para a pose \#7. Neste caso, foi obtida uma taxa de erro igual a $6,05 \%$, ou seja, das 1272 imagens da pose \#7, 77 imagens foram classificadas incorretamente. O segundo pior desempenho foi obtido para a pose \#6. Neste caso, a taxa de erro foi igual a $5,11 \%$. Observe que o desempenho alcançado pelo melhor sistema multimodal para poses menos frontais (poses \#1, \#2, \#6 e \#7) foi 5,00\% superior ao obtido pelo melhor sistema unimodal. Isto demonstra que a concatenação das imagens da íris com as imagens de face pode contribuir para melhorar o desempenho do sistema em situações que carecem de mais informação para realizar o reconhecimento.

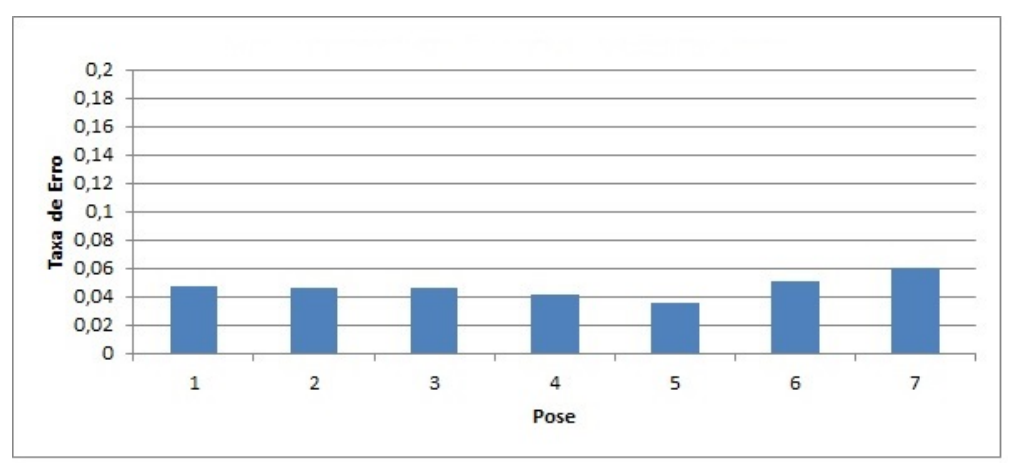

Figura 70 - Distribuição das taxas de erro obtidas pelo melhor sistema multimodal para cada pose.

A Figura 71 apresenta a distribuição das imagens classificadas incorretamente por classe geradas pelo melhor sistemas multimodal para a pose \#7. O pior desempenho foi obtido para a classe \#8. Neste caso, 6 das 12 imagens foram classificadas incorretamente. 90 classes tiveram uma, ou nenhuma, imagem desta pose classificada incorretamente considerando as 12 imagens possíveis. 


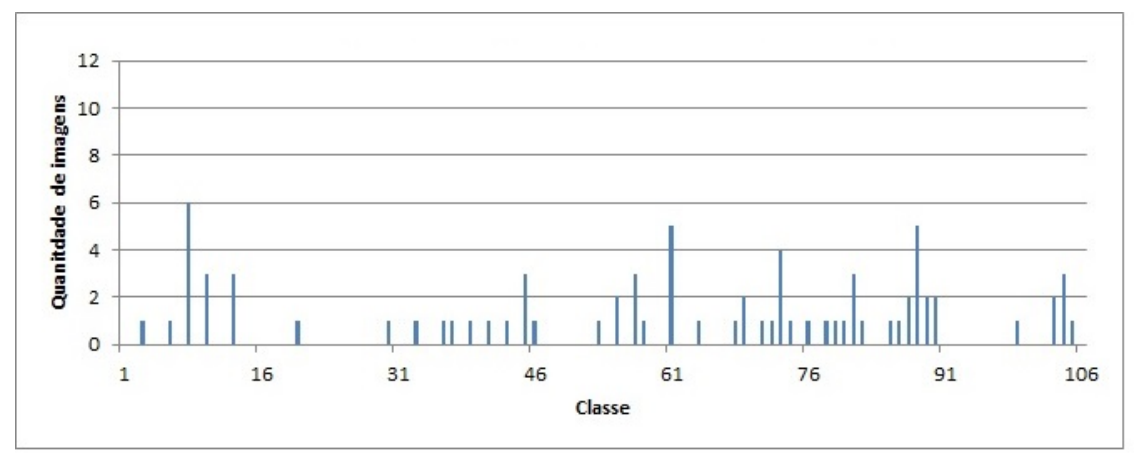

Figura 71 - Distribuição das imagens classificadas incorretamente por classe geradas pelo melhor sistema multimodal para a pose \#7.

Na Figura 72 é apresentado a distribuição da taxa de erro para diferentes variações nas condições do ambiente (a Figura 40 apresenta as diferentes variações do ambiente) geradas pelo melhor sistema multimodal. Observe que o pior desempenho foi obtido para a variação no ambiente \#7. Neste caso, foi obtida uma taxa de erro igual a $7,14 \%$. Vale a pena lembrar que a variação no ambiente \#7 corresponde a uma grande variação de iluminação. Apesar disso, o sistema multimodal obteve uma melhora para esta variação em torno de 11,00\# quando comparado ao melhor sistema unimodal.

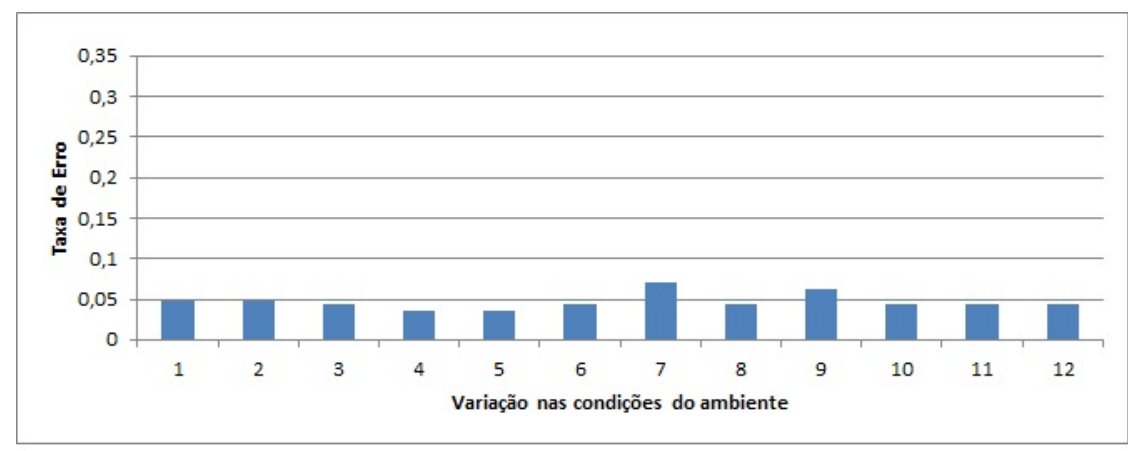

Figura 72 - Distribuição das taxas de erro geradas pelo melhor sistema multimodal para diferentes variações nas condições do ambiente.

A Figura 73 apresenta a distribuição das imagens classificadas incorretamente por classe geradas pelo melhor sistema multimodal para a variação no ambiente \#9. Observe que para esta variação no ambiente, no pior caso, o sistema multimodal classificou 2 imagens incorretamente. 


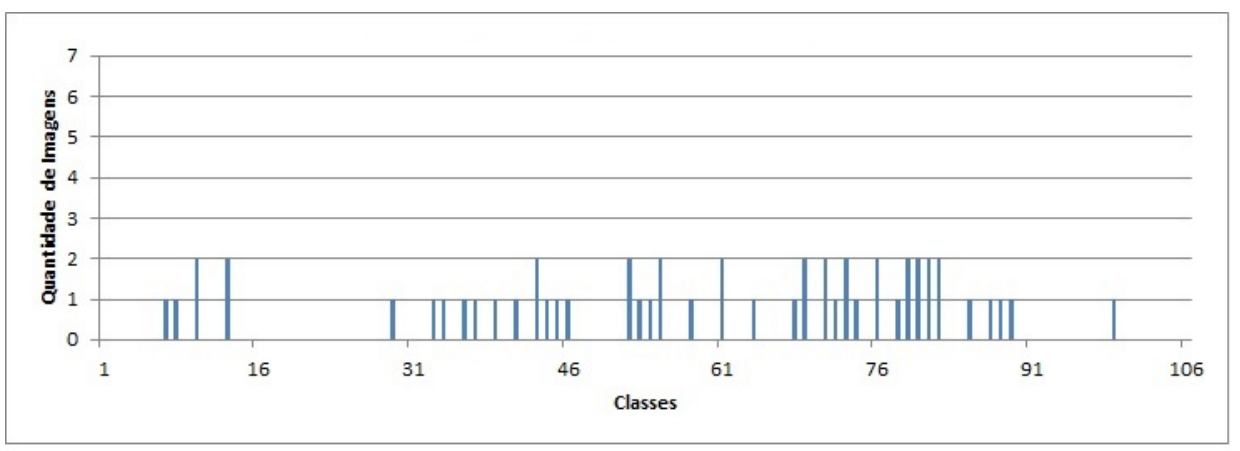

Figura 73 - Distribuição das imagens classificadas incorretamente por classe geradas pelo melhor sistema multimodal para a variação no ambiente \#7.

\subsubsection{Melhor ensemble envolvendo sistemas biométricos multimodais}

Na Figura 74 são apresentadas as taxas de FAR e FRR para o melhor ensemble envolvendo sistemas multimodais. Para o limiar de semelhança igual a 0,57, as taxas de FAR e FRR se igualam. Neste ponto, ambas as taxas apresentam um valor próximo de 0,27. Este limiar de semelhança é mais baixo que o obtido pelo melhor sistema multimodal. A combinação das saidas geradas pelos sistemas multimodais equivale a uma combinação no espaço de alta dimensão. Provavelmente a combinação neste espaço gerou um aumento na semelhança intra-classe e uma diminuição na semelhança entre-classe. Em função disso, o ensemble conseguiu obter uma menor taxa de erro. Neste caso, foi obtida uma taxa de erro igual a $2,09 \%$.

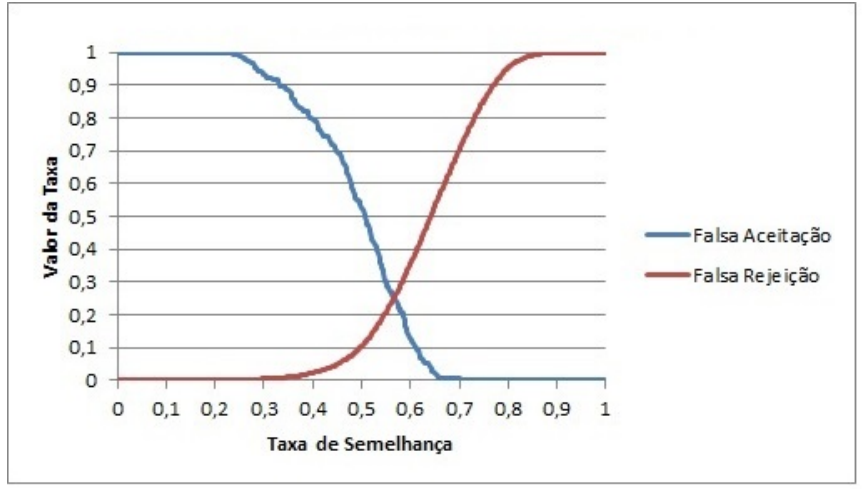

Figura 74 - Curva com a Taxa de Falsa Aceitação versus Taxa de Falsa Rejeição alcançada pelo melhor ensemble envolvendo sistemas multimodais.

Na Figura 75 é apresentada a taxa de erro obtida pelo melhor ensemble envolvendo sistemas multimodais para cada classe. Note que o ensemble apresentou o pior desempenho para a classe referente ao usuário \#10. Neste caso, foi obtida uma taxa de erro igual a 
13, 09\%. A distribuição das saídas geradas pelo ensemble para o usuário \#10 é apresentada na Figura 76. Observe que das 84 imagens referente ao usuário \#10, 11 imagens foram classificadas de forma incorreta. Dessas 11 imagens, 8 imagens foram classificadas como pertencentes a classe \#33.

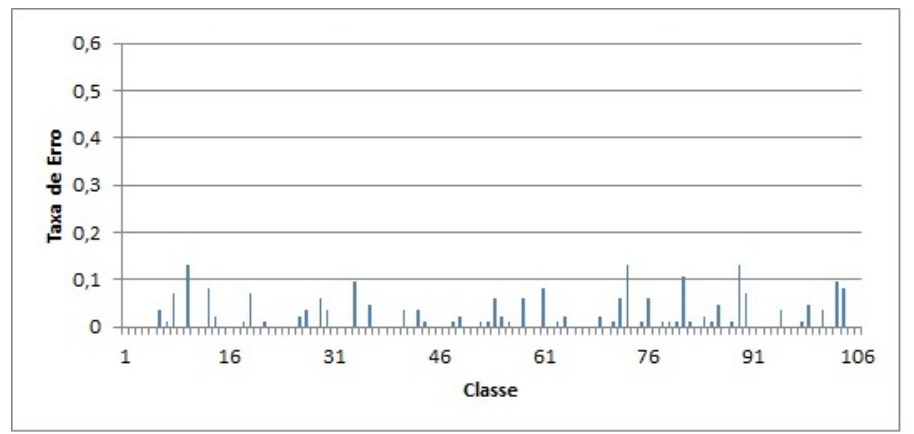

Figura 75 - Distribuição das taxas de erro obtida pelo melhor ensemble envolvendo sistemas multimodais para cada classe.
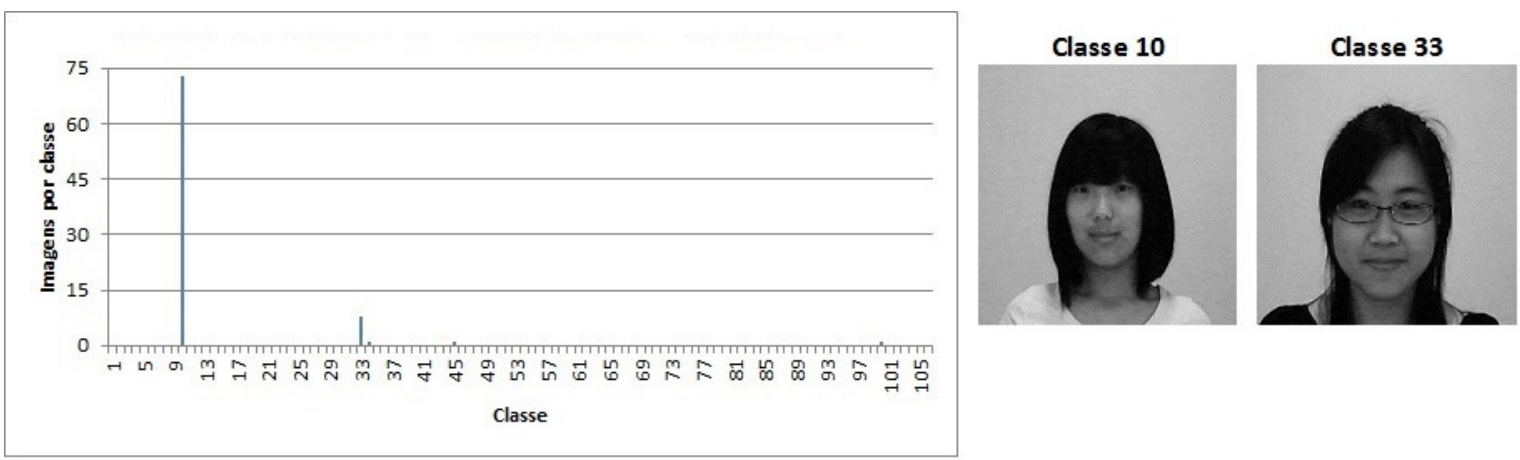

Figura 76 - Distribuição das saídas geradas pelo melhor ensemble envolvendo sistemas multimodais para a classe \#10.

Na Figura 77 é apresentada a taxa de erro obtida pelo ensemble envolvendo sistemas multimodais para cada pose (a Figura 39 apresenta as diferentes poses). Observe que o pior desempenho foi obtido para a pose \#7. Neste caso, foi obtida uma taxa de erro igual a 3, 14\%, ou seja, das 1272 imagens da pose \#7, 40 imagens foram classificadas incorretamente. O segundo pior desempenho foi obtido para as poses \#1 e \#6. Neste caso, foi obtida uma taxa de erro igual 2,59\%. Vale a pena destacar que o melhor ensemble conseguiu superar o desempenho alcançado por todos os outros sistemas biométricos propostos nesta dissertação para todas as poses, com exceção da pose \#4. Isto demonstra que o ensemble pode melhorar o desempenho obtido pelos sistemas unimodais e multimodais para imagens com grande variação de orientação. 


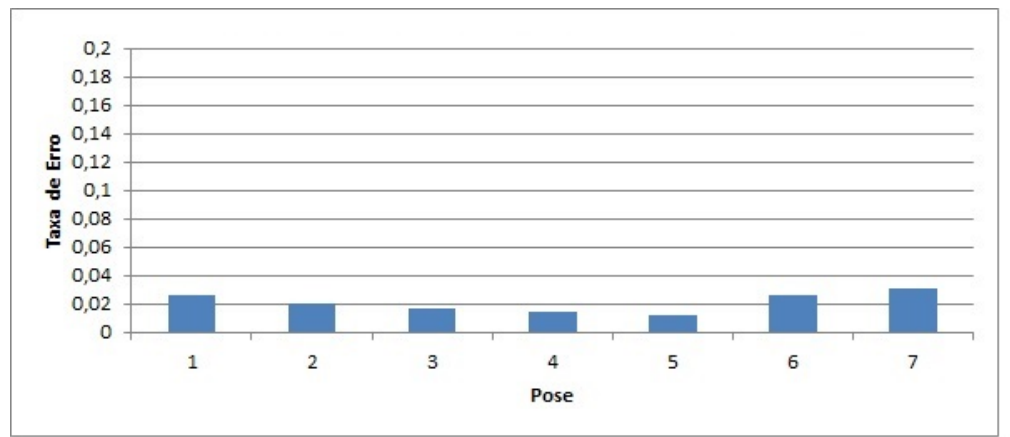

Figura 77 - Distribuição das taxas de erro geradas pelo melhor ensemble envolvendo sistemas multimodais para cada pose.

A Figura 78 apresenta a distribuição das imagens classificadas incorretamente por classe geradas pelo melhor ensemble envolvendo sistemas multimodais para a pose \#7. Para 3 classes, o ensemble classificou incorretamente 3 imagens das 12 imagens possíveis de pose. Por outro lado, 98 classes tiveram uma, ou nenhuma, imagem desta pose classificada incorretamente.

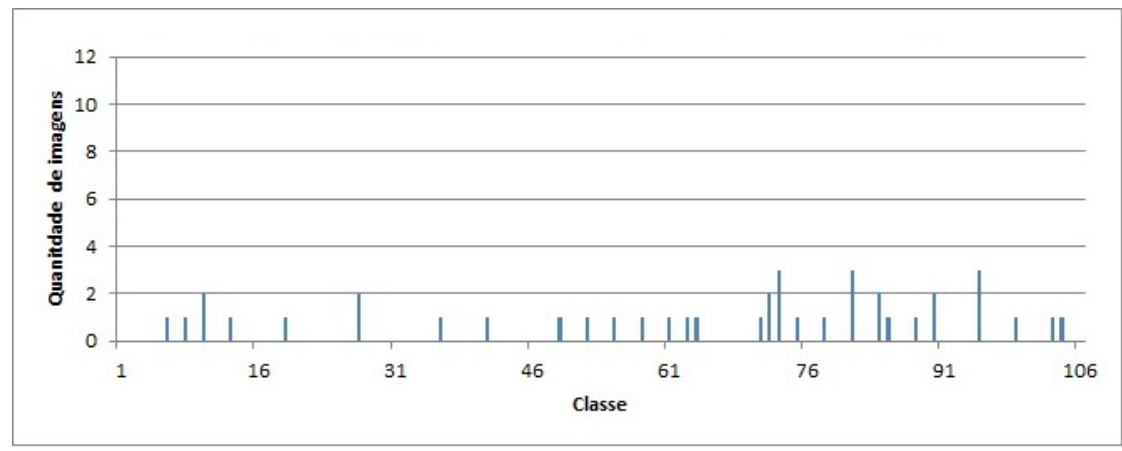

Figura 78 - Distribuição das imagens classificadas incorretamente por classe geradas pelo melhor ensemble envolvendo sistemas multimodais para a pose \#7.

Na Figura 79 é apresentado a distribuição da taxa de erro para diferentes variações nas condições do ambiente (a Figura 40 apresenta as diferentes variações do ambiente) geradas pelo melhor ensemble envolvendo sistemas multimodais. Observe que o pior desempenho foi obtido para a variação no ambiente \#7. Neste caso, foi obtida uma taxa de erro igual a 3,63\%. Vale ressaltar que para 7 das 12 variações no ambiente o melhor ensemble conseguiu uma melhora no desempenho quando comparado com o melhor sistema multimodal.

A Figura 80 apresenta a distribuição das imagens classificadas incorretamente por classe geradas pelo melhor ensemble envolvendo sistemas multimodais para a variação no 


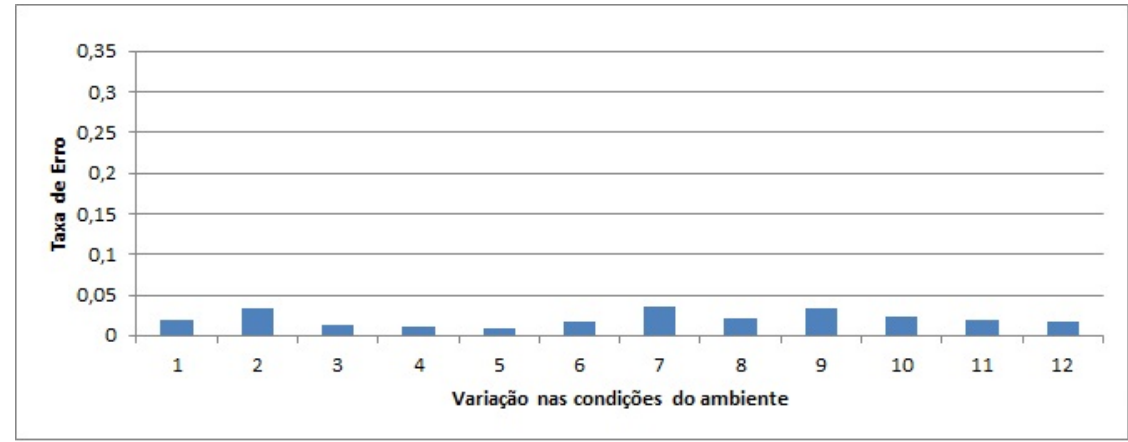

Figura 79 - Distribuição das taxas de erro geradas pelo melhor ensemble envolvendo sistemas multimodais para diferentes variações nas condições do ambiente.

ambiente \#7. Observe que para 99 classes, no pior caso, o ensemble obteve apenas 1 erro de classificação.

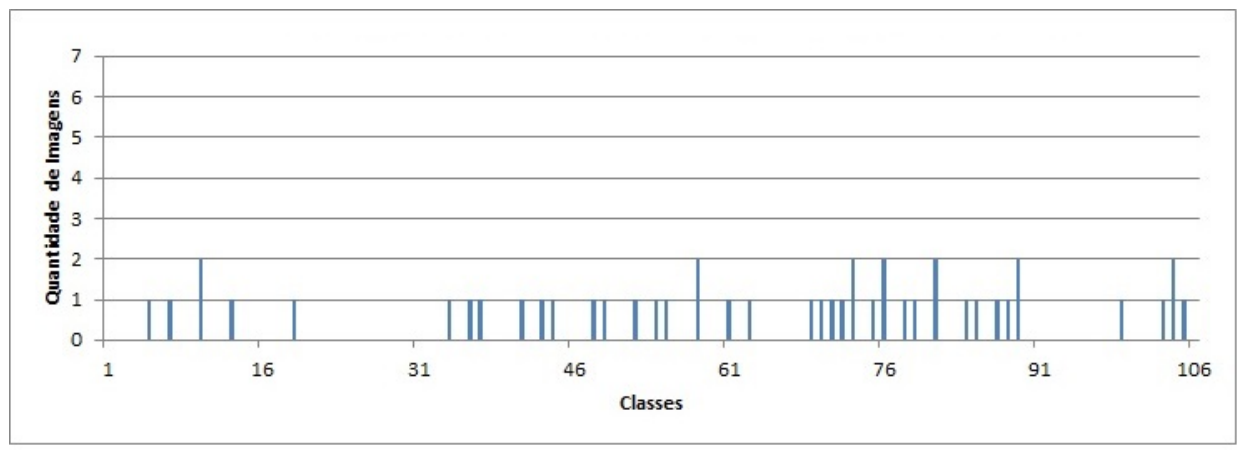

Figura 80 - Distribuição das imagens classificadas incorretamente por classe geradas pelo melhor ensemble envolvendo sistemas multimodais para a variação no ambiente $\# 7$.

\subsubsection{Taxa de Falsa Aceitação e Falsa Rejeição}

A Tabela 49 apresenta a variação na taxa de erro obtida pelos vários sistemas biométricos propostos nesta dissertação ao utilizar o ponto de cruzamento das curvas de FAR e FRR como critério de tomada de decisão no processo de reconhecimento do usuário. Note que, em alguns casos, os desempenhos obtidos pelos sistemas biométricos sofreram uma queda de cerca de $20 \%$.

Conforme já mencionado anteriormente, as SVMs e LS-SVMs baseadas na estratégia um-contra-todos produzem como saída apenas o rótulo da classe. Neste caso, não é possível calcular o grau de semelhança de dada instância para o conjunto de dados. Nesta dissertação foi proposta uma estratégia para cálculo dessa semelhança. No entanto, esse cálculo é 


\begin{tabular}{|c|c|c|}
\hline Sistema & Taxa de Erro Original & Taxa de Erro no Ponto de Cruzamento \\
\hline Face & $6,36 \%$ & $24,01 \%$ \\
\hline Face - Ensemble & $7,41 \%$ & $25,46 \%$ \\
\hline Íris & $9,71 \%$ & $30,75 \%$ \\
\hline Íris - Ensemble & $8,49 \%$ & $24,06 \%$ \\
\hline Multimodal & $4,70 \%$ & $20,50 \%$ \\
\hline Multimodal - Ensemble & $2,09 \%$ & $25,51 \%$ \\
\hline
\end{tabular}

Tabela 49 - Variação da taxa de erro gerada pelos sistemas biométricos ao utilizar o ponto de cruzamento das curvas de FAR e FRR como limiar de decisão.

realizado no espaço original e não no espaço mapeado pela função Kernel. Geralmente, nesse espaço mapeado pela função Kernel há uma maior separação entre as instâncias de classes diferentes. Isto justifica a queda no desempenho ocorrida quando se utiliza o ponto de cruzamento das curvas FAR e FRR como critério para definir a saída final, isto é, identificar o usuário..

\subsubsection{Estudo comparativo}

A Figura 81 apresenta a taxa de erro por classe obtida pelos vários sistemas biométricos abordados nesta dissertação. Observe que o ensemble envolvendo sistemas multimodais conseguiu obter menor taxa de erro para 93 classes das 106 classes possíveis. Isto demonstra que o ensemble pode melhorar o desempenho dos sistemas biométricos unimodais e multimodais.

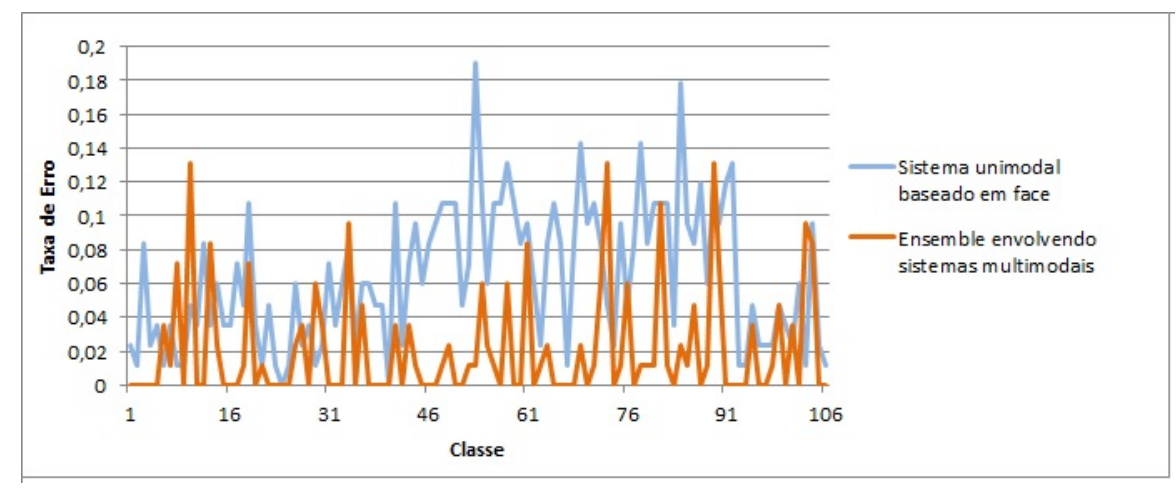

Figura 81 - Comparação da taxa de erro por classe gerada pelos melhores sistemas biométricos abordados nesta dissertação

Na Figura 82 é apresentado a taxa de erro por classe gerada pelos vários sistemas biométricos abordados nesta dissertação. Note que o sistema unimodal apresentou desempenho superior em relação aos outros sistemas para a pose \#4 (imagem frontal). Por outro lado, ensemble envolvendo sistemas multimodais conseguiu produzir uma melhora 
no desempenho quando comparado aos outros sistemas para todas as outras poses. Neste caso, a melhora produzida foi de aproximadamente 5,00\% por pose.

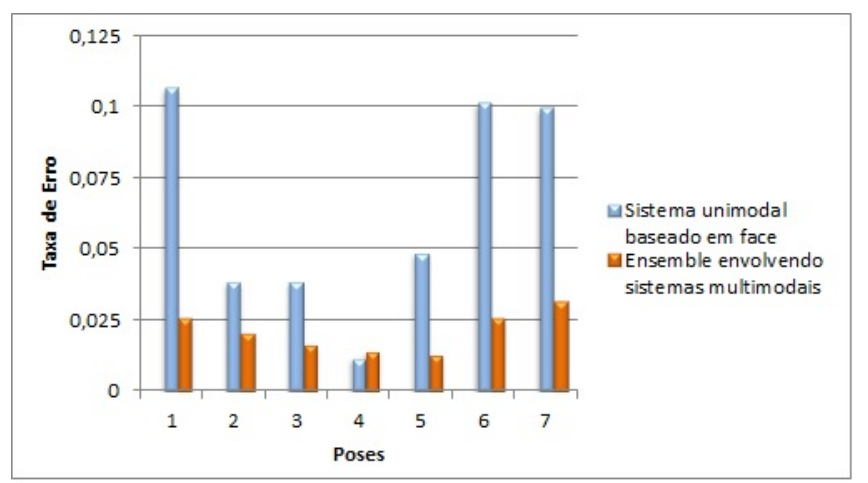

Figura 82 - Comparação da taxa de erro por pose gerada pelos melhores sistemas biométricos abordados nesta dissertação.

A Figura 83 apresenta a distribuição da taxa de erro para diferentes variações nas condições do ambiente gerada pelos melhores sistemas biométricos abordados. Note que, para imagens que apresentam pouca variação na iluminação, o melhor sistema biométrico baseado em face conseguiu superar o desempenho alcançado por todos os outros sistemas biométricos abordados. Isto mostra que sistema unimodal baseado em face é indicado para ambientes controlados. Por outro lado, o melhor sistema multimodal conseguiu melhorar o desempenho alcançado pelos sistemas unimodais em aproximadamente $10 \%$ para imagens com grande variação na iluminação (variações no ambiente \#7, \#8 e \#9). Além disso, os sistemas multimodais conseguiram obter taxa de erro abaixo de $5.00 \%$ para todos os casos.

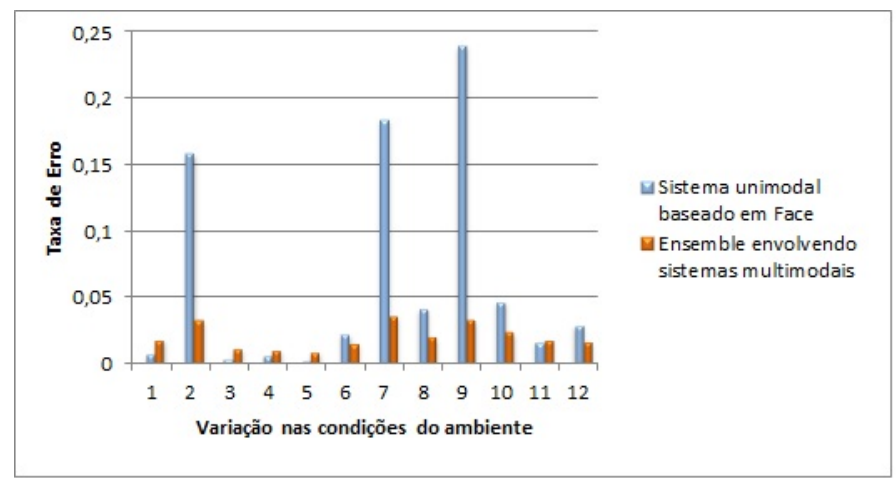

Figura 83 - Comparação da distribuição das taxas de erro obtidas pelo melhores sistemas biométricos para diferentes variações nas condições do ambiente. 


\section{Conclusão}

Essa dissertação realizou um estudo comparativo envolvendo sistemas unimodais, multimodais e a abordagem de ensemble usando diferentes técnicas de extração de características. Com relação aos sistemas multimodais, foram propostas algumas estratégias de fusão para o nível de característica. Dois tipos de ensemble foram propostos: ensemble envolvendo sistemas unimodais e ensemble envolvendo sistemas multimodais.

Do ponto de vista das técnicas de extração de características, pode se dizer que a transformada Wavelet conseguiu obter uma melhor representação para íris. O melhor sistema unimodal baseado em íris foi projetado com os coeficientes de Wavelet. Este obteve uma taxa de erro igual a 9,71\%. Já a transformada Curvelet conseguiu obter uma melhor representação para a face. Neste caso, o melhor sistema unimodal baseado em face obteve uma taxa de acerto igual a 6,36\%. A transformada Contourlet produziu resultados satisfatório para íris. Entretanto, os sistemas baseados em face, que foram projetados com os coeficientes da transformada Contourlet, apresentaram um péssimo desempenho comparado aos outros sistemas. Acredita-se que este desempenho ruim possa ter sido causado pelas diferentes configurações das imagens de face.

Em relação às estratégias de fusão empregadas nos sistemas multimodais, estas conseguiram gerar sistemas biométricos com desempenho satisfatório. Os sistemas multimodais que empregaram a estratégia de fusão baseada em contornos alcançaram o pior desempenho. Esta estratégia foi proposta para fusão de imagens de tomografias que apresentam o mesmo espectro de cores. No entanto, nesta dissertação, esta estratégia foi aplicada para fusão de imagens de face e íris, as quais apresentam características distintas. Acredita-se que esta tenha sido umas das causas do desempenho ruim alcançado pelos sistemas que utilizaram esta estratégia de fusão. Por outro lado, as estratégias de fusão baseada na concatenação e no mínimo dos coeficientes de aproximação e máximo dos coeficientes de detalhes conseguiram projetar sistemas multimodais que apresentaram, na maioria dos casos, os melhores resultados, independente do tipo de transformada utilizada para extração dos coeficientes.

Os classificadores SVM e LS-SVM apresentaram um comportamento bastante similar, ambos conseguiram obter taxas de acerto acima de $90 \%$ para alguns casos. Em relação ao parâmetro $\sigma$ do Kernel RBF, é possível afirmar que há um intervalo de busca 
adequado para cada transformada: [16,256] para a transformada Wavelet e Contourlet e $[32,512]$ para transformada Curvelet.

Ensemble envolvendo sistemas multimodais conseguiu produzir o melhor desempenho global. No melhor caso, foi obtido uma taxa de erro igual a 2,09\%. Para alguns casos, o ensemble não conseguiu superar o desempenho alcançado pelos sistemas unimodais ou multimodais. No entanto, no pior caso, o ensemble obteve um desempenho inferior a 1,5\% em relação ao melhor sistema. Apesar disso, o ensemble demonstrou ser uma abordagem bastante promissora para projeto de sistemas biométricos, uma vez que alivia o problema de seleção de parâmetros do modelo. Pode-se construir um ensemble a partir de sistemas biométricos unimodais ou multimodais, desde que apresentem um desempenho satisfatório. Neste caso não é necessário que os sistemas que irão compor o ensemble tenham seus parâmetros otimizados. O ensemble gerado pode obter um desempenho próximo do obtido pelo melhor sistema.

\subsection{Questões em aberto}

As perspectivas futuras incluem tanto aqueles tópicos que não foram devidamente abordados ao longo da pesquisa, por diversas razões, quanto tópicos que ganharam importância a partir dos resultados da própria pesquisa. São elas:

- Empregar a abordagem proposta em outras bases de dados multimodais visando averiguar se a presença de outras etnias, visto que a base de dados utilizada contém apenas oriental, pode causar algum impacto no desempenho da abordagem proposta;

- Utilizar outras formas de construção de comitês de máquinas, como por exemplo, Mistura de Especialistas e Ensemble via Correlação Negativa;

- Empregar outras técnicas de extração de características, como por exemplo, Decomposição em Modos Empíricos;

- Incorporar outras modalidades biométricas físicas ou comportamentais ao ensemble, tais como impressão digital, forma de andar e fala.

- Aplicar a abordagem proposta para reconhecimento biométrico baseado em sinais biomédicos, tais como, eletrocardiograma, eletroencefalograma, eletromiograma;

- Empregar outros classificadores que não sejam baseados em máquinas de Kernel, tais como, Florestas de Caminhos Ótimos (OPF); 


\subsection{Publicações vinculadas a dissertação}

Os artigos científicos listados a seguir estão diretamente vinculados à dissertação e foram produzidos ao longo do desenvolvimento do plano de trabalho vinculado ao Projeto de Pesquisa. Eles serão apresentados em ordem cronológica de publicação.

- Face Recognition using Support Vector Machines and Multiscale Directional Image Representation Methods: A Comparative Study - International Joint Conference on Neural Networks 2015 (COSTA et al., 2015c);

- Floresta de Caminhos Ótimos aplicado ao Reconhecimento Biométrico Multimodal Congresso Brasileiro de Inteligência Computacional 2015 (COSTA et al., 2015);

- Um estudo comparativo das estratégias de fusão no nível de características para sistemas biométricos multimodais baseado em face e íris - Simpósio Brasileiro de Sistemas de Informação 2015 (COSTA et al., 2015b);

- Face Recognition Systems Based on Wavelet Transform and SVM Ensembles Workshop de Visão Computacional 2014 (COSTA et al., 2014);

- Iris Recognition using Support Vector Machine and Least Squares Support Vector Machine: A Comparative Study - Workshop de Visão Computacional 2015 (COSTA et al., 2015a). 


\section{Referências $^{1}$}

AHMAD, M. I.; WOO, W.; DLAY, S. Multimodal biometric fusion at feature level: Face and palmprint. In: Communication Systems Networks and Digital Signal Processing (CSNDSP), 2010 7th International Symposium on. [S.l.: s.n.], 2010. p. 801-805. Citado na página 73.

AKHTAR, Z.; MICHELONI, C.; FORESTI, G. Biometric liveness detection: Challenges and research opportunities. Security Privacy, IEEE, v. 13, n. 5, p. 63-72, Sept 2015. ISSN 1540-7993. Citado 2 vezes nas páginas 29 e 33.

AL-RAISI, A. N.; AL-KHOURI, A. M. Iris recognition and the challenge of homeland and border control security in uae. Telematics and Informatics, v. 25, n. 2, p. 117-132, 2008. Citado na página 20.

ALZUBI, S.; ISLAM, N.; ABBOD, M. Multiresolution analysis using wavelet, ridgelet, and curvelet transforms for medical image segmentation. Journal of Biomedical Imaging, Hindawi Publishing Corp., New York, NY, United States, v. 2011, p. 4:1-4:18, jan. 2011. ISSN 1687-4188. Citado na página 52.

BACHOO, A. K.; TAPAMO, J.-R. Texture detection for segmentation of iris images. In: Proceedings of the 2005 Annual Research Conference of the South African Institute of Computer Scientists and Information Technologists on IT Research in Developing Countries. Republic of South Africa: South African Institute for Computer Scientists and Information Technologists, 2005. (SAICSIT '05), p. 236-243. ISBN 1-59593-258-5. Citado na página 34.

BALA, D. Biometrics and information security. In: Proceedings of the 5th Annual Conference on Information Security Curriculum Development. New York, NY, USA: ACM, 2008. (InfoSecCD ’08), p. 64-66. ISBN 978-1-60558-333-4. Citado na página 22.

BAMBERGER, R.; SMITH, M. J. T. A filter bank for the directional decomposition of images: theory and design. Signal Processing, IEEE Transactions on, v. 40, n. 4, p. 882-893, 1992. ISSN 1053-587X. Citado na página 49.

BIRGALE, L.; KOKARE, M. Iris recognition using discrete wavelet transform. In: Digital Image Processing, 2009 International Conference on. [S.l.: s.n.], 2009. p. 147-151. Citado na página 23.

BLEHA, S.; SLIVINSKY, C.; HUSSIEN, B. Computer-access security systems using keystroke dynamics. Pattern Analysis and Machine Intelligence, IEEE Transactions on, v. 12, n. 12, p. 1217-1222, 1990. ISSN 0162-8828. Citado na página 34.

BREIMAN, L. Bagging predictors. Mach. Learn., Kluwer Academic Publishers, Hingham, MA, USA, v. 24, n. 2, p. 123-140, ago. 1996. ISSN 0885-6125. Citado na página 65.

BURRUS, C. S. C. S.; GOPINATH, R. A.; GUO, H. Introduction to wavelets and wavelet transforms : a primer. [S.l.]: Upper Saddle River, N.J. Prentice Hall, 1998. ISBN 0-13-489600-9. Citado 3 vezes nas páginas 23, 47 e 48.

1 De acordo com a Associação Brasileira de Normas Técnicas. NBR 6023. 
BURT, P.; ADELSON, E. The laplacian pyramid as a compact image code. Communications, IEEE Transactions on, v. 31, n. 4, p. 532-540, 1983. ISSN 0090-6778. Citado na página 49.

CAMUS, T.; WILDES, R. Reliable and fast eye finding in close-up images. In: Pattern Recognition, 2002. Proceedings. 16th International Conference on. [S.l.: s.n.], 2002. v. 1, p. 389-394 vol.1. ISSN 1051-4651. Citado 2 vezes nas páginas 34 e 35.

CANDèS, E. et al. Fast Discrete Curvelet Transforms. 2005. Citado na página 52.

CANDèS, E. J.; DONOHO, D. L. Ridgelets: a key to higher-dimensional intermittency? Philosophical Transactions of the Royal Society of London A: Mathematical, Physical and Engineering Sciences, The Royal Society, v. 357, n. 1760, p. 2495-2509, 1999. ISSN 1364-503X. Citado na página 52.

CANDèS, E. J.; DONOHO, D. L. Curvelets - A Surprisingly Effective Nonadaptive Representation For Objects with Edges. 2000. Citado 3 vezes nas páginas 23, 51 e 52.

CANNY, J. A computational approach to edge detection. Pattern Analysis and Machine Intelligence, IEEE Transactions on, PAMI-8, n. 6, p. 679-698, Nov 1986. ISSN 0162-8828. Citado na página 37.

CATARINO, F. Segmentação da íris em imagem com ruído. Dissertação (Mestrado) Universidade da Beira Interior, 2009. Citado 2 vezes nas páginas 34 e 37.

CHANG, K. I. et al. Comparison and combination of ear and face images in appearance-based biometrics. IEEE Trans. Pattern Anal. Mach. Intell., v. 25, n. 9, p. 1160-1165, 2003. Citado na página 43.

CHAPELLE, O. et al. Choosing multiple parameters for support vector machines. Mach. Learn., Kluwer Academic Publishers, Hingham, MA, USA, v. 46, n. 1-3, p. 131-159, mar. 2002. ISSN 0885-6125. Citado na página 56.

CHERKASSKY, V.; MA, Y. Practical selection of svm parameters and noise estimation for svm regression. Neural Networks, v. 17, n. 1, p. 113 - 126, 2004. ISSN 0893-6080. Citado na página 56.

COELHO, A.; LIMA, C.; ZUBEN, F. V. Ga-based selection of components for heterogeneous ensembles of support vector machines. In: Evolutionary Computation, 2003. CEC '03. The 2003 Congress on. [S.1.: s.n.], 2003. v. 3, p. 2238-2245 Vol.3. Citado na página 62.

COELHO, A. L. V. Evolução, simbiose e hibridismo aplicados à engenharia de sistemas inteligentes modulares: Investigações em redes neurais, comitês de máquinas e sistemas multiagentes. Tese (Doutorado) - Faculdade de Engenharia Elétrica e de Computação UNICAMP, 2004. Citado 3 vezes nas páginas 62, 66 e 67.

CORTES, C.; VAPNIK, V. Support-vector networks. Mach. Learn., Kluwer Academic Publishers, Hingham, MA, USA, v. 20, n. 3, p. 273-297, set. 1995. ISSN 0885-6125. Citado na página 56.

COSTA, D. da et al. Iris recognition using support vector machine and least squares support vector. In: XI Workshop de Visão Computacional (WVC). [S.l.: s.n.], 2015. p. 446-451. Citado na página 136. 
COSTA, D. da et al. Um estudo comparativo das estratégias de fusão no nível de características para sistemas biométricos multimodais baseados em face e íris. In: $X I$ Simpósio Brasileiro de Sistemas de Informação (SBSI). [S.l.: s.n.], 2015. p. 219-226. Citado na página 136.

COSTA, D. da et al. Face recognition using support vector machine and multiscale directional image representation methods: A comparative study. In: Neural Networks (IJCNN), 2015 International Joint Conference on. [S.l.: s.n.], 2015. p. 1-8. Citado na página 136.

COSTA, D. da et al. Face recognition systems based on wavelet transform and svm ensembles. In: X Workshop de Visão Computacional (WVC). [S.l.: s.n.], 2014. p. 321-326. Citado na página 136.

COSTA, D. da et al. Floresta de caminhos Ótimos aplicado ao reconhecimento biométrico multimodal. In: Anais do 12 Congresso Brasileiro de Inteligência Computacional (CBIC). [S.l.: s.n.], 2015. p. 1-6. Citado na página 136.

COSTA, S. M. F. Classificação e Verificação de Impressões de Digitais. Dissertação (Mestrado) - Escola Politécnica da Universidade de São Paulo, 2001. Citado na página 38.

COVER, T. M. Geometrical and statistical properties of systems of linear inequalities with applications in pattern recognition. Electronic Computers, IEEE Transactions on, EC-14, n. 3, p. 326-334, 1965. Citado na página 57.

CRISTIANINI, N.; SHAWE-TAYLOR, J. An Introduction to Support Vector Machines: And Other Kernel-based Learning Methods. New York, NY, USA: Cambridge University Press, 2000. ISBN 0-521-78019-5. Citado na página 55.

DANDAWATE, Y.; INAMDAR, S. Fusion based multimodal biometric cryptosystem. In: Industrial Instrumentation and Control (ICIC), 2015 International Conference on. [S.1.: s.n.], 2015. p. 1484-1489. Citado na página 23.

DAUGMAN, J. High confidence visual recognition of persons by a test of statistical independence. Pattern Analysis and Machine Intelligence, IEEE Transactions on, v. 15, n. 11, p. 1148-1161, Nov 1993. ISSN 0162-8828. Citado 3 vezes nas páginas 34, 35 e 36.

DAUGMAN, J. How iris recognition works. IEEE Transactions on Circuits and Systems for Video Technology, v. 14, p. 21-30, 2002. Citado na página 33.

DELAC, K.; GRGIC, M. A survey of biometric recognition methods. In: Electronics in Marine, 2004. Proceedings Elmar 2004. 46th International Symposium. [S.l.: s.n.], 2004. p. 184-193. ISSN 1334-2630. Citado 2 vezes nas páginas 27 e 37.

DESHMUKH, A.; PAWAR, S.; JOSHI, M. Feature level fusion of face and fingerprint modalities using gabor filter bank. In: Signal Processing, Computing and Control (ISPCC), 2013 IEEE International Conference on. [S.l.: s.n.], 2013. p. 1-5. Citado na página 73.

DEZHONG, Z.; FAYI, C. Face recognition based on wavelet transform and image comparison. In: Computational Intelligence and Design, 2008. ISCID '08. International Symposium on. [S.l.: s.n.], 2008. v. 2, p. 24-29. Citado na página 23. 
DHARAVATH, K.; TALUKDAR, F.; LASKAR, R. Study on biometric authentication systems, challenges and future trends: A review. In: Computational Intelligence and Computing Research (ICCIC), 2013 IEEE International Conference on. [S.l.: s.n.], 2013. p. 1-7. Citado 2 vezes nas páginas 30 e 33.

DIVYALOSHINI, V.; SARASWATHI, M. Performance evaluation of image fusion techniques and its implementation in biometric recognition. International Journal of Technology Enhancements and Emerging Engineering Research, v. 2, n. 3, 2014. Citado 3 vezes nas páginas 72,73 e 74 .

DO, M. N.; VETTERLI, M. The contourlet transform: An efficient directional multiresolution image representation. Trans. Img. Proc., IEEE Press, Piscataway, NJ, USA, v. 14, n. 12, p. 2091-2106, dez. 2005. ISSN 1057-7149. Citado 5 vezes nas páginas $9,23,49,50$ e 51 .

FARUQE, M.; HASAN, M. A. M. Face recognition using pca and svm. In: Anticounterfeiting, Security, and Identification in Communication, 2009. ASID 2009. 3rd International Conference on. [S.1.: s.n.], 2009. p. 97-101. Citado na página 22.

FLOM, L.; SAFFIR, A. Iris Recognition System. 1987. U.S Patent 4641394 . Citado na página 34.

FREUND, Y.; SCHAPIRE, R. E. Experiments with a New Boosting Algorithm. 1996. Citado na página 66.

FREUND, Y.; SCHAPIRE, R. E. A short introduction to boosting. In: In Proceedings of the Sixteenth International Joint Conference on Artificial Intelligence. [S.l.]: Morgan Kaufmann, 1999. p. 1401-1406. Citado na página 32.

GESTEL, T. V. et al. Benchmarking least squares support vector machine classifiers. Mach. Learn., Kluwer Academic Publishers, Hingham, MA, USA, v. 54, n. 1, p. 5-32, jan. 2004. ISSN 0885-6125. Citado 2 vezes nas páginas 56 e 57.

GUESMI, H. et al. Iris verification system based on curvelet transform. In: Cognitive Informatics Cognitive Computing $\left(I C C I^{*} C C\right)$, 2012 IEEE 11th International Conference on. [S.l.: s.n.], 2012. p. 226-229. Citado 3 vezes nas páginas 22, 23 e 47.

HANMANDLU, M. et al. Fusion of hand based biometrics using particle swarm optimization. In: Information Technology: New Generations, 2008. ITNG 2008. Fifth International Conference on. [S.l.: s.n.], 2008. p. 783-788. Citado na página 46.

HANSEN, L.; SALAMON, P. Neural network ensembles. Pattern Analysis and Machine Intelligence, IEEE Transactions on, v. 12, n. 10, p. 993-1001, Oct 1990. ISSN 0162-8828. Citado na página 63.

HARIPRASATH, S.; PRABAKAR, T. Multimodal biometric recognition using iris feature extraction and palmprint features. In: Advances in Engineering, Science and Management (ICAESM), 2012 International Conference on. [S.l.: s.n.], 2012. p. 174-179. Citado na página 23.

HASHEM, S. Optimal linear combinations of neural networks. Neural Networks, v. 10, n. 4, p. 599 - 614, 1997. ISSN 0893-6080. Citado na página 61. 
HASTIE, T.; TIBSHIRANI, R.; FRIEDMAN, J. The Elements of Statistical Learning: Data Mining, Inference, and Prediction, Second Edition. [S.1.]: Springer, 2009. ISBN 9780387848587. Citado 2 vezes nas páginas 55 e 62.

HAYKIN, S. Neural Networks and Learning Machines. [S.l.]: Prentice Hall, 2008. Citado na página 22.

HAYKIN, S. Neural Networks and Learning Machines. [S.l.]: Prentice Hall, 2009. ISBN 9780131471399. Citado na página 55.

HONG, L.; JAIN, A. Integrating faces and fingerprints for personal identification. IEEE transactions on pattern analysis and machine intelligence, v. 20, p. 1295-1307, 1998. Citado na página 30.

JACOBS, R. A. et al. Adaptive mixtures of local experts. Neural Comput., MIT Press, Cambridge, MA, USA, v. 3, n. 1, p. 79-87, mar. 1991. ISSN 0899-7667. Citado na página 61.

JADHAV, D. V.; HOLAMBE, R. S. Feature extraction using radon and wavelet transforms with application to face recognition. Neurocomputing, v. 72, p. $1951-1959$, 2009. ISSN 0925-2312. Citado na página 47.

JAIN, A.; ROSS, A.; PRABHAKAR, S. An introduction to biometric recognition. Circuits and Systems for Video Technology, IEEE Transactions on, v. 14, n. 1, p. 4-20, 2004. ISSN 1051-8215. Citado 3 vezes nas páginas 26, 30 e 34.

JAIN, A. K.; FLYNN, P.; ROSS, A. A. Handbook of Biometrics. Secaucus, NJ, USA: Springer-Verlag New York, Inc., 2007. ISBN 038771040X. Citado na página 20.

JAIN, A. K.; ROSS, A. Multibiometric systems. Commun. ACM, ACM, New York, NY, USA, v. 47, n. 1, p. 34-40, jan. 2004. ISSN 0001-0782. Citado 4 vezes nas páginas 21, 29, 39 e 40 .

JEMAA, Y. B.; KHANFIR, S. Automatic gabor features extraction for face recognition using neural networks. In: Image Processing Theory, Tools and Applications, 2008. IPTA 2008. First Workshops on. [S.l.: s.n.], 2008. p. 1-6. Citado na página 22.

KHARE, A.; SRIVASTAVA, R.; SINGH, R. Edge preserving image fusion based on contourlet transform. In: Proceedings of the 5th International Conference on Image and Signal Processing. Berlin, Heidelberg: Springer-Verlag, 2012. (ICISP'12), p. 93-102. ISBN 978-3-642-31253-3. Citado 2 vezes nas páginas 72 e 73.

KINNUNEN, T.; HAUTAMAKI, V.; FRANTI, P. Fusion of Spectral Feature Sets for Accurate Speaker Identification. In: Proceeding of International Conference Speech and Computer. [S.l.: s.n.], 2004. p. 361-365. Citado na página 23.

KUNCHEVA, L. I. Combining Pattern Classifiers: Methods and Algorithms. [S.1.]: Wiley-Interscience, 2004. ISBN 0471210781. Citado 2 vezes nas páginas 61 e 62.

LEE, Y.-J.; MANGASARIAN, O. Ssvm: A smooth support vector machine for classification. Computational Optimization and Applications, v. 20, n. 1, p. 5-22. ISSN 1573-2894. Citado na página 56. 
LIAU, H. F.; ISA, D. Feature selection for support vector machine-based face-iris multimodal biometric system. Expert Systems with Applications, v. 38, n. 9, p. 11105 11111, 2011. ISSN 0957-4174. Citado na página 57.

LIMA, C.; COELHO, A.; ZUBEN, F. V. Ensembles of support vector machines for regression problems. In: Neural Networks, 2002. IJCNN '02. Proceedings of the 2002 International Joint Conference on. [S.l.: s.n.], 2002. v. 3, p. 2381-2386. ISSN 1098-7576. Citado 2 vezes nas páginas 57 e 62.

LIMA, C.; COELHO, A.; ZUBEN, F. V. Fuzzy systems design via ensembles of anfis. In: Fuzzy Systems, 2002. FUZZ-IEEE'02. Proceedings of the 2002 IEEE International Conference on. [S.l.: s.n.], 2002. v. 1, p. 506-511. Citado na página 62.

LIMA, C. A. de M. Comitê de Máquinas: Uma Abordagem Unificada Empregando Máquinas de Vetores Suporte. Tese (Doutorado) — Faculdade de Engenharia Elétrica e de Computação - UNICAMP, 2004. Citado 6 vezes nas páginas 9, 58, 63, 64, 65 e 67.

LIMA, C. A. M.; COELHO, A. L. V.; ZUBEN, F. J. Applications and science in soft computing. In: ___ Berlin, Heidelberg: Springer Berlin Heidelberg, 2004. cap. Embedding Support Vector Machines into Localised Mixtures of Experts, p. 155-162. ISBN 978-3-540-45240-9. Citado na página 61.

LIU, Z.; ZHANG, L.; ZHU, L. An improved face recognition method based on gabor wavelet transform and svm. In: Computational Intelligence and Design (ISCID), 2012 Fifth International Symposium on. [S.1.: s.n.], 2012. v. 1, p. 378-381. Citado 3 vezes nas páginas 23, 47 e 57.

LOURENçO, A.; SILVA, H.; FRED, A. Ecg-based biometrics: A real time classification approach. In: Proceedings of the 22nd IEEE International Workshop on Machine Learning for Signal Processing. [S.1.: s.n.], 2012. Citado na página 57.

MALLAT, S. A Wavelet Tour of Signal Processing, Third Edition: The Sparse Way. 3rd. ed. [S.l.]: Academic Press, 2008. ISBN 0123743702, 9780123743701. Citado 2 vezes nas páginas 47 e 48.

MANGASARIAN, O. L.; MUSICANT, D. R. Lagrangian support vector machines. J. Mach. Learn. Res., JMLR.org, v. 1, p. 161-177, set. 2001. ISSN 1532-4435. Citado na página 56.

MARCIALIS, G. L.; ROLI, F. Fingerprint verification by fusion of optical and capacitive sensors. Pattern Recogn. Lett., Elsevier Science Inc., New York, NY, USA, v. 25, n. 11, p. 1315-1322, ago. 2004. ISSN 0167-8655. Citado na página 44.

MASEK, L. Recognition of Human Iris Patterns for Biometric Identification. [S.1.], 2003. Citado na página 37.

MASTALI, N.; AGBINYA, J. Authentication of subjects and devices using biometrics and identity management systems for persuasive mobile computing: A survey paper. In: Broadband and Biomedical Communications (IB2Com), 2010 Fifth International Conference on. [S.l.: s.n.], 2010. p. 1-6. Citado na página 30.

MüLLER, K.-R. et al. An introduction to kernel-based learning algorithms. IEEE Transactions on Neural Networks, v. 12, n. 2, p. 181-202, 2001. Citado 2 vezes nas páginas 55 e 56. 
MOGUERZA, J. M.; MUNõZ, A. Support Vector Machies with Applications. [S.1.], 206. Citado na página 55.

MONWAR, M.; GAVRILOVA, M. Multimodal biometric system using rank-level fusion approach. Systems, Man, and Cybernetics, Part B: Cybernetics, IEEE Transactions on, v. 39, n. 4, p. 867-878, Aug 2009. ISSN 1083-4419. Citado 2 vezes nas páginas 23 e 41.

MÜLLER, K.-R. et al. An introduction to kernel-based learning algorithms. IEEE Transactions on Neural Networks, v. 12, n. 2, p. 181-201, mar. 2001. Citado 2 vezes nas páginas 55 e 56 .

NILSSON, N. J. et al. Learning Machines. 1965. Citado na página 22.

OZA, N. C. Multiple classifier systems: 4th international workshop, mcs 2003 guildford, uk, june 11-13, 2003 proceedings. In: __ Berlin, Heidelberg: Springer Berlin Heidelberg, 2003. cap. Boosting with Averaged Weight Vectors, p. 15-24. ISBN 978-3-540-44938-6. Citado na página 66.

PRABHAKAR, S.; PANKANTI, S.; JAIN, A. Biometric recognition: security and privacy concerns. Security Privacy, IEEE, v. 1, n. 2, p. 33-42, Mar 2003. ISSN 1540-7993. Citado na página 37.

PROENCA, H.; ALEXANDRE, L. Iris recognition: An analysis of the aliasing problem in the iris normalization stage. In: Computational Intelligence and Security, 2006 International Conference on. [S.l.: s.n.], 2006. v. 2, p. 1771-1774. Citado 2 vezes nas páginas 34 e 35.

RATTANI, A. et al. Robust feature-level multibiometric classification. In: Biometric Consortium Conference, 2006 Biometrics Symposium: Special Session on Research at the. [S.l.: s.n.], 2006. p. 1-6. Citado na página 72.

ROSS, A.; JAIN, A. Information fusion in biometrics. Pattern Recognition Letters, v. 24, p. 2115-2125, 2003. Citado 5 vezes nas páginas 20, 22, 23, 44 e 45.

ROSS, A.; JAIN, A. Fusion techniques in multibiometric systems. In: Face Biometrics for Personal Identification. [S.l.]: Springer Berlin Heidelberg, 2007, (Signals and Communication Technology). p. 185-212. ISBN 978-3-540-49344-0. Citado na página 42.

ROSS, A.; ROHIN, G. B. Feature Level Fusion Using Hand and Face Biometrics. 2005. Citado 2 vezes nas páginas 23 e 43.

ROSS, A. A.; NANDAKUMAR, K.; JAIN, A. K. Handbook of Multibiometrics (International Series on Biometrics). Secaucus, NJ, USA: Springer-Verlag New York, Inc., 2006. ISBN 0387222960. Citado na página 22.

SALGADO, R. et al. A hybrid ensemble model applied to the short-term load forecasting problem. In: Neural Networks, 2006. IJCNN '06. International Joint Conference on. [S.l.: s.n.], 2006. p. 2627-2634. Citado na página 62.

SCHAPIRE, R. E. The Strength of Weak Learnability. 1990. Citado 2 vezes nas páginas 65 e 66. 
SCHOLKOPF, B.; SMOLA, A. J. Learning with Kernels: Support Vector Machines, Regularization, Optimization, and Beyond. Cambridge, MA, USA: MIT Press, 2001. ISBN 0262194759. Citado 2 vezes nas páginas 58 e 59.

SHARKEY, A. J. (Ed.). Combining Artificial Neural Nets: Ensemble and Modular Multi-Net Systems. 1st. ed. Secaucus, NJ, USA: Springer-Verlag New York, Inc., 1999. ISBN 185233004X. Citado na página 61.

SHAWE-TAYLOR, J.; CRISTIANINI, N. Kernel Methods for Pattern Analysis. New York, NY, USA: Cambridge University Press, 2004. ISBN 0521813972. Citado na página 55.

SHEN, Q.; LIU, R. Face recognition based on lfda and ls-svm. In: Education Technology and Training, 2009. ETT '09. Second International Conference on. [S.l.: s.n.], 2009. p. 136-139. Citado na página 22.

SHI, J.-X.; GU, X.-F. The comparison of iris recognition using principal component analysis, independent component analysis and gabor wavelets. In: Computer Science and Information Technology (ICCSIT), 2010 3rd IEEE International Conference on. [S.1.: s.n.], 2010. v. 1, p. 61-64. Citado na página 23.

SUYKENS, J. A. K.; VANDEWALLE, J. Least squares support vector machine classifiers. Neural Process. Lett., Kluwer Academic Publishers, Hingham, MA, USA, v. 9, n. 3, p. 293-300, jun. 1999. ISSN 1370-4621. Citado 3 vezes nas páginas 22, 56 e 59.

TAO, Q.; VELDHUIS, R. Threshold-optimized decision-level fusion and its application to biometrics. Pattern Recognition, v. 42, n. 5, p. 823 - 836, 2009. ISSN 0031-3203. Citado na página 46.

THARWAT, A.; IBRAHIM, A.; ALI, H. Multimodal biometric authentication algorithm using ear and finger knuckle images. In: Computer Engineering Systems (ICCES), 2012 Seventh International Conference on. [S.l.: s.n.], 2012. p. 176-179. Citado 2 vezes nas páginas 23 e 41.

THE US Federal Comission Report. [S.l.], 2012. Citado na página 20.

THEPADE, S.; BIDWAI, P. Iris recognition using fractional coefficients of transforms, wavelet transforms and hybrid wavelet transforms. In: Control Computing Communication Materials (ICCCCM), 2013 International Conference on. [S.l.: s.n.], 2013. p. 1-5. Citado na página 47.

TIPPING, M. E. The Relevance Vector Machine. 2000. Citado na página 56.

TRESP, V. Committee machines. Neural Computation, v. 12, p. 2000, 2001. Citado na página 61.

VAPNIK, V. N. The nature of statistical learning theory. New York, NY, USA:

Springer-Verlag New York, Inc., 1995. ISBN 0-387-94559-8. Citado 2 vezes nas páginas 22 e 55.

VAPNIK, V. N. Statistical Learning Theory. [S.l.]: Wiley-Interscience, 1998. Citado 3 vezes nas páginas 57,58 e 59. 
VIOLA, P.; JONES, M. Robust real-time face detection. International Journal of Comp. Vision, Kluwer Academic Publishers, v. 57, n. 2, p. 137-154, 2004. ISSN 0920-5691. Citado 4 vezes nas páginas 9, 30, 33 e 47.

WANG, B. et al. An efficient method for face feature extraction based on contourlet transform and fast independent component analysis. In: Computational Intelligence and Design (ISCID), 2011 Fourth International Symposium on. [S.1.: s.n.], 2011. v. 1, p. 344-347. Citado 2 vezes nas páginas 23 e 47.

WANG, Y. et al. The contourlet transfrom and svm classification for face recognition. In: Apperceiving Computing and Intelligence Analysis, 2008. ICACIA 2008. International Conference on. [S.l.: s.n.], 2008. p. 208-211. Citado na página 23.

WANG, Z. et al. Feature-level fusion of iris and face for personal identification. In: YU, W.; HE, H.; ZHANG, N. (Ed.). Advances in Neural Networks. [S.1.]: Springer Berlin Heidelberg, 2009, (Lecture Notes in Computer Science, v. 5553). p. 356-364. ISBN 978-3-642-01512-0. Citado 4 vezes nas páginas 22, 43, 72 e 74.

$\mathrm{XU}, \mathrm{Y}$. et al. Joint iris and facial recognition based on feature fusion and biomimetic pattern recognition. In: Wavelet Analysis and Pattern Recognition (ICWAPR), 2013 International Conference on. [S.l.: s.n.], 2013. p. 202-208. ISSN 2158-5695. Citado 2 vezes nas páginas 23 e 47.

XU, Y.; ZHANG, D.; YANG, J.-Y. A feature extraction method for use with bimodal biometrics. Pattern Recognition, v. 43, n. 3, p. 1106-1115, 2010. Citado na página 41.

YIN, Y.; LIU, L.; SUN, X. Sdumla-hmt: A multimodal biometric database. In: SUN, Z. et al. (Ed.). CCBR. [S.1.]: Springer, 2011. (Lecture Notes in Computer Science, v. 7098), p. 260-268. ISBN 978-3-642-25448-2. Citado na página 78.

ZHAI, Y. et al. A novel iris recognition method based on the contourlet transform and biomimetic pattern recognition algorithm. In: Signal Processing (ICSP), 2010 IEEE 10th International Conference on. [S.l.: s.n.], 2010. p. 1390-1393. Citado na página 23.

ZHANG, Y.; YU, B.; GU, H. Face recognition using curvelet-based two-dimensional principle component analysis. International Journal of Pattern Recognition and Artificial Intelligence, v. 26, n. 03, p. 1256009, 2012. Citado 2 vezes nas páginas 23 e 47. 